\title{
AIR SEPARATION BY PRESSURE SWING ADSORPTION USING SUPERIOR ADSORBENTS
}

\author{
DE-FG26-98FT40115
}

\author{
FINAL TECHNICAL REPORT \\ September 1, 1998 - August 31, 2001
}

\author{
Submitted to \\ Dr. Kamalendu Das \\ U.S. Department of Energy \\ Federal Energy Technology Center \\ 3610 Collins Ferry Road \\ P.O. Box 880 \\ Morgantown, WV 26507-0880 \\ And \\ FETC AAD Document Center \\ Federal Energy Technology Center \\ U.S. Department of Energy \\ P. O. Box 10940 \\ Pittsburgh, PA 15236-0940
}

By

Ralph T. Yang

Authors: Nick D. Hutson, Stefan C. Zajic, Salil U. Rege and Ralph T. Yang

Department of Chemical Engineering

University of Michigan

Ann Arbor, MI 48109-2136 
Table of Contents

Page

Disclaimer

Executive Summary $\quad 4$

Chapter 1. Adsorption Properties and Structures

of Pure Ag-Faujasites

Chapter 2. Mixed Ag-Li-X Zeolites and Their

PSA Air Separation

Chapter 3. Structural Effects on Adsorption of Atmospheric

Gases in Mixed Li,Ag- X Zeolite

Chapter 4. Effects of Residual Water on the Adsorption of Atmospheric Gases in Li-X Zeolite:

Experiment and Simulation

Chapter 5. Synthesis and Characterization of the Sorption Properties of Oxygen-Binding Cobalt

Complexes Immobilized in Nanoporous Materials

Conclusion 


\section{Disclaimer}

This report was prepared as an account of work sponsored by an agency of the United States Government. Neither the United States Government nor any agency thereof, nor any of their employees, makes any warranty, express or implied, or assumes any legal liability or responsibility for the accuracy, completeness or usefulness of any information, apparatus, product, or process disclosed, or represents that its use would not infringe privately owned rights. Reference herein to any specific commercial product, process or service by trade name, trademark, manufacturer, or otherwise does not necessarily constitute or imply its endorsement, recommendation, or favoring by the United States Government or any agency thereof. The views or opinions of authors expressed herein do not necessarily state or reflect those of the United States Government or any agency thereof. 


\section{EXECUTIVE SUMMARY}

$\mathrm{Li}-\mathrm{X}$ zeolite $(\mathrm{Si} / \mathrm{Al}=1.0)$ is currently the best sorbent for use in the separation of air by adsorption processes. In particular, pressure swing adsorption (PSA) using zeolite sorbents is being increasingly used for air separation. Silver is also known to strongly affect the adsorptive properties of zeolites; and it is known that thermal vacuum dehydration of silver zeolites leads to the formation of silver clusters within the zeolite. In this work we have synthesized type $\mathrm{X}$ zeolites containing $\mathrm{Ag}$ and also varying mixtures of $\mathrm{Li}$ and $\mathrm{Ag}$. In this project, we developed the $\mathrm{Ag}$-containing zeolite as the best sorbent for air separation. We have also studied Co-ligand compounds as oxygenselective sorbents. Syntheses, structural characterization and adsorption properties have been performed on all sorbents. The results are described in detail in 5 chapters.

In Chapter 1, we report the structure of pure Ag-X zeolites. We also studied the adsorption properties in relation to the structure of pure Ag-faujasite zeolites. We first synthesized silver zeolites of the types $\mathrm{Y}, \mathrm{X}$ and low silica X (LSX). The zeolites were treated in such a way as to promote the formation of intracrystalline charged silver clusters. Equilibrium isotherms were measured for adsorption of nitrogen for each of the zeolites after various heat treatments and dehydration. Silver cations and clusters were quantitatively located using Reitveld refinement of neutron powder diffraction data. The

neutron diffraction experiments were performed at NIST. Color changes upon heat treatment and subsequent X-ray photoemission spectroscopy confirmed some reduction of $\mathrm{Ag}^{+} \rightarrow \mathrm{Ag}^{0}$. The effects of various dehydration conditions, including the time, temperature and atmosphere, are discussed. Silver clusters in Ag-LSX zeolites showed 
thermally induced mobility, moving from beta cage - hexagonal prism locations to the beta cage. Silver clusters in this latter position enhanced nitrogen adsorption due to increased exposure of the Ag-cation in the site II* location, which is less shielded by framework oxygen atoms than that at all other cation sites. $\mathrm{Ag}^{+}$at site $\mathrm{II}^{*}$ hence has stronger interactions (including weak -complexation) with $\mathrm{N}_{2}$ in the supercage.

In Chapter Two, we studied the air separation performance of mixed AgLiX zeolite. The addition of very small amounts of $\mathrm{Ag}$ and the proper dehydration conditions resulted in the formation of silver clusters and enhanced adsorptive characteristics and increased energetic heterogeneity as compared to those of the near fully exchanged $\mathrm{Li}^{+}-$ zeolites. The performance for air separation by the best of these sorbents, containing, on average, only one Ag per unit cell, was compared to that of the near fully $\mathrm{Li}^{+}$-exchanged zeolite using a standard PSA cycle by numerical simulation. The results show that the new sorbent provides a significantly higher $(>10 \%)$ product throughput, at the same product purity and recovery, when compared to that of the near fully $\mathrm{Li}^{+}$-exchanged zeolite.

In Chapter 3, we report the structural effects on adsorption of atmospheric gases in mixed Li,Ag- X zeolite. Neutron diffraction and Reitveld refinement analysis were used to determine the zeolite structure and the cation sites. These were correlated with the adsorption properties.

In Chapter 4, the effects of residual water on the adsorption of atmospheric gases in Li-X zeolite were determined. In addition, a Monte Calro simulation study was performed. The residual water has a very strong effect in decreasing the adsorption of nitrogen and oxygen. The effects were iluustrated well by Lonte Carlo results. 
Chapter 5 deals with the synthesis and the characterization of the sorption properties of oxygen-binding cobalt complexes immobilized in nanoporous materials. Cobalt (II) bis(3-fluoro-salicylaldehyde) ethylenediamine (Co(fluomine)), an organometallic complex of known oxygen-binding capacity, has been synthesized in such a way as to anchor this material on the anion sites of selected nanoporous substrates. The $\mathrm{O}_{2}$ and $\mathrm{N}_{2}$ binding capacities of the resulting bulk materials were then characterized. The resulting $\mathrm{O}_{2}$ sorption isotherms of these materials were more reversible than those of the free material. They also exhibit the positive slope with oxygen pressure that is desirable for applications. X-ray photoemission spectroscopy (XPS) analysis indicated a difference in the electronic nature of the cobalt atoms present in the free $\mathrm{Co}$ (fluomine) as compared to those of the material immobilized on the surface of type $\mathrm{X}$ zeolite, indicating possible coordination of $\mathrm{Co}$ (II) at the axial position by zeolitic framework oxygen. Stability testing of these materials, however, did not result in increased stability over that observed in the free $\mathrm{Co}$ (fluomine). 


\title{
CHAPTER ONE
}

\section{ADSORPTION PROPERTIES AND STRUCTURES OF PURE}

\author{
Ag-FAUJASITES
}




\section{Introduction}

Since their introduction in the 1950's, synthetic zeolites have been used in numerous applications such as catalysis, ion exchange, drying, and separation by selective adsorption. Among the most commonly used in these applications (especially in the selective adsorption of gases) are the faujasite analogs (types $\mathrm{X}$ and $\mathrm{Y}$ ). Faujasite zeolites are composed of silica and alumina tetrahedra which are joined together to form the truncated octahedral or sodalite structure. These sodalite units are connected with tertiary units (hexagonal prisms in faujasite) to form the structured zeolite unit cell. In these structures, the $\mathrm{SiO}_{2}$ groups are electroneutral, but the $\left(\mathrm{AlO}_{2}\right)^{-}$groups are not, and thus introduce a negative charge to the structure which is offset by the presence of a charge compensating, non-framework cation (e.g., $\mathrm{Na}^{+}, \mathrm{Li}^{+}, \mathrm{Ca}^{2+}$ ). For the faujasite zeolites, the cation site designations are conventionally designated as SI (the center of the hexagonal prism), SI' (opposite SI but located in the cubooctahedron), SII (single six-ring in the supercage), SII' (opposite SII but inside the cubooctahedron), and SIII (near the four-ring windows in the supercage). The unit cell, including cation sites, for faujasitetype zeolites is shown in Figure 1.

It is known that the extraframework cations in the zeolite are largely responsible for the adsorptive capacity of these materials. ${ }^{1,2}$ This is due primarily to van der Waals and Coulombic interactions between the charge compensating cations of the zeolite and the adsorbing gas. Because the extraframework cations so significantly influence the adsorption properties of the zeolites, numerous attempts have been made to optimize these properties by (1) increasing the number of cation sites (the cation exchange 
capacity, CEC) by creating zeolites with high aluminum content, and (2) by synthesizing zeolites containing various combinations of alkaline and alkaline earth cations.

Kuhl reported a procedure for the synthesis of low silica X-type zeolite (LSX). This material is an aluminum saturated $\mathrm{X}$-type zeolite with a silica-to-alumina ratio of 2.0 (or $\mathrm{Si} / \mathrm{Al}=1.0){ }^{3}$ Commercial $\mathrm{X}$-zeolite, which is typically available as the $\mathrm{Na}^{+}$form (known commercially as $13 \mathrm{X}$ ), is not aluminum saturated and contains 86 aluminum atoms per unit cell, while the LSX zeolite contains 96 aluminum atoms per unit cell.

Silver is known to strongly influence the adsorption characteristics of some aluminosilicate zeolites. Habgood measured isotherms for $\mathrm{N}_{2}, \mathrm{O}_{2}, \mathrm{C}_{2} \mathrm{H}_{6}$ and $\mathrm{C}_{2} \mathrm{H}_{4}$ adsorbed on $\mathrm{Ag}-\mathrm{X}$ zeolite and compared to those same gas isotherms measured on alkali and alkaline earth cation exchanged $\mathrm{X}$ zeolite. ${ }^{4}$ The author points out that the alkali and alkaline earth cations are all of a stable noble metal electronic configuration whereas the d orbitals of the silver ion give it much more intense directional properties. The author concluded that the silver ion has a much stronger polarizing power than the sodium ion which is of the same total charge and very similar in size. Huang measured adsorption of $\mathrm{CO}, \mathrm{N}_{2}, \mathrm{O}_{2}, \mathrm{CO}_{2}$ and $\mathrm{C}_{2} \mathrm{H}_{4}$ on $\mathrm{Ag}-\mathrm{X}$ and $\mathrm{Ag}-\mathrm{Y}$ zeolites. ${ }^{5}$

Yang et al. reported the synthesis of a mixed Li/Ag ion-exchanged X-type zeolite $\left(\mathrm{Si} / \mathrm{Al}=1.25\right.$ with approximately $17 \mathrm{Ag}^{+}$per unit cell $)$, and discussed its possible superior properties for air separation. ${ }^{6}$ This sorbent utilized the very strong adsorptive properties of the $\mathrm{Ag}^{+}$ion which provided for increased capacity over that of the $\mathrm{Li}-\mathrm{X}$ while maintaining some degree of the advantageous isotherm linearity that is seen with Li-X. Noting the high isosteric heat of adsorption for $\mathrm{N}_{2}$ on $\mathrm{Ag}-\mathrm{X}$ zeolites combined with a relatively slow desorption of $\mathrm{N}_{2}$ on the same, the author proposed some degree of 
weak $\pi$-complexation. The $\pi$-complexation character of the interaction was subsequently confirmed by ab inito molecular orbital calculations using $\mathrm{N}_{2}$ and an $\mathrm{Ag}-\mathrm{X}$ cluster model and was referred to as "weak chemisorption-assisted adsorption". ${ }^{7}$ Hutson et al. have recently reported the synthesis of mixed Li/Ag X-type zeolite in which the addition of very small amounts of $\mathrm{Ag}$ and the proper dehydration conditions resulted in enhanced adsorptive characteristics and increased energetic heterogeneity as compared to those of the near fully exchanged $\mathrm{Li}^{+}$-zeolites. ${ }^{8}$ The performance for air separation by the best of these sorbents, containing, on average, only one Ag per unit cell, was compared to that of the near fully $\mathrm{Li}^{+}$-exchanged zeolite using a standard PSA cycle by numerical simulation. The results showed that the new sorbent provides a significantly higher $(>10 \%)$ product throughput, at the same product purity and recovery, when compared to that of the near fully $\mathrm{Li}^{+}$-exchanged zeolite.

Numerous attempts have been made to reduce transition metal ions in zeolites for the purpose of forming highly dispersed metallic clusters for use as catalysts. These attempts have typically been completed via treatment at elevated temperatures and/or in reducing atmospheres (e.g., sodium vapor, hydrogen gas, carbon monoxide gas). However, color changes upon vacuum dehydration of silver-exchanged A-type zeolites were found to be related to the formation of metallic clusters within the sodalite cage or the 6-prism of the zeolite..$^{9,10,11}$ Using volumetric sorption techniques and temperature programmed desorption, Jacobs et al. were able to relate these color changes to an autoreductive process involving framework oxygen. ${ }^{11}$ Autoreduction is the reduction of the transition metal ion and the oxidation of water or lattice oxygen; this has been observed 
for both $\mathrm{Ag}^{+}$and $\mathrm{Cu}^{2+}$ ions in zeolites $\mathrm{A}, \mathrm{X}$ and $\mathrm{Y}$, and has been shown to take place by two mechanism in two clearly defined temperature regions: ${ }^{11,12}$

(i) autoreduction in the presence of zeolite water $(25-250$ C)

$$
2\left(\mathrm{Ag}^{+}-\mathrm{Z}-\mathrm{O}^{-}\right)+\mathrm{H}_{2} \mathrm{O}---->2 \mathrm{Ag}^{0}+(1 / 2) \mathrm{O}_{2}+2 \mathrm{Z}-\mathrm{OH}
$$

and

(ii) autoreduction by oxygen from the zeolite lattice $(127-380$ C $)$

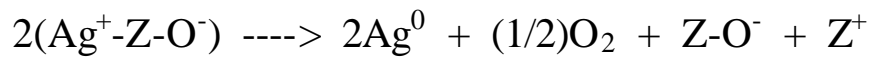

Kim and Seff proposed the formation of octahedral hexasilver metal clusters stabilized by coordination to six silver ions $\left(\left(\mathrm{Ag}^{+}\right)_{6}(\mathrm{Ag})^{6}\right)$ from structural determinations of a dehydrated silver-exchanged zeolite A. ${ }^{9,10}$ However, Jacobs et al. suggested that the formation of such large metal clusters is improbable since color changes are seen even at low temperatures and low silver loadings where extensive migration of neutral silver atoms and subsequent sintering into $\mathrm{Ag}_{6}$ metal clusters is highly unlikely. ${ }^{9,10}$ Alternatively, Jacobs et al. suggested, based on structural studies of Ag-A zeolites, the formation of linear $\left(\mathrm{Ag}_{3}\right)^{2+}$ charged clusters $\left(\mathrm{Ag}^{+}-\mathrm{Ag}^{0}-\mathrm{Ag}^{+}\right)$upon thermal dehydration of the zeolite. ${ }^{11}$

Gellens et al. followed color changes and concomitant silver cluster formation in A, X, and Y zeolites using X-ray diffraction (XRD) techniques. ${ }^{13,14,15}$ They found that the number of clusters increases with framework Al content. It was also noted that in synthetic analogs of the faujasite zeolite (types $\mathrm{X}$ and $\mathrm{Y}$ ), the dehydrated zeolites displayed a yellow color which increased in intensity with the number of clusters, while silver-exchanged A zeolites took a yellow color with dehydration at low temperatures, eventually becoming brick red after treatment at higher temperatures. Further 
information can be found in a comprehensive review of silver clusters and chemistry in zeolites by Sun and Seff. ${ }^{16}$

The location of the extraframework silver in relation to the aluminosilicate framework is of primary importance for elucidating the effect of silver clustering on the adsorptive characteristics of the zeolite. This is not a trivial endeavor. Numerous studies have been undertaken to identify the location of $\mathrm{Ag}^{+}$ions and $\mathrm{Ag}$-clusters in argentiferous zeolites. These have mostly been for Ag-A and have included X-ray diffraction methods ${ }^{9,10,13,14}$ and far-infrared spectroscopy. ${ }^{12,17}$ It was found that, for dehydrated, fully $\mathrm{Ag}^{+}$-exchanged faujasite-type zeolites, the silver molecules were distributed among the six-ring sites (SI, SI', and SII for faujasites) and, for samples with high $\mathrm{Al}$ content, in the SIII locations. Gellens et al. ${ }^{14}$ and Baker et al. ${ }^{12}$ showed the simultaneous occupancy of sites SI and $\mathrm{SI}^{\prime}$ by linear $\left(\mathrm{Ag}^{+}-\mathrm{Ag}^{0}-\mathrm{Ag}^{+}\right)$clusters.

In this work we have synthesized $\mathrm{Ag}^{+}$ion-exchanged zeolites and treated these materials in ways which promote the formation of intra-crystalline silver clusters. Silver cations and clusters were quantitatively located using Rietveld refinement of neutron powder diffraction data. We have then evaluated the resulting nitrogen adsorptive characteristics of these materials and related adsorptive capacity to the cation/cluster locations within each zeolite.

\section{Experimental Details}

Materials. The zeolites used in this work, LSX zeolite $(\mathrm{Si} / \mathrm{Al}=1.0$, Praxair, No. 16193-42), $\mathrm{X}$ zeolite $(\mathrm{Si} / \mathrm{Al}=1.25$, Linde, Lot 945084060002) and Y zeolite (Strem, Lot 128671-S), were obtained from commercial sources as binderless, hydrated powders and 
were used as is. Silver nitrate $\left(\mathrm{AgNO}_{3}, 99.9 \%\right.$, Strem) was used in the preparation of ionexchange solutions. Deionized water was used for the preparation of all ion-exchange solutions and for sample washing. Helium (99.995\%) and nitrogen (99.998\%) were obtained from Cryogenic Gases and were used for isotherm adsorption measurements without further purification.

Synthesis of Ag-exchanged Faujasites. The silver zeolites were prepared using standard ion-exchange methods. A zeolite sample was exchanged by contacting the material two times with a $0.5 \mathrm{M}$ aqueous $\mathrm{AgNO}_{3}$ solution. Each silver solution contained a cation content which was in two-fold excess of what was required to achieve $100 \%$ exchange. The ion-exchange solution was heated to a mild boil with constant agitation and immediately allowed to cool and settle. After the first ion-exchange, the solution was decanted, fresh solution was added, and the mixture was reheated. After the second ionexchange, the material was vacuum filtered and washed with copious amounts of water until no precipitate was seen upon treatment with free chloride. The silver exchanged samples were dried at room temperature and atmospheric conditions in a dark area. The resulting materials were dehydrated prior to analysis, as described below.

Sample Dehydration. Zeolites have a strong affinity for water; and some molecules are tenaciously held. The presence of adventitious water will affect both the cation coordination in the zeolites, as determined through powder diffraction analysis, and the adsorption of guest molecules, as measured by adsorption isotherms. Furthermore, dehydration conditions strongly influence the formation of silver clusters. To separate these effects, the atmosphere, temperature and length of time of dehydration were rigorously controlled. 
Temperature. Samples of $\mathrm{Ag}-\mathrm{Y}, \mathrm{Ag}-\mathrm{X}$, and $\mathrm{Ag}-\mathrm{LSX}$ were dehydrated under vacuum at temperatures ranging from $100{ }^{\circ} \mathrm{C}$ to $600{ }^{\circ} \mathrm{C}$ at times ranging from 1 hour to 24 hours. The samples were heated at approximately $20^{\circ} \mathrm{C} / \mathrm{min}$ to "hold points" in $100 \mathrm{C}$ intervals, the samples were then held for approximately 30 minutes before being ramped up to the next hold point. When the sample was raised to the desired final dehydration temperature, it was soaked at that temperature for a specified amount of time, then allowed to cool to room temperature with no further applied heating. Throughout this paper, samples are referred to as $\mathrm{Ag}-\mathrm{M}-\mathrm{N}$, where $\mathrm{M}$ specifies the identity of the zeolite (X, Y, or LSX) and $\mathrm{N}$ denotes the dehydration temperature.

Time. In order to determine the effect of dehydration time on cluster formation and the resulting adsorptive characteristics of Ag-LSX, a sample was vacuum dehydrated at $450 \mathrm{C}$ for varying amounts of times, and the resulting $\mathrm{N}_{2}$ adsorption isotherms were measured.

Atmosphere. Atmospheric effects on dehydration of Ag-LSX by controlling both sample drying and dehydration. Samples were treated in the following ways: (1) dried in a dark area at room temperature, then dehydrated under vacuum for 4 hours at $450 \mathrm{C}$, (2) dried in a standard convection oven at $100 \mathrm{C}$ in air, then dehydrated under vacuum for 4 hours at $450 \mathrm{C}$, (3) heated slowly $\left(<10{ }^{\circ} \mathrm{C} / \mathrm{min}\right)$ in a furnace to $450 \mathrm{C}$ in air, then dehydrated under vacuum for 4 hours at $450 \mathrm{C}$.

Neutron Activation Analysis. Chemical analysis was performed by neutron activation analysis (NAA) at the research nuclear reactor of the Phoenix Memorial Laboratory at the University of Michigan. The samples were irradiated sequentially for one minute at a core-face location with an average thermal neutron flux of $2 \times 10^{12}$ 
$\mathrm{n} / \mathrm{cm}^{2} / \mathrm{s}$. Two separate gamma-ray spectra were collected for 500 seconds real time for each sample using a high resolution germanium detector. The collection after a 13 minute decay was used to determine the concentrations of aluminum and silver, while data collected after1 hour and 56 min decay were used to analyze for sodium and potassium. Four replicates of NBS-SRM-1633a (coal fly ash) and silver foil were used as standard reference materials and check standards.

Adsorption Isotherm Measurements. The adsorption isotherms were measured using a static volumetric system (Micromeritics ASAP-2010). Additions of the adsorbate gas were made at volumes required to achieve a targeted set of pressures. A minimum equilibrium interval of 5 seconds with a tolerance of $5 \%$ of the target pressure (or 5 torr, whichever is smaller) was used to determine equilibrium for each measurement point.

X-ray Photoelectron Spectroscopy. X-ray photoemission spectra were obtained from thin wafers of the zeolites using a Perkin-Elmer PHI 5400 ESCA system with a Mg anode. A lack of surface charging was verified by measuring the binding energy of adventitious carbon. The generally accepted reference for the binding energy of $\mathrm{C} 1 \mathrm{~s}$ photoelectrons is $285 \pm 0.2 \mathrm{eV}^{18}$

Samples of fully exchanged Ag-LSX zeolite which was (1) fully hydrated, (2) heated in a vacuum at $200 \mathrm{C}$, and (3) heated in a vacuum at $450 \mathrm{C}$ were formed into very thin wafers using a laboratory press. The wafers were then degassed in the XPS staging cell at $10^{-8}-10^{-9}$ torr for two days at room temperature prior to analysis.

Powder Neutron Diffraction Data Collection. Powder neutron diffraction data were collected for Ag-Y-450, Ag-X-450, Ag-LSX-350, and Ag-LSX-450. Each of the samples was initially dehydrated under vacuum for 12 hours, as described in the sample 
dehydration protocol. The samples were exposed to atmospheric conditions during transport to the NIST Center for Neutron Research. In preparation for the diffraction experiment, roughly $10-15 \mathrm{~g}$ of each sample was dehydrated under vacuum $\left(<10^{-5}\right.$ torr $)$. Each sample was heated to the temperature which was used in the prior heat treatment. Samples were heated at a rate of approximately $10 \% \mathrm{~min}$, held at constant temperature for a minimum of 4 hours, then were allowed to cool to room temperature. The samples were transferred to $50 \mathrm{~mm}$ long and $15.6 \mathrm{~mm}$ wide vanadium cans and subsequently sealed in a helium environment with low water and oxygen levels $(<10 \mathrm{ppm})$. Neutron diffraction data were collected using the 32 detector BT-1 neutron powder diffractometer at the NIST Center for Neutron Research NBSR reactor. Measurements were made using a $\operatorname{Ge}(311)$ monochromator with $\lambda=2.0783(2) \AA\left(1 \AA=10^{-10} \mathrm{~m}\right)$ at ambient temperature. Data were collected over the range of $1.3-166.3^{\circ} 2 \theta$ with a step size of $0.05^{\circ}$. The data collection time for each sample was approximately 8 hours. The BT-1 instrument is described at the NCNR WWW site (http://www.ncnr.nist.gov/).

\section{Results and Discussion}

Chemical Analysis. The unit cell compositions for each of the materials studied are listed in Table 1. Each zeolite analyzed has a silver content in excess of the expected value based upon aluminum analysis. This is mostly likely due to the presence of silver metal particles present on the outside surface of the zeolite crystallites. This phenomena has been seen previously in other $\mathrm{Ag}^{+}$-exchanged members of the faujasite family. ${ }^{14}$

Effect of Sample Preparation on Nitrogen Adsorption. Dehydration conditions, particularly the atmosphere, duration, and dehydration temperature used, 
strongly influence the formation of the silver clusters. ${ }^{9,10,13.14}$ The effect of the dehydration conditions on extraframework silver can be assessed by looking at the effects of dehydration treatment on sample color and nitrogen adsorption.

Temperature effects. Color changes upon vacuum dehydration of silverexchanged A-type zeolite were found to be related to the formation of metallic clusters within the sodalite cage or the 6-prism of the zeolite..$^{9,10,11}$ These color changes are also evident in X-type zeolite. A summary of some dehydration conditions and the resulting color changes in the zeolites of interest in this study are given in Table 2. The Ag-X and Ag-LSX behaved very similarly, both becoming deep golden yellow with thermal vacuum dehydration. Gellens et al. observed that the yellow color occurred in Ag-A when, on average, only one cluster per sodalite cage was formed. ${ }^{13,14}$ The Ag-X and AgLSX zeolites maintain the yellow color because there is no interaction between silver clusters. These authors also noted that more Ag present in the faujasite-type zeolite resulted in brighter color upon thermal vacuum dehydration.

Effects of dehydration temperature. In order to determine the effect of temperature on silver cluster formation and the subsequent adsorptive characteristics, samples of the air-dried Ag-LSX zeolite were heated to various temperatures in a vacuum. The $\mathrm{N}_{2}$ adsorption isotherm was then measured for each of the heat-treated materials. The results are shown in Figure 2. In this plot the Ag-LSX sample shows a considerable increase in $\mathrm{N}_{2}$ capacity after dehydration at $450 \mathrm{C}$ over that of the same sample dehydrated at $350 \mathrm{C}$ (at 1 atm, 22 molecules of $\mathrm{N}_{2}$ and 19 molecules of $\mathrm{N}_{2}$ per unit cell respectively). This increase cannot be attributed to a loss of water since all but the most tenaciously held water is removed by $350 \mathrm{C}^{2}$; and there is no increase in the $\mathrm{N}_{2}$ 
capacity for other zeolite forms $\left(\mathrm{Li}^{+}, \mathrm{Na}^{+}, \mathrm{K}^{+}\right.$, etc. $)$with dehydration at temperatures beyond 350 C. Ag-LSX zeolites which had been dehydrated in vacuum at $550 \mathrm{C}$ and $600 \mathrm{C}$ had $\mathrm{N}_{2}$ capacities which were considerably lower than those dehydrated in vacuum at $450-500$ C. Similarly, $\mathrm{N}_{2}$ adsorption isotherms were measured for the $\mathrm{Ag}-\mathrm{X}$ zeolites after thermal vacuum dehydration at $350 \mathrm{C}$ and $450 \mathrm{C}$. This sample did not show the same increase in $\mathrm{N}_{2}$ adsorption capacity with the higher temperature dehydration (at 1 atm both samples adsorbed approximately 15.5 molecules of $\mathrm{N}_{2}$ per unit cell).

Effects of duration of dehydration. Migration of silver ions, most likely to or from the sodalite cage and hexagonal prism, and possibly from one unit cell to another, is necessary to form the charged metallic clusters. Using a theoretical model of diffusion into a sphere, Cvjeticanin and Petranovic showed that the diffusion of $\mathrm{Ag}+$ is the rate determining step in silver cluster formation.19 In order to determine the effect of dehydration time on cluster formation, and the resulting adsorptive characteristics, the Ag-LSX sample was vacuum dehydrated at $450 \quad \mathrm{C}$ at various times; and the resulting N2 adsorption isotherms were measured. These are shown in Figure 3. From these results one can see that the N2 adsorption capacity increased sharply between 2 and 3 hours of dehydration and finally peaked at about 4 hours. No further enhancement of the adsorption capacity was seen after the peak at 4 hours. The initial sharp increase in the adsorptive capacity was due to loss of water in the zeolite. It also appears that the silver clusters, which presumably are responsible for the enhanced adsorptive capacity of the $450 \mathrm{C}$ dehydrated sample, are formed within the first 4 hours of dehydration. Because of this, all subsequent samples were dehydrated for a minimum of 4 hours (but usually 
longer).

Effects of dehydration atmosphere. Because the formation of charged silver clusters is a reductive process, the presence of gaseous oxygen during the dehydration process is expected to hinder the autoreduction reaction. In order to evaluate this, samples of the Ag-LSX zeolites were dehydrated in the following ways: (1) allowed to dry in a dark area at room temperature $\left(\begin{array}{ll}25 & \mathrm{C}\end{array}\right)$ before vacuum dehydration at $450 \mathrm{C}$, (2) dried in a standard convection oven at $100 \mathrm{C}$ in air before being vacuum dehydration at $450 \mathrm{C}$, (3) heated slowly in air in a furnace to $450 \mathrm{C}$ before being heated in a vacuum to $450 \mathrm{C}$. The isotherms for adsorption of $\mathrm{N} 2$ on each of the resulting materials is shown in Figure 4. One can see that any heating in air results in a reduction in the ultimate adsorptive capacity of the Ag-zeolite; and heating to a high temperature (i.e., to $450 \mathrm{C}$ ) in air resulted in a considerable reduction in the ultimate adsorptive capacity as compared to that of the material which was dried at room temperature and dehydrated entirely in a vacuum. Samples of the $\mathrm{Ag}-\mathrm{X}$ zeolite were also dehydrated using methods (1) and (2) as described above and are shown in Figure 5. Contrary to the Ag-LSX results, there was little difference in the adsorptive capacity of these samples (both adsorbed approximately 15.5 molecules of $\mathrm{N} 2$ per unit cell at $1 \mathrm{~atm})$.

XPS Analysis. X-ray photoemission spectroscopy (XPS or ESCA) is a surface analysis tool which is commonly used because of its ability to identify chemical states of atoms based on shifts of core-level binding energies. While most studies of silver systems indicate an anomalous negative shift in binding energy (BE) of the $\mathrm{Ag} 3 \mathrm{~d}$ peaks as the oxidation state is increased, other studies show no BE shift with increasing oxidation state.20 Even in cases where there has been a reported binding energy shift, 
shifts tend to be small $(0.1-0.8 \mathrm{eV})$ which further complicates the interpretation of the spectra.

The Ag 3d peaks obtained from the Ag-LSX zeolite samples are shown in Figure 6. The observed Ag 3d binding energies for the silver zeolites and some other silver compounds are listed in Table 3. As a hydrated Ag-LSX sample is taken from room temperature to $450 \mathrm{C}$, there is an observable negative shift in the binding energy as referenced to the Fermi level. This shift is suggestive of some reduction of the silver cations in the zeolite. While this shift is an indication of silver reduction in the sample, the source of the silver could be either extraframework charge compensating cations or the excess surface silver that has been postulated for these materials. Nevertheless, the results indicate that there is reduction of some of the silver present in the Ag-LSX sample upon vacuum dehydration.

Structural Characterization of Ag-exchanged Faujasites. Neutron powder diffraction data were analyzed using the Rietveld technique in conjunction with the GSAS (Generalized Structure Analysis System) suite of Larson and Von Dreele. 21,22 To determine the best expected fit to the data, the LeBail intensity extraction method was first used, in effect simulating a fit with an idealized crystallographic model.23 Background was fit using a Chebychev polynomial with a variable number of terms (between 8-12). Lattice constants and zero point shifts were then introduced and optimized. The peak asymmetry at low angles was treated using the model of Finger et al. and asymmetric peak broadening was treated using the model of Stephens.24,25 Scattering factors and lengths were set to standard values for neutral atoms, as supplied in the GSAS package. 
Initial fractional atomic coordinates for the framework constituents in space groups were based upon the model determined by Lobo et al. for Li-LSX.26 The distribution of aluminum and silicon on the $\mathrm{T}$ sites was based on the assumption that $\mathrm{T}(1)$ is a pure $\mathrm{Si}$ site and $\mathrm{T}(2)$ has both $\mathrm{Al}$ and $\mathrm{Si}$ fixed in accordance with the chemical analysis. The $\mathrm{T}(2)$ site was modeled using both aluminum and silicon with their fractional occupancies fixed in accordance with chemical analysis to account for the difference in scattering between aluminum and silicon. Throughout the refinement, the positions and thermal parameters of aluminum and silicon on $\mathrm{T}(2)$ were constrained to be identical. Interatomic distances were used to supplement the observed data, with Si-O distances set to the sum of their ionic radii and $\mathrm{T}(2)-\mathrm{O}$ distances set to the weighted average, based upon chemical analysis, of the sum of the Al-O and $\mathrm{Si}-\mathrm{O}$ atomic radii.27 The isotropic atomic displacement parameters were grouped, using one value for framework $\mathrm{T}$ atoms, a second value for framework $\mathrm{O}$ atoms, and a third for extraframework $\mathrm{Ag}+$. Details concerning the location of extraframework cations for each material and the final stages of refinement are given in the following sections. The results of the Rietveld refinement are given in Tables 4-7. The results of the Rietveld refinements are summarized in Table 4. Positional coordinates, occupancies, and atomic displacement parameters for each sample are listed in Table 5. Selected bond lengths $(\AA)$ and angles (degrees) are given in Table 6 and Table 7. A comparison of the cation site occupancies determined in this study and a previous determination of the structure of Ag-faujasites is given in Table 8 .

Ag-Y-450. The agreement of the experimental and the refined model are good $(\mathrm{Rf} 2=0.0458,2=1.772)$. All silver atoms were located in this sample. The silver was 
located entirely in the six-ring sites SI, SI(, and SII with an additional small occupancy at SII. No silver was located in the supercage SIII locations.

The material never took the characteristic golden yellow color associated with silver clusters and the interatomic distance for the SI-SI' sites is too low, at $2.43 \AA$, for simultaneous occupancy. Likewise, the SII-SII' interatomic distance, at $2.77 \AA$, is short, and the simultaneous occupancy necessary for cluster formation is unlikely. The $\operatorname{Ag}\left(\mathrm{I}^{\prime}\right)-$ $\mathrm{Ag}\left(\mathrm{II}^{\prime}\right)$ interatomic distance, however, at $2.98 \AA$ is near that of the linear clusters reported by Gellens et al. thus there may be some interaction in the form of a diatomic $\left(\mathrm{Ag}_{2}\right)$ cluster at the $\mathrm{SI}^{\prime}-\mathrm{SII}^{\prime}$ location. ${ }^{14}$ If this is the case, it would seem that, because of the short distance, there is reduction to silver metal such that the cluster is $\left(\mathrm{Ag}_{2}\right)^{+}$(i.e., $\mathrm{Ag}^{0}$ $\left.\mathrm{Ag}^{+}\right)$. The $\mathrm{Ag}\left(\mathrm{I}^{\prime}\right)-\mathrm{O} 3$ interatomic distance, $2.28 \AA$, is consistent with 3-coordination when compared to reference values of 2.17 and $2.52 \AA$ for $\mathrm{Ag}^{+}$in 2- and 4coordination. ${ }^{15,27}$ The $\mathrm{Ag}(\mathrm{II})-\mathrm{O} 2$ distance, at $2.42 \AA$, is slightly higher than expected but easily within reason for $\mathrm{Ag}^{+}$in 3-coordination.

When compared with the previous results of Gellens et al., as shown in Table 8, the occupancies are quite similar with Gellens reporting a higher population at SI (12.8/uc versus 9.9/uc reported here). ${ }^{14}$ However, we have located considerably more Ag in SII (27.2/uc reported here versus 19.5/uc by Gellens).

$A g-X-450$. For reasons unknown, this data proved to be the most challenging to refine. Nevertheless, as with the Ag-Y sample, the agreement of the experimental and the refined model are good $\left(\mathrm{R}_{\mathrm{f}}^{2}=0.0589, \chi^{2}=2.132\right)$. An excess $(107 \%)$ of the expected silver atoms were located in this sample. All efforts to reduce this amount were unsuccessful; so these results are reported. Silver was primarily found in the six-ring 
sites SI, SI', SII, and SII' with an approximately 17.5 silver atoms located in supercage SIII locations. As mentioned earlier, the population at $\mathrm{SI}^{\prime}$ were split into two sites, referred to as $\mathrm{SI}^{\prime}$ and $\mathrm{SI}^{*}$; and the silver in site $\mathrm{II}^{\prime}$ was found in two sites, referred to as $\mathrm{SII}^{\prime}$ and $\mathrm{SII}^{*}$. The interatomic distances between $\operatorname{Ag}(\mathrm{I})$ and $\operatorname{Ag}\left(\mathrm{I}^{\prime}\right)$ and $\operatorname{Ag}\left(\mathrm{I}^{*}\right)$ are too short (at $1.30 \AA$ and $2.23 \AA$ A respectively) to occur simultaneously. Contrary to previously reported results, no cations were found at SI' positions which would allow SI'-SI-SI' triatomic clusters. However, there are silvers clusters are present since the material, upon vacuum heating, turned the characteristic golden yellow color associated with charged silver clusters. The $\operatorname{Ag}\left(\mathrm{I}^{\prime}\right)-\operatorname{Ag}\left(\mathrm{II}^{\prime}\right)$ distance, at $3.17 \AA$, is consistent with that expected for clusters. ${ }^{14}$ However, if there are clusters at these positions, then it would seem unlikely that they also exist at the same locations in the Ag-Y zeolite, since the Ag-Y sample did not turn yellow with vacuum dehydration. The $\operatorname{Ag}\left(\mathrm{I}^{\prime}\right)-\mathrm{O} 3, \mathrm{Ag}(\mathrm{II})-\mathrm{O} 2$, and $\mathrm{Ag}\left(\mathrm{II}^{\prime *}\right)-\mathrm{O} 2$ interatomic distances, at $2.29 \AA, 2.30 \AA$ and $2.29 \AA$ respectively, are all consistent with $\mathrm{Ag}^{+}$in 3-coordination.

When compared with the previous results, as shown in Table 8, the occupancies are somewhat similar to those reported by Gellens. ${ }^{14}$ Contrary to that predicted from previous studies, there is a small population of $\mathrm{Ag}$ at SI (only 3.1 of a possible 16 per unit cell). However, there is a excess population in the site I locations. The $32.5 / \mathrm{uc}$ at the site $\mathrm{I}^{\prime}$ locations ( $\mathrm{SI}^{\prime}$ and $\mathrm{SI}^{\prime *}$ ) and the 3.1/uc at SI exceeds the allowable amount for these sites. This may be the result of tenaciously held water molecules at the SI location. The explanation helps to explain the excess of $\mathrm{Ag}$ atoms found for the entire model. The population at SII was very similar to that for $\mathrm{Ag}-\mathrm{Y}$ indicating a strong preference for this site among the faujasite zeolites. The total population at sites II, $\mathrm{II}^{\prime}$ and $\mathrm{II}^{\prime *}$ exceeds that 
which is allowable without some simultaneous occupancy (which are not allowed due to the short interatomic distances).

$A g-L S X-350$ and $A g-L S X-450$. As with previous samples, the agreement of the experimental data and the refined model are good $\left(\mathrm{R}_{\mathrm{f}}^{2}=0.0818, \chi^{2}=1.631\right.$ for Ag-LSX350 and $\mathrm{R}_{\mathrm{q}}^{2}=0.0825, \chi^{2}=1.686$ for Ag-LSX-450) and nearly all silver atoms were located in both samples. The silver was primarily found in the six-ring sites with 17.2 silver atoms per unit cell were located in SIII locations for Ag-LSX-350 and approximately 19/uc were located for Ag-LSX-450. However, since more total cations were located for the Ag-LSX-450 sample (96.7 versus 92.9 for the Ag-LSX-350 sample), the occupancy of SIII for these zeolites are actually likely to be practically the same. As with the Ag-X sample, the site $\mathrm{I}^{\prime}$ population was split into the two sites $\mathrm{SI}^{\prime}$ and $\mathrm{SI}^{*}$ for both samples. Unlike previous samples, both of these sample also had a split population of cations in site II, in the distinct sites SII and SII*.

Both of these samples contain silver clusters, since, upon vacuum heating, both turned the characteristic deep golden yellow color associated with charged silver clusters in faujasite zeolites. The inter-atomic distance for the SI-SI' sites, at $3.14 \AA$ for both samples, is consistent with those reported ${ }^{14}$ for the linear $(\mathrm{Ag})_{3}$ clusters at $\mathrm{SI}^{\prime}-\mathrm{SI}^{-} \mathrm{SI}^{\prime}$. The short distance between $\operatorname{Ag}\left(\mathrm{I}^{\prime}\right)$ and $\operatorname{Ag}\left(\mathrm{I}^{*}\right)$, at approximately $0.83 \AA$, and the $\operatorname{Ag}(\mathrm{I})$ $\operatorname{Ag}\left(I^{\prime *}\right)$ distance of $2.30 \AA$ are too short to allow simultaneous occupancy of these sites. However, the $\operatorname{Ag}\left(\mathrm{I}^{*}\right)-\operatorname{Ag}\left(\mathrm{II}^{\prime}\right)$ interatomic distance of $3.10 \AA$ is consistent with previously reported $\mathrm{Ag}$ cluster distances and, while the distance between $\mathrm{Ag}(\mathrm{II})-\mathrm{Ag}(\mathrm{II})$, at $2.09 \AA$, is too short to allow simultaneous occupancy, the $\mathrm{Ag}\left(\mathrm{II}^{\prime}\right)-\mathrm{Ag}(\mathrm{II} *)$ distance, at $3.33 \AA$ for the Ag-LSX-450 and $3.53 \AA$ for the Ag-LSX-350 sample, is not. ${ }^{14}$ Therefore, it seems likely 
that there are triatomic linear clusters at the SI'-SI-SI' location (this has been reported previously ${ }^{14}$ ) and diatomic clusters at $\mathrm{SI}^{\prime *}{ }_{-} \mathrm{SII}^{\prime}$ (or possibly triatomic clusters at $\mathrm{SI}^{\prime *}-\mathrm{SII}^{\prime}-$ SII*). These two configurations are shown in Figure 7. The $\mathrm{Ag}\left(\mathrm{I}^{\prime}\right)-\mathrm{O} 3$ interatomic distances, $2.64 \AA$ for Ag-LSX-350 and $2.60 \AA$ for Ag-LSX-450, is long for $\mathrm{Ag}^{+}$in 3coordination and is probably due to repulsion from the $\mathrm{Ag}$ in the SI location. Likewise, the $\mathrm{Ag}\left(\mathrm{II}^{*}\right)-\mathrm{O} 2$ distances, $2.65 \AA$ for $\mathrm{Ag}$-LSX-350 and $2.60 \AA$ for Ag-LSX-450, are likely due to repulsion from the silver at the simultaneous occupied SII' site. Ag(II)-O2 and $\mathrm{Ag}\left(\mathrm{I}^{*}\right)-\mathrm{O} 3$ distances, at $2.19 \AA$ to $2.23 \AA$ are a bit low and are more consistent with $\mathrm{Ag}^{+}$in 2-coordination than in the expected 3-coordination. The $\mathrm{Ag}\left(\mathrm{I}^{*}\right)-\mathrm{O} 3$ may be low due to repulsion from silver in the SII' location.

While each of the samples seem to contain diatomic clusters at $\operatorname{Ag}\left(\mathrm{I}^{\prime *}\right)-\operatorname{Ag}\left(\mathrm{II}^{\prime}\right)$ (or at $\mathrm{Ag}\left(\mathrm{I}^{\prime}\right)-\mathrm{Ag}\left(\mathrm{II}^{\prime}\right)$ for $\left.\mathrm{Ag}-\mathrm{Y}\right)$, only the $\mathrm{Ag}-\mathrm{LSX}$ samples contained the expected triatomic cluster at the SI'-SI-SI' locations. Neither the Ag-Y nor the Ag-X sample contained silver in the SII* location; but both Ag-LSX samples contained silver at this site. The Ag-LSX-350 sample contained $6 \mathrm{Ag}$ in the SII* location while Ag-LSX-450 contained almost $9 \mathrm{Ag}$ in the SII* location. This may be an indication of some thermally induced migration of $\mathrm{Ag}$ from $\mathrm{SI}^{\prime *}$ to $\mathrm{SII}^{\prime}$ which in turn increases the population of $\mathrm{Ag}$ in $\mathrm{SII}^{*}$ (due to repulsion).

Migration of cations often occurs in zeolites when adsorbing water and during dehydration. Hydrated zeolites typically contain cations which are coordinated to both framework oxygen and zeolitic water molecules. This acts to maximize the coordination and thus to stabilize the position of the cation. ${ }^{28}$ Upon dehydration the coordination changes and the cations may migrate to different locations in order to obtain a more 
favorable energetic environment in a higher coordination. If the silver clusters are formed according to eqs. (1) and (2), then there is a loss of zeolitic framework oxygen with the reduction of $\mathrm{Ag}$. This, along with the creation of a Lewis acid site, can create an energetically unfavorable environment and promote the migration of the silver cluster to a site of higher coordination.

It is worth noting here that neutron powder diffraction spectra was also collected for an additional Ag-LSX sample which had been heat treated in an open air furnace at $450 \mathrm{C}$ for 12 hours (followed by vacuum dehydration before loading into the vanadium canister as described earlier). This sample showed very little diffraction indicating a break down of the zeolitic crystallinity. This explains the very low $\mathrm{N}_{2}$ adsorption observed for a material which had been prepared in and identical manner (the isotherm is shown in Figure 4).

Model for the Adsorption of Nitrogen by Ag-Exchanged Faujasites. There are several observations which can be made from the various $\mathrm{N}_{2}$ adsorption isotherms which were shown earlier in Figures 2, 4 and 5. Firstly, the adsorption of $\mathrm{N}_{2}$ on $\mathrm{Ag}-\mathrm{Y}$ is quite low. The Ag-Y zeolite contained no SIII cations; and no cations at the SII*; although it did contain a significant number of cations in SII (similar to that of the Ag-X and AgLSX samples). The Ag-X sample had a higher $\mathrm{N}_{2}$ adsorptive capacity than that of Ag-Y. The sample, however, did not show any increase in $\mathrm{N}_{2}$ adsorption with heat treatment at $450 \mathrm{C}$ over Ag-X which had been heat treated at $350 \mathrm{C}$; and the sample did not seem to be sensitive to heating in air. The $\mathrm{Ag}-\mathrm{X}$ sample had a population of supercage cations in the SIII and SII locations. However, there were no cations in the SII* position. The $\mathrm{N}_{2}$ adsorptive capacity for the Ag-LSX sample increased with vacuum dehydration at 
$450 \mathrm{C}$ over that dehydrated at $350 \mathrm{C}$. The material was also sensitive to heating in air with a reduced capacity when initially dried in air at $100 \mathrm{C}$ before being fully dehydrated in a vacuum. The material was especially sensitive to heating to dehydration temperatures (350 $\mathrm{C}$ and higher) in air. Both $\mathrm{Ag}$-LSX samples contained supercage cations in the SIII, SII, and SII* positions with the Ag-LSX-450 zeolite containing approximately 3 more SII* cations per unit cell than the Ag-LSX-350 sample.

The total energy of physical adsorption, $\phi_{\mathrm{T}}$, is the result of the adsorbateadsorbate interactions and adsorbate-zeolite interactions. ${ }^{29}$ The $\phi_{\mathrm{T}}$ is comprised of dispersive (D), repulsive (R), polarization (P), field-dipole (FD) interactions, fieldquadrupole interactions, and adsorbate-adsorbate energies and can be written as follows:

$$
\phi_{\mathrm{T}}=-\left(\phi_{\mathrm{D}}-\phi_{\mathrm{R}}\right)-\phi_{\mathrm{P}}-\phi_{\mathrm{FD}}-\phi_{\mathrm{FQ}}-\phi_{\mathrm{AA}}
$$

In this case, nitrogen does not have a permanent dipole and the coverages considered here are low; therefore, the field-dipole and adsorbate-adsorbate interactions can be ignored and eq. (3) can be reduced to:

$$
\phi_{\mathrm{T}}=-\left(\phi_{\mathrm{D}}-\phi_{\mathrm{R}}\right)-\phi_{\mathrm{P}}-\phi_{\mathrm{FQ}}
$$

Substituting the terms for various interactions, eq. (4) can be written as:

$$
\phi_{T}=-\frac{1}{4} Q \frac{\partial F}{\partial r}-\frac{1}{2} \frac{\alpha_{s}}{k} F^{2}-\sum \frac{A}{r^{6}}+\sum \frac{B}{r^{12}}
$$

where $\mathrm{Q}$ is the adsorbate quadrupole moment, $k$ is a constant (in SI units $k=9 \times 10^{9}$ ), $\mathbf{F}$ is the electric field, $r$ is the distance between the adsorbate and the zeolite surface site, and $\alpha_{\mathrm{s}}$ is polarizability of the adsorbate molecule. ${ }^{30}$ The values of A, the repulsion constant, and $\mathrm{B}$, the dispersion constant, may be calculated using a number of theoretical equations. $^{1,29}$ 
The discussion above does not include -complexation bonds between $\mathrm{Ag}^{+}$and $\mathrm{N}_{2}$. Based on ab initio molecular orbital calculation results using a cluster model for zeolite framework, $\mathrm{Ag}\left(\mathrm{AlO}_{4} \mathrm{H}_{4}\right)\left(\mathrm{SiO}_{4} \mathrm{H}_{4}\right)$, a weak -complexation bond between $\mathrm{N}_{2}$ and the Ag-zeolite was observed. ${ }^{7}$

The adsorbate-zeolite interactions correspond to those between the adsorbing gas and the surface oxygen and charge compensating cations. Since the alumina and silica groups are in a tetrahedral structure, the aluminum an silicon atoms of the zeolite framework are obscured by the oxygen atoms ${ }^{31}$ Interactions between the adsorbate and the silicon and aluminum atoms are shielded and are therefore neglected. ${ }^{1}$ In faujasite zeolites, the cations in the beta-cages and the double 6-ring (hexagonal prism) are sterically inaccessible to nitrogen; and so only the supercage (II, II*, and III) cations interact with the nitrogen gas. However, the electric field around these supercage cations are partially shielded by the surrounding oxygen atoms. Because of this shielding, the electrostatic and induction interactions are expected to be lower than that of an isolated ion. Further, the dispersion forces acting on the molecule will be higher since adsorbate molecules also interact with oxygen atoms of the zeolite. ${ }^{30}$

From this summary then it follows that silver cations in the SII* position will have a higher electrical field than those in the SII position. This higher electrical field and concomitant -complexation between $\mathrm{N}_{2}$ and $\mathrm{Ag}^{+}$act to increase the adsorption of $\mathrm{N}_{2}$ for those zeolites which contain the SII* cations. Actually, since the Ag-Y zeolite contains a large population (27.2/uc) of $\mathrm{Ag}$ in the SII and a relatively small $\mathrm{N}_{2}$ adsorptive capacity (approximately $5 \mathrm{~N}_{2}$ molec/uc at 1 atm, $25 \mathrm{C}$ ), the SII cations have little influence on the adsorptive capacity of the faujasite zeolites because of high shielding 
from the surrounding oxygen in the 6-ring. The $\mathrm{Ag}-\mathrm{X}$ zeolite contains supercage $\mathrm{Ag}$ in the relatively lower shielded 4-ring SIII locations. These cations are responsible for the bulk of the adsorptive capacity of this zeolite. Since no SII cations move to the SII* positions upon heating, there is no corresponding increase in the adsorptive capacity with heating from $350 \mathrm{C}$ to $450 \mathrm{C}$.

The Ag-LSX-450 sample had a higher $\mathrm{N}_{2}$ adsorptive capacity than the Ag-LSX-350 sample. The the $\mathrm{N}_{2}$ adsorption capacity is a result of an increase in the number of SII* cations. This increase in $\mathrm{SII}^{*}$ cations is a result of thermally induced silver migration from $\mathrm{SI}^{*}$ to $\mathrm{SII}^{\prime}$ which, as a result of repulsion, forces migration of $\mathrm{Ag}$ in the SII position upward into the supercage in the SII* location.

The presence of three types of supercage cations (at the SII, SII*, and SIII sites) results in an adsc rest of the intra-crystalline volume. This may be due to a mixed intra-crystalline cation population or to high energy cations positioned in sites with low shielding.

The presence of energetic heterogeneity of a system can be determined by plotting the isosteric heat of adsorption versus the amount adsorbed. Energetic heterogeneity of the system will result in a decrease in the isosteric heat of adsorption as the amount adsorbed increases. For small uptakes, the isosteric heat may decrease rather strongly with the amount adsorbed. At intermediate uptakes, the slope of this plot will usually decrease and become nearly horizontal.

The measurement of adsorption isotherms at different temperatures permits the calculation of the heat of adsorption as a function of surface coverage. The isosteric heat of adsorption can be calculated from a series of isotherms by application of the ClausiusClaperyron equation as follows: 


$$
\Delta H_{a d s}=R\left(\frac{d \ln P}{d(1 / T)}\right)_{n}
$$

Using the data from adsorption isotherms measured at $50 \mathrm{C}, 25 \mathrm{C}$, and $0 \mathrm{C}$, the isosteric heats of adsorption for $\mathrm{N}_{2}$ on Ag-LSX (which had been vacuum dehydrated at $450 \mathrm{C})$ and $\mathrm{Li}-\mathrm{LSX}\left(\mathrm{Li}^{+}\right.$ion-exchanged LSX zeolite) were determined by evaluating the slope of a plot of $\ln (\mathrm{P})$ versus $(1 / \mathrm{T})$ at several coverages and are shown in Figure 8. This plot shows that for $\mathrm{N}_{2}$ on Ag-LSX-450 there is a high initial heat of adsorption which initially drops quickly the gradually to become nearly horizontal at high adsorbate coverage. This energetic heterogeneity indicates the presence of local intra-crystalline positions where the adsorbate is preferentially adsorbed more exothermally than in the rest of the intra-crystalline volume. For comparison, the heat of adsorption for $\mathrm{N}_{2}$ on $\mathrm{Li}$ LSX was also included. This is a very energetically homogeneous adsorptive surface with $\mathrm{Li}$ in SII having no interaction with the $\mathrm{N}_{2}$ gas. Only Li in the SIII interact with the $\mathrm{N}_{2} \cdot{ }^{8,31}$

\section{References}

(1) Barrer, R. M., Zeolites and Clay Minerals as Sorbents and Molecular Sieves, Academic Press: London, 1978.

(2) Breck, D. W., Zeolite Molecular Sieves, R. E. Krieger Publishing: Malabar, FL, 1984.

(3) Kuhl, G.H. Zeolites. 1987, 7, 451.

(4) Habgood, H. W. Can. J. Chem. 1964, 42, 2340.

(5) Huang, Y. J. Catalysis 1974, 32, 482. 
(6) Yang, R.T.; Chen, Y. D.; Peck, J. D.; Chen, N. Ind. Eng. Chem. Res. 1996, 35, 3093.

(7) Chen, N.; Yang, R. T. Ind. Eng. Chem. Res. 1996, 35, 4020.

(8) Hutson, N. D.; Rege, R. U.; Yang, R. T. AIChE J. 1999, 45, 724.

(9) Kim, Y.; Seff, K. J. Am. Chem. Soc. 1978, 100, 175.

(10) Kim, Y.; Seff. K. J. Am. Chem. Soc. 1978, 100, 6989.

(11) Jacobs, P. A.; Uytterhoeven, J. B.; Beyer, H. K. J. Chem. Soc. Faraday Trans.1979, $75,56$.

(12) Baker, M. D.; Ozin, G. A.; Godber, J. J. Phys, Chem. 1985, 89, 305.

(13) Gellens, L. R.; Mortier, W. J.; Schoonheydt, R. A.; Uytterhoeven, J. B. J. Phys. Chem. 1981, 85, 2783.

(14) Gellens, L. R.; Mortier, W. J.; Uytterhoeven Zeolites 1981, 1, 11.

(15) Gellens, L. R.; Smith, J. V.; Pluth, J. J. J. Am. Chem. Soc. 1983, 105, 51.

(16) Sun, T; Seff, K. Chem. Rev. 1994, 94, 857.

(17) Ozin, G. A.; Baker, M. D.; Godber, J. J. Phys. Chem. 1984, 88, 4902.

(18) Briggs, B; Shea, M. P., Practical Surface Analysis. Volume 1. Auger and X-ray Photoemission Spectroscopy, John Wiley and Sons, New York, 1990, p. 543.

(19) Cvjeticanin, N. D.; Petranovic, N. A., Zeolites 1994, 14, 35.

(20) Wolan, J. T.; Hoflund, G. B.Appl. Surf. Sci. 1998, 125, 251.

(21) Rietveld, H. M. Acta Crystallogr. 1967, 22, 151.

(22) Larson, A. C; van Dreele, R. B.GSAS: General Structure Analysis System Manual; Los Alamos National Laboratory: Los Alamos, NM, 1986.

(23) Le Bail, A.; Duroy, H.; Fourquet, J. L Mater. Res. Bull. 1988, 23, 447.

(24) Finger, L. W.; Cox, D. E.; Jephcoat, A. P. J. Appl. Crystallogr. 1994, 27, 892.

(25) Stephens, P. W. J. Appl. Crystallogr. 1999, 32, 281.

(26) Feuerstein, M.; Lobo, R. F.; Chem. Mater. 1998, 10, 2197. 
(27) Shannon, R. D.; Prewitt, C. T. Acta Crystallogr 1969, B25, 925.

(28) Norby, P.; Poshni, F. I.; Gualtieri, A. F.; Hanson, J. C.; Grey, C. P. J. Phys. Chem. B 1998, 102, 839.

(29) Razmuz, D. M.; Hall, C. K. AIChE. J. 1991, 37, 769.

(30) Jasra, R. V.; Choudary, N. V.; Bhat, S. G. T. Ind. Eng. Chem. Res. 1996, 35, 4221.

(31) Coe, C. G. In Access in Nanoporous Materials, Pinnavaia, T.J.Thorpe, M.F., Eds., Plenum Press: New York, 1995, p. 213.

(32) Wagner, C. D.; Riggs, W. M.; Davis, L. E.; Moulder, J. F.; Mullenberg, G. E., Eds. Handbook of X-ray Photoelectron Spectroscopy, Perkin-Elmer Corporation, 1979.

(33) Gaarenstroom, S. W.; Winograd, N. J. Chem. Phys. 1977, 67, 3500. 
Table 1. Unit Cell Composition (in atoms/unit cell) for Each Ag-Faujasite Sample

$\begin{array}{lrrr}\text { Comp } & \begin{array}{l}\text { Ag-LSX } \\ \text { atm/uc }\end{array} & \begin{array}{l}\text { Ag-X } \\ \text { atm/uc }\end{array} & \begin{array}{r}\text { Ag-Y } \\ \text { atm/uc }\end{array} \\ \mathrm{Al} & 96.0 & 86.0 & 56.0 \\ \mathrm{Ag} & 112.5 & 98.2 & 59.6 \\ \mathrm{Na} & 0.2 & 0.4 & 2.4 \\ \mathrm{Si} & 96.0 & 106.0 & 136.0 \\ \mathrm{O} & 384.0 & 384.0 & 384.0\end{array}$

Table 2. Heat Treatment Conditions and Resulting Color Changes for Ag-Zeolites

\begin{tabular}{|c|c|c|}
\hline Zeolite & Heat Treatment & Color Change \\
\hline \multirow[t]{3}{*}{$\mathrm{Ag}-\mathrm{Y}$} & initial & white \\
\hline & $200 \mathrm{C}$ in vac, $4 \mathrm{hrs}$ & slightly gray \\
\hline & $450 \mathrm{C}$ in vac, $4 \mathrm{hrs}$ & dark gray \\
\hline \multirow[t]{6}{*}{$\mathrm{Ag}-\mathrm{X}$} & initial & gray \\
\hline & $160 \mathrm{C}$ in vac, $1 \mathrm{hr}$ & gray tan \\
\hline & $250 \mathrm{C}$ in vac, $1 \mathrm{hr}$ & pale yellow \\
\hline & $350 \mathrm{C}$ in vac, $1 \mathrm{hr}$ & yellow \\
\hline & $450 \mathrm{C}$ in vac, $1 \mathrm{hr}$ & golden yellow \\
\hline & $450 \mathrm{C}$ in vac, $4 \mathrm{hrs}$ & deep golden yellow \\
\hline \multirow[t]{6}{*}{ Ag-LSX } & initial & gray \\
\hline & $100 \mathrm{C}$ in vac, $24 \mathrm{hrs}$ & gray \\
\hline & $200 \mathrm{C}$ in vac, $4 \mathrm{hrs}$ & brownish yellow \\
\hline & $300 \mathrm{C}$ in vac, $4 \mathrm{hrs}$ & yellow \\
\hline & $350 \mathrm{C}$ in vac, $4 \mathrm{hrs}$ & golden yellow \\
\hline & $450 \mathrm{C}$ in vac, $4 \mathrm{hrs}$ & deep golden yellow \\
\hline
\end{tabular}


Table 3. X-ray photoemission spectroscopy data for silver zeolites and other silver compounds of interest

\begin{tabular}{|c|c|c|}
\hline Material & BE $\left(3 d_{5 / 2}\right), e V$ & $\mathrm{BE}\left(3 \mathrm{~d}_{3 / 2}\right), \mathrm{eV}$ \\
\hline Ag-LSX (hydrated) & 369.0 & 374.8 \\
\hline Ag-LSX (200 C vac) & 368.8 & 375.0 \\
\hline Ag-LSX (450 C vac) & 369.8 & 375.6 \\
\hline Ag metal & 367.9 & 373.9 \\
\hline $\mathrm{Ag}_{2} \mathrm{O}$ & 367.8 & 373.8 \\
\hline $\mathrm{AgF}^{32}$ & 367.8 & 373.7 \\
\hline $\mathrm{AgF}_{2} 33$ & 367.3 & 373.4 \\
\hline
\end{tabular}

Table 4. Refinement details and agreement factors for the four samples

\begin{tabular}{|c|c|c|c|c|}
\hline & Ag-Y & $\underline{\operatorname{Ag}-X}$ & $\underline{\text { Ag-LSX-350 }}$ & Ag-LSX-450 \\
\hline dehyd temp ( & C) 450 & 450 & 350 & 450 \\
\hline space group & $F d \overline{3}(203)$ & $F d \overline{3}(203)$ & $F d \overline{3}(203)$ & $F d \overline{3}(203)$ \\
\hline $\mathrm{a}=\mathrm{b}=\mathrm{c}(\AA)$ & $24.87291(21)$ & $25.20082(41)$ & $25.1524(7)$ & $25.1119(10)$ \\
\hline wRp & 0.0558 & 0.0603 & 0.0591 & 0.0582 \\
\hline $\mathrm{Rp}$ & 0.0454 & 0.0508 & 0.0474 & 0.0485 \\
\hline $\mathrm{R}_{\text {Bragg }}$ & 0.0458 & 0.0589 & 0.0818 & 0.0826 \\
\hline$\chi^{2}$ & 1.772 & 2.132 & 1.631 & 1.686 \\
\hline
\end{tabular}


Table 5. Positional parameters and refinement information for each zeolite sample

\begin{tabular}{|c|c|c|c|c|c|}
\hline & & $\underline{\operatorname{Ag}-Y-450}$ & Ag-X-450 & Ag-LSX-350 & Ag-LSX-450 \\
\hline $\mathrm{T}(1)(\mathrm{Si})$ & $\mathrm{x}$ & $-0.05550(34)$ & $-0.0536(4)$ & $-0.0509(4)$ & $-0.0500(4)$ \\
\hline \multirow[t]{3}{*}{$96 \mathrm{~g}$} & $\mathrm{y}$ & $0.1248(4)$ & $0.1241(5)$ & $0.1220(5)$ & $0.1212(5)$ \\
\hline & $\mathrm{z}$ & $0.0347(4)$ & $0.0380(4)$ & $0.0325(4)$ & $0.0321(4)$ \\
\hline & $\mathrm{U}_{\mathrm{i}} / \mathrm{U}_{\mathrm{e}} * 100$ & $0.5566(0)$ & $1.547(0)$ & $1.9341(0)$ & $1.8509(0)$ \\
\hline $\mathrm{T}(2)(\mathrm{Si})$ & $\mathrm{x}$ & $-0.0541(4)$ & $-0.0554(4)$ & - & - \\
\hline \multirow[t]{3}{*}{$96 \mathrm{~g}$} & $\mathrm{y}$ & $0.0348(4)$ & $0.0380(4)$ & - & - \\
\hline & $\mathrm{z}$ & $0.1221(4)$ & $0.1242(5)$ & - & - \\
\hline & occupancy & $0.417(0)$ & $0.104(0)$ & - & - \\
\hline $\mathrm{T}(2)(\mathrm{Al})$ & $\mathrm{x}$ & $-0.0541(4)$ & $-0.0553(4)$ & $-0.0548(4)$ & $-0.0550(4)$ \\
\hline \multirow[t]{3}{*}{$96 \mathrm{~g}$} & $\mathrm{y}$ & $0.0348(4)$ & $0.0380(4)$ & $0.0396(4)$ & $0.0400(4)$ \\
\hline & $\mathrm{z}$ & $0.1221(4)$ & $0.1242(5)$ & $0.1239(5)$ & $0.1235(4)$ \\
\hline & occupancy & $0.583(0)$ & $0.896(0)$ & $1.000(0)$ & $1.000(0)$ \\
\hline $\mathrm{O}(1)$ & $\mathrm{x}$ & $-0.11033(27)$ & $-0.10997(26)$ & $-0.11007(31)$ & $-0.11061(30)$ \\
\hline \multirow[t]{3}{*}{$96 \mathrm{~g}$} & $\mathrm{y}$ & $0.00599(31)$ & $0.0055(4)$ & $0.0055(5)$ & $0.0069(5)$ \\
\hline & $\mathrm{z}$ & $0.10385(29)$ & $0.10272(32)$ & $0.1010(4)$ & $0.1000(4)$ \\
\hline & $\mathrm{U}_{\mathrm{i}} / \mathrm{U}_{\mathrm{e}} * 100$ & $2.18(0)$ & $2.488(0)$ & $2.4341(0)$ & $2.274(0)$ \\
\hline $\mathrm{O}(2)$ & $\mathrm{x}$ & $-0.00231(30)$ & $-0.00406(30)$ & $-0.0035(4)$ & $-0.0042(4)$ \\
\hline \multirow[t]{2}{*}{$96 \mathrm{~g}$} & $\mathrm{y}$ & $-0.00285(31)$ & $-0.00154(30)$ & $-0.0016(4)$ & $-0.0008(4)$ \\
\hline & $\mathrm{z}$ & $0.14211(18)$ & $0.14228(20)$ & $0.14521(29)$ & $0.14601(31)$ \\
\hline $\mathrm{O}(3)$ & $\mathrm{x}$ & $-0.03309(19)$ & $-0.03534(23)$ & $-0.03301(31)$ & $-0.03127(33)$ \\
\hline \multirow[t]{2}{*}{$96 \mathrm{~g}$} & $\mathrm{y}$ & $0.07257(31)$ & $0.07316(31)$ & $0.0708(4)$ & $0.07035(35)$ \\
\hline & $\mathrm{z}$ & $0.06950(34)$ & $0.06943(32)$ & $0.06742(34)$ & $0.06692(32)$ \\
\hline $\mathrm{O}(4)$ & $\mathrm{x}$ & $-0.06716(20)$ & $-0.06857(24)$ & $-0.06930(33)$ & $-0.0693(4)$ \\
\hline \multirow[t]{2}{*}{$96 \mathrm{~g}$} & $\mathrm{y}$ & $0.0753(4)$ & $0.0761(4)$ & $0.0807(4)$ & $0.0808(4)$ \\
\hline & $\mathrm{z}$ & $0.17550(33)$ & $0.17805(34)$ & $0.1771(4)$ & $0.1775(4)$ \\
\hline $\operatorname{Ag}(\mathrm{I})$ & $\mathrm{x}=\mathrm{y}=\mathrm{z}$ & $0.00000(0)$ & $0.00000(0)$ & $0.00000(0)$ & $0.00000(0)$ \\
\hline \multirow{2}{*}{$16 \mathrm{a}$} & occupancy & $0.618(12)$ & $0.194(25)$ & $0.458(31)$ & $0.434(33)$ \\
\hline & $\mathrm{U}_{\mathrm{i}} / \mathrm{U}_{\mathrm{e}} * 100$ & $5.84(0)$ & $4.887(0)$ & $5.11(0)$ & $5.27(0)$ \\
\hline $\operatorname{Ag}\left(I^{\prime}\right)$ & $\mathrm{x}=\mathrm{y}=\mathrm{z}$ & $0.05630(0)$ & $0.0510(0)$ & $0.0720000(0)$ & $0.0722000(0)$ \\
\hline $32 \mathrm{e}$ & occupancy & $0.382(12)$ & $0.604(12)$ & $0.382(19)$ & $0.499(21)$ \\
\hline $\operatorname{Ag}\left(\mathrm{I}^{\prime} *\right)$ & $\mathrm{x}=\mathrm{y}=\mathrm{z}$ & - & $0.0298(0)$ & $0.0527000(0)$ & $0.0534000(0)$ \\
\hline $32 \mathrm{e}$ & occupancy & - & $0.382(16)$ & $0.564(24)$ & $0.448(26)$ \\
\hline $\operatorname{Ag}(\mathrm{II})$ & $x=y=z$ & $0.23680(0)$ & $0.2230(0)$ & $0.2175000(0)$ & $0.2182180(0)$ \\
\hline $32 \mathrm{e}$ & occupancy & $0.850(9)$ & $0.872(13)$ & $0.813(20)$ & $0.725(21)$ \\
\hline $\operatorname{Ag}(\mathrm{II} *)$ & $x=y=z$ & - & - & $0.2506000(0)$ & $0.2493000(0)$ \\
\hline $32 \mathrm{e}$ & occupancy & - & - & $0.187(20)$ & $0.275(21)$ \\
\hline $\operatorname{Ag}\left(I I^{\prime} *\right)$ & $x=y=z$ & - & $0.2095(0)$ & - & - \\
\hline $32 \mathrm{e}$ & occupancy & - & $0.209(22)$ & - & - \\
\hline $\operatorname{Ag}\left(\mathrm{II}^{\prime}\right)$ & $x=y=z$ & $0.17250(0)$ & $0.1697(0)$ & $0.1695000(0)$ & $0.1727600(0)$ \\
\hline $32 \mathrm{e}$ & occupancy & $0.154(9)$ & $0.161(13)$ & $0.189(18)$ & $0.275(19)$ \\
\hline $\operatorname{Ag}(\mathrm{III})$ & $\mathrm{x}$ & - & $0.3468000(0)$ & $0.3538020(0)$ & $0.3475760(0)$ \\
\hline \multirow[t]{3}{*}{$96 \mathrm{~g}$} & $\mathrm{y}$ & - & $0.3468000(0)$ & $0.3573160(0)$ & $0.3510310(0)$ \\
\hline & $\mathrm{z}$ & - & $0.1618000(0)$ & $0.1475580(0)$ & $0.1555700(0)$ \\
\hline & occupancy & - & $0.182(10)$ & $0.179(12)$ & $0.194(14)$ \\
\hline
\end{tabular}


Table 6. Framework interatomic distances $(\AA)$ and angles (degrees) for each zeolite sample

\begin{tabular}{|c|c|c|c|c|}
\hline & $\underline{\text { Ag-Y-450 }}$ & Ag-X-450 & Ag-LSX-350 & Ag-LSX-450 \\
\hline T1_T2 & $2.970(9)$ & $3.063(10)$ & $3.097(13)$ & $3.073(14)$ \\
\hline $\mathrm{T} 1 \_\mathrm{T} 2$ & $3.119(8)$ & & $3.084(12)$ & $3.075(13)$ \\
\hline mean & 3.045 & 3.063 & 3.091 & 3.074 \\
\hline T1_O1 & $1.612(9)$ & $1.614(10)$ & $1.607(11)$ & $1.614(11)$ \\
\hline T1_O2 & $1.658(12)$ & $1.675(13)$ & $1.643(17)$ & $1.657(17)$ \\
\hline T1_O3 & $1.657(9)$ & $1.643(10)$ & $1.624(10)$ & $1.618(10)$ \\
\hline T1_O4 & $1.614(9)$ & $1.635(9)$ & $1.634(10)$ & $1.646(10)$ \\
\hline mean & 1.635 & 1.642 & 1.627 & 1.634 \\
\hline T2_O1 & $1.635(8)$ & $1.691(8)$ & $1.733(10)$ & $1.730(11)$ \\
\hline T2_O2 & $1.669(9)$ & $1.696(9)$ & $1.740(11)$ & $1.730(11)$ \\
\hline $\mathrm{T} 2-\mathrm{O} 3$ & $1.692(9)$ & $1.715(9)$ & $1.713(11)$ & $1.719(11)$ \\
\hline T2_O4 & $1.699(9)$ & $1.695(9)$ & $1.728(10)$ & $1.739(11)$ \\
\hline mean & 1.674 & 1.699 & 1.729 & 1.730 \\
\hline O1_T1_O2 & $107.4(6)$ & $108.9(7)$ & $109.3(7)$ & $107.9(7)$ \\
\hline O1_T1_O3 & $113.9(7)$ & $112.2(7)$ & $113.0(8)$ & $115.0(8)$ \\
\hline O1_T1_O4 & $115.0(7)$ & $110.7(7)$ & $106.5(8)$ & $105.4(9)$ \\
\hline O2_T1_O3 & $103.2(6)$ & $107.8(7)$ & $111.8(8)$ & $112.2(9)$ \\
\hline O2_T1_O4 & $106.4(6)$ & 107.8(7) & 107.3(7) & $106.5(8)$ \\
\hline O3_T1_O4 & $110.0(6)$ & $109.3(6)$ & $108.6(7)$ & $109.4(7)$ \\
\hline mean & 109.3 & 109.5 & 109.4 & 109.4 \\
\hline O1_T2_O2 & $119.8(7)$ & $114.9(7)$ & $113.7(8)$ & $115.0(8)$ \\
\hline O1_T2_O3 & 107.1(6) & $103.5(7)$ & $102.0(8)$ & $102.2(8)$ \\
\hline O1_T2_O4 & 108.3(6) & $111.7(7)$ & $112.6(8)$ & $112.4(8)$ \\
\hline O2_T2_O3 & 107.7(6) & 107.2(6) & $106.9(7)$ & 106.1(7) \\
\hline O2_T2_O4 & $104.3(6)$ & $105.5(7)$ & $105.9(7)$ & 104.3(8) \\
\hline O3_T2_O4 & $109.5(6)$ & $114.2(6)$ & $115.9(7)$ & $117.1(8)$ \\
\hline mean & 109.5 & 109.5 & 109.5 & 109.5 \\
\hline T1_O1_T2 & $132.3(4)$ & $135.8(5)$ & $134.8(7)$ & $133.7(7)$ \\
\hline T1_O2_T2 & $142.6(4)$ & $144.4(5)$ & $138.5(6)$ & $136.4(7)$ \\
\hline T1_O3_T2 & 137.3(4) & $140.3(5)$ & $136.3(7)$ & 134.1(8) \\
\hline T1_O4_T2 & $154.4(4)$ & $150.2(5)$ & 149.1(7) & $148.2(7)$ \\
\hline mean & 141.7 & 142.7 & 139.7 & 138.1 \\
\hline
\end{tabular}


Table 7. Silver interatomic distances $(\AA)$ and angles (degrees) for each zeolite sample

\begin{tabular}{|c|c|c|c|c|}
\hline & $\underline{\operatorname{Ag}-Y-450}$ & Ag-X-450 & Ag-LSX-350 & Ag-LSX-450 \\
\hline $\mathrm{Ag}(\mathrm{I}) \_\mathrm{O} 3$ & $2.632(5)$ & $2.693(6)$ & $2.595(7)$ & $2.562(7)$ \\
\hline $\operatorname{Ag}(\mathrm{I}) \_\mathrm{Ag}\left(\mathrm{I}^{\prime} *\right)$ & - & $1.30074(2)$ & $2.29589(5)$ & $2.32264(7)$ \\
\hline $\mathrm{Ag}(\mathrm{I}) \_\mathrm{Ag}\left(\mathrm{I}^{\prime}\right)$ & $2.42555(3)$ & $2.22610(3)$ & $3.13670(7)$ & $3.14035(9)$ \\
\hline Ag( $\left(\mathrm{I}^{\prime}\right) \_\mathrm{O} 3$ & $2.284(5)$ & $2.294(6)$ & $2.644(8)$ & $2.602(8)$ \\
\hline $\operatorname{Ag}\left(I^{\prime}\right) \_\operatorname{Ag}\left(I^{\prime} *\right)$ & - & $0.92536(1)$ & $0.84081(2)$ & $0.81771(2)$ \\
\hline $\operatorname{Ag}\left(\mathrm{I}^{\prime}\right) \_\mathrm{Ag}\left(\mathrm{II}^{\prime}\right)$ & $2.98499(4)$ & $3.16836(5)$ & $2.47093(7)$ & $2.53159(10)$ \\
\hline $\operatorname{Ag}\left(I^{\prime} *\right) \_T 2$ & - & $3.210(11)$ & & $3.151(11)$ \\
\hline $\mathrm{Ag}\left(\mathrm{I}^{\prime} *\right) \_\mathrm{O} 3$ & - & $2.2160(6)$ & $2.234(8)$ & $2.195(8)$ \\
\hline $\operatorname{Ag}\left(I^{\prime} *\right) \_A g\left(I I^{\prime}\right)$ & - & & $3.09977(8)$ & $3.11464(11)$ \\
\hline $\operatorname{Ag}\left(\mathrm{I}^{\prime} *\right) \_\mathrm{Ag}\left(\mathrm{I}^{\prime} *\right)$ & - & $2.60149(3)$ & & \\
\hline Ag(II)_T2 & & & $3.225(11)$ & $3.232(11)$ \\
\hline Ag(II)_O2 & $2.420(4)$ & $2.295(5)$ & $2.206(7)$ & $2.186(8)$ \\
\hline $\operatorname{Ag}(\mathrm{II}) \_\mathrm{Ag}(\mathrm{II} *)$ & - & & $1.44201(3)$ & $1.35191(4)$ \\
\hline $\mathrm{Ag}\left(\mathrm{II}{ }^{*}\right) \_\mathrm{O} 2$ & - & - & $2.652(7)$ & $2.597(8)$ \\
\hline Ag(II')_Ag(II) & $2.77021(3)$ & $2.32650(3)$ & 2.09113(4) & $1.97720(6)$ \\
\hline Ag(II')_Ag(II') & & $3.18616(4)$ & $3.16581(6)$ & \\
\hline $\operatorname{Ag}\left(\mathrm{II}^{\prime}\right) \_\mathrm{Ag}\left(\mathrm{II}^{\prime} *\right)$ & - & $1.73723(2)$ & - & - \\
\hline $\mathrm{Ag}\left(\mathrm{II}^{\prime} *\right) \_\mathrm{Ag}(\mathrm{II})$ & - & $0.58926(1)$ & - & - \\
\hline $\mathrm{Ag}\left(\mathrm{II}^{\prime} *\right) \_\mathrm{T} 2$ & - & $3.235(10)$ & - & - \\
\hline $\mathrm{Ag}\left(\mathrm{II}^{\prime} *\right) \_\mathrm{O} 2$ & - & $2.292(5)$ & - & - \\
\hline Ag(III)_T1 & - & $3.141(9)$ & $3.108(10)$ & \\
\hline $\mathrm{Ag}(\mathrm{III}) \_\mathrm{T} 2$ & - & $3.141(9)$ & $2.867(11)$ & $2.966(11)$ \\
\hline Ag(III)_O1 & - & $2.650(9)$ & $2.652(12)$ & $2.542(12)$ \\
\hline Ag(III)_O4 & - & & $2.709(9)$ & \\
\hline Ag(III)_Ag(III) & - & $2.01006(3)$ & $1.38871(4)$ & $1.82927(7)$ \\
\hline O3_Ag( $\left(I^{\prime} *\right) \_O 3$ & - & $118.64(6)$ & $108.82(18)$ & $107.92(19)$ \\
\hline O2_Ag(II)_O2 & - & $118.24(6)$ & 119.981(9) & $119.944(17)$ \\
\hline O2_Ag(II)_Ag( II' $\left.^{\prime}\right)$ & - & $82.31(13)$ & $89.20(19)$ & $88.64(21)$ \\
\hline O2_Ag(II)_Ag(II*) & - & - & $90.80(19)$ & $91.36(21)$ \\
\hline
\end{tabular}


Table 8. Site occupancy (Ag/uc) for each zeolite compared to previously reported occupancies.

\begin{tabular}{|c|c|c|c|c|c|c|c|}
\hline \multirow{2}{*}{$\begin{array}{l}\text { Site } \\
\text { dehyd cond. } \\
420 \quad C^{* *}\end{array}$} & \multicolumn{2}{|c|}{ Ag-Y } & \multicolumn{2}{|c|}{ Ag-X } & \multicolumn{3}{|c|}{ Ag-LSX } \\
\hline & $450 \quad C^{*}$ & $\begin{array}{ll}420 & C^{* *} \\
\end{array}$ & $450 \quad C^{*}$ & $\begin{array}{ll}420 & C^{* *} \\
\end{array}$ & $\underline{350 \quad C^{*}}$ & $450 \quad C^{*}$ & \\
\hline $\bar{I}$ & 9.9 & 12.8 & 3.1 & 14.7 & 7.3 & 6.9 & 15.2 \\
\hline $\mathrm{I}^{\prime}$ & 12.2 & 13.1 & 19.3 & 21.1 & 12.2 & 16.0 & 25.0 \\
\hline$I^{\prime *}$ & - & - & 12.2 & - & 18.0 & 14.3 & - \\
\hline II & 27.2 & 19.5 & 27.9 & 20.5 & 26.0 & 23.2 & 24.6 \\
\hline II* & - & - & - & - & 6.0 & 8.8 & - \\
\hline $\mathrm{II}^{\prime}$ & 4.9 & 5.4 & 5.2 & 9.0 & 6.1 & 8.8 & 8.0 \\
\hline $\mathrm{II}^{\prime} *$ & - & - & 6.7 & - & - & - & - \\
\hline III & - & - & 17.5 & 14.4 & 17.2 & 18.7 & 19.0 \\
\hline Total & 54.2 & 50.8 & 91.9 & 79.7 & 92.9 & 96.7 & 91.8 \\
\hline Expected & 53.6 & 56.0 & 85.6 & 86.0 & 95.8 & 95.8 & 101.0 \\
\hline$\%$ located & $101.2 \%$ & $90.7 \%$ & $107.3 \%$ & $92.7 \%$ & $96.9 \%$ & $101.0 \%$ & $90.9 \%$ \\
\hline
\end{tabular}




\section{Figure Captions}

Figure 1. Unit cell, including cation sites, for faujasite zeolites.

Figure 2. $\quad \mathrm{N}_{2}$ adsorption isotherms, measured at $25 \mathrm{C}$, for (a) Ag-LSX-450 (vacuum dehydrated at $450^{\circ} \mathrm{C}$ ), (b) Ag-LSX-350 (vacuum dehydrated at $350^{\circ} \mathrm{C}$ ), (c) Ag-X, and (d) Ag-Y.

Figure 3. Amount of $\mathrm{N}_{2}$ adsorbed at $25 \mathrm{C}$ and 1 atm versus dehydration time for $\mathrm{Ag}$ LSX. All samples were vacuum dehydrated at 500 C.

Figure 4. $\mathrm{N}_{2}$ adsorption isotherms, measured at $25 \mathrm{C}$, for Ag-LSX (a) after drying at room temperature followed by vacuum dehydration at $450 \mathrm{C}$, (b) after drying at room temperature followed by vacuum dehydration at $350 \mathrm{C}$, (c) after drying in air at $100 \mathrm{C}$ followed by vacuum dehydration at $350 \mathrm{C}$ and (d) after drying in air at $100 \mathrm{C}$ in air followed by heat treatment in air at $450 \mathrm{C}$ and finally vacuum dehydration at $450 \mathrm{C}$.

Figure 5. $\quad \mathrm{N}_{2}$ adsorption isotherms, measured at $25 \mathrm{C}$, for $\mathrm{Ag}-\mathrm{X}$ (a) after drying at room temperature followed by vacuum dehydration at $450 \mathrm{C}$, and (b) after drying in air at $100 \mathrm{C}$ followed by vacuum dehydration at $350 \mathrm{C}$.

Figure 6. X-ray photoemission spectroscopy (XPS) spectra for Ag-LSX. The spectra were collected after (a) no thermal treatment, (b) heating at $200 \mathrm{C}$ in vacuum and (c) heating at $450 \mathrm{C}$ in vacuum.

Figure 7. Sodalite and hexagonal prism site I and II cation locations in Ag-faujasites. Configuration (a) shows the normal cation locations with occupied sites at SI, SI' and SII. Configuration (b) shows cation sites which have resulted from cation and/or cluster migration upon vacuum thermal treatment. This configuration shows occupied sites at $\mathrm{SI}^{*}$, SII' and SII*.

Figure 8. Heat of adsorption ( $\mathrm{kcal} / \mathrm{mol})$ versus surface coverage (molec/uc) for $\mathrm{N}_{2}$ adsorption on (a) Ag-LSX-450 and (b) Li-LSX-450. 


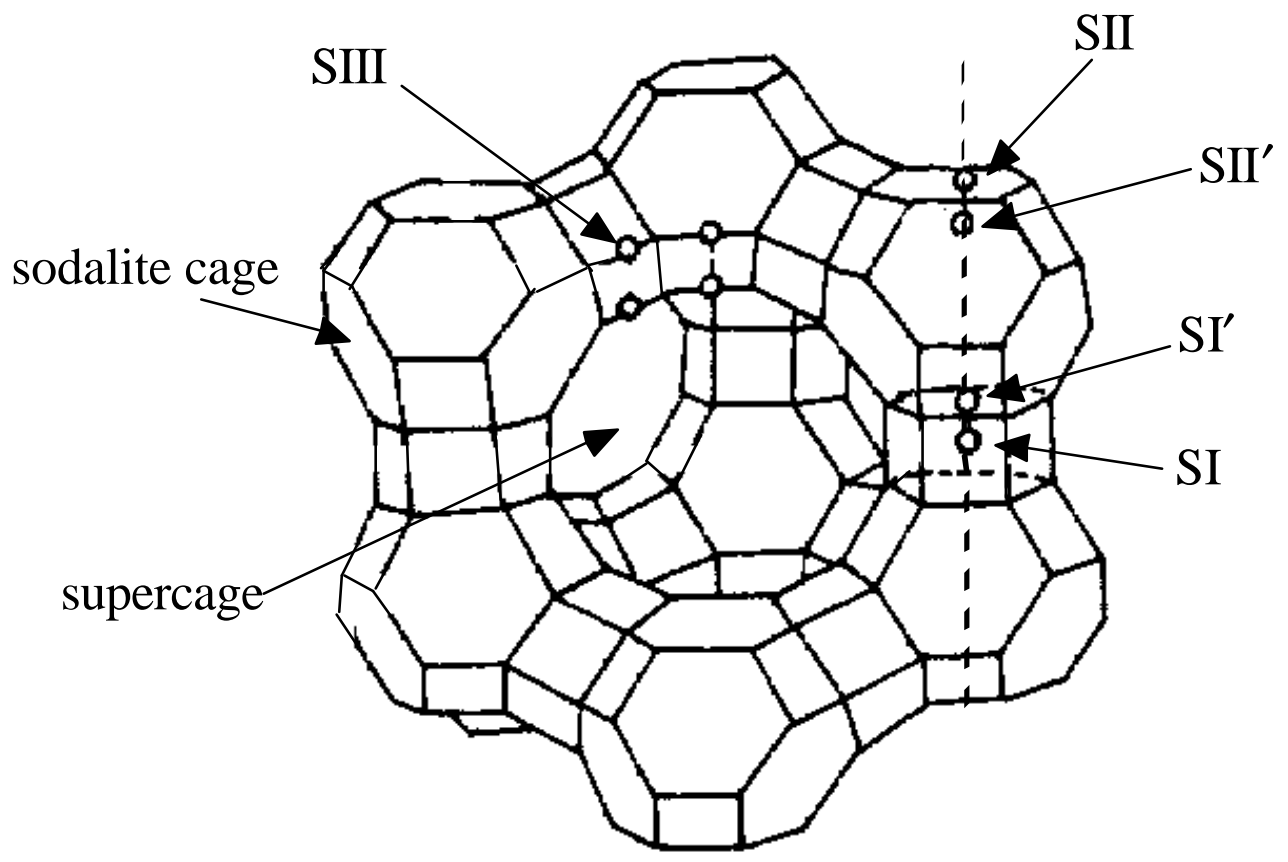

Figure 1. Unit cell, including cation sites, for faujasite zeolites. 


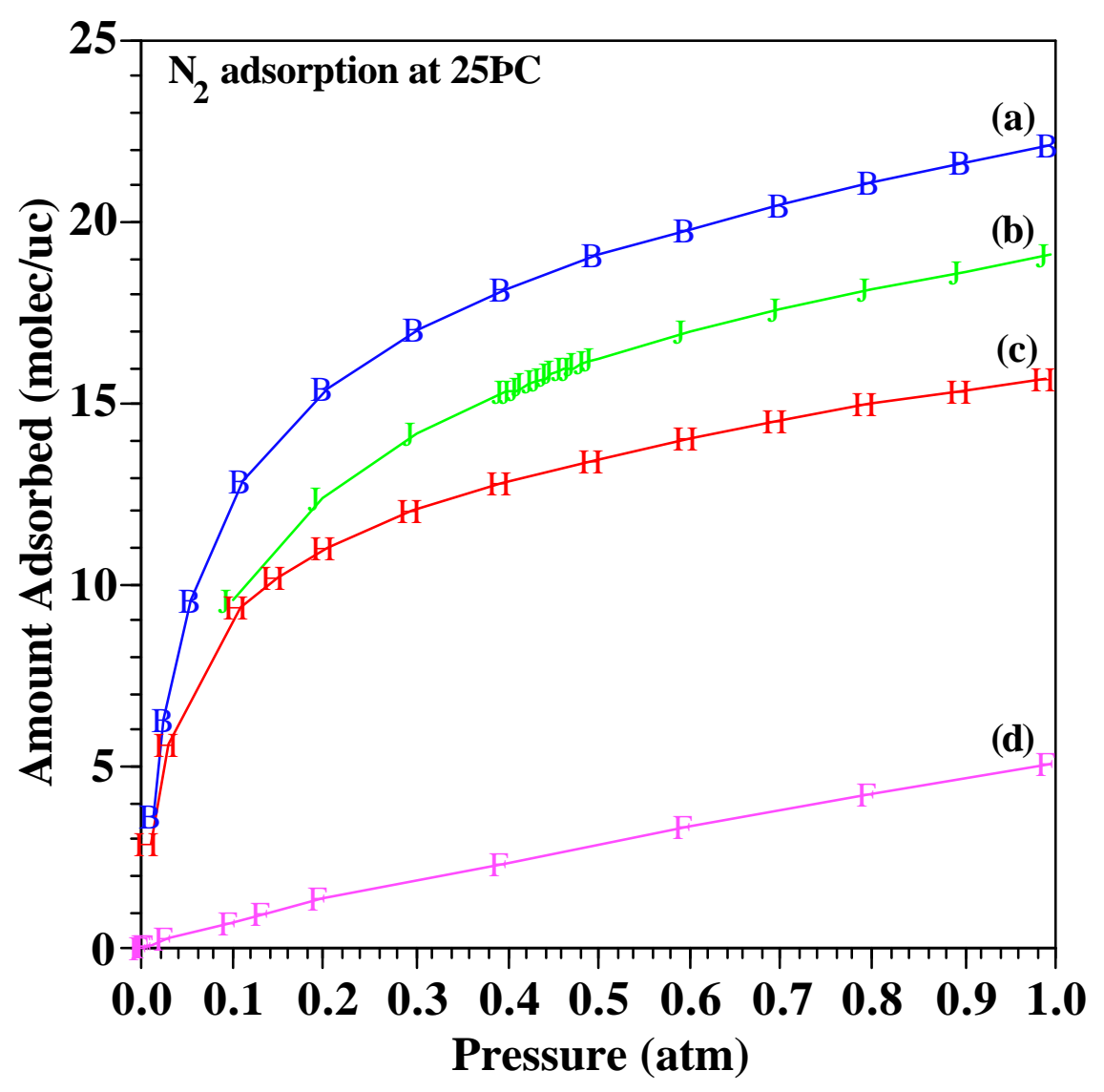

Figure 2. $\quad \mathrm{N}_{2}$ adsorption isotherms, measured at $25 \mathrm{C}$, for (a) Ag-LSX-450, (b) Ag-LSX-350, (c) Ag-X, and (d) Ag-Y. 


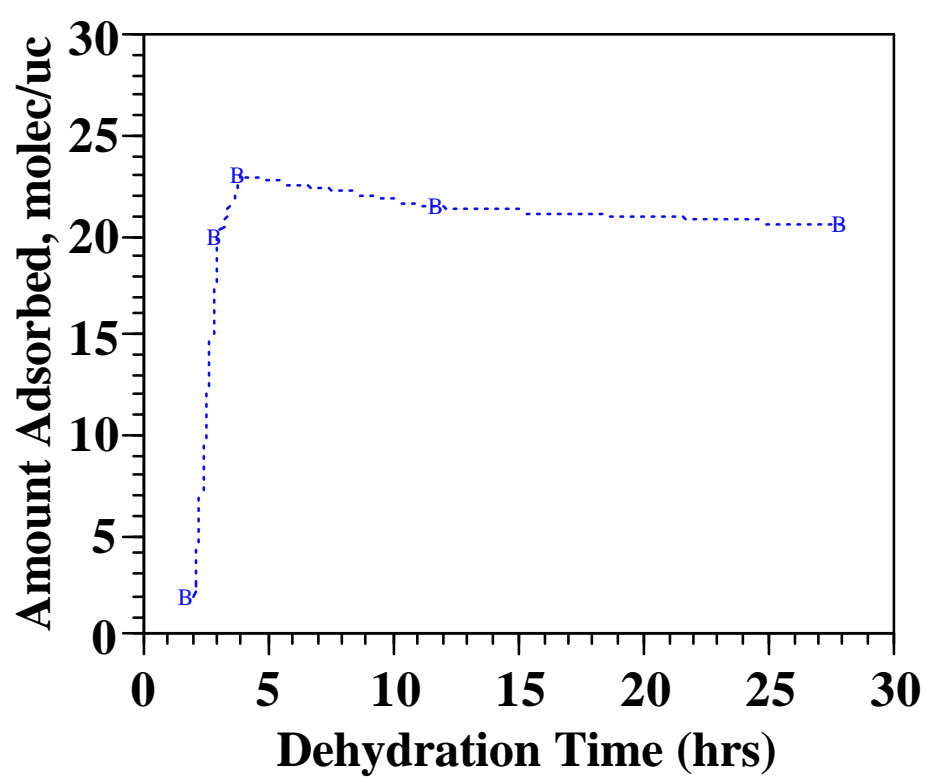

Figure 3. Amount of $\mathrm{N}_{2}$ adsorbed at $25 \mathrm{C}$ and $1 \mathrm{~atm}$ versus dehydration time for Ag-LSX. All samples were vacuum dehydrated at $500 \mathrm{C}$.

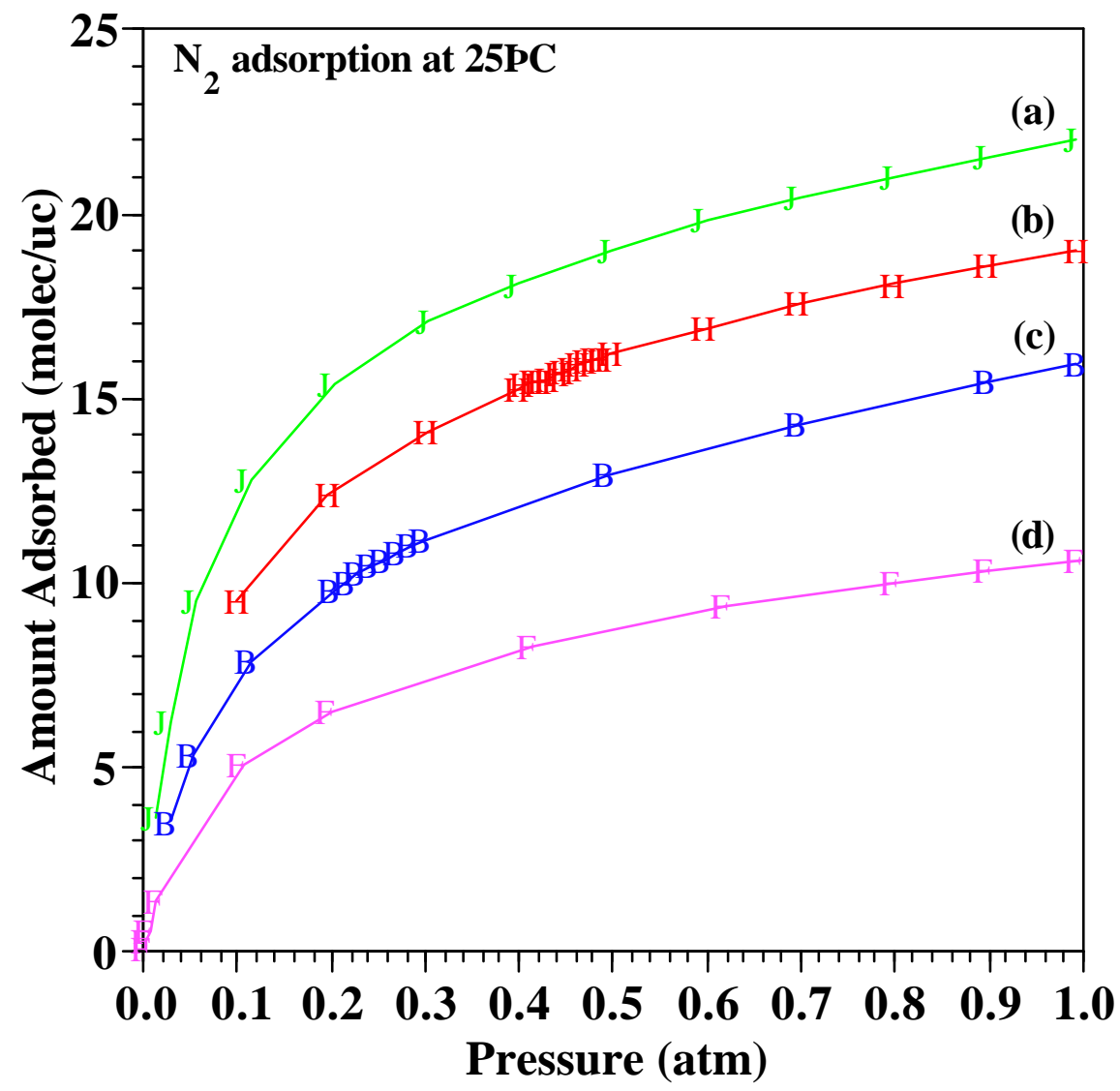


Figure 4. $\quad \mathrm{N}_{2}$ adsorption isotherms, measured at $25 \mathrm{C}$, for Ag-LSX (a) after drying at room temperature followed by vacuum dehydration at $450 \mathrm{C}$, (b) after drying at room temperature followed by vacuum dehydration at $350 \mathrm{C}$, (c) after drying in air at $100 \mathrm{C}$ followed by vacuum dehydration at $350 \mathrm{C}$ and (d) after drying in air at $100 \mathrm{C}$ in air followed by heat treatment in air at $450 \mathrm{C}$ and finally vacuum dehydration at $450 \mathrm{C}$.

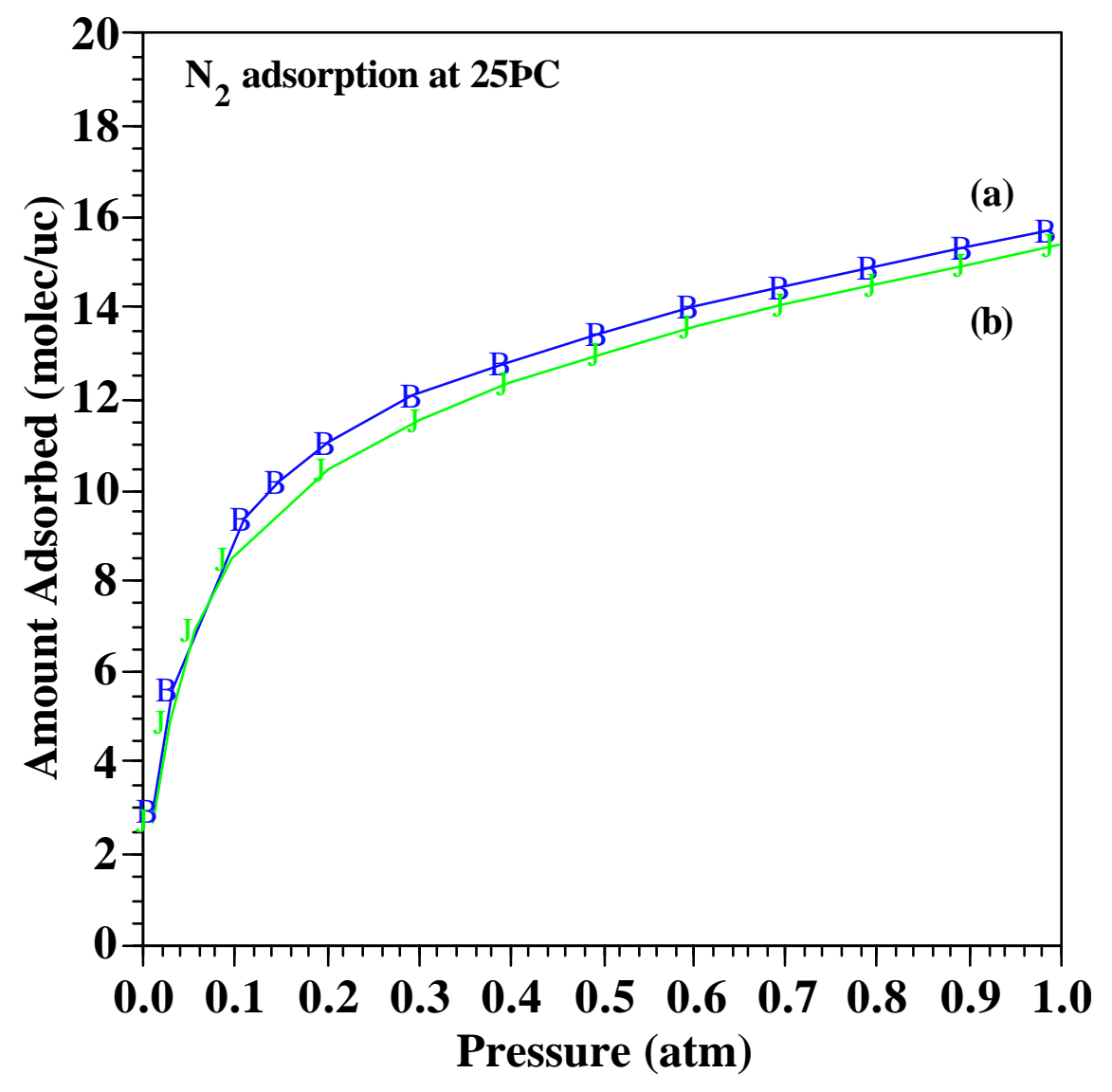

Figure 5. $\quad \mathrm{N}_{2}$ adsorption isotherms, measured at $25 \mathrm{C}$, for $\mathrm{Ag}-\mathrm{X}$ (a) after drying at room temperature followed by vacuum dehydration at $450 \mathrm{C}$, and (b) after drying in air at $100 \mathrm{C}$ followed by vacuum dehydration at $350 \mathrm{C}$. 


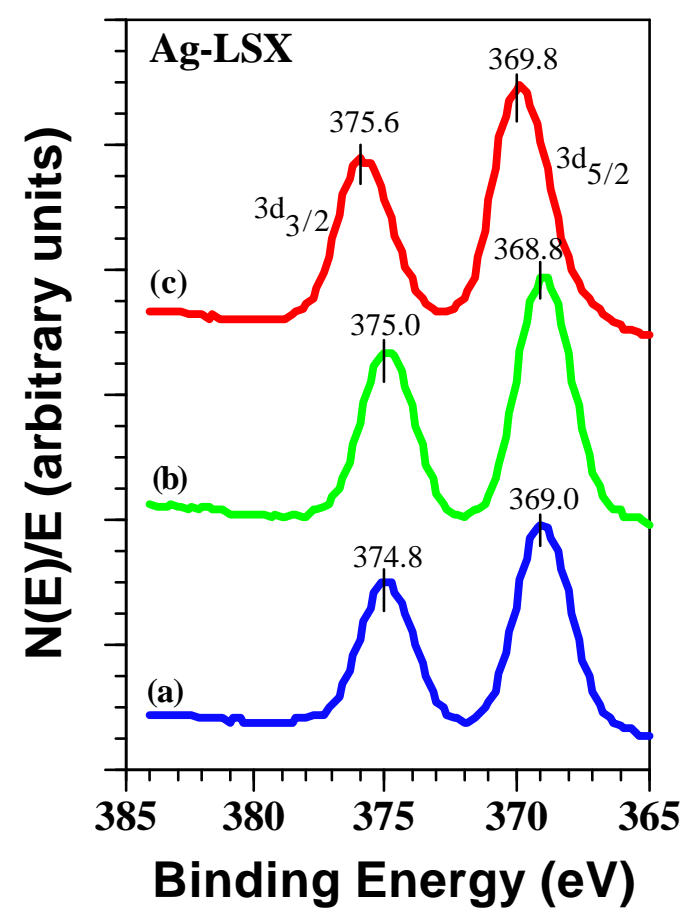

Figure 6. X-ray photoemission spectroscopy (XPS) spectra for Ag-LSX. The spectra were collected after (a) no thermal treatment, (b) heating at $200 \mathrm{C}$ in vacuum and (c) heating at $450 \mathrm{C}$ in vacuum. 


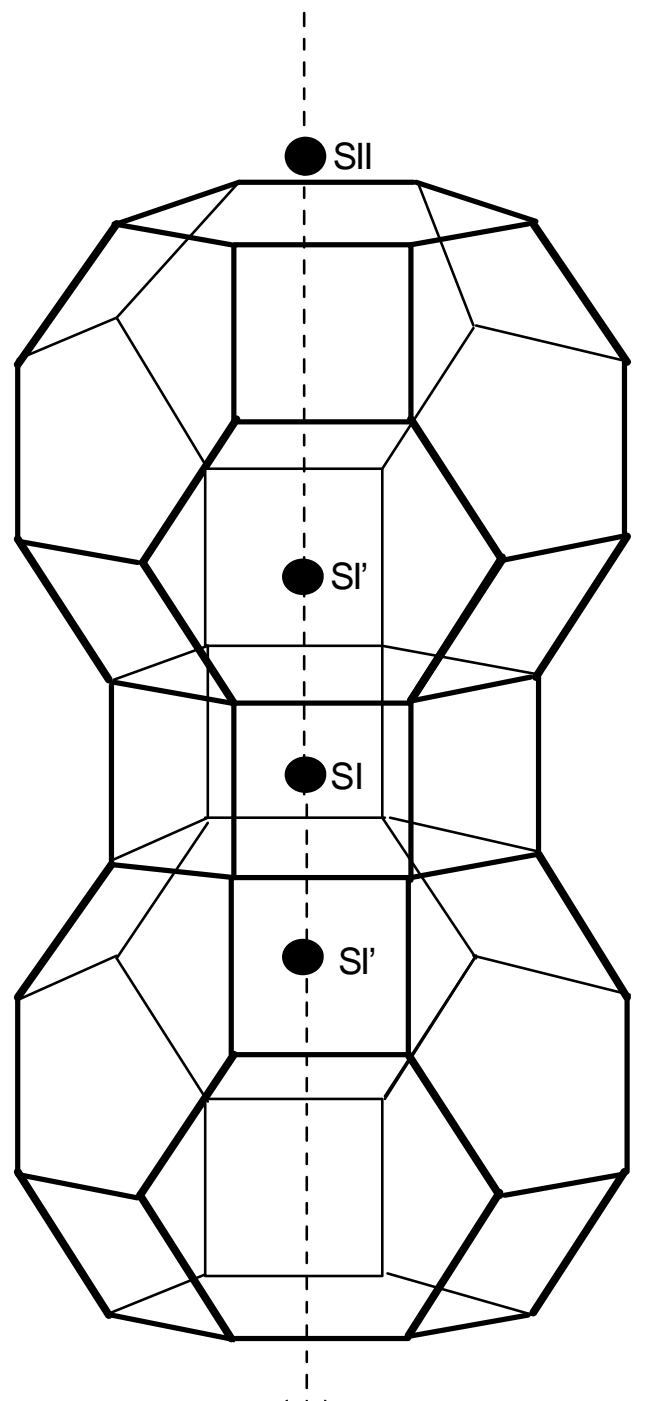

(à)

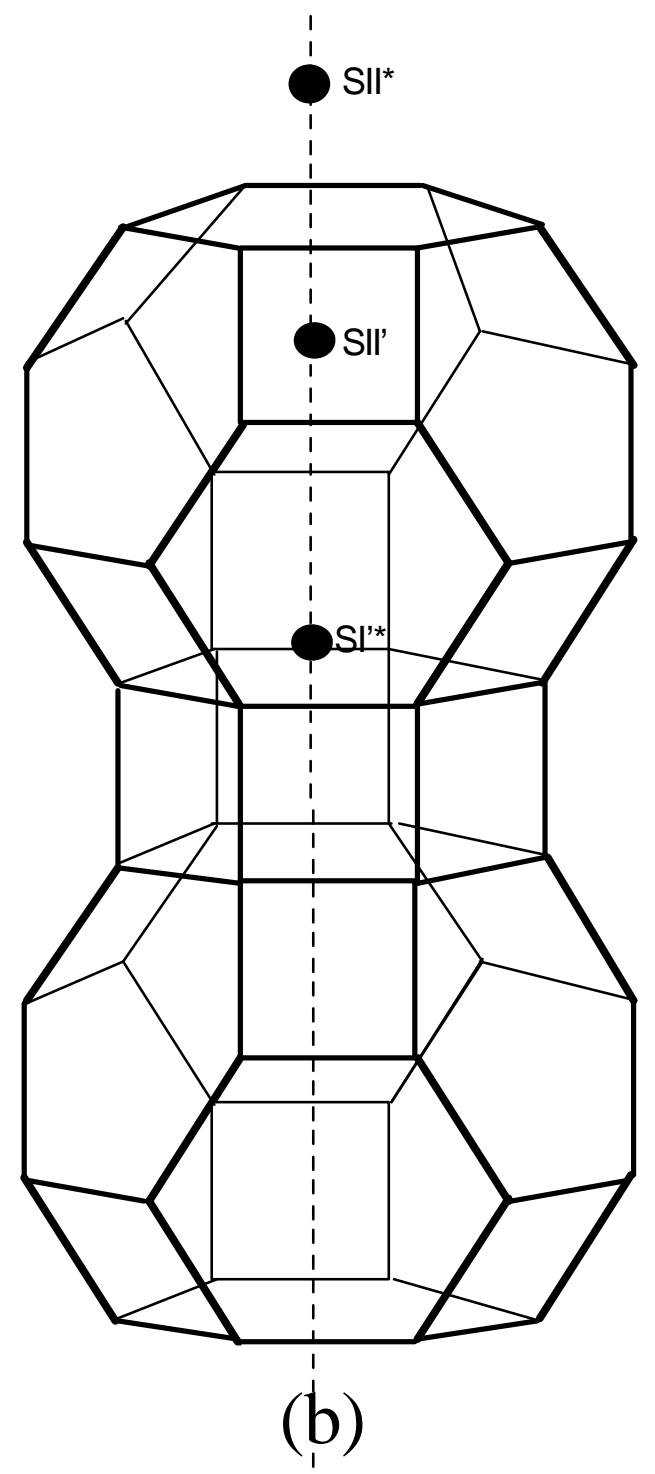

Figure 7. Sodalite and hexagonal prism site I and II cation locations in Agfaujasites. Configuration (a) shows the normal cation locations with occupied sites at SI, SI' and SII. Configuration (b) shows cation sites which have resulted from cation and/or cluster migration upon vacuum thermal treatment. This configuration shows occupied sites at SI'*, SII' and SII*. 


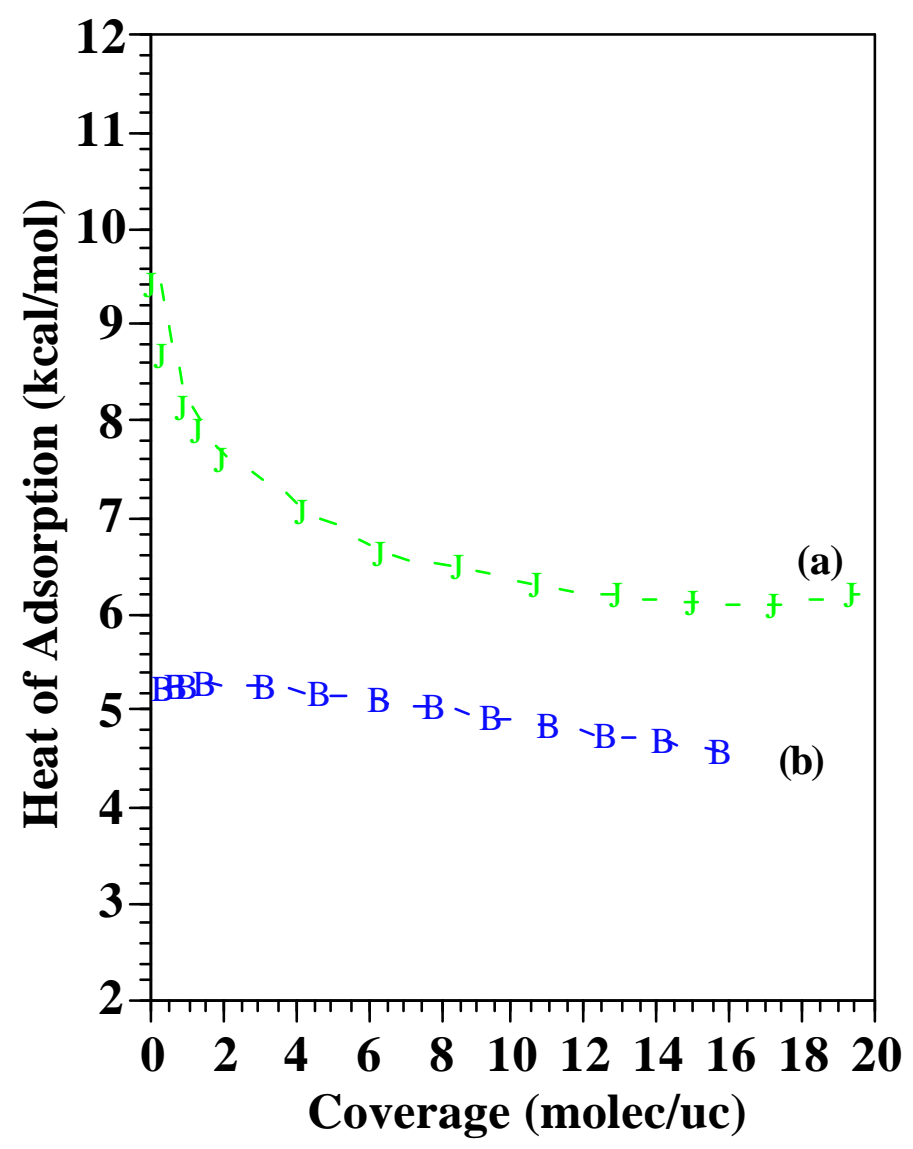

Figure 8. Heat of adsorption ( $\mathrm{kcal} / \mathrm{mol}$ ) versus surface coverage (molec/uc) for $\mathrm{N}_{2}$ adsorption on (a) Ag-LSX-450 and (b) Li-LSX-450. 


\section{CHAPTER TWO}

MIXED Ag-Li-X ZEOLITES AND THEIR PSA AIR SEPARATION 


\section{Introduction}

The separation of air for the production of nitrogen and oxygen is a very important operation in the chemical processing industry. Historically, this separation has been done predominately by cryogenic distillation; though, as adsorption systems have become more efficient and new, more effective sorbents have been synthesized, separation by adsorption processes (e.g., pressure swing adsorption (PSA), and vacuum swing adsorption (VSA)) have become increasingly competitive and are already favorable for small-to-medium scale operations. ${ }^{1}$ Currently, approximately $20 \%$ of air separations are accomplished using adsorption technologies. ${ }^{2}$

Since their introduction in the 1950's, synthetic zeolites have been used in numerous applications such as catalysis, ion exchange, drying, and separation by selective adsorption. In the separation of air, zeolites of type A and X have typically been used. The $\mathrm{A}$ and $\mathrm{X}$ type zeolites are composed of silica and alumina tetrahedra which are joined together to form the truncated octahedral or sodalite structure. These sodalite units are connected with tertiary units to form the structured zeolite unit cell. While the $\mathrm{SiO}_{2}$ groups are electroneutral, the $\left(\mathrm{AlO}_{2}\right)^{-}$groups are not, and thus introduce a negative charge to the structure which is offset by the presence of a charge compensating, non-framework cation (e.g., $\mathrm{Na}^{+}, \mathrm{Li}^{+}, \mathrm{Ca}^{2+}$ ). Type $\mathrm{X}$ zeolites contain between 77 and 96 Al per unit cell. The unit cell, including cation sites, for type $\mathrm{X}$ zeolite is shown in Figure 1.

It is known that the extra-framework cations in the zeolite are largely responsible for the nitrogen selectivity of these materials. ${ }^{3,4}$ These zeolites adsorb nitrogen preferentially to oxygen (usually at a ratio of about $4: 1$ ) due primarily to the interaction 
between the charge compensating cations of the zeolite and the quadrupole moment of the adsorbing gas $\left(\mathrm{N}_{2}\right.$ or $\left.\mathrm{O}_{2}\right)$. The quadrupole moment of $\mathrm{N}_{2}$ is approximately four times that of $\mathrm{O}_{2}$. Because the extra-framework cations so significantly influence the adsorption properties of the zeolites, numerous attempts have been made to optimize these properties by (1) increasing the number of cation sites (the cation exchange capacity, CEC) by creating zeolites with high aluminum content, and (2) by synthesizing zeolites containing various combinations of alkaline and alkaline earth cations.

Kuhl reported a procedure for the synthesis of low silica X-type zeolite (LSX). This material is an aluminum saturated X-type zeolite with a silica-to-alumina ratio of 2.0 (or $\mathrm{Si} / \mathrm{Al}=1.0) .{ }^{5}$ Commercial X-zeolite, which is typically available as the $\mathrm{Na}^{+}$form (known commercially as 13X), is not aluminum saturated and contains 86 aluminum atoms per unit cell, while the low silica $\mathrm{X}$ zeolite contains 96 aluminum atoms per unit cell.

While it has long been known that $\mathrm{Li}^{+}$is among the strongest cations, with respect to its interaction with $\mathrm{N}_{2},{ }^{6}$ its use was greatly increased with two recent advances. Firstly, it was found that $\mathrm{Li}^{+}$ion-exchange in X-type zeolite must exceed an approximate $70 \%$ threshold before the $\mathrm{Li}^{+}$has any effect on the adsorptive properties of the material. ${ }^{7-}$

10 Secondly, a significant increase in the $\mathrm{N}_{2}$ adsorption capacity was seen in $\mathrm{Li}^{+}$ion exchanged low silica X-type zeolites over that of the typical commercial material ( $\mathrm{Si} / \mathrm{Al}$ $=1.25)$. Because of these advances, $\mathrm{Li}-\mathrm{X}(\mathrm{Si} / \mathrm{Al}=1.0)$ is now the best sorbent in industrial use for separation of air by adsorption processes. ${ }^{2,11}$

Coe et al. reported the use of a binary exchanged X-zeolite having lithium and calcium and/or lithium and strontium ions in a ratio of $5 \%$ to $50 \%$ calcium and/or 
strontium and $50 \%$ to $95 \%$ lithium. ${ }^{9}$ This material provided for enhanced nitrogen adsorption over those of the $\mathrm{Na}-\mathrm{X}, \mathrm{Li}-\mathrm{X}$, and $\mathrm{Ca}-\mathrm{X}$ zeolites. Chao et al. reported the use of mixed ion-exchanged $\mathrm{A}$ and $\mathrm{X}$ zeolites with lithium and an alkaline earth metal (e.g., $\left.\mathrm{Ca}^{2+}, \mathrm{Sr}^{2+}\right) .{ }^{8}$ In this case the zeolite contained lithium and the alkaline earth cations in a mixture of $10 \%$ to $70 \%$ alkaline earth and $30 \%$ to $90 \%$ lithium. These mixed cation zeolites provided high adsorption capacity and high thermal stability. Fitch et al. reported good $\mathrm{N}_{2} / \mathrm{O}_{2}$ selectivity and $\mathrm{N}_{2}$ capacity with mixed $\mathrm{Li}_{\mathrm{x}} \mathrm{Al}_{\mathrm{y}}-\mathrm{X}$ zeolite (i.e., using $\mathrm{Ag}^{3+}$ as the non-framework charge-compensating cation). ${ }^{12}$

Silver is also known to have very strong effects on the adsorption characteristics of zeolites. ${ }^{13,14}$ Yang et al. reported the synthesis of a mixed lithium-silver (80/20) ionexchanged X-type zeolite ( $\mathrm{Si} / \mathrm{Al}=1.25$ with approximately $17 \mathrm{Ag}^{+}$per unit cell), and discussed its possible superior properties for air separation. ${ }^{15}$ This sorbent utilized the very strong adsorptive properties of the $\mathrm{Ag}^{+}$ion which provided for increased capacity over that of the Li-X while maintaining some degree of the advantageous isotherm linearity that is seen with $\mathrm{Li}-\mathrm{X}$. Ab inito molecular orbital calculations showed the adsorption of nitrogen was enhanced by weak chemical interaction (through a classical $\pi$ complexation bond) with the $\mathrm{Ag}^{+}$cation on the zeolite framework. ${ }^{16}$

Numerous attempts have been made to reduce transition metal ions in zeolites for the purpose of forming highly dispersed metallic clusters for use as catalysts. These attempts have typically been completed via treatment at elevated temperatures and/or in reducing atmospheres (e.g., sodium vapor, hydrogen gas, carbon monoxide gas). However, color changes upon vacuum dehydration of silver-exchanged A-type zeolites were found to be related to the formation of metallic clusters within the sodalite cage or 
the 6-prism of the zeolite. ${ }^{17-19}$ Using volumetric sorption techniques and temperature programmed desorption, Jacobs et al. were able to relate these color changes to an autoreductive process involving framework oxygen. ${ }^{19}$ Autoreduction is the reduction of the transition metal ion and the oxidation of water or lattice oxygen; this has been observed for both $\mathrm{Ag}^{+}$and $\mathrm{Cu}^{2+}$ ions in zeolites $\mathrm{A}, \mathrm{X}$ and $\mathrm{Y}$, and has been shown to take place by two mechanism in two clearly defined temperature regions: ${ }^{19,20}$

(i) autoreduction in the presence of zeolite water $(25-250$ C $)$

$$
2\left(\mathrm{Ag}^{+}-\mathrm{Z}-\mathrm{O}^{-}\right)+\mathrm{H}_{2} \mathrm{O}--\rightarrow 2 \mathrm{Ag}^{0}+(1 / 2) \mathrm{O}_{2}+2 \mathrm{Z}-\mathrm{OH}
$$

and

$\begin{array}{lll}\text { (ii) autoreduction by oxygen from the zeolite lattice }(127-380 & \text { C) }\end{array}$

$$
2\left(\mathrm{Ag}^{+}-\mathrm{Z}-\mathrm{O}^{-}\right)--\rightarrow 2 \mathrm{Ag}^{0}+(1 / 2) \mathrm{O}_{2}+\mathrm{Z}^{-} \mathrm{O}^{-}+\mathrm{Z}^{+}
$$

Kim and Seff proposed the formation of octahedral hexasilver metal clusters stabilized by coordination to six silver ions $\left(\left(\mathrm{Ag}^{+}\right)_{6}(\mathrm{Ag})^{6}\right)$ from $\mathrm{x}$-ray structural determinations of a dehydrated silver-exchanged zeolite A. ${ }^{17,18}$ However, Jacobs et al. suggested that the formation of such large metal clusters is improbable since color changes are seen even at low temperatures and low silver loadings where extensive migration of neutral silver atoms and subsequent sintering into $\mathrm{Ag}_{6}$ metal clusters is highly unlikely. ${ }^{19}$ Alternatively, Jacobs et al. suggested, based on structural studies of Ag-A zeolites, the formation of linear $\left(\mathrm{Ag}_{3}\right)^{2+}$ charged clusters $\left(\mathrm{Ag}^{+}-\mathrm{Ag}^{0}-\mathrm{Ag}^{+}\right)$upon thermal dehydration of the zeolite. ${ }^{19}$

Gellens et al. followed color changes and concomitant silver cluster formation in A, X, and Y zeolites using X-ray diffraction (XRD) techniques. ${ }^{21-23}$ They found that the 
number of clusters increases with framework $\mathrm{Al}$ content. It was also noted that in synthetic analogs of the faujasite zeolite (types $\mathrm{X}$ and $\mathrm{Y}$ ), the dehydrated zeolites displayed a yellow color which increased in intensity with the number of clusters, while silver-exchanged A zeolites took a yellow color with dehydration at low temperatures, eventually becoming brick red after treatment at higher temperatures.

In this work we have synthesized type $\mathrm{X}$ eolites containing varying amounts of $\mathrm{Li}$ and Ag. We have treated these materials in a way which promotes the promotion of intracrystalline silver clusters; and we have evaluated the resulting adsorptive characteristics with respect to the gases which are of primary interest in the separation of air: $\mathrm{N}_{2}, \mathrm{O}_{2}$ and Ar. The performance of the best of these materials was compared to that of the fully $\mathrm{Li}^{+}$-exchanged zeolite using a numerical simulation of a standard five-step PSA cycle (that is used in industry); and the results are given below.

\section{Experimental Section}

Materials. Two type-X zeolites, differing only by the $\mathrm{Si} / \mathrm{Al}$ ratio, were used in this work. These were: (1) X-type zeolite with a Si/Al of 1.0 (Praxair, \#16193-42, sometimes referred to as LSX, low silica X-zeolite), and (2) X-type zeolite with a Si/Al of 1.25 (Linde, lot 945084060002). Both of these materials were binderless, hydrated powders.

Helium (99.995\%, prepurified), oxygen (99.6\%, extra dry), nitrogen $(99.998 \%$, prepurified), and argon (99.998\% prepurified) were obtained from Cryogenic Gases. All water used was deionized. 
Cation Exchange. Since the sodium form of the zeolite exchanges more readily with most cations in consideration, all zeolites were first ion-exchanged with a solution of sodium chloride in order to convert to the $\mathrm{Na}^{+}$form. A dilute $\mathrm{NaOH}$ solution was used to keep the $\mathrm{NaCl}$ solution at $\mathrm{pH} \quad 9$. This helps to prevent hydrolysis and breakdown of the zeolite crystal structure during the ion-exchange process. The resultant $\mathrm{Na}^{+}-$-zeolite was then used as the starting material for all other syntheses.

Preparation of Li-Zeolites. The lithium zeolites were prepared by 5 consecutive static ion-exchanges using a 6.3-fold excess (over that necessary for full ion-exchange) of a 2.2 M solution of $\mathrm{LiCl}$. This was done in a $0.01 \mathrm{M}$ solution of $\mathrm{LiOH}$ at a $\mathrm{pH} \quad$ 9. The lithium ion-exchange solution was heated to a mild boil and then allowed to cool and settle. The solution was decanted, a fresh $6.3 \mathrm{X} \mathrm{LiCl}$ solution was added, and the procedure was repeated for a total of 5 exchanges. After the final ion-exchange, the material was vacuum filtered and washed with copious amounts of deionized water until no free ions were present in the filter water (i.e., no $\mathrm{AgCl}$ precipitation upon treatment with $\mathrm{Ag}^{+}$). The resulting lithium exchanged zeolites were dried overnight at $100 \mathrm{C}$ in a conventional oven before being dehydrated in vacuo prior to measurement of adsorption isotherms.

Preparation of Ag-Zeolites. The silver zeolites were prepared by 2 consecutive ion-exchanges using a $0.05 \mathrm{M}$ solution of $\mathrm{AgNO}_{3}$. Each silver solution contained a cation content which was double that required for $100 \%$ exchange. The silver ionexchange solution was heated to a mild boil and immediately allowed to cool and settle. As with the lithium ion-exchange, the solution was decanted, fresh $\mathrm{AgNO}_{3}$ solution was added, and the procedure was repeated for a total of 2 exchanges. After the second ion- 
exchange, the material was vacuum filtered and washed with copious amounts of deionized water until no free ions were present in the filter water (i.e., no precipitation upon treatment with $\mathrm{CI}$ ). The silver exchanged materials were dried at room temperature and atmospheric conditions in a dark area. The resulting materials were then stored in a dark area until they were dehydrated in vacuo prior to analysis.

Preparation of $\mathbf{L i}_{\mathbf{x}} \mathbf{A g}_{\mathbf{y}}$-Zeolites. The $\mathrm{Li}_{\mathrm{x}} \mathrm{Ag}_{\mathrm{y}}$-zeolites (which may more accurately be referred to as $\mathrm{Li}_{\mathrm{x}} \mathrm{Na}_{\mathrm{y}} \mathrm{Ag}_{\mathrm{z}}$-zeolites since ion exchange is rarely exhaustive and there is almost always some residual $\mathrm{Na}+$ present in the starting Li-zeolite) were prepared by ion exchange of a Li-zeolite (prepared as described above) with a $0.05 \mathrm{M}$ solution of $\mathrm{AgNO}_{3}$. This silver solution contained a cation content which was equivalent to the targeted amount. This is possible with silver ion-exchange because the silver cation is quickly and easily exchanged. ${ }^{4}$ The silver ion-exchange solution was heated to a mild boil and immediately allowed to cool and settle. The resulting material was vacuum filtered and washed with copious amounts of deionized water. Complete incorporation of the targeted silver ions was verified when no precipitation was observed in the filtered water upon treatment with $\mathrm{Cl}$. These mixed cation zeolites were then dried at room temperature and atmospheric conditions in a dark area and were stored in a dark area until they were dehydrated in vacuo prior to analysis.

Dehydration. Prior to measurement of the adsorption isotherms or uptake rates, it is necessary to dehydrate the zeolite sample. Zeolites have a strong affinity for water; and some molecules are tenaciously held. The presence of water in the zeolite significantly affects the validity of the adsorption measurement. Prior to analysis, all samples were heated in order to remove water. Differential thermal analysis (DTA) of 
zeolite $\mathrm{X}$ has shown a continuous loss of water over a broad range of temperatures, starting at slightly above room temperature up to $350 \mathrm{C}$ with a maximum at about 250 C. ${ }^{4}$ Specific dehydration conditions varied from sample to sample and are given for each sample.

Characterization. The samples were compositionally characterized using neutron activation analysis (NAA) in the research nuclear reactor of the Phoenix Memorial Laboratory at the University of Michigan. The samples were irradiated sequentially for one minute at a core-face location with an average thermal neutron flux of $2 \times 10^{12} \mathrm{n} / \mathrm{cm}^{2} / \mathrm{s}$. Two separate gamma-ray spectra were then collected for each sample with a high resolution germanium detector: one after a 13 minute decay to determine the concentrations of $\mathrm{Al}$ and $\mathrm{Ag}$, and a second after a 1 hour and 56 min decay to analyze for $\mathrm{Na}$ and $\mathrm{K}$; both were for 500 seconds real time. Four replicates of NBSSRM-1633a (coal fly ash) and silver foil were used as standard reference materials and check standards.

The samples were also analyzed for Li content using an inductively coupled plasma mass spectrometer (ICP-MS, Hewlett Packard HP 4500). The samples were first digested in concentrated nitric acid solution at $100 \mathrm{C}$ for $20 \mathrm{~min}$. At the end of digestion, the samples were further diluted and filtered before the ICP-MS analyses.

The adsorption isotherms were measured using a static volumetric system (Micromeritics ASAP-2010). Additions of the analysis gas were made at volumes required to achieve a targeted set of pressures. A minimum equilibrium interval of 9 seconds with a tolerance of $5 \%$ of the target pressure (or 0.007 atm, whichever is smaller) was used to determine equilibrium for each measurement point. The pressure transducers 
in the ASAP-2010 are accurate to $<0.2 \%$ for the pressure range of $0-1 \mathrm{~atm}$. The sample weights were obtained using a digital laboratory balance which is accurate to $\pm 0.01 \mathrm{~g}$. The isotherm measurements and the samples themselves were found to be highly reproducible.

\section{Results and Discussion}

All samples are identified according to the type of zeolite, the number of charge compensating cation(s) present in a unit cell, and the $\mathrm{Si} / \mathrm{Al}$ ratio. For example $\mathrm{Li}_{86} \mathrm{X}-$ 1.25 refers to an $\mathrm{X}$-type zeolite with $\mathrm{Si} / \mathrm{Al}=1.25$ which has been fully exchanged to contain $86 \mathrm{Li}^{+}$cations per unit cell. The sample $\mathrm{Li}_{94.2} \mathrm{Na}_{0.7} \mathrm{Ag}_{1.1}-\mathrm{X}-1.0$ refers to an $\mathrm{X}$-type zeolite with $\mathrm{Si} / \mathrm{Al}=1.0$ which contains, on average, $94.2 \mathrm{Li}^{+}, 0.7 \mathrm{Na}^{+}$, and $1.1 \mathrm{Ag}^{+}$(or other forms of Ag) per unit cell, as determined from the neutron activation (NA) and ICPMS analyses.

Analytical Characterization As mentioned earlier, the samples were compositionally characterized using neutron activation analysis (NAA) and inductively coupled plasma mass spectroscopy (ICP-MS). Results of these analyses are given in Table 1. The unit cell compositions for those analyzed samples are given in Table 2.

Adsorption Isotherms for Fully Exchanged Li and Ag Zeolites. Figure 2 shows the $\mathrm{N}_{2}, \mathrm{O}_{2}$ and Ar adsorption isotherms, measured at $25 \mathrm{C}$, for $\mathrm{Li}_{94.5} \mathrm{Na}_{1.5}-\mathrm{X}-1.0$ after vacuum dehydration at $350 \mathrm{C}$. This zeolite is used in adsorptive air separation because of its very high $\mathrm{N}_{2}$ capacity and very favorable $\mathrm{N}_{2}: \mathrm{O}_{2}$ selectivity (approximately 6:1 at $1 \mathrm{~atm}$ ) as well as its $\mathrm{N}_{2}$ isotherm linearity. 
Figure 3 shows $\mathrm{N}_{2}, \mathrm{O}_{2}$ and $\mathrm{Ar}$ adsorption isotherms for $\mathrm{Ag}_{95.7} \mathrm{Na}_{0.3}-\mathrm{X}-1.0$, all measured at $25 \mathrm{C}$, after vacuum dehydration at $450 \mathrm{C}$ for a minimum of 4 hours. These samples were all initially gray in color, but after vacuum dehydration turned to a deep golden yellow, indicating the formation of silver clusters. While the near fully exchanged Ag-zeolites, like their Li-zeolite analogs, have very high $\mathrm{N}_{2}$ capacity and favorable $\mathrm{N}_{2}: \mathrm{O}_{2}$ selectivity, they are not favorable for use in adsorption-based separations. Because of the strong adsorption of $\mathrm{N}_{2}$ at low pressure, creating a low pressure "knee" in the adsorption isotherm shown in Figure 3, the working capacity (i.e., the $\mathrm{Q}$, the change in the adsorptive capacity from the typically used adsorption pressure of 1.0 to a desorptive pressure of $0.33 \mathrm{~atm}$ ) is very small; and the material must be exposed to very low pressure conditions in order to increase that working capacity.

Some Ag-zeolites have been shown to have a selectivity for $\operatorname{Ar}$ over $\mathrm{O}_{2},{ }^{24}$ and, in our work, the Ag-zeolites which had been dehydrated in vacuo at $350 \mathrm{C}$ also showed a selectivity for Ar over $\mathrm{O}_{2}$. However, the $\mathrm{Ag}$-zeolites which had been dehydrated in vacuo at $450 \mathrm{C}$ had approximately the same adsorption capacity for $\mathrm{Ar}$ and $\mathrm{O}_{2}$ (as shown in Figure 3). This is probably due to increased interaction between the charged Ag-clusters and the quadrupole moment of the $\mathrm{O}_{2}$ molecule (whereas, the $\mathrm{Ar}$ has no quadrupole moment).

Adsorption Isotherms for Mixed Cation $\left(\mathbf{L i}_{\mathbf{x}} \mathbf{A g} \mathbf{y}\right)$ Zeolites. The $\mathrm{N}_{2}$ adsorption isotherms, measured at $25 \mathrm{C}$, for $\mathrm{Li}_{\mathrm{x}} \mathrm{Ag}_{\mathrm{y}}-\mathrm{X}-1.0$ zeolites after vacuum dehydration at $450 \mathrm{C}$ for a minimum of 4 hours are shown in Figure 4 (where the amount adsorbed is given in $\mathrm{mmol} / \mathrm{g}$ ) and Figure 5 (where the amount adsorbed is given in molec/uc). These zeolites contained varying amounts of Ag per unit cell ranging from zero (i.e., the near 
fully exchanged $\mathrm{Li}_{94.5} \mathrm{Na}_{1.5}-\mathrm{X}-1.0$ sample) to 21 (the $\mathrm{Li}_{7.8} \mathrm{Na}_{1.2} \mathrm{Ag}_{21}-\mathrm{X}-1.0$ sample). This plot reveals that the incorporation of only a small amount of silver changes the adsorptive properties of the near fully exchanged $\mathrm{Li}_{94.5} \mathrm{Na}_{1.5}-\mathrm{X}-1.0$ zeolite. With increasing additions of $\mathrm{Ag}^{+}$(and corresponding removal of $\mathrm{Li}^{+}$and $\mathrm{Na}^{+}$) the adsorption isotherms begin to take on more of the characteristics of the near fully exchanged $\mathrm{Ag}_{95.3} \mathrm{Na}_{0.3}-\mathrm{X}-1.0$ material (i.e., the high "knee" at low pressures).

Dehydration and Formation of Ag-clusters. As mentioned earlier, zeolites have a strong affinity for water; and some molecules are held tenaciously. The materials must be completely dehydrated prior to measurement of the adsorption isotherms in order to guarantee the validity of the result. Further, the dehydration conditions have a significant effect on the formation of silver clusters, with the atmosphere and temperature of the dehydration being the most important. ${ }^{17,18,21,23}$ For the near fully exchanged $\mathrm{Li}$ material there is no significant increase in the $\mathrm{N}_{2}$ capacity (or in the shape of the adsorption isotherm) for the material dehydrated at $450 \mathrm{C}$ over that dehydrated at 350 C. This is expected as the majority of zeolitic water is easily removed by $250 \mathrm{C}$ and most tenaciously held water molecules are removed by $350 \mathrm{C}^{4}{ }^{4}$ However, the near fully exchanged $\mathrm{Ag}_{95.7} \mathrm{Na}_{0.3}-\mathrm{X}-1.0$ sample does show an increase in $\mathrm{N}_{2}$ capacity after dehydration at $450 \mathrm{C}$ over that of the same sample dehydrated at $350 \mathrm{C}$. This increase cannot be attributed a loss of water since all but the most tenaciously held water is removed by $350 \mathrm{C}$; and there is no increase in the $\mathrm{N}_{2}$ capacity for other zeolite forms $\left(\mathrm{Li}^{+}, \mathrm{Na}^{+}, \mathrm{K}^{+}\right.$, etc. $)$with dehydration at temperatures beyond $350 \mathrm{C}$. This increase, therefore, was the result of the formation of charged silver clusters in the zeolite with dehydration at high temperature. 
A series of $\mathrm{N}_{2}$ adsorption isotherms was measured for $\mathrm{Ag}_{95.7} \mathrm{Na}_{0.3}-\mathrm{X}-1.0$ and $\mathrm{Li}_{73.8} \mathrm{Na}_{1.2} \mathrm{Ag}_{21}-\mathrm{X}-1.0$ after partial or full dehydration in vacuum at various temperatures. The results for both zeolites showed a continual increase in the $\mathrm{N}_{2}$ adsorption capacity (at $1 \mathrm{~atm})$ with increasing dehydration temperature up to 450 - 500 C. Materials which had been dehydrated in vacuum at $550 \mathrm{C}$ and $600 \mathrm{C}$ had $\mathrm{N}_{2}$ capacities which were considerably lower than those dehydrated in vacuum at $450-500 \mathrm{C}$.

It is obvious that the ultimate adsorptive characteristics of the silver-containing zeolites are very dependent upon the formation of silver clusters and, therefore, on the dehydration conditions. We have found that best results are given when the silvercontaining zeolites are dried at room temperature before being completely dehydrated in vacuum at a temperature of at least $450 \mathrm{C}$, but no greater than $500 \mathrm{C}$. The zeolites should be held at the dehydration temperature for a minimum of 4 hours.

Heat of Adsorption and Energetic Heterogeneity. Heterogeneity in zeolites may result from a number of causes including a mixed population of charge compensating cations. If the intracrystalline cation composition is mixed, sites in the vicinity of a cation will differ for each cation whether or not they occupy equivalent crystallographic positions. Further, in a mixed cation population the proportion of one cation to another may vary from one cavity to another so that the behavior of the cavities as multiple sorption sites may vary throughout the crystal. ${ }^{3}$

The presence of energetic heterogeneity of a system can be determined by plotting the isosteric heat of adsorption versus the amount adsorbed. Energetic heterogeneity of the system will result in a decrease in the isosteric heat of adsorption as the amount sorbed increases. For small uptakes, the isosteric heat may decrease rather strongly with 
the amount adsorbed. This would be an indication that there are some local intracrystalline positions where the guest molecules are preferentially sorbed more exothermally than in the rest of the intracrystalline volume. At intermediate uptakes, the slope of this plot will usually decrease and become nearly constant.

The measurement of adsorption isotherms at different temperatures permits the calculation of the heat of adsorption as a function of surface coverage. When experimental data are reported as a set of adsorption isotherms for a particular gasadsorbent system, the isosteric heat of adsorption is usually calculated. ${ }^{25}$ The isosteric heat of adsorption can be calculated from a series of isotherms by application of the Clausius-Claperyron equation as follows:

$$
\Delta H_{a d s}=R\left(\frac{d \ln P}{d(1 / T)}\right)_{n}
$$

Using the data from nitrogen and oxygen adsorption isotherms measured at $50 \mathrm{C}, 25 \mathrm{C}$, and $0 \mathrm{C}$, the isosteric heats of adsorption were determined by evaluating the slope of a plot of $\ln (\mathrm{P})$ versus $(1 / \mathrm{T})$ at several coverages. The plots of $\ln \left(\mathrm{P}_{\mathrm{N} 2}\right)$ versus (1/T) at several coverages for $\mathrm{Li}_{94.5} \mathrm{Na}_{1.5}-\mathrm{X}-1.0$ (top) and $\mathrm{Li}_{94.2} \mathrm{Na}_{0.7} \mathrm{Ag}_{1.1}-\mathrm{X}-1.0$ (bottom) are shown in Figure 6. The isosteric heats of adsorption at different coverages were calculated for each of these materials (and for the fully exchanged Ag-X-1.0) and are shown in Figure 7. A similar analysis was also done for the oxygen and argon data, but these results are not shown. From the plots of the heats of nitrogen adsorption, shown in Figure 7, one can see that the isosteric heat of adsorption for $\mathrm{N}_{2}$ on $\mathrm{Li}_{94.2} \mathrm{Na}_{0.7} \mathrm{Ag}_{1.1}-\mathrm{X}-1.0$ is quite high ( $8 \mathrm{kcal} / \mathrm{mol}$ ) at low coverages, but immediately drops sharply to become nearly horizontal. This indicates the presence of local intracrystalline sites where the $\mathrm{N}_{2}$ is preferentially sorbed more strongly than at other sites within the intracrystalline 
volume. A comparison with the same plot of the isosteric heat of adsorption for $\mathrm{N}_{2}$ on for $\mathrm{Li}_{94.5} \mathrm{Na}_{1.5} \mathrm{X}-1.0$, which is essentially horizontal, shows that the energetic heterogeneity of the $\mathrm{Li}_{9.2} \mathrm{Na}_{0.7} \mathrm{Ag}_{1.1} \mathrm{X}-1.0$ zeolite is due entirely to the incorporation of the approximately one Ag per unit cell. The plots of the heats of adsorption for $\mathrm{O}_{2}$ and $\mathrm{Ar}$ were horizontal with coverage, indicating the interaction between the silver clusters and these guest molecules is much less than with the $\mathrm{N}_{2}$. The approximately constant heat of adsorption with increasing coverage for the $\mathrm{Li}_{94.5} \mathrm{Na}_{1.5}-\mathrm{X}-1.0$ is consistent with previously reported results, ${ }^{25}$ and likely indicates an energetically homogeneous surface.

Cation Site Location For the $\mathrm{X}$ zeolites, the cation site designations are conventionally designated as SI (the center of the hexagonal prism), SI' (opposite SI but located in the cubooctahedron), SII (single six-ring in the supercage), SII' (opposite SII but inside the cubooctahedron), and SIII (near the four-ring windows in the supercage). ${ }^{4}$

Several studies have been employed in order to locate extraframework $\mathrm{Li}^{+}$cations in $\mathrm{X}, \mathrm{Y}$ and A zeolites using solid state NMR and neutron diffraction methods. ${ }^{26,27}$ It was found that the $\mathrm{Li}^{+}$ions fully occupy all 32 SI' sites and all 32 SII sites. The SIII sites were then occupied with the remaining $\mathrm{Li}^{+}$ions, 22 for $\mathrm{Li}_{86}-\mathrm{X}-1.25$ and 32 for $\mathrm{Li}_{96}-\mathrm{X}-1.0$. No occupancy of the SI sites was observed. Coe reported an occupancy "threshold" of 64 cations. ${ }^{10}$ Mixed $\mathrm{Li}_{\mathrm{x}} \mathrm{Na}_{\mathrm{y}}-\mathrm{X}$ zeolites which contained less $\mathrm{Li}^{+}$than this threshold amount did not show any increase in the $\mathrm{N}_{2}$ adsorption capacity over that of the fully $\mathrm{Na}^{+}-$ exchanged materials. This indicated that only those $\mathrm{Li}^{+}$ions located in the SIII cation sites were interacting with the $\mathrm{N}_{2}$ molecules. This result is interesting because, even though the SI and SI' sites are sterically inaccessible to the $\mathrm{N}_{2}$ molecules, the SII sites are not; and other cations, such as $\mathrm{Ca}^{2+}$, do interact with $\mathrm{N}_{2}$ when located in the SII positions. 
Numerous studies have also been undertaken to identify the location of $\mathrm{Ag}^{+}$ions and Ag-clusters, typically by X-ray diffraction methods ${ }^{17,18,21,22}$ and far-infrared spectroscopy. ${ }^{20,28}$ It was found that, for dehydrated, fully $\mathrm{Ag}^{+}$-exchanged faujasite-type zeolites, the silver cations (or ground state atoms) were distributed among the six-ring sites (SI, SI', and SII for type X) and, for samples with high Al content, in the SIII locations. Gellens et al. and Baker et al. showed the simultaneous occupancy of sites SI and SI' by linear $\left(\mathrm{Ag}^{+}-\mathrm{Ag}^{0}-\mathrm{Ag}^{+}\right)$clusters. ${ }^{20,21}$ In general, all studies seemed to indicate that the $\mathrm{Ag}$ cations and atoms preferred the SI and SI' sites.

No studies have been conducted to identify the location of $\mathrm{Li}^{+}$and $\mathrm{Ag}^{+}$cations in mixed $\mathrm{Li}_{\mathrm{x}} \mathrm{Ag}_{\mathrm{y}}$-zeolites. While it has been shown that the $\mathrm{Ag}^{+}$ions prefer the SI and SI' locations, it is known that the $\mathrm{Li}^{+}$ions also strongly prefer the SI' sites. Both of these sites are sterically inaccessible to the $\mathrm{N}_{2}$ and $\mathrm{O}_{2}$ molecules; so the formation of silver clusters in these locations may not have a strong effect on the overall adsorptive characteristics of the mixed $\mathrm{Li}_{\mathrm{x}} \mathrm{Ag}_{\mathrm{y}}-\mathrm{X}$ zeolites. Therefore, it is expected that the clusters, in these mixed cation zeolites, are instead formed at the $\mathrm{N}_{2}$ and $\mathrm{O}_{2}$ accessible SII and/or SIII locations due to competition with the $\mathrm{Li}^{+}$cations for the preferred $\mathrm{SI}$ and $\mathrm{SI}$ locations. Logically, Ag-cluster formation at the SII sites would most enhance the adsorptive characteristics of mixed $\mathrm{Li}_{\mathrm{x}} \mathrm{Ag}_{\mathrm{y}} \mathrm{X}$ zeolites since these sites have been shown to be non-interactive when occupied with $\mathrm{Li}^{+}$ions. Kim and Seff identified the location of $\mathrm{Ag}$ in mixed $\mathrm{Na}_{\mathrm{x}} \mathrm{Ag}_{\mathrm{y}}-\mathrm{A}$ zeolites and found that the $\mathrm{Ag}$ ions prefer six-ring sites (such as the SI, SI' and SII in the X zeolites). ${ }^{29}$ This may indicate a preference for the SII sites in type X zeolites when the SI and SI' sites are unavailable (due to competition with $\mathrm{Li}^{+}$). 
Another possibility is that the Ag clusters were formed in the SI-SI' sites, and due to the strong field gradient that is generated by $\mathrm{Ag}^{+}$, enhanced interactions with the $\mathrm{N}_{2}$ molecules is still possible. This possibility would account for the fact that the optimal sorbent contained only, on average, approximately one Ag per unit cell, because each $\mathrm{Ag}_{3}{ }^{2+}$ cluster was shared by three supercage cavities. Further work to identify the $\mathrm{Ag}$ cluster location(s) is in progress.

The Nature of the Interaction. The total energy of physical adsorption, $\phi_{\mathrm{T}}$, is the result of the interactions between adsorbate molecules and interactions between the adsorbate molecules and the zeolite cavity wall. ${ }^{30}$ The $\phi_{\mathrm{T}}$ is comprised of dispersive (D), repulsive $(\mathrm{R})$, polarization $(\mathrm{P})$, field-dipole $(\mathrm{FD})$ interactions, field-quadrupole (FQ) interactions, and adsorbate-adsorbate energies and can be written as follows:

$$
\phi_{\mathrm{T}}=-\left(\phi_{\mathrm{D}}-\phi_{\mathrm{R}}\right)-\phi_{\mathrm{P}}-\phi_{\mathrm{FD}}-\phi_{\mathrm{FQ}}-\phi_{\mathrm{AA}}
$$

The adsorbates of interest in this evaluation $\left(\mathrm{N}_{2}, \mathrm{O}_{2}\right.$, and $\left.\mathrm{Ar}\right)$ do not have permanent dipoles; and the coverages are low. Therefore, the field-dipole and adsorbate-adsorbate interactions can be ignored and eq. (4) can be reduced to:

$$
\phi_{\mathrm{T}}=-\left(\phi_{\mathrm{D}}-\phi_{\mathrm{R}}\right)-\phi_{\mathrm{P}}-\phi_{\mathrm{FQ}}
$$

Because the $\mathrm{N}_{2}$ and $\mathrm{O}_{2}$ molecules are very similar in size and have comparable polarizabilities, the dispersive, repulsive and polarization energies between the adsorbate and the extra-framework cations are very similar. The quadrupole moment of the $\mathrm{N}_{2}$ molecule is approximately four times that of the $\mathrm{O}_{2}$ molecule and is primarily responsible for the difference in the adsorptive capacity for $\mathrm{N}_{2}$ over that of $\mathrm{O}_{2}$. Argon, which does not have a quadrupole moment, is more greatly affected by the polarization energy; and for most zeolites, the Ar capacity is about the same as that of $\mathrm{O}_{2}$. 
The very high heat of binding of the $\mathrm{N}_{2}$ molecules at very low pressures is probably due to very high electrostatic fields near the exposed charged Ag-clusters and their interaction with the quadrupole moment of the $\mathrm{N}_{2}$ molecule. However, because there is also an increase in the adsorption of argon, which does not have a quadrupole moment, these charged clusters must also contribute to the total energy of physical adsorption by increased van der Waals and field-induced dipole energies and could possibly have a higher polarizing power than that of isolated silver cations.

Physical adsorption, however, is likely not the only contribution to $\mathrm{N}_{2}$ adsorption in silver-containing zeolites. Yang et al, noting the high isosteric heat of adsorption for $\mathrm{N}_{2}$ on $\mathrm{Ag}_{86}-\mathrm{X}-1.25$ zeolites combined with a relatively slow desorption of $\mathrm{N}_{2}$ on the same, proposed some degree of weak $\pi$-complexation. ${ }^{15}$ The $\pi$-complexation character of the interaction was subsequently confirmed by ab inito molecular orbital calculations using $\mathrm{N}_{2}$ and an $\mathrm{Ag}-\mathrm{X}$ cluster model and was referred to as "weak chemisorption-assisted adsorption". ${ }^{16}$

PSA Cycle Description. A standard five-step PSA cycle that is presently used in industry for air separation (Leavitt, 1991) was used in this study. The steps involved in each cycle are as follows: (step I) pressurization with the feed gas, namely, $22 \% \mathrm{O}_{2}$ (mixture of $\mathrm{O}_{2}$ and $\mathrm{Ar}$ ) and $78 \% \mathrm{~N}_{2}$; (step II) high pressure adsorption with the feed gas, or feed step; (step III) cocurrent depressurization; (step IV) countercurrent blowdown; and (step V) countercurrent low pressure purge with the product of the feed step (oxygen).

All the above steps were of equal duration (30 seconds); thus the time required for the completion of each PSA cycle was 2.5 minutes. The model assumed only two 
adsorbable components, $\mathrm{O}_{2}$ and $\mathrm{N}_{2}$. The oxygen component (22\%) was actually a mixture of $\mathrm{O}_{2}$ and Ar which have very similar adsorption isotherms for the sorbents of interest. The product of each cycle was comprised of a volumetric mixture of the output stream of the feed step and the cocurrent depressurization step. A portion of this product stream was used to purge the bed countercurrently in step V.

In order to compare the performance of the $\mathrm{Li}_{94.5} \mathrm{Na}_{1.5}-\mathrm{X}-1.0$ and the $\mathrm{Li}_{94.2} \mathrm{Na}_{0.7} \mathrm{Ag}_{1.1}-\mathrm{X}-1.0$ sorbent developed in this work, the product throughputs of the two sorbents were studied under two different cycle conditions using computer simulations. In order to facilitate a fair comparison of the sorbent performance, the cycle conditions were optimized such that the product purity and product recovery obtained were the same for both the sorbents in each respective simulation run. In this work, the product purity, product recovery and product throughput are defined as follows :

$$
\begin{aligned}
& \text { product purity }=\frac{(\text { amount of } \mathrm{O} 2 \text { from steps II and III })}{(\text { amount of N2 and O2 from steps II and III })} \\
& \text { product recovery }=\frac{(\mathrm{O} 2 \text { from steps II and III })-(\mathrm{O} 2 \text { used in step V })}{(\mathrm{O} 2 \text { fed in step I and step II })} \\
& \text { product throughput }=\frac{(\text { amount of } \mathrm{O} 2 \text { produced per hour }(\mathrm{kg} / \mathrm{hr}))}{(\text { amount of adsorbent used in the bed }(\mathrm{kg}))}
\end{aligned}
$$

The mathematical model and the numerical method used for the PSA simulations in this study has been explained in detail in an earlier work. ${ }^{2}$ Hence, only the basic assumptions will be listed here. The model used assumes the flow of a gaseous mixture 
of two components in a fixed bed packed with spherical adsorbent particles. The bed is considered to be adiabatic and diffusional resistance is assumed to be negligible since the diffusion of $\mathrm{O}_{2}$ and $\mathrm{N}_{2}$ in the adsorbents is essentially instantaneous, as observed in this study. Thus, there is local equilibrium between the gas and the solid phase of each gas component. Axial dispersion for mass and heat transfer is assumed but dispersion in the radial direction is taken to be negligible. Axial pressure drop is neglected and ideal gas law is assumed to hold since pressures involved are near atmospheric. Also the gas is assumed to have constant viscosity and heat capacity.

The pure component equilibrium amounts adsorbed on the respective adsorbents were fit using th

$$
\mathrm{q}_{\mathrm{k}}^{*}=\frac{\mathrm{q}_{\mathrm{k}} \mathrm{b}_{\mathrm{k}} \mathrm{p}_{\mathrm{k}}}{1+\sum_{\mathrm{j}=1}^{\mathrm{m}} \mathrm{b}_{\mathrm{j}} \mathrm{p}_{\mathrm{j}}} \quad \mathrm{k}=1,2
$$

The temperature dependence of the Langmuir parameters is assumed to be as follows:

$$
\mathrm{q}_{\mathrm{m}}=\mathrm{k}_{1} \exp \left(\mathrm{k}_{2} / \mathrm{T}\right) \quad \text { and } \quad \mathrm{b}=\mathrm{k}_{3} \exp \left(\mathrm{k}_{4} / \mathrm{T}\right)
$$

The values of the Langmuir equation terms for $\mathrm{Li}_{94.5} \mathrm{Na}_{1.5}-\mathrm{X}-1.0$ and $\mathrm{Li}_{94.2} \mathrm{Na}_{0.7} \mathrm{Ag}_{1.1}-\mathrm{X}-$ 1.0 sorbents, as well as the heats of adsorption are given in Table 3.

Simulation Results. The PSA bed characteristics and the operating conditions used are summarized in Table 4. The PSA cycle parameters were chosen as close to industrially acceptable values as possible. The pressure ratio, which is the ratio of the feed pressure $\left(\mathrm{P}_{\mathrm{H}}\right)$ to the desorption pressure $\left(\mathrm{P}_{\mathrm{L}}\right)$, is an important operating characteristic and it has been shown that a value of 3 suffices for an optimal PSA performance using the Li-X-1.0 sorbent. $^{2}$ The same pressure ratio was employed for the comparison of the 
$\mathrm{Li}_{94.5} \mathrm{Na}_{1.5} \mathrm{X}-1.0$ and $\mathrm{Li}_{94.2} \mathrm{Na}_{0.7} \mathrm{Ag}_{1.1}-\mathrm{X}-1.0$ sorbents in this work. As can been seen from Table 5, run 1 comprised of a feed pressure of 1.0 atm while run 2 was carried out at a higher feed pressure of $1.2 \mathrm{~atm}$. The cocurrent depressurization pressure, feed velocity and purge velocity were optimized so as to obtain the same product purity and recovery for both the sorbents. As seen from the $\mathrm{O}_{2}$ and $\mathrm{N}_{2}$ isotherms in Figure 8, the Li94.2 $\mathrm{Na}_{0.7} \mathrm{Ag}_{1.1}-\mathrm{X}-1.0$ sorbent has a higher capacity for $\mathrm{N}_{2}$. From the extended Langmuir isotherm (eq. 9), it follows that the higher $\mathrm{N}_{2}$ loading further suppresses the $\mathrm{O}_{2}$ loading under mixture conditions, and as a result the working capacity of the $\mathrm{Li}_{94.2} \mathrm{Na}_{0.7} \mathrm{Ag}_{1.1} \mathrm{X}$ 1.0 sorbent further increases. Hence the amount of bed utilization (or the depth of propagation of the $\mathrm{N}_{2}$ wavefront in the bed) of the $\mathrm{Li}_{94.2} \mathrm{Na}_{0.7} \mathrm{Ag}_{1.1}-\mathrm{X}-1.0$ sorbent was lower than that of the $\mathrm{Li}_{94.5} \mathrm{Na}_{1.5} \mathrm{X}-1.0$ sorbent under identical cycle conditions. The higher capacity of the $\mathrm{Li}_{94.2} \mathrm{Na}_{0.7} \mathrm{Ag}_{1.1}-\mathrm{X}-1.0$ sorbent could be exploited by employing higher feed throughputs and lower cocurrent depressurization pressure without significantly lowering product purity and recovery. An obvious outcome of the higher capacity of the $\mathrm{Li}_{94.2} \mathrm{Na}_{0.7} \mathrm{Ag}_{1.1}-\mathrm{X}-1.0$ sorbent was a higher product throughput compared to that of the $\mathrm{Li}_{94.5} \mathrm{Na}_{1.5}-\mathrm{X}-1.0$ sorbent when the other performance parameters (i.e., product purity and recovery) were kept the same. However, the heats of adsorption of the two components on the $\mathrm{Li}_{94.2} \mathrm{Na}_{0.7} \mathrm{Ag}_{1.1}-\mathrm{X}-1.0$ sorbent were also higher than those on the Li $94.5 \mathrm{Na}_{1.5}-\mathrm{X}-1.0$ sorbent. Severe temperature rise during adsorption is known to adversely affect PSA separation performance. Hence a PSA simulation run became necessary to critically evaluate the importance of higher $\mathrm{N}_{2}$ loading in case of Li ${ }_{94.2} \mathrm{Na}_{0.7} \mathrm{Ag}_{1.1} \mathrm{X}-1.0$ sorbent and the accompanying heat effects. 
The results of the simulation runs are shown in Table 3. It can be seen from run 1 (feed pressure: $1 \mathrm{~atm}$ ), the $\mathrm{O}_{2}$ product throughput obtained by using $\mathrm{Li}_{94.2} \mathrm{Na}_{0.7} \mathrm{Ag}_{1.1}-\mathrm{X}$ 1.0 sorbent was $5.4 \times 10^{-2} \mathrm{~kg} \mathrm{O}_{2} / \mathrm{h} / \mathrm{kg}$-sorbent compared to the throughput of $4.8 \times 10^{-2} \mathrm{~kg}$ $\mathrm{O}_{2} / \mathrm{h} / \mathrm{kg}$-sorbent offered by $\mathrm{Li}_{94.5} \mathrm{Na}_{1.5}-\mathrm{X}-1.0$ sorbent. The corresponding $\mathrm{O}_{2}$ product purity and recovery were approximately $96 \%$ and $62 \%$ respectively. There is an improvement of $12.5 \%$ in the product throughput which translates into considerable savings in capital and operating costs since a higher product throughput implies a smaller bed requirement for the same desired production. Another run was done at a different feed pressure of 1.2 atm with the cycle conditions optimized to produce $\mathrm{O}_{2}$ product at $90.7 \%$ purity and $78 \%$ recovery. In this case as well, the product throughput of the $\mathrm{Li}_{94.2} \mathrm{Na}_{0.7} \mathrm{Ag}_{1.1}-\mathrm{X}-1.0$ sorbent was found to be higher $\left(7 \times 10^{-2} \mathrm{~kg} \mathrm{O} / \mathrm{h} / \mathrm{kg}\right.$-sorbent$)$, compared to that of the $\mathrm{Li}_{94.5} \mathrm{Na}_{1.5}-\mathrm{X}-1.0$ sorbent $\left(6.3 \times 10^{-2} \mathrm{~kg} \mathrm{O}_{2} / \mathrm{h} / \mathrm{kg}\right.$-sorbent $)$. Thus, the product throughput of the $\mathrm{Li}_{94.2} \mathrm{Na}_{0.7} \mathrm{Ag}_{1.1}-\mathrm{X}-1.0$ sorbent is higher by $11 \%$ even at a lower $\mathrm{O}_{2}$ product purity requirement. The values of the throughputs obtained in this study were found to have an order of magnitude agreement with those published for LiX-1.0 sorbent in literature. ${ }^{31}$ From the simulated bed profiles, it was observed that temperature deviations from the feed temperature of $25^{\circ} \mathrm{C}$ due to the adsorption heat effects were about $17^{\circ} \mathrm{C}$ for the $\mathrm{Li}_{94.2} \mathrm{Na}_{0.7} \mathrm{Ag}_{1.1}-\mathrm{X}-1.0$ sorbent while it was only $12^{\circ} \mathrm{C}$ for the $\mathrm{Li}_{94.5} \mathrm{Na}_{1.5}-\mathrm{X}-1.0$ sorbent. However, from the results it appears that the advantage of higher $\mathrm{N}_{2}$ loading on the $\mathrm{Li}_{9.2} \mathrm{Na}_{0.7} \mathrm{Ag}_{1.1}-\mathrm{X}-1.0$ more than compensates the lowering of PSA performance due to higher heat effects. Hence it is evident from the previous two examples that the $\mathrm{Li}_{94.2} \mathrm{Na}_{0.7} \mathrm{Ag}_{1.1}-\mathrm{X}-1.0$ sorbent is superior to the $\mathrm{Li}_{4.5} \mathrm{Na}_{1.5}-\mathrm{X}-1.0$ sorbent for air separation by PSA. 


\section{Notation}

$$
\begin{aligned}
\mathrm{b} & =\text { Langmuir parameter, } \mathrm{atm}^{-1} \\
\mathrm{D}_{\mathrm{ax}} & =\text { Axial dispersion coefficient in adsorbent particles, } \mathrm{m}^{2} / \mathrm{s} \\
\mathrm{H} & =\text { Heat of adsorption, } \mathrm{kcal} / \mathrm{mol} \\
\mathrm{k}_{1} & =\text { Langmuir temperature dependence constant, } \mathrm{mmol} / \mathrm{g} \\
\mathrm{k}_{2}, \mathrm{k}_{4} & =\text { Langmuir temperature dependence constant, } \mathrm{K} \\
\mathrm{k}_{3} & =\text { Langmuir temperature dependence constant, atm }{ }^{-1} \\
\mathrm{p} & =\text { Partial pressure, atm } \\
\mathrm{P} & =\text { Total pressure, atm } \\
\mathrm{q}_{\mathrm{m}} & =\text { Langmuir parameter, mmol } / \mathrm{g} / \mathrm{atm} \\
\mathrm{q}^{*} & =\text { Equilibrium adsorbate loading, mmol } / \mathrm{g} \\
\mathrm{T} & =\text { Temperature, } \mathrm{K} \\
\mathrm{U} & =\text { Interstitial gas velocity, } \mathrm{m} / \mathrm{s}
\end{aligned}
$$

\section{Subscripts :}

$$
\begin{aligned}
& \mathrm{CD} \quad=\text { Intermediate pressure corresponding to the co-current depressurization step } \\
& \mathrm{H} \quad=\text { Corresponding to the feed step } \\
& \mathrm{i} \quad=\text { Species ' } \mathrm{i} \\
& \mathrm{j}, \mathrm{k} \quad=\text { Gas phase component index } \\
& \mathrm{L} \quad=\text { Low pressure corresponding to purge step. }
\end{aligned}
$$




\section{Literature Sited}

(1) Yang, R. T. Gas Separation by Adsorption Processes . Butterworth: Boston, 1987; reprinted (in paperback) by Imperial College Press: London and World Scientific Publishing Co.: River Edge, NJ, 1997.

(2) Rege, S. U., and R. T. Yang, "Limits for Air Separation by Adsorption with LiX Zeolite”, Ind. Eng. Chem. Res., 36, 5358 (1997).

(3) Barrer, R. M., Zeolites and Clay Minerals as Sorbents and Molecular Sieves, Academic Press, London, 1978.

(4) Breck, D. W., Zeolite Molecular Sieves; R. E. Krieger Publishing, Malabar, FL, 1984.

(5) Kuhl, G. H., "Crys tallization of Low-Silica Faujasite $\left(\mathrm{SiO}_{2} / \mathrm{Al}_{2} \mathrm{O}_{3} \quad\right.$ 2.0)", Zeolites, 7, 451 (1987).

(6) McKee, D. W., "Separation of an Oxygen-Nitrogen Mixture", U.S. Patent 3,140,933, 1964.

(7) Chao, C. C., "Process for Separating Nitrogen from Mixtures Thereof with Less Polar Substances", US Patent 4,859,217 (1989).

(8) Chao, C. C., J. D. Sherman, J. T. Mullhaupt, and C. M. Bolinger, "Mixed Ionexhanged Zeolites and Processes for the Use Thereof in Gas Separations", U. S. Patent 5,174,979 (1992).

(9) Coe, C. G., J. F. Kirner, R. Pierantozzi, and T. R. White, "Nitrogen Adsorption with a Ca and/or Sr Exchanged Zeolite", U. S. Patent 5,152,813 (1992).

(10) Coe, C. G., in Access in Nanoporous Materials, T. J. Pinnavaia and M. F. Thorpe (Eds.), Plenum Press, New York, 1995 (p. 213).

(11) Yang, R. T., "Recent Advances and New Horizons in Gas Adsorption - with a Focus on New Sorbents", in Preprints Topical Conf. Separ. Sci. Tech. (Eds.: W. S. W. Ho and R. G. Luo) AIChE, New York (1997), p. 14.

(12) Fitch, F. R., M. Bulow, and A. F. Ojo, "Adsorptive Separation of Nitrogen and Other Gases", U. S. Patent 5,464,467 (1995).

(13) Habgood, H. W., "Adsorptive and Gas Chromatographic Properties of Various Cationic Forms of Zeolite X”, Can. J. Chem., 42, 2340 (1964).

(14) Huang, Y., "Adsorption in AgX and AgY Zeolites by Carbon Monoxide and Other Simple Molecules”, J. Catalysis, 32, 482 (1974). 
(15) Yang, R. T., Y. D. Chen, J. D. Peck, and N. Chen, "Zeolites Containing Mixed Cations for Air Separation by Weak Chemisorption-Assisted Adsorption", Ind. Eng. Chem. Res., 35, 3093 (1996).

(16) Chen, N., and R. T. Yang, "An ab Initio Molecular Orbital Study of Adsorption of Oxygen, Nitrogen and Ethylene on Silver-Zeolite and Silver Halides", Ind. Eng. Chem. Res., 35, 4020 (1996).

(17) Kim, Y., and Seff. K., "The Octahedral Hexasilver Molecule. Seven Crystal Structures of Variously Vacuum-Dehydrated Fully $\mathrm{Ag}^{+}$-Exchanged Zeolite A, J. Am. Chem. Soc., 100, 6989 (1978a).

(18) Kim, Y., and K. Seff, "The Hexasilver Molecule Stabilized by Coordination to Six Silver Ions. The Structure of $\left(\mathrm{Ag}^{+}\right)_{6}\left(\mathrm{Ag}_{6}\right)$. The Crystal Structure of an Ethylene Sorption Complex of Partially Decomposed Fully $\mathrm{Ag}^{+}$-Exchanged Zeolite A", $J$. Am. Chem. Soc., 100, 175 (1978b).

(19) Jacobs, P. A., J. B. Uytterhoeven, and H. K. Beyer, "Some Unusual Properties of Activated and Reduced AgNaA Zeolites", J. Chem. Soc. Faraday Trans. 1, 75, 56 (1979).

(20) Baker, M. D., G. A. Ozin, and J. Godber, "Far-Infrared Studies of Silver Atoms, Silver Ions, and Silver Clusters in Zeolites A and Y", J. Phys, Chem., 89, 305 (1985).

(21) Gellens, L. R., W. J. Mortier, and J. B. Uytterhoeven, "On the Nature of the Charged Silver Clusters in Zeolites of Type A, X and Y", Zeolites, 1, 11 (1981a).

(22) Gellens, L. R., W. J. Mortier, R. A. Schoonheydt, and J. B. Uytterhoeven, "The Nature of the Charged Silver Clusters in Dehydrated Zeolites of Type A", J. Phys. Chem., 85, 2783 (1981b).

(23) Gellens, L. R., J. V. Smith, and J. J. Pluth, "Crystal Structure of VacuumDehydrated Silver Hydrogen Zeolite A", J. Am. Chem. Soc., 105, 51 (1983).

(24) Knaebel, K. S., and A. Kandybin, "Pressure Swing Adsorption System to Purify Oxygen", US Patent 5,226,933, 1993.

(25) Bajusz, I. G., and J. G. Goodwin, "N $\mathrm{N}_{2}$ Adsorption in LiX Zeolite: Isotopic Transient Analysis", Langmuir, 13, 6550 (1997).

(26) Feuerstein, M., and R. F. Lobo, "Characterization of Li Cations in Zeolite LiX by Solid-State NMR Spectroscopy and Neutron Diffraction", Chem. Mater., 10, 2197 (1998). 
(27) Herden, H., W. D. Einicke, R. Schollner, W. J. Mortier, L. R. Gellens, and J. B. Uytterhoeven, "Location of Li-ions in Synthetic Zeolites X and Y", Zeolites, 2, 131 (1982).

(28) Ozin, G. A., M. D. Baker, and J. Godber, "Direct Observation of the Reversible Redox Couple $\mathrm{Ag}_{3}{ }^{2+} \Leftrightarrow \mathrm{Ag}_{3}{ }^{0}$ in Silver Zeolite A by Fourier Transform FarInfrared Spectroscopy", J. Phys. Chem., 88, 4902 (1984).

(29) Kim, Y., and K. Seff, "Crystal Structure of Fully Dehydrated, Partially $\mathrm{Ag}^{+}-$ Exchanged Zeolite 4A, $\mathrm{Ag}_{7.6} \mathrm{Na}_{4.4}-\mathrm{A}$. $\mathrm{Ag}^{+}$Ions Prefer 6-Ring Sites. One $\mathrm{Ag}^{+}$Ion is Reduced", J. Phys. Chem., 91, 671 (1987).

(30) Razmuz, D. M., and C. K. Hall, "Prediction of Gas Adsorption in 5A Zeolites Using Monte Carlo Simulation”, A. I. Ch. E. J., 37, 769 (1991).

(31) Leavitt, F. W., "Air separation pressure swing adsorption process", U.S. Patent $5,074,892,1991$. 
Table 1. Parameters in the temperature dependent Langmuir isotherms of $\mathbf{N}_{2}$ and $\mathrm{O}_{2}$ for the $\mathrm{Li}_{96}-\mathrm{X}-1.0$ and $\mathrm{Li}_{95} \mathrm{Ag}_{1}-\mathrm{X}-1.0$ adsorbents.

\begin{tabular}{|l|l|l|l|l|l|l|}
\hline Sorbent & Sorbate & $\begin{array}{l}\mathbf{k}_{\mathbf{1}} \\
(\mathbf{m m o l} / \mathbf{g})\end{array}$ & $\begin{array}{l}\mathbf{k}_{\mathbf{2}} \\
(\mathbf{K})\end{array}$ & $\begin{array}{l}\mathbf{k}_{\mathbf{3}} \\
\left(\mathbf{a t m}^{-\mathbf{1}}\right)\end{array}$ & $\begin{array}{l}\mathbf{k}_{\mathbf{4}} \\
(\mathbf{K})\end{array}$ & $\begin{array}{l}-\mathbf{\Delta H} \\
(\mathbf{k c a l} / \mathbf{m o l})\end{array}$ \\
\hline $\mathrm{Li}{ }_{96}-\mathrm{X}-1.0$ & $\mathrm{O}_{2}$ & 1.14 & 239.2 & $2.20 \times 10^{-3}$ & 1092 & 2.66 \\
\hline $\mathrm{Li}_{96}-\mathrm{X}-1.0$ & $\mathrm{~N}_{2}$ & 1.69 & 134.4 & $1.19 \times 10^{-3}$ & 1990 & 5.16 \\
\hline $\mathrm{Li}_{95} \mathrm{Ag}_{1}-\mathrm{X}-1.0$ & $\mathrm{O}_{2}$ & 0.965 & 196.0 & $2.25 \times 10^{-3}$ & 1212 & 3.00 \\
\hline $\mathrm{Li}_{95} \mathrm{Ag}_{1}-\mathrm{X}-1.0$ & $\mathrm{~N}_{2}$ & 2.12 & 64.82 & $7.78 \times 10^{-3}$ & 1494 & 5.39 \\
\hline
\end{tabular}


Table 2. Adsorption bed characteristics and operating conditions used in the PSA simulations.

Bed length

Diameter of adsorber bed

Bed external porosity

Bed density

Heat capacity of gases

Heat capacity of bed

Wall temperature

Feed gas composition

Feed gas temperature

Axial dispersion coefficient $\left(D_{\mathrm{ax}}\right)$
$2.5 \mathrm{~m}$

$1.0 \mathrm{~m}$

0.40

$720 \mathrm{~kg} / \mathrm{m}^{3}$

$6.87 \mathrm{cal} / \mathrm{mol} / \mathrm{K}$

$0.28 \mathrm{cal} / \mathrm{g} / \mathrm{K}$

$298 \mathrm{~K}$ (ambient)

$78 \% \mathrm{~N}_{2}, 22 \% \mathrm{O}_{2}$

$298 \mathrm{~K}$

$5 \times 10^{-3} \mathrm{~m}^{2} / \mathrm{s}$ 
Table 3. PSA simulation operating conditions and results.

Run 1.

\begin{tabular}{|c|c|c|c|c|c|c|c|c|}
\hline Sorbent & $\begin{array}{c}\mathbf{P}_{\mathbf{H}} \\
(\text { atm) }\end{array}$ & $\begin{array}{c}\mathbf{P}_{\mathbf{L}} \\
(\mathbf{a t m})\end{array}$ & $\begin{array}{l}\mathbf{P}_{\mathrm{CD}} \\
(\mathbf{a t m})\end{array}$ & $\begin{array}{c}\mathbf{U}_{\mathbf{H}} \\
(\mathbf{m} / \mathbf{s})\end{array}$ & $\begin{array}{c}\mathbf{U}_{\mathbf{L}} \\
(\mathbf{m} / \mathbf{s})\end{array}$ & $\begin{array}{c}\mathbf{O}_{2} \\
\text { Product } \\
\text { Purity } \\
(\%)\end{array}$ & $\begin{array}{c}\mathrm{O}_{2} \\
\text { Product } \\
\text { Recovery } \\
(\%)\end{array}$ & $\begin{array}{c}\text { Product } \\
\text { throughput } \\
\text { (kg } \mathrm{O}_{2} / \mathrm{h} / \mathrm{kg} \\
\text { adsorbent) }\end{array}$ \\
\hline $\mathrm{Li}_{96}-\mathrm{X}-1.0$ & 1.0 & 0.33 & 0.70 & 0.48 & 0.38 & 96.11 & 62.03 & $4.84 \times 10^{-2}$ \\
\hline $\mathrm{Li}_{9} \mathrm{Ag}_{1}-\mathrm{X}-1.0$ & 1.0 & 0.33 & 0.69 & 0.60 & 0.42 & 96.42 & 62.74 & $5.40 \times 10^{-2}$ \\
\hline
\end{tabular}

\section{Run 2.}

\begin{tabular}{|c|c|c|c|c|c|c|c|c|}
\hline Sorbent & $\begin{array}{c}\mathbf{P}_{\mathrm{H}} \\
(\text { atm) }\end{array}$ & $\begin{array}{c}\mathbf{P}_{\mathbf{L}} \\
(\mathbf{a t m})\end{array}$ & $\begin{array}{l}\mathbf{P}_{\mathrm{CD}} \\
\text { (atm) }\end{array}$ & $\begin{array}{c}\mathbf{U}_{\mathbf{H}} \\
(\mathbf{m} / \mathbf{s})\end{array}$ & $\begin{array}{c}\mathbf{U}_{\mathbf{L}} \\
(\mathbf{m} / \mathbf{s})\end{array}$ & $\begin{array}{c}\mathrm{O}_{2} \\
\text { Product } \\
\text { Purity } \\
(\%)\end{array}$ & $\begin{array}{c}\mathrm{O}_{2} \\
\text { Product } \\
\text { Recovery } \\
(\%)\end{array}$ & $\begin{array}{c}\text { Product } \\
\text { throughput } \\
\left(\mathrm{kg} \mathrm{O} \mathrm{O}_{2} / \mathrm{h} / \mathrm{kg}\right. \\
\text { adsorbent) }\end{array}$ \\
\hline $\mathrm{Li}_{96}-\mathrm{X}-1.0$ & 1.2 & 0.4 & 0.70 & 0.40 & 0.38 & 90.68 & 78.02 & $6.31 \times 10^{-2}$ \\
\hline $\mathrm{Li}_{95} \mathrm{Ag}_{1}-\mathrm{X}-1.0$ & 1.2 & 0.4 & 0.71 & 0.50 & 0.38 & 90.83 & 78.48 & $7.01 \times 10^{-2}$ \\
\hline
\end{tabular}




\section{Figure Captions}

Figure 1. Unit cell of faujasite-type (X and Y) zeolites including cation sites.

Figure 2. Adsorption isotherms for $\mathrm{N}_{2}, \mathrm{O}_{2}$ and $\mathrm{Ar}$ measured at $25 \mathrm{C}$ for $\mathrm{Li}_{94.5} \mathrm{Na}_{1.5}-\mathrm{X}-$ 1.0 dehydrated in vacuo at $350 \mathrm{C}$.

Figure 3. Adsorption isotherms measured at $25 \mathrm{C}$ for $\mathrm{N}_{2}, \mathrm{O}_{2}$ and $\mathrm{Ar}$ on $\mathrm{Ag}_{95.7} \mathrm{Na}_{0.3}-\mathrm{X}-$ 1.0 dehydrated in vacuo at $450 \mathrm{C}$

Figure 4. $\mathrm{N}_{2}$ adsorption isotherm, measured at $25 \mathrm{C}$, for $\mathrm{Li}_{\mathrm{x}} \mathrm{Ag}_{\mathrm{y}}-\mathrm{X}-1.0$ zeolites dehydrated in vacuo at $450 \mathrm{C}$. This shows that the addition of increasing amounts of $\mathrm{Ag}$ results in a change in the general aspect of isotherm toward that of the nearl fully $\mathrm{Ag}^{+}-$ exchanged material. The amount adsorbed is given in $\mathrm{mmol} / \mathrm{g}$.

Figure 5. $\mathrm{N}_{2}$ adsorption isotherm, measured at $25 \mathrm{C}$, for $\mathrm{Li}_{\mathrm{x}} \mathrm{Ag}_{\mathrm{y}}-\mathrm{X}-1.0$ zeolites dehydrated in vacuo at 450 C. This shows that the addition of increasing amounts of $\mathrm{Ag}$ results in a change in the general aspect of isotherm toward that of the nearl fully $\mathrm{Ag}^{+}-$ exchanged material. The amount adsorbed is given in molec/uc.

Figure 6. Plots of $\ln (\mathrm{P})$ vs $1 / \mathrm{T}$ at different coverages for $\mathrm{Li}_{44.5} \mathrm{Na}_{1.5}-\mathrm{X}-1.0$ (top) and $\mathrm{Li}_{94.2} \mathrm{Na}_{0.7} \mathrm{Ag}_{1.1}-\mathrm{X}-1.0$ (bottom).

Figure 7. Isosteric heats of adsorption of $\mathrm{N}_{2}$ for $\mathrm{Ag}_{96}-\mathrm{X}-1.0, \mathrm{Li}_{94.5} \mathrm{Na}_{1.5} \mathrm{X}-1.0$ and $\mathrm{Li}_{94.2} \mathrm{Na}_{0.7} \mathrm{Ag}_{1.1}-\mathrm{X}-1.0$.

Figure 8. $\mathrm{N}_{2}$ and $\mathrm{O}_{2}$ isotherms for $\mathrm{Li}_{94.2} \mathrm{Na}_{0.7} \mathrm{Ag}_{1.1}-\mathrm{X}-1.0$ dehydrated in vacuo at $450 \mathrm{C}$ and for for $\mathrm{Li}_{9.5} \mathrm{Na}_{1.5}-\mathrm{X}-1.0$ dehydrated in vacuo at 350 C. All isotherms were measured at $25 \mathrm{C}$. 


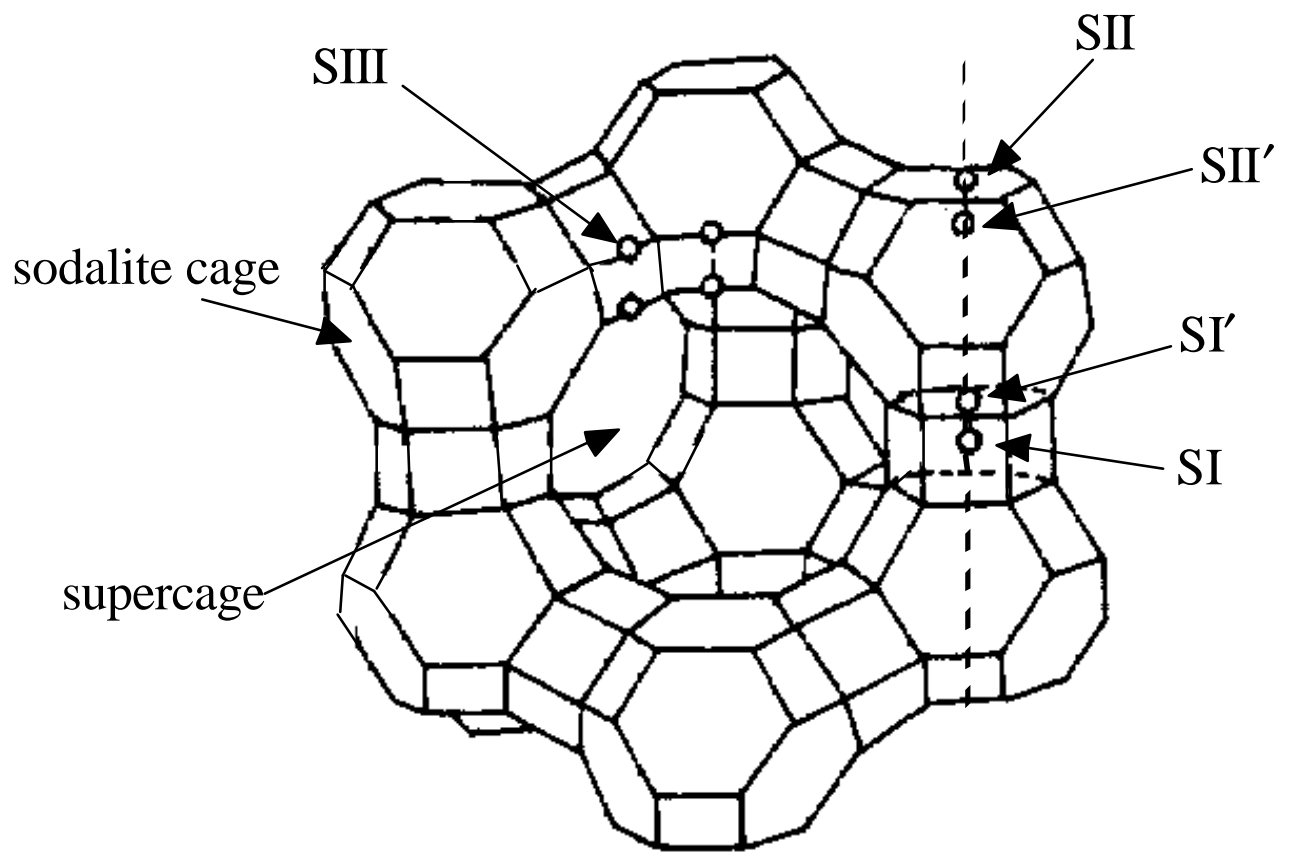

Figure 1. Unit cell of faujasite-type (X and Y) zeolites including cation sites. 


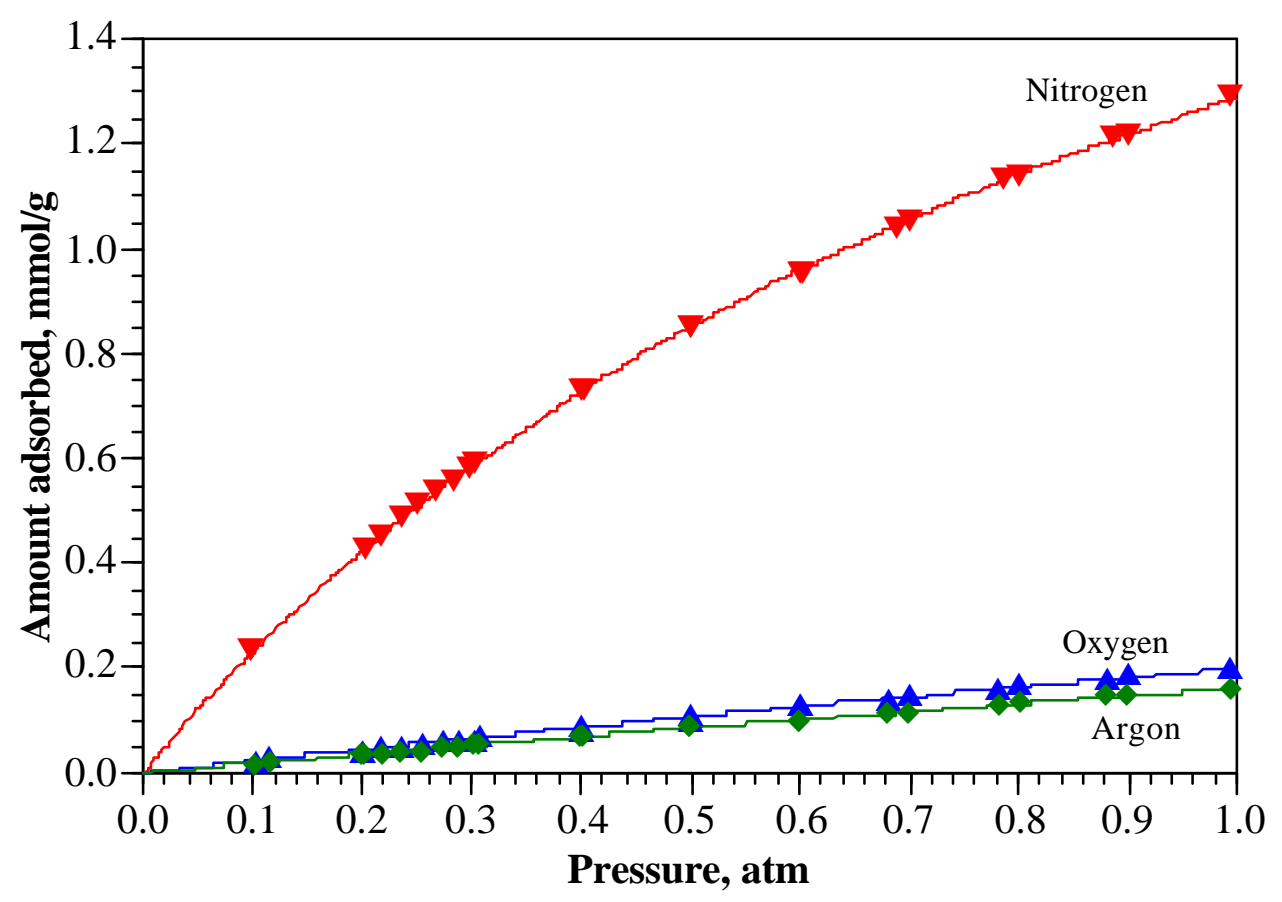

Figure 2. Adsorption isotherms for $\mathrm{N}_{2}, \mathrm{O}_{2}$ and Ar measured at $25 \mathrm{C}$ for $\mathrm{Li}_{94.5} \mathrm{Na}_{1.5}-\mathrm{X}$ 1.0 dehydrated in vacuo at $350 \mathrm{C}$. 


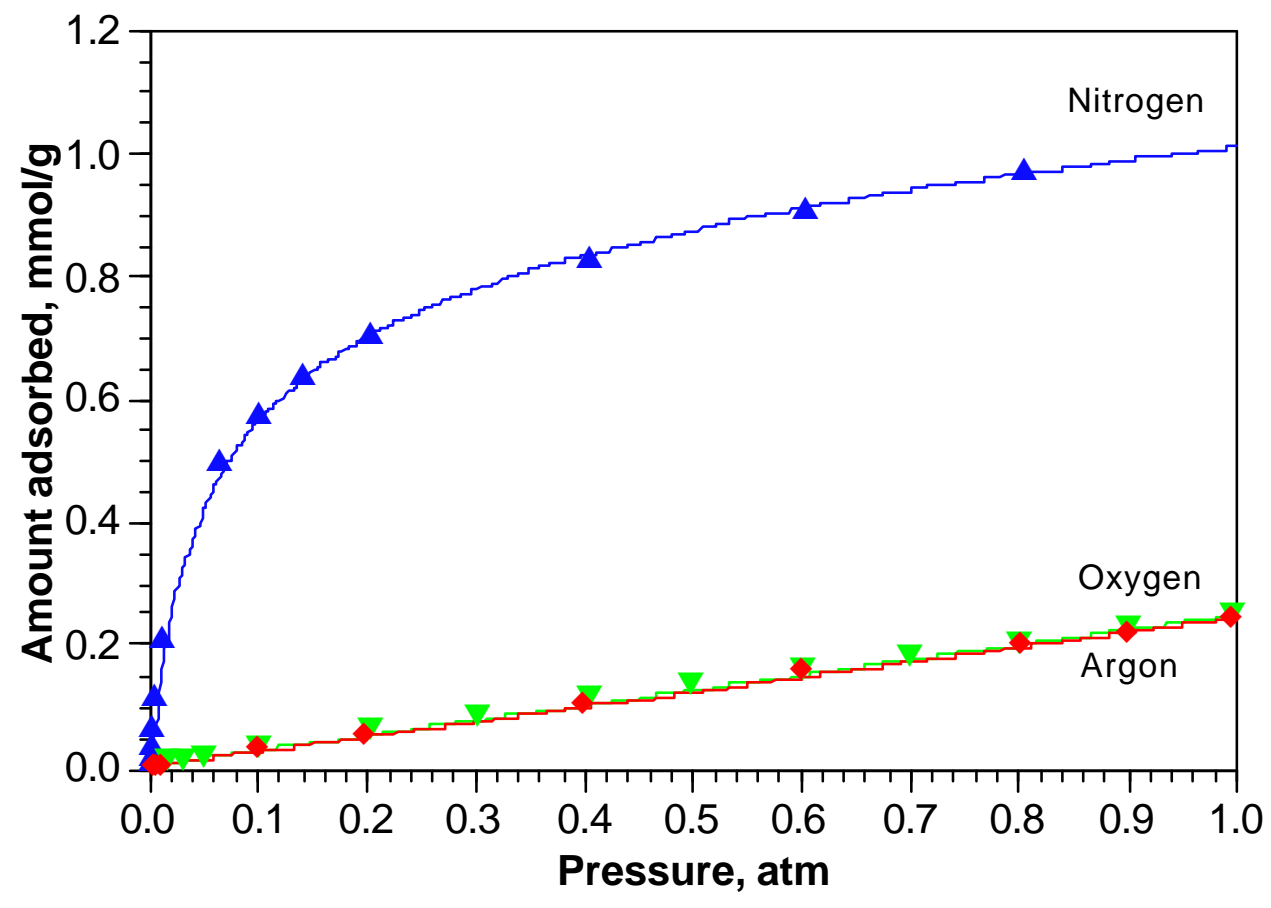

Figure 3. Adsorption isotherms measured at $25 \mathrm{C}$ for $\mathrm{N}_{2}, \mathrm{O}_{2}$ and $\mathrm{Ar}$ on $\mathrm{Ag}_{95.7} \mathrm{Na}_{0.3}-\mathrm{X}-$ 1.0 dehydrated in vacuo at 450 C. 


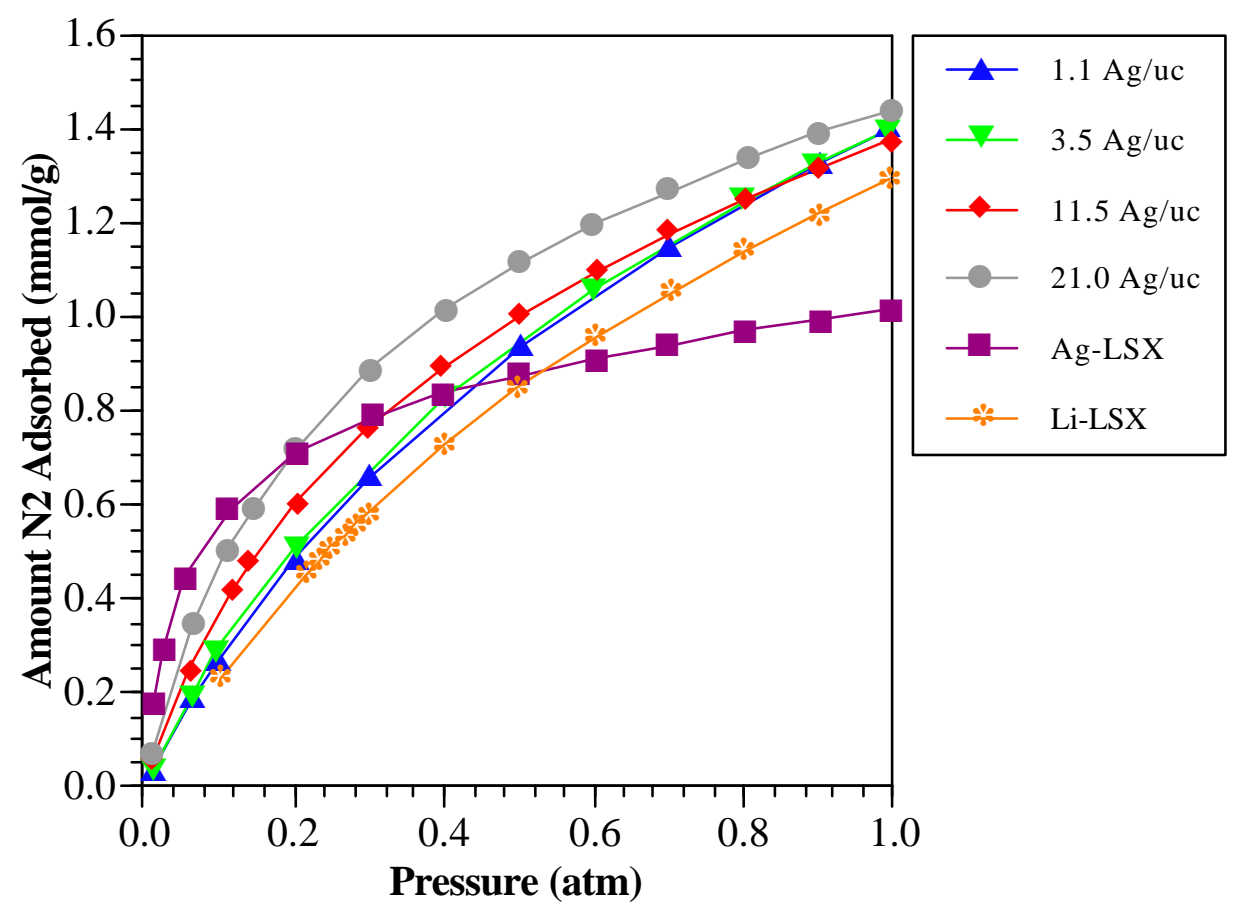

Figure 4. $\mathrm{N}_{2}$ adsorption isotherm, measured at $25 \mathrm{C}$, for $\mathrm{Li}_{\mathrm{x}} \mathrm{Ag}_{\mathrm{y}}-\mathrm{X}-1.0$ zeolites dehydrated in vacuo at 450 C. This shows that the addition of increasing amounts of $\mathrm{Ag}$ results in a change in the general aspect of isotherm toward that of the nearl fully $\mathrm{Ag}^{+}-$ exchanged material. The amount adsorbed is given in $\mathrm{mmol} / \mathrm{g}$. 


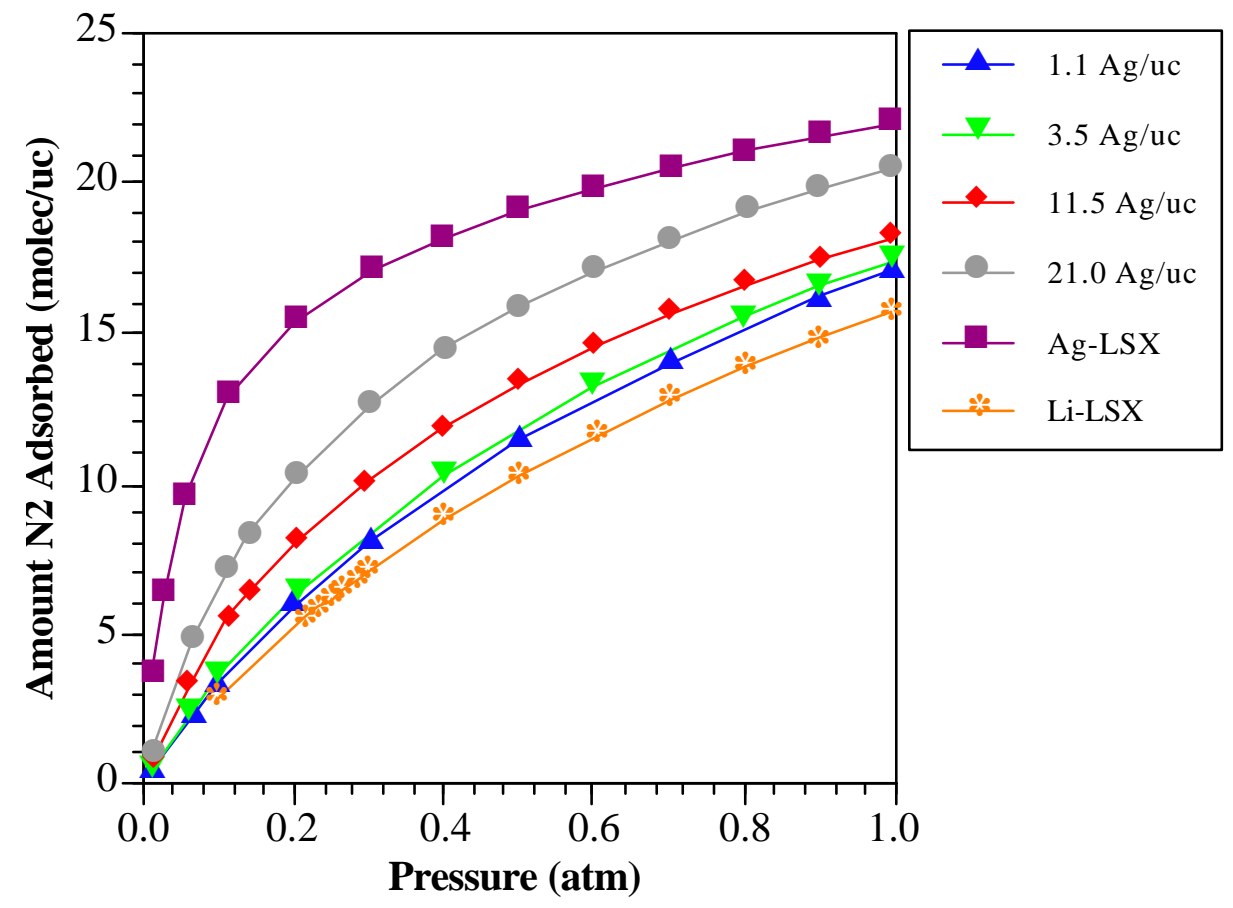

Figure 5. $\mathrm{N}_{2}$ adsorption isotherm, measured at $25 \mathrm{C}$, for $\mathrm{Li}_{\mathrm{x}} \mathrm{Ag}_{\mathrm{y}}-\mathrm{X}-1.0$ zeolites dehydrated in vacuo at $450 \mathrm{C}$. This shows that the addition of increasing amounts of $\mathrm{Ag}$ results in a change in the general aspect of isotherm toward that of the nearl fully $\mathrm{Ag}^{+}-$ exchanged material. The amount adsorbed is given in molec/uc. 

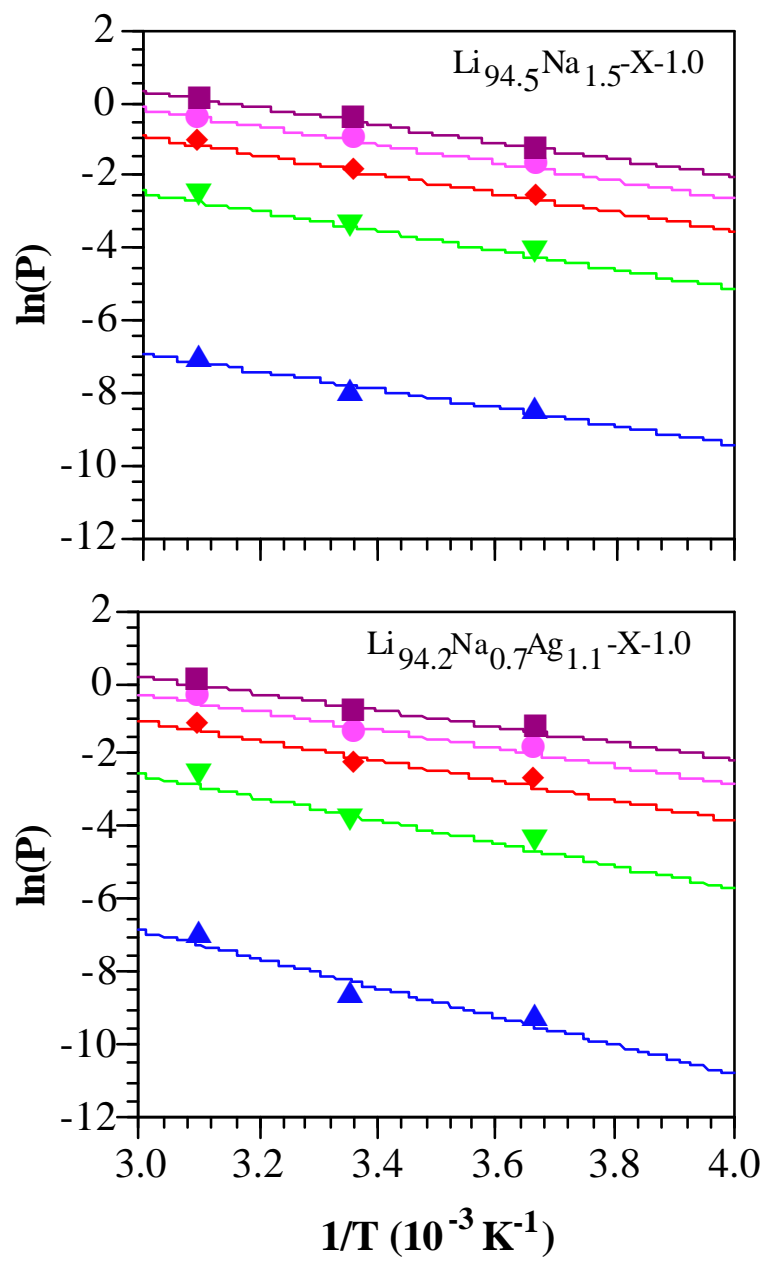

Figure 6. Plots of $\ln (\mathrm{P})$ vs $1 / \mathrm{T}$ at different coverages for $\mathrm{Li}_{94.5} \mathrm{Na}_{1.5}-\mathrm{X}-1.0$ (top) and $\mathrm{Li}_{94.2} \mathrm{Na}_{0.7} \mathrm{Ag}_{1.1}-\mathrm{X}-1.0$ (bottom). 


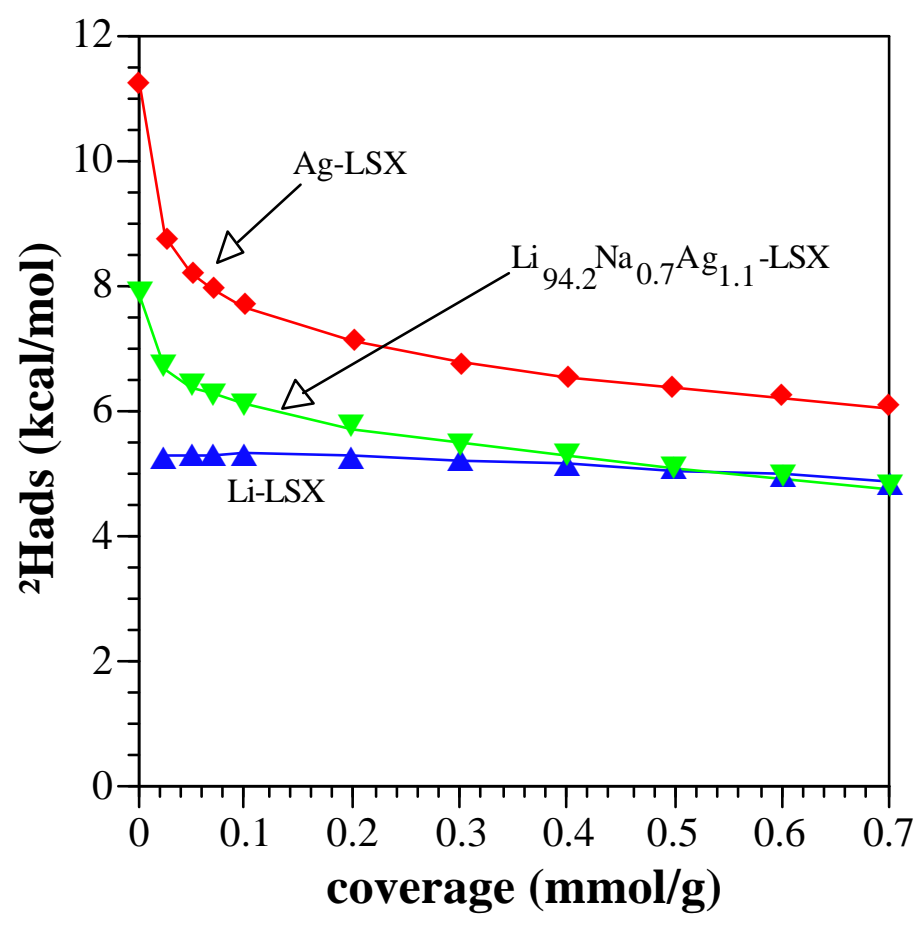

Figure 7. Isosteric heats of adsorption of $\mathrm{N}_{2}$ for $\mathrm{Ag}_{96}-\mathrm{X}-1.0$, $\mathrm{Li}_{94.5} \mathrm{Na}_{1.5} \mathrm{X}-1.0$ and $\mathrm{Li}_{94.2} \mathrm{Na}_{0.7} \mathrm{Ag}_{1.1}$-X-1.0. 


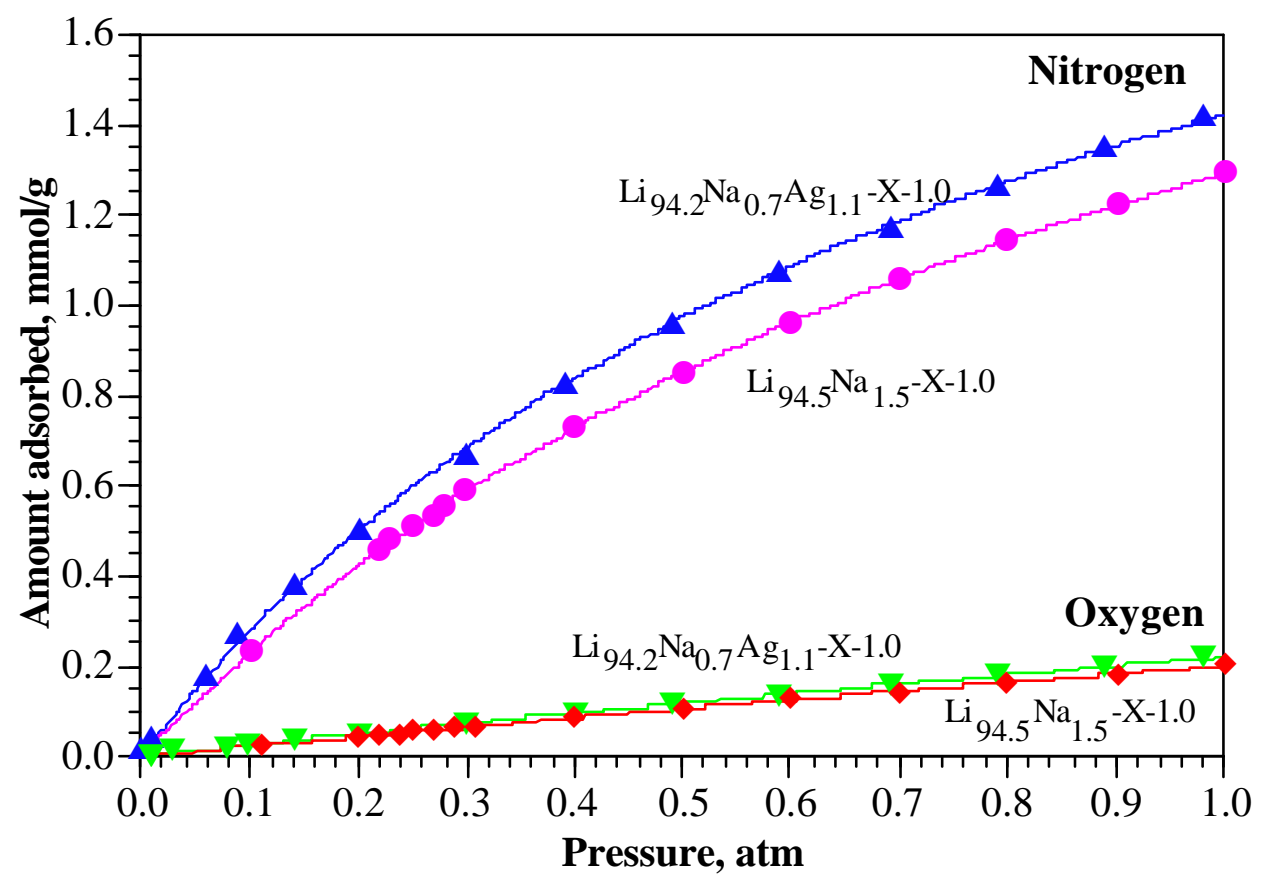

Figure 8. $\mathrm{N}_{2}$ and $\mathrm{O}_{2}$ isotherms for $\mathrm{Li}_{94.2} \mathrm{Na}_{0.7} \mathrm{Ag}_{1.1}-\mathrm{X}-1.0$ dehydrated in vacuo at $450 \mathrm{C}$ and for for $\mathrm{Li}_{94.5} \mathrm{Na}_{1.5} \mathrm{X}-1.0$ dehydrated in vacuo at $350 \mathrm{C}$. All isotherms were measured at $25 \mathrm{C}$. 


\title{
CHAPTER 3
}

Structural Effects on Adsorption of Atmospheric Gases

\author{
in Mixed Li,Ag- X Zeolite
}




\section{Introduction}

The separation of air for the production of nitrogen and oxygen is an important operation in the chemical processing industry. Historically, this separation has been done by cryogenic distillation. As adsorption systems have become more efficient and new, more effective sorbents have been synthesized, separation by adsorption processes $(e . g$., pressure swing adsorption (PSA), and vacuum swing adsorption (VSA)) have become increasingly competitive and are already favorable for small-to-medium scale operations (Yang, 1997). Currently, approximately 20\% of air separations are accomplished using adsorption technologies (Rege and Yang, 1997).

While it has long been known that $\mathrm{Li}^{+}$is among the strongest cations, with respect to its interaction with $\mathrm{N}_{2}$ (McKee, 1964), its use was greatly increased with two recent advances. Firstly, it was found that $\mathrm{Li}^{+}$ion-exchange in X-type zeolite must exceed an approximate $70 \%$ threshold before the $\mathrm{Li}^{+}$has any effect on the adsorptive properties of the material (Chao, 1989; Chao et al., 1992; Coe et al., 1992; Coe, 1995). Secondly, a significant increase in the $\mathrm{N}_{2}$ adsorption capacity was seen in $\mathrm{Li}^{+}$ion-exchanged low silica X (LSX) zeolite over that of the typical commercial material (Si/Al 1.25). Because of these advances, Li-LSX is now the best sorbent in industrial use for separation of air by adsorption processes (Rege and Yang, 1997).

Examples of mixed-cation zeolites have also been given. Coe et al. (1992) reported the use of a binary exchanged X-zeolite having lithium and calcium and/or lithium and strontium ions in a ratio of $5 \%$ to $50 \%$ calcium and/or strontium and $50 \%$ to 95\% lithium. This material provided for enhanced nitrogen adsorption over those of the Na-X, Li-X, and Ca-X zeolites. Chao et al. (1992)showed the use of mixed ion- 
exchanged $\mathrm{A}$ and $\mathrm{X}$ zeolites with lithium and an alkaline earth metal (e.g., $\left.\mathrm{Ca}^{2+}, \mathrm{Sr}^{2+}\right)$. In this case the zeolite contained lithium and the alkaline earth cations in a mixture of $10 \%$ to $70 \%$ alkaline earth and $30 \%$ to $90 \%$ lithium. These mixed cation zeolites provided high adsorption capacity and high thermal stability. Fitch et al. (1995) reported good $\mathrm{N}_{2} / \mathrm{O}_{2}$ selectivity and $\mathrm{N}_{2}$ capacity with mixed $\mathrm{Li}_{\mathrm{x}} \mathrm{Al}_{\mathrm{y}}-\mathrm{X}$ zeolite (i.e., using $\mathrm{Al}^{3+}$ as the nonframework charge-compensating cation).

Silver is also known to have very strong effects on the adsorption characteristics of zeolites (Habgood, 1964; Huang, 1974; Hutson et al., 2000). Yang et al. (1996) reported the synthesis of a mixed lithium-silver (80/20) ion-exchanged X-type zeolite ( $\mathrm{Si} / \mathrm{Al} 1.25$ with approximately $17 \mathrm{Ag}^{+}$per unit cell), and discussed its potential use in air separation. This sorbent utilized the very strong adsorptive properties of the $\mathrm{Ag}^{+}$ion that provided for increased capacity over that of the Li-X while maintaining some degree of the advantageous isotherm linearity that is seen with Li-X. Ab inito molecular orbital calculations showed the adsorption of nitrogen was enhanced by weak chemical interaction (through a classical $\pi$-complexation bond) with the $\mathrm{Ag}^{+}$cation on the zeolite framework (Chen and Yang, 1996).

Hutson et al. (1999) have reported the synthesis of mixed Li,Ag low-silica X-type zeolite in which the addition of very small amounts of silver and specific dehydration conditions resulted in enhanced adsorptive characteristics and increased energetic heterogeneity relative to those of the fully (or near-fully) exchanged $\mathrm{Li}^{+}$-zeolites. The performance for air separation by the best of these sorbents, containing, on average, only one Ag per unit cell, was compared to that of the fully (or near-fully) $\mathrm{Li}^{+}$-exchanged zeolite using a standard pressure swing adsorption (PSA) cycle by numerical simulation. 
The results showed that the new sorbent provides a significantly higher (>10\%) product throughput, at the same product purity and recovery, when compared to that of the fully $\mathrm{Li}^{+}$-exchanged zeolite (Yang and Hutson, 1999).

The location of the extraframework silver in relation to the aluminosilicate framework is of primary importance for elucidating the effect of silver cations or clusters on the adsorptive characteristics of the zeolite. In this work, we have synthesized mixed $\mathrm{Li}, \mathrm{Ag}$ ion-exchanged zeolites and treated these materials in ways that promote the formation of intracrystalline silver clusters. These samples were structurally characterized using Rietveld refinement of neutron powder diffraction data. The structural data were then related to the adsorptive characteristics of the mixed-cation zeolites for the gases that are of primary interest in the separation of air: $\mathrm{N}_{2}, \mathrm{O}_{2}$ and Ar.

\section{Synthesis and Analysis}

Two type-X zeolites, differing only by the $\mathrm{Si} / \mathrm{Al}$ ratio, were used in this work. These were: (1) X-type zeolite with a Si/Al of 1.0 (Praxair, \#16193-42, sometimes referred to as LSX, low silica X-zeolite), and (2) X-type zeolite with a Si/Al of 1.25 (Linde, lot 945084060002). Both of these materials were binderless, hydrated powders. The unit cell for faujasite zeolites (Y, X, LSX), including conventional designation of cation sites, is shown in Figure 1.

Since the sodium form of the zeolite exchanges more readily with most cations in consideration, all zeolites were first ion-exchanged with a solution of sodium chloride in order to convert to the $\mathrm{Na}^{+}$form. A dilute $\mathrm{NaOH}$ solution was used to keep the $\mathrm{NaCl}$ solution at $\mathrm{pH}$ 9. This helps to prevent hydrolysis and breakdown of the zeolite crystal 
structure during the ion-exchange process. The resultant $\mathrm{Na}^{+}$-zeolite was then used as the starting material for subsequent syntheses.

The lithium zeolites were prepared by 5 consecutive static ion-exchanges using a 6.3-fold excess (over that necessary for full ion-exchange) of a 2.2 M solution of LiCl. This was done in a $0.01 \mathrm{M}$ solution of $\mathrm{LiOH}$ at a $\mathrm{pH}$ 9. The lithium ion-exchange solution was heated to a mild boil and then allowed to cool and settle. The solution was decanted, a fresh $6.3 \mathrm{X} \mathrm{LiCl}$ solution was added, and the procedure was repeated for a total of 5 exchanges. After the final ion-exchange, the material was vacuum filtered and washed with copious amounts of deionized water until no free ions were present in the filter water (i.e., no $\mathrm{AgCl}$ precipitation upon treatment with $\mathrm{Ag}^{+}$). The resulting lithium exchanged zeolites were dried overnight at $100 \mathrm{C}$ in a conventional oven before being dehydrated in vacuo prior to measurement of adsorption isotherms.

The silver zeolites were prepared by 2 consecutive ion-exchanges using a $0.05 \mathrm{M}$ solution of $\mathrm{AgNO}_{3}$. Each silver solution contained a cation content that was double that required for $100 \%$ exchange. The silver ion-exchange solution was heated to a mild boil and immediately allowed to cool and settle. As with the lithium ion-exchange, the solution was decanted, fresh $\mathrm{AgNO}_{3}$ solution was added, and the procedure was repeated for a total of 2 exchanges. After the second ion-exchange, the material was vacuum filtered and washed with copious amounts of deionized water until no free ions were present in the filter water (i.e., no precipitation upon treatment with $\mathrm{CI}$ ). The silver exchanged materials were dried at room temperature and atmospheric conditions in a dark area. The resulting materials were then stored in a dark area until they were dehydrated in vacuo prior to analysis. 
The $\mathrm{Li}_{\mathrm{x}} \mathrm{Ag}_{\mathrm{y}}$-zeolites (which may more accurately be referred to as $\mathrm{Li}_{\mathrm{x}} \mathrm{Na}_{\mathrm{y}} \mathrm{Ag}_{\mathrm{z}}-$ zeolites since ion-exchange is rarely exhaustive and there is almost always some residual $\mathrm{Na}^{+}$present in the starting Li-zeolite) were prepared by ion-exchange of a Li-zeolite (prepared as described above) with a $0.05 \mathrm{M}$ solution of $\mathrm{AgNO}_{3}$. This silver solution contained a cation content that was equivalent to the targeted amount. This is possible with silver ion-exchange because the silver cation is quickly and easily exchanged (Breck, 1984). The silver ion-exchange solution was heated to a mild boil and immediately allowed to cool and settle. The resulting material was vacuum filtered and washed with copious amounts of deionized water. Complete incorporation of the targeted silver ions was verified when no precipitation was observed in the filtered water upon treatment with $\mathrm{Cl}$. These mixed cation zeolites were then dried at room temperature and atmospheric conditions in a dark area and were stored in a dark area until they were dehydrated in vacuo prior to analysis.

The samples were compositionally characterized using neutron activation analysis (NAA) at the research nuclear reactor of the Phoenix Memorial Laboratory at the University of Michigan. The samples were irradiated sequentially for one minute at a core-face location with an average thermal neutron flux of $2 \times 10^{12} \mathrm{n} / \mathrm{cm}^{2} / \mathrm{s}$. Two separate gamma-ray spectra were collected for 500 seconds real time for each sample using a high resolution germanium detector. The collection after a 13 minute decay was used to determine the concentrations of aluminum and silver, while data collected after 1 hour and 56 min decay were used to analyze for sodium and potassium. Four replicates of NBS-SRM-1633a (coal fly ash) and silver foil were used as standard reference materials and check standards. 
The samples were also analyzed for Li content using an inductively coupled plasma mass spectrometer (ICP-MS, Hewlett Packard HP 4500). The samples were first digested in concentrated nitric acid solution at $100 \mathrm{C}$ for $20 \mathrm{~min}$. At the end of digestion, the samples were further diluted and filtered before the ICP-MS analyses. Results of these analyses are given in Table 1. The unit cell compositions for those analyzed samples are given in Table 2 .

From this point, all samples will be identified according to the type of zeolite and the number of charge compensating cation(s) present in a unit cell. For example $\mathrm{Li}_{86}-\mathrm{X}$ refers to an $\mathrm{X}$-type zeolite (with $\mathrm{Si} / \mathrm{Al} 1.25$ ) that has been fully exchanged to contain $86 \mathrm{Li}^{+}$cations per unit cell. The sample $\mathrm{Li}_{94.2} \mathrm{Ag}_{1.1} \mathrm{Na}_{0.7}-\mathrm{LSX}$ refers to a low silica X-type zeolite (with $\mathrm{Si} / \mathrm{Al}=1.0$ ) that contains, on average, $94.2 \mathrm{Li}^{+}, 1.1 \mathrm{Ag}^{+}$(or other form of $\mathrm{Ag}$ ) and $0.7 \mathrm{Na}^{+}$per unit cell, as determined from the neutron activation (NA) and ICPMS analyses.

\section{Structural Characterization}

A separate set of mixed Li,Ag-LSX zeolites was prepared using the previously described procedure. These samples were used in the structural characterization. They were chemically characterized using neutron activation analysis (as described earlier). The unit cell composition for each of the materials is listed in Table 3.

\section{Neutron Powder Diffraction}

Powder neutron diffraction data were collected for each of the samples shown in Table 3. Each of the samples was initially dehydrated under vacuum for 12 hours at a prescribed temperature (as given in the sample name). The samples were exposed to atmospheric conditions during transport to the NIST Center for Neutron Research. In 
preparation for the diffraction experiment, approximately $10-15 \mathrm{~mL}$ of each sample was dehydrated under vacuum $\left(<10^{-5}\right.$ torr $)$. Each sample was heated to the temperature that was used in the prior heat treatment. Samples were heated at a rate of approximately $10 \mathrm{C} / \mathrm{min}$, held at constant temperature for a minimum of 4 hours, then were allowed to cool to room temperature. The samples were transferred to $50 \mathrm{~mm}$ long and $15.6 \mathrm{~mm}$ wide vanadium cans and subsequently sealed in a helium environment with low water and oxygen levels $(<10 \mathrm{ppm})$. Neutron diffraction data were collected using the 32 detector BT-1 neutron powder diffractometer at the NIST Center for Neutron Research NBSR reactor (Gaithersburg, MD). Measurements were made using a $\mathrm{Ge}(311)$ monochromator with $\lambda=2.0783(2) \AA\left(1 \AA=10^{-10} \mathrm{~m}\right)$ at ambient temperature. Data were collected over the range of $1.3-166.3^{\circ} 2 \theta$ with a step size of $0.05^{\circ}$. The data collection time for each sample was approximately 8 hours.

\section{Rietveld Refinement}

Neutron powder diffraction data were analyzed using the Rietveld (1967) technique in conjunction with the GSAS (Generalized Structure Analysis System) suite of Larson and Von Dreele (1986). To determine the best expected fit to the data, the LeBail intensity extraction method was first used, in effect simulating a fit with an idealized crystallographic model (Le Bail et al., 1988). Background was fit using a Chebychev polynomial with a variable number of terms (between 8-12). Lattice constants and zero point shifts were then introduced and optimized. The peak asymmetry at low angles was treated using the model of Finger et al. (1994). Scattering factors and lengths were set to standard values for neutral atoms, as supplied in the GSAS package. Initial fractional atomic coordinates for the framework constituents in space group 
$F d \overline{3}$ (203) were based upon the model determined by Feuerstein and Lobo (1998) for LiLSX. In this refinement, since the material is an aluminum saturated zeolite, T(1) is modeled as a pure Si site and $\mathrm{T}(2)$ is modeled as a pure $\mathrm{Al}$ site. The isotropic atomic displacement parameters were grouped, using one value for framework $\mathrm{T}$ atoms, a second value for framework $\mathrm{O}$ atoms, and a third for extraframework cations. Details concerning the location of extraframework cations for each material and the final stages of refinement are given in the following sections. The results of the Rietveld refinement are given in Tables $4-8$. The results of the Rietveld refinements are summarized in Table 4. Positional coordinates, occupancies, and atomic displacement parameters for each sample are listed in Tables 5 and 6. Selected bond lengths $(\AA)$ and angles (degrees) are given in Table 7 and Table 8. A comparison of the cation site occupancies determined in this study is given in Table 9.

\section{$\operatorname{Li}_{95.8} \mathrm{Na}_{0.2}-\mathrm{LSX}$ Structure}

The results of the Rietveld refinement for this near-fully Li-exchanged zeolite are shown in Table 4. The agreement of the experimental and the refined model were quite good $\left.\chi^{2}=1.352\right)$ and agreed very well with results reported from a previous study by Feuerstein and Lobo (1998). Almost all of the lithium cations were located (93.5 of the 95.8 expected). The lithium cations were located in the six-ring sites, SI $^{\prime}$ and SII, and in the supercage 4-ring SIII site. A slight over-population was located at the SII site (33.9 cations); this was also the case with the study by Feuerstein and Lobo (1998).

Lithium cations in the site SII were at a distance of $1.97 \AA$ from the closest framework oxygen (i.e., $\mathrm{Li}(\mathrm{II}) \_\mathrm{O}(2)=1.97 \AA ̊$ ). This short distance allows the cation to sit very deep in the face of the six-ring, effectively shielding the electrostatic energy of the 
cation and preventing interaction with adsorbates such as nitrogen, oxygen, and argon. A schematic of the sodalite cage and double six-ring (hexagonal prism) showing the sites of lithium is shown in Figure 2.

\section{$\mathrm{Li}_{54.0} A \mathrm{~g}_{41.8} \mathrm{Na} a_{0.2}-\mathrm{LSX}$ Structure}

The results of the Rietveld refinement for the $\mathrm{Li}_{54.0} \mathrm{Ag}_{41.8} \mathrm{Na}_{0.2}$ - $\mathrm{SX}$ zeolite are shown in Table 4; and the agreement of the experimental and the refined model were very good $\left(\chi^{2}=1.456\right)$. The lithium cations of this sample were located only in the sixring sites, SI' and SII. No site SIII supercage lithium cations were located. As with the near-fully Li-exchanged sample, an over-population of Li was located at the SII site (40.3 cations). However, if one assumes that only $32 \mathrm{Li}$ cations are located at this site, the total is very near the expected total value of lithium (55.4 of the expected 54.0). Because of this, it is likely that the GSAS suite, using Rietveld refinement, consistently over estimates the population of SII lithium.

Most of the silver was found in the SIII supercage sites (approximately 80\% of the total found). This is an indication that the smaller lithium cations, when in competition with silver cations, prefer to occupy the six-ring sites. However, it may also be the result of the order of ion-exchange. Since the low silica $X$ zeolite was first ionexchanged with lithium and then subsequently with silver, the lithium cations had the first opportunity to occupy the more energetically favorable six-ring sites. If the ionexchange was done in the opposite order, silver cation may very well have retained occupancy of the six-ring sites (for silver, those would include SI, SI', SII', SII, and SII*, see Figure 3). 
Small amounts of silver were also located in sodalite six-ring sites (SI', SII, and SII*). There was no silver associated with the single six-ring (SI) or inside the sodalite cage (SII'). The silver site II is approximately in the plane of the six-ring. A new site, which is labeled SII* to distinguish it from the conventional SII (see Figure 3) was found in this sample. Site $\mathrm{II}^{*}$ is still observed on the supercage side of the six-ring, but is shifted further away from the plane of the six-ring. Only about $70 \%$ of the expected silver were located using Rietveld refinement. One explanation for this result is that there may be reduced silver crystallites on the exterior of the zeolite. This was discussed in a previous work for near-fully Ag-exchanged faujasites (Hutson et al., 2000). This explanation also helps to explain the higher than expected lithium. A schematic of the sodalite cage and double six-ring (hexagonal prism) showing the sites for lithium and silver occupancy is shown in Figure 3.

Fourier difference analysis indicated the presence of scattering density at the center of the sodalite cage and approximately $1.7 \AA$ away from this site. One likely explanation for this extra scattering density is the presence of extraframework alumina in the center of the sodalite cage. This was also noted in a neutron diffraction structural analysis of near-fully exchanged Ag-X and Ag-LSX zeolites. Even when carefully dehydrated, $\mathrm{X}$ and LSX tend to lose framework alumina through self-steaming to void spaces in the zeolite (the sodalite cage and supercage). An extraframework tetrahedral $\left[\mathrm{AlO}_{4}\right]^{-}$unit was added to the model with the $\mathrm{Al}^{3+}$ located at the center of the sodalite cage and oxygen atoms along the (111) axis. The fractional occupancies for these two atoms were constrained to be the same. Isotropic atomic displacement parameters were constrained to be the same as that of the extraframework silver. 


\section{$\mathrm{Li}_{93.3} \mathrm{Ag}_{2.0} \mathrm{Na}_{0.7}-\mathrm{LSX}$ Structure}

These samples contained only a small amount of silver and, as a result, there was only a slight difference in the diffraction pattern as compared to that of fully Li-exhanged LSX. This makes the Rietveld refinement very difficult (Reisner, 2000). In approaching this refinement, it was necessary to use information of the behavior of lithium and silver from the previous samples. It was also necessary to use what was already know of the behavior of silver in near-fully exchanged LSX zeolite (Hutson et al., 2000).

The results of the Rietveld refinement for the $\mathrm{Li}_{93.3} \mathrm{Ag}_{2.0} \mathrm{Na}_{0.7}-\mathrm{LSX}$ zeolite (after vacuum dehydration at $350 \mathrm{C}$ and at $450 \mathrm{C}$ ) are shown in Table 4; and the agreement of the experimental and the refined model were very good $\chi^{2}=1.233$ for the sample heated to $350 \mathrm{C}$ and $\chi^{2}=1.319$ for the sample heated to $450 \mathrm{C}$ ). The overall structures of these samples are very similar to that described earlier for the $\mathrm{Li}_{9.8} \mathrm{Na}_{0.2}-\mathrm{LSX}$ sample. Almost all of the lithium cations were located (86.4 and 89.5 of the 93.3 expected). As with the $\mathrm{Li}_{9.8} \mathrm{Na}_{0.2}-\mathrm{LSX}$ sample, the lithium cations were located in the six-ring sites, $\mathrm{SI}^{\prime}$ and SII, and in the supercage 4-ring SIII site; and a slight over-population was located at the SII site (34.9 cations at SII for both samples).

The mixed Li,Ag-LSX sample that had been heated to $350 \mathrm{C}$ only had silver located in the SII' location. Almost all of the silver was located (1.7 of the expected 2.0 per unit cell). The sample that had been heated to $450 \mathrm{C}$, however, had a population of 0.9 silver in both SII and SII' (which provided the location of 1.8 of the $2.0 \mathrm{Ag}$ expected). A schematic of the sodalite cage and double six-ring (hexagonal prism) showing the sites for lithium and silver occupancy is shown in Figure 3.

\section{Adsorption}




\section{Adsorption Isotherms}

The adsorption isotherms were measured using a static volumetric system (Micromeritics ASAP-2010). Additions of the analysis gas were made at volumes required to achieve a targeted set of pressures. A minimum equilibrium interval of 9 seconds with a tolerance of $5 \%$ of the target pressure (or 0.007 atm, whichever is smaller) was used to determine equilibrium for each measurement point. The pressure transducers in the ASAP-2010 are accurate to $<0.2 \%$ for the pressure range of $0-1$ atm. The sample weights were obtained using a digital laboratory balance that is accurate to $\pm 0.01 \mathrm{~g}$. The isotherm measurements and the samples themselves were found to be highly reproducible. Helium (99.995\%, prepurified), oxygen (99.6\%, extra dry), nitrogen (99.998\%, prepurified), and argon (99.998\% prepurified) were obtained from Cryogenic Gases.

Adsorption isotherms are often reported as the amount (in mmol or vol-stp) of gas adsorbed per mass (in gram) of dehydrated sorbent. However, since there is a considerable change in the density of the resultant zeolite with the ion-exchange of low mass lithium cations for the much heavier silver cations, it is more meaningful to present adsorption data as the molecules of adsorbate in each unit cell of the sorbent Li,Agzeolite. Conversion factors for this conversion are given for each of the samples in Table 11.

Figure 4 shows the $\mathrm{N}_{2}, \mathrm{O}_{2}$ and Ar adsorption isotherms, measured at $25 \mathrm{C}$, for $\mathrm{Li}_{94.5} \mathrm{Na}_{1.5}$-LSX after vacuum dehydration at 350 C. This zeolite is used in adsorptive air separation because of its very high $\mathrm{N}_{2}$ capacity and very favorable $\mathrm{N}_{2}: \mathrm{O}_{2}$ selectivity (approximately 6:1 at $1 \mathrm{~atm}$ ) as well as its $\mathrm{N}_{2}$ isotherm linearity. Figure 5 shows the 
enhancement in the $\mathrm{N}_{2}$ adsorption capacity for $\mathrm{Li}_{94.5} \mathrm{Na}_{1.5}$ - LSX over that of $\mathrm{Li}_{7.0} \mathrm{Na}_{9.0} \mathrm{X}$. The data are shown in both mmol of adsorbate per gram of sorbent (top) and molecule of adsorbate per unit cell of sorbent (bottom).

Figure 6 shows $\mathrm{N}_{2}, \mathrm{O}_{2}$ and $\mathrm{Ar}$ adsorption isotherms for $\mathrm{Ag}_{95.7} \mathrm{Na}_{0.3}-\mathrm{LSX}$, all measured at $25 \mathrm{C}$, after vacuum dehydration at $450 \mathrm{C}$ for a minimum of 4 hours. These samples were all initially gray in color, but after vacuum dehydration turned to a deep golden yellow, indicating the formation of silver clusters (Sun and Seff, 1994). Figure 7 shows the enhancement in the $\mathrm{N}_{2}$ adsorption capacity for $\mathrm{Ag}_{95.7} \mathrm{Na}_{0.3}$-LSX over that of the $\mathrm{Ag}_{85.7} \mathrm{Na}_{0.3}-\mathrm{X}$. As before, the data are shown in both mmol of adsorbate per gram of sorbent (top) and molecule of adsorbate per unit cell of sorbent (bottom).

While the near-fully exchanged Ag-zeolites, like their Li-zeolite analogs, have very high $\mathrm{N}_{2}$ capacity and favorable $\mathrm{N}_{2}: \mathrm{O}_{2}$ selectivity, they are not favorable for use in adsorption-based separations. Because of the strong adsorption of $\mathrm{N}_{2}$ at low pressure, creating a low pressure "knee" in the adsorption isotherm shown in Figure 6, the working capacity (i.e., the $\mathrm{Q}$, the change in the adsorptive capacity from the typically used adsorption pressure of 1.0 to a desorptive pressure of $0.33 \mathrm{~atm}$ ) is very small; and the material must be exposed to very low pressure conditions in order to increase that working capacity.

Some Ag-zeolites have been shown to have a selectivity for $\mathrm{Ar}$ over $\mathrm{O}_{2}$ (Knaebel and Kandybin, 1993); and, in this work, the Ag-zeolites that had been vacuum dehydrated at $350 \mathrm{C}$ also showed a selectivity for $\mathrm{Ar}$ over $\mathrm{O}_{2}$. However, the Ag-zeolites that had been vacuum dehydrated at $450 \mathrm{C}$ had approximately the same adsorption capacity for Ar and $\mathrm{O}_{2}$ (as shown in Figures 4 and 6). This is likely due to increased interaction 
between the charged $\mathrm{Ag}$-clusters $\left(\mathrm{Ag}^{+}\right.$at $\left.\mathrm{SII}\right)$ and the quadrupole moment of the $\mathrm{O}_{2}$ molecule (whereas, the Ar has no quadrupole moment).

The $\mathrm{N}_{2}$ adsorption isotherms, measured at $25 \mathrm{C}$, for $\mathrm{Li}_{\mathrm{x}} \mathrm{Ag}_{\mathrm{y}}-\mathrm{LSX}$ zeolites after vacuum dehydration at $450 \mathrm{C}$ for a minimum of 4 hours are shown in Figure 8 where the amount adsorbed is given in both $\mathrm{mmol} / \mathrm{g}$ (top) and molec/uc (bottom). These zeolites contained varying amounts of Ag per unit cell ranging from zero f.e., the near-fully exchanged $\mathrm{Li}_{94.5} \mathrm{Na}_{1.5}$-LSX sample) to 21 (the $\mathrm{Li}_{3.8} \mathrm{Ag}_{21} \mathrm{Na}_{1.2}$-LSX sample). This plot reveals that the incorporation of only a small amount of silver changes the adsorptive properties of the near-fully exchanged $\mathrm{Li}_{94.5} \mathrm{Na}_{1.5}$-LSX zeolite. With increasing additions of $\mathrm{Ag}^{+}$(and corresponding removal of $\mathrm{Li}^{+}$and $\mathrm{Na}^{+}$) the adsorption isotherms begin to take on more of the characteristics of the near-fully exchanged $\mathrm{Ag}_{95.3} \mathrm{Na}_{0.3}$ - $\mathrm{LSX}$ material (i.e., the high "knee" at low pressures).

\section{Heats of Adsorption}

Heterogeneity in zeolites may result from a number of causes including a mixed population of charge compensating cations. If the intracrystalline cation composition is mixed, sites in the vicinity of a cation will differ for each cation whether or not they occupy equivalent crystallographic positions. Further, in a mixed cation population the proportion of one cation to another may vary from one cavity to another so that the behavior of the cavities as multiple sorption sites may vary throughout the crystal (Barrer, 1978).

The presence of energetic heterogeneity of a system can be determined by plotting the isosteric heat of adsorption versus the amount adsorbed. Energetic heterogeneity of the system will result in a decrease in the isosteric heat of adsorption as the amount 
sorbed increases. For small uptakes, the isosteric heat may decrease rather strongly with the amount adsorbed. This would be an indication that there are some local intracrystalline positions where the guest molecules are preferentially sorbed more exothermally than in the rest of the intracrystalline volume.

The measurement of adsorption isotherms at different temperatures permits the calculation of the heat of adsorption as a function of surface coverage. When experimental data are reported as a set of adsorption isotherms for a particular gasadsorbent system, the isosteric heat of adsorption is usually calculated (Bajusz and Goodwin, 1997). The isosteric heat of adsorption can be calculated from a series of isotherms by application of the Clausius-Claperyron equation as follows:

$$
\Delta H_{a d s}=R\left(\frac{d \ln P}{d(1 / T)}\right)_{n}
$$

Using the data from nitrogen adsorption isotherms measured at $50 \mathrm{C}, 25 \mathrm{C}$, and $0 \mathrm{C}$ (shown in Figure 9), the isosteric heats of adsorption were determined by evaluating the slope of a plot of $\ln (\mathrm{P})$ versus $(1 / \mathrm{T})$ at several coverages. The plots of $\ln \left(\mathrm{P}_{\mathrm{N} 2}\right)$ versus (1/T) at several coverages for $\mathrm{Li}_{94.5} \mathrm{Na}_{1.5}-\mathrm{LSX}$ (top) and $\mathrm{Li}_{94.2} \mathrm{Ag}_{1.1} \mathrm{Na}_{0.7}-\mathrm{LSX}$ (bottom) are shown in Figure 10. The isosteric heats of adsorption at different coverages were calculated for each of these materials and are shown in Figure 11. The plots are shown as the heat of adsorption (in $\mathrm{kcal} / \mathrm{mol}$ ) versus coverage in molecules of adsorbate per cavity (based on 5.7 cavities per unit cell (Breck, 1984)). From the plots of the heats of nitrogen adsorption, one can see that the isosteric heat of adsorption for $\mathrm{N}_{2}$ on $\operatorname{Li}_{94.2} \mathrm{Ag}_{1.1} \mathrm{Na}_{0.7}-$ LSX is quite high ( $8 \mathrm{kcal} / \mathrm{mol}$ ) at low coverages, but immediately drops sharply to become nearly horizontal. This is very similar to that of the near-fully exchanged AgLSX and indicates the presence of local sites where the $\mathrm{N}_{2}$ is preferentially sorbed more 
strongly than at other sites within the intracrystalline volume. The heat of adsorption becomes horizontal with adsorption of approximately one $\mathrm{N}_{2}$ molecule per cavity. A comparison with the same plot of the isosteric heat of adsorption for $\mathrm{N}_{2}$ on for $\mathrm{Li}_{94.5} \mathrm{Na}_{1.5^{-}}$ LSX, which is essentially horizontal, shows that the energetic heterogeneity of the $\mathrm{Li}_{94.2} \mathrm{Ag}_{1.1} \mathrm{Na}_{0.7}$-LSX zeolite is due entirely to the incorporation of the approximately one Ag per unit cell. The approximately constant heat of adsorption with increasing coverage for the $\mathrm{Li}_{94.5} \mathrm{Na}_{1.5}$-LSX is consistent with previously reported results (Bajusz and Goodwin, 1997), and likely indicates an energetically homogeneous surface.

\section{Structural Effects on Adsorption}

The adsorbate-zeolite interactions correspond to those between the adsorbing gas and the surface oxygen and charge compensating cations. In faujasite zeolites, the cations in the beta-cages and the double 6-ring (hexagonal prism) are sterically inaccessible to nitrogen; and so only the supercage (SII, SII*, and SIII) cations interact with the gases of interest in air separation $\left(\mathrm{N}_{2}, \mathrm{O}_{2}\right.$, and Ar). However, the electric field around these supercage cations is partially shielded by the surrounding oxygen atoms. Because of this shielding, the electrostatic and induction interactions are expected to be lower than that of an isolated ion. Further, dispersion forces acting on the molecule will be higher since adsorbate molecules also interact with oxygen atoms of the zeolite.

From the analysis of the structural data and the resulting effects on the adsorption of nitrogen for the near-fully $\mathrm{Ag}^{+}$-exchanged LSX (Hutson et al., 2000), one can make inferences of what are the similar effects for mixed Li,Ag-LSX. We mentioned earlier that lithium cations located in SII locations do not interact with atmospheric gases because of the short distance, and resulting shielding, to the framework oxygen. Silver 
cations in the SII locations, similarly, have little effect on the adsorptive properties, again, because of the shielding provided by framework oxygen (Ag-Y zeolites have very low $\mathrm{N}_{2}$ adsorptive capacity despite having a full occupancy of SII). However, silver in SII*, are very active (Hutson et al., 2000). This helps to explain the increase in the adsorptive capacity of $\mathrm{Li}_{9.2} \mathrm{Ag}_{1.1} \mathrm{Na}_{0.7}-\mathrm{LSX}$ after vacuum dehydration at $450 \mathrm{C}$ over that of both the $\mathrm{Li}_{94.2} \mathrm{Ag}_{1.1} \mathrm{Na}_{0.7}$-LSX after vacuum dehydration at $350 \mathrm{C}$ and the $\mathrm{Li}_{94.5} \mathrm{Na}_{1.5}-$ LSX. From the structural determinations, only the $\mathrm{Li}_{94.2} \mathrm{Ag}_{1.1} \mathrm{Na}_{0.7}-\mathrm{LSX}$ zeolite, after vacuum dehydration at $450 \mathrm{C}$, contain silver in the SII* location. This is supported by the fact that this is the only one of these two samples that showed the enhancement in adsorptive capacity over the near-fully $\mathrm{Li}^{+}$-exchanged LSX sample. The same sample, vacuum dehydrated at $350 \mathrm{C}$, did not show an enhancement in the adsorptive capacity, because the silver is located in the inaccessible SII' location.

This boost in the adsorption capacity is a result of an increase in the number of SII* cations. This increase in SII* cations is a result of thermally induced silver migration from the SII' location. This thermally induced silver migration is likely the result of a partial breakdown of the framework from autoreduction of silver with framework oxygen as shown in Eq. 2 (Hutson et al., 2000).

$$
2\left(\mathrm{Ag}^{+}-\mathrm{Z}-\mathrm{O}^{-}\right) \rightarrow 2 \mathrm{Ag}^{0}+\left(\frac{1}{2}\right) \mathrm{O}_{2}+Z-\mathrm{O}^{-}+Z^{+}
$$

The breakdown is not significant enough to destroy the crystallinity of the zeolite, and it is random enough to prevent its detection using X-ray or neutron diffraction. However, the breakdown likely creates an energetically unfavorable environment for the silver. As a result, silver in the SII' then moves to the SII or SII* location. Repulsive forces (probably from silver in the SII' location) then push the Ag into the adsorbate 
accessible SII* supercage position. The presence of this supercage cation (at the SII* site) results in an adsorptive surface which is energetic heterogeneous.

\section{Literature Cited}

Bajusz, I. G., and J. G. Goodwin, " $\mathrm{N}_{2}$ Adsorption in LiX Zeolite: Isotopic Transient Analysis", Langmuir, 13, 6550 (1997).

Barrer, R. M.; Zeolites and Clay Minerals as Sorbents and Molecular Sieves, Academic Press: London, 1978.

Breck, D. W.; Zeolite Molecular Sieves, R. E. Krieger Publishing: Malabar, FL, 1984.

Chao, C. C., "Process for Separating Nitrogen from Mixtures Thereof with Less Polar Substances", US Patent 4,859,217 (1989).

Chao, C. C., J. D. Sherman, J. T. Mullhaupt, and C. M. Bolinger, "Mixed Ion-exhanged Zeolites and Processes for the Use Thereof in Gas Separations", U. S. Patent 5,174,979 (1992).

Chen, N., and R. T. Yang, "An ab Initio Molecular Orbital Study of Adsorption of Oxygen, Nitrogen and Ethylene on Silver-Zeolite and Silver Halides", Ind. Eng. Chem. Res., 35, 4020 (1996).

Coe, C. G., J. F. Kirner, R. Pierantozzi, and T. R. White, "Nitrogen Adsorption with a Ca and/or Sr Exchanged Zeolite”, U. S. Patent 5,152,813 (1992).

Coe, C. G., in Access in Nanoporous Materials, T. J. Pinnavaia and M. F. Thorpe (Eds.), Plenum Press, New York, 1995 (p. 213).

Feuerstein, M., and R. F. Lobo, "Characterization of Li Cations in Zeolite LiX by SolidState NMR Spectroscopy and Neutron Diffraction”, Chem. Mater., 10, 2197 (1998).

Finger, L. W., D. E. Cox, and A. P. Jephcoat, "Correction for Powder Diffraction Peak Asymmetry Due to Axial Divergence", J. Appl. Crystallogr., 27, 892 (1994).

Fitch, F. R., M. Bulow, and A. F. Ojo, "Adsorptive Separation of Nitrogen and Other Gases", U. S. Patent 5,464,467 (1995).

Freeman, C. M., C. R. A. Catlow, J. M. Thomas, and S. Brode, "Computing the Location and Energetics of Organic Molecules in Microporous Adsorbents and Catalysts: a Hybrid Approach Applied to Isomeric Butenes in a Model Zeolite," Chem. Phys. Lett., 186, 137 (1991). 
Habgood, H. W., "Adsorptive and Gas Chromatographic Properties of Various Cationic Forms of Zeolite X”, Can. J. Chem., 42, 2340 (1964).

Huang, Y., "Adsorption in AgX and AgY Zeolites by Carbon Monoxide and Other Simple Molecules”, J. Catalysis, 32, 482 (1974).

Hutson, N. D., S. U. Rege, and R. T. Yang, "Mixed Cation Zeolites: $\operatorname{Li}_{\mathrm{x}} \mathrm{Ag}_{\mathrm{y}} \mathrm{X}$ as a Superior Adsorbent for Air Separation", AIChE J., 45,724 (1999).

Hutson, N. D.; Reisner, B. A.; Yang, R. T.; Toby, B. H.; "Silver Ion-Exchanged Zeolites Y, X, and Low Silica X: Observations of Thermally Induced Cation/Cluster Migration and the Resulting Effects on the Equilibrium Adsorption of Nitrogen", Chem. Mater., submitted (2000).

Knaebel, K. S., and A. Kandybin, "Pressure Swing Adsorption System to Purify Oxygen”, US Patent 5,226,933 (1993).

Larson, A. C.; van Dreele, R. B.; GSAS: General Structure Analysis System Manual; Los Alamos Report LAUR 86-748; Los Alamos National Laboratory: Los Alamos, NM, 1986.

Le Bail, A., H. Duroy, and J. L. Fourquet, "Ab Initio Structure Determination of $\mathrm{LiSbWO}_{6}$ by X-ray Powder Diffraction", Mater. Res. Bull., 23, 447 (1988).

McKee, D. W., "Separation of an Oxygen-Nitrogen Mixture”, U.S. Patent 3,140,933 (1964).

Rege, S. U., and R. T. Yang, "Limits for Air Separation by Adsorption with LiX Zeolite", Ind. Eng. Chem. Res., 36, 5358 (1997).

Reisner, B. A., Personal communication with Dr. Barbara Reisner, Crystallography Team, NIST Center for Neutron Research (NCNR), National Institute of Standards and Technology (NIST), Gaithersburg, MD (January, 2000).

Rietveld, H. M., "Line Profiles of Neutron Powder-Diffraction Peaks for Structure Refinement," Acta Crystallogr. 1967, 22, 151.

Sun, T; and Seff, K., "Silver Clusters and Chemistry in Zeolites," Chem. Rev. (Washington, D.C.), 1994, 94, 857.

Yang, R. T.; Gas Separation by Adsorption Processes, Butterworth: Boston, 1987; reprinted (in paperback) by Imperial College Press: London and World Scientific Publishing Co.: River Edge, NJ, 1997. 
Yang, R. T., Y. D. Chen, J. D. Peck, and N. Chen, "Zeolites Containing Mixed Cations for Air Separation by Weak Chemisorption-Assisted Adsorption", Ind. Eng. Chem. Res., 35, 3093 (1996).

Yang, R. T., and N. D. Hutson, "Lithium Based Zeolites Containing Silver and Copper and Use Thereof for Selective Adsorption," U.S. Patent Pending, U. S. Patent Office No. 60/114, 371 (1999).

Table 1. Elemental composition of the $\operatorname{Li}_{x} A g_{y}-L S X$ zeolite samples.

\begin{tabular}{lcccccccccccc}
\hline & \multicolumn{2}{c}{ sample 1 } & \multicolumn{2}{c}{ sample 2 } & \multicolumn{2}{c}{ sample 3 } & \multicolumn{2}{c}{ sample 4 } & \multicolumn{2}{c}{ sample 5 } & \multicolumn{2}{c}{ sample 6 } \\
Comp & wt\% & $+/ /-$ & wt\% & $+/-$ & wt\% & $+/-$ & wt\% & $+/-$ & wt\% & $+/-$ & wt\% & + +/- \\
\hline $\mathrm{Al}$ & 0.38 & 0.88 & 0.19 & 0.87 & 0.80 & 0.85 & 9.45 & 0.81 & 8.37 & 0.75 & 1.91 & 0.49 \\
$\mathrm{Ag}$ & 0.00 & - & 0.93 & 0.06 & 0.04 & 0.06 & 0.57 & 0.16 & 5.64 & 0.12 & 5.49 & 0.27 \\
$\mathrm{Na}$ & 0.28 & 0.02 & 0.14 & 0.01 & 0.10 & 0.01 & 0.11 & 0.01 & 0.22 & 0.01 & 0.03 & 0.01 \\
$\mathrm{Li}$ & 0.59 & & 0.21 & - & 0.99 & - & 0.76 & - & 0.85 & - & 0.00 & - \\
\hline
\end{tabular}

Note: Lithium was measured by Inductively Coupled Plasma - Mass Spectroscopy (ICP-MS). All others were measured by Neutron Activation Analysis (NAA). 
Table 2. Unit cell composition for each of the $\operatorname{Li}_{x} A_{y}-L S X$ samples.

\begin{tabular}{lcccccc}
\hline atm/uc & $\begin{array}{c}\mathbf{1} \\
\mathbf{a t m} / \mathbf{u c}\end{array}$ & $\begin{array}{c}\mathbf{2} \\
\text { Atm/uc }\end{array}$ & $\begin{array}{c}\mathbf{3} \\
\mathbf{a t m} / \mathbf{u c}\end{array}$ & $\begin{array}{c}\mathbf{4} \\
\mathbf{a t m} / \mathbf{u c}\end{array}$ & $\begin{array}{c}\mathbf{5} \\
\mathbf{a t m} / \mathbf{u c}\end{array}$ & $\begin{array}{c}\mathbf{6} \\
\mathbf{a t m} / \mathbf{u c}\end{array}$ \\
\hline $\mathrm{Al}$ & 96.0 & 96.0 & 96.0 & 96.0 & 96.0 & 96.0 \\
$\mathrm{Ag}$ & 0.0 & 1.1 & 3.5 & 11.5 & 21.0 & 95.7 \\
$\mathrm{Na}$ & 1.5 & 0.7 & 0.5 & 0.6 & 1.2 & 0.3 \\
$\mathrm{Si}$ & 96.0 & 96.0 & 96.0 & 96.0 & 96.0 & 96.0 \\
$\mathrm{Li}$ & 94.5 & 94.2 & 92.0 & 83.9 & 73.8 & 0.0 \\
$\mathrm{O}$ & 384.0 & 384.0 & 384.0 & 384.0 & 384.0 & 384.0 \\
\hline
\end{tabular}


Table 3. Unit cell composition (in atoms/unit cell) for each $\operatorname{Li}_{x} A_{y_{y}}-\mathbf{L S X}$ sample used in the structural determination.

\begin{tabular}{|c|c|c|c|}
\hline \multirow{2}{*}{$\begin{array}{l}\text { Component } \\
\mathrm{Al}\end{array}$} & \multirow{2}{*}{$\begin{array}{c}\begin{array}{c}\text { Li-LSX } \\
\text { atm/uc }\end{array} \\
96\end{array}$} & \multicolumn{2}{|c|}{$\begin{array}{c}\mathbf{L i}_{\mathbf{x}} \mathbf{A g}_{\mathbf{y}}-\mathbf{L S X} \\
\mathrm{atm} / \mathrm{uc}\end{array}$} \\
\hline & & 96 & 96 \\
\hline $\mathrm{Ag}$ & 0 & 2.0 & 41.8 \\
\hline $\mathrm{Na}$ & 0.2 & 0.7 & 0.2 \\
\hline $\mathrm{Si}$ & 96 & 96 & 96 \\
\hline $\mathrm{O}$ & 384 & 384 & 384 \\
\hline $\mathrm{Li}$ & 95.8 & 93.3 & 54 \\
\hline
\end{tabular}


Table 4. Cell parameters and agreement factors for the four Li,Ag-LSX samples. The agreement factors for each crystallographic model is compared to an ideal (Le Bail) fit. Standard uncertainties are given in parentheses.

\begin{tabular}{|c|c|c|c|c|}
\hline parameter & $\begin{array}{l}\mathrm{Li}_{95.8} \mathrm{Na}_{0.2} \text {-LSX- } \\
450\end{array}$ & $\begin{array}{l}\mathrm{Li}_{54.0} \mathrm{Ag}_{41.8} \mathrm{Na}_{0.2}{ }^{-} \\
\mathrm{LSX-450}\end{array}$ & $\begin{array}{l}\text { Li }_{93.3} \mathrm{Ag}_{2.0} \mathrm{Na}_{0.7} \\
\text { LSX-350 } \\
\end{array}$ & $\begin{array}{l}\mathrm{Li}_{93.3} \mathrm{Ag}_{2.0} \mathrm{Na}_{0.7}-\mathrm{LSX}- \\
450\end{array}$ \\
\hline Space group & $F d \overline{3}(203)$ & $F d \overline{3}(203)$ & $F d \overline{3}(203)$ & $F d \overline{3}(203)$ \\
\hline $\mathrm{a}=\mathrm{b}=\mathrm{c}(\AA)$ & $24.68256(27)$ & $24.72728(33)$ & $24.68317(30)$ & $24.68379(28)$ \\
\hline $\mathrm{R}_{\mathrm{wp}}($ Rietveld $)$ & 0.0513 & 0.0579 & 0.0510 & 0.0514 \\
\hline $\mathrm{R}_{\text {Bragg }}$ (Rietveld) & 0.0424 & 0.0456 & 0.0421 & 0.0421 \\
\hline$\chi^{2}$ (Rietveld) & 1.352 & 1.456 & 1.233 & 1.319 \\
\hline
\end{tabular}


Table 5. Framework atomic parameters for the Li,Ag-LSX samples from Rietveld refinements of neutron powder diffraction data. Standard uncertainties are given in parentheses.

\begin{tabular}{|c|c|c|c|c|c|c|}
\hline Atom & Site & & $\begin{array}{r}\mathbf{L i}_{95.8} \mathrm{Na}_{0.2-}^{-} \\
\text {LSX-450 } \\
\end{array}$ & $\begin{array}{r}\mathrm{Li}_{54.0} \mathrm{Ag}_{41.8} \mathrm{Na}_{0.2}- \\
\text { LSX-450 } \\
\end{array}$ & $\begin{array}{r}\mathbf{L i}_{93.3} \mathbf{A g}_{2.0} \mathrm{Na}_{0.7-}^{-} \\
\mathbf{L S X}-350 \\
\end{array}$ & $\begin{array}{r}\mathbf{L i}_{\mathbf{9}_{3.3}} \mathbf{A g}_{2.0} \mathbf{N a}_{0.7-}^{-} \\
\mathbf{L S X}-450 \\
\end{array}$ \\
\hline \multirow[t]{4}{*}{$\mathrm{T}(1)^{\mathrm{a}}$} & $96 \mathrm{~g}$ & $\mathrm{x}$ & $-0.0475(4)$ & $-0.0485(4)$ & $-0.0477(4)$ & $-0.04875(29)$ \\
\hline & & $\mathrm{y}$ & $0.1254(4)$ & $0.1258(4)$ & $0.1256(4)$ & $0.1247(4)$ \\
\hline & & $\mathrm{z}$ & $0.0392(4)$ & $0.0368(5)$ & $0.0397(4)$ & $0.0373(4)$ \\
\hline & & $\mathrm{B}\left(\AA^{2}\right)^{\mathrm{b}}$ & 0.011425 & 0.01514 & 0.01299 & 0.01223 \\
\hline \multirow[t]{3}{*}{$\mathrm{T}(2)^{\mathrm{a}}$} & $96 \mathrm{~g}$ & $\mathrm{x}$ & $-0.0528(4)$ & $-0.0498(4)$ & $-0.0523(4)$ & $-0.05009(34)$ \\
\hline & & $\mathrm{y}$ & $0.0361(5)$ & $.0384(5)$ & $.0359(5)$ & $0.0378(4)$ \\
\hline & & $\mathrm{Z}$ & $0.1224(4)$ & $0.1221(4)$ & $.1226(4)$ & $0.1229(4)$ \\
\hline \multirow[t]{4}{*}{$\mathrm{O}(1)$} & $96 \mathrm{~g}$ & $\mathrm{x}$ & $-0.10383(2)$ & $-0.1023(4)$ & $-0.10306(2)$ & $-0.10426(21)$ \\
\hline & & $\mathrm{y}$ & $0.00341(3)$ & $0.0021(5)$ & $0.00381(32)$ & $0.00367(31)$ \\
\hline & & $\mathrm{z}$ & $0.09756(2)$ & $0.0967(4)$ & $0.09785(23)$ & $0.09684(22)$ \\
\hline & & $\mathrm{B}\left(\AA^{2}\right)^{\mathrm{b}}$ & 0.0195 & 0.01861 & 0.02099 & 0.02023 \\
\hline \multirow[t]{3}{*}{$\mathrm{O}(2)$} & $96 \mathrm{~g}$ & $\mathrm{x}$ & $0.00060(3)$ & $-0.00040(33)$ & $0.00052(30)$ & $0.00027(26)$ \\
\hline & & $\mathrm{y}$ & $-0.00129(3)$ & $-0.00026(33)$ & $-0.00148(29)$ & $-0.00093(26)$ \\
\hline & & $\mathrm{z}$ & $0.15314(1)$ & $0.15355(19)$ & $0.15358(15)$ & $0.15300(15)$ \\
\hline \multirow[t]{3}{*}{$\mathrm{O}(3)$} & $96 \mathrm{~g}$ & $\mathrm{x}$ & $-0.02202(1)$ & $-0.02227(19)$ & $-0.02261(15)$ & $-0.02232(15)$ \\
\hline & & $\mathrm{y}$ & $0.07273(3)$ & $0.07392(31)$ & $0.07289(29)$ & $0.07333(26)$ \\
\hline & & $\mathrm{z}$ & $0.06963(3)$ & $0.06850(35)$ & $0.06875(28)$ & $0.06920(27)$ \\
\hline \multirow[t]{3}{*}{$\mathrm{O}(4)$} & $96 \mathrm{~g}$ & $\mathrm{x}$ & $-0.07403(1)$ & $-0.07414(23)$ & $-0.07399(17)$ & $-0.07414(17)$ \\
\hline & & $\mathrm{y}$ & $0.08149(3)$ & $0.0808(4)$ & $0.08120(32)$ & $0.08156(29)$ \\
\hline & & $\mathrm{z}$ & $0.17121(3)$ & $0.1717(4)$ & $0.17176(29)$ & $0.17165(27)$ \\
\hline
\end{tabular}

\footnotetext{
${ }^{a}$ The $\mathrm{T}(1)$ site is completely occupied by $\mathrm{Si}$. The T(2) site is completely occupied by Al.

b Displacement parameters were fixed for each refinement as follows:

$\mathrm{T}(1)=\mathrm{T}(2), \mathrm{O}(1)=\mathrm{O}(2)=\mathrm{O}(3)=\mathrm{O}(4)$
} 
Table 6. Extraframework atomic parameters for the Li,Ag-LSX samples from Rietveld refinements of neutron powder diffraction data. Standard uncertainties are given in parentheses.

\begin{tabular}{|c|c|c|c|c|c|c|}
\hline Atom & Site & & $\begin{array}{r}\mathrm{Li}_{95.8} \mathrm{Na}_{0.2-} \\
\mathrm{LSX}-450 \\
\end{array}$ & $\begin{array}{r}\mathbf{L i}_{54.0} \mathbf{A g}_{41.8} \mathrm{Na}_{0.2-} \\
\mathbf{L S X - 4 5 0} \\
\end{array}$ & $\begin{array}{r}\mathrm{Li}_{93.3} \mathrm{Ag}_{2.0} \mathrm{Na}_{0.7}- \\
\mathrm{LSX}-350 \\
\end{array}$ & $\begin{array}{r}\mathbf{L i}_{93.3} \mathbf{A g}_{2.0} \mathrm{Na}_{0.7} \\
\text { LSX-450 } \\
\end{array}$ \\
\hline \multirow[t]{3}{*}{$\overline{\operatorname{Li}\left(I^{\prime}\right)}$} & $32 \mathrm{e}$ & $\mathrm{x}=\mathrm{y}=\mathrm{z}$ & $0.0455(5)$ & $0.0403(7)$ & $0.0438(4)$ & $0.0452(4)$ \\
\hline & & Occup. & $0.85(4)$ & $0.73(4)$ & $0.890(31)$ & $0.915(32)$ \\
\hline & & $\mathrm{B}\left(\AA^{\frac{1}{2}}\right)$ & 0.0415 & 0.02739 & 0.03054 & 0.03325 \\
\hline \multirow[t]{3}{*}{$\mathrm{Li}(\mathrm{II})$} & $32 \mathrm{e}$ & $\mathrm{x}=\mathrm{y}=\mathrm{z}$ & $0.2227(4)$ & $0.2228(7)$ & $0.2230(4)$ & $0.2237(4)$ \\
\hline & & Occup. & $1.06(4)$ & $1.26(8)$ & $1.09(4)$ & $1.09(4)$ \\
\hline & & $\mathrm{B}\left(\AA^{2}\right)$ & 0.0305 & - & - & - \\
\hline \multirow[t]{5}{*}{ Li(III) } & $96 \mathrm{~g}$ & $\mathrm{X}$ & $0.395(5)$ & - & $0.3885(20)$ & $0.401(4)$ \\
\hline & & $\mathrm{y}$ & $0.399(5)$ & - & $0.4052(19)$ & $0.4038(33)$ \\
\hline & & $\mathrm{Z}$ & $0.1264(2)$ & - & $0.1287(20)$ & $0.1260(16)$ \\
\hline & & Occup. & $0.337(24)$ & - & $0.240(16)$ & $0.264(16)$ \\
\hline & & $\mathrm{B}\left(\AA^{\frac{1}{2}}\right)$ & 0.1201 & - & - & - \\
\hline \multirow[t]{2}{*}{$\operatorname{Ag}\left(I^{\prime}\right)$} & $32 \mathrm{e}$ & $\mathrm{x}=\mathrm{y}=\mathrm{z}$ & - & $0.0818(34)$ & - & - \\
\hline & & Occup. & - & $0.058(11)$ & - & - \\
\hline \multirow[t]{2}{*}{$\operatorname{Ag}\left(\mathrm{II}^{\prime}\right)$} & $32 \mathrm{e}$ & $\mathrm{x}=\mathrm{y}=\mathrm{z}$ & - & - & $0.1674(28)$ & $0.170(6)$ \\
\hline & & Occup. & - & - & $0.053(8)$ & $0.029(7)$ \\
\hline \multirow[t]{2}{*}{$\operatorname{Ag}(\mathrm{II})$} & $32 \mathrm{e}$ & $\mathrm{x}=\mathrm{y}=\mathrm{z}$ & - & $0.203(5)$ & - & - \\
\hline & & Occup. & - & $0.062(22)$ & - & - \\
\hline \multirow[t]{2}{*}{$\operatorname{Ag}\left(\mathrm{II}^{*}\right)$} & $32 \mathrm{e}$ & $\mathrm{x}=\mathrm{y}=\mathrm{z}$ & - & $0.2560(34)$ & - & $0.263(5)$ \\
\hline & & Occup. & - & $0.053(16)$ & - & $0.029(7)$ \\
\hline \multirow[t]{4}{*}{$\operatorname{Ag}(\mathrm{III})$} & $96 g$ & $\mathrm{x}$ & - & $0.269(5)$ & - & - \\
\hline & & $\mathrm{y}$ & - & $0.359(5)$ & - & - \\
\hline & & $\mathrm{Z}$ & - & $0.123(5)$ & - & - \\
\hline & & Occup. & - & $0.053(12)$ & - & - \\
\hline \multirow[t]{4}{*}{ Ag(III') } & $96 \mathrm{~g}$ & $\mathrm{X}$ & - & $0.3924(27)$ & - & - \\
\hline & & $\mathrm{y}$ & - & $0.3912(28)$ & - & - \\
\hline & & Z & - & $0.1451(9)$ & - & - \\
\hline & & Occup. & - & $0.186(7)$ & - & - \\
\hline \multirow{2}{*}{$\begin{array}{l}\mathrm{Al}(\mathrm{ALUM} \\
\text { ) }\end{array}$} & $8 \mathrm{a}$ & $\mathrm{x}=\mathrm{y}=\mathrm{z}$ & - & $0.125(0)$ & - & - \\
\hline & & Occup. & - & $0.037(12)$ & - & - \\
\hline \multirow[t]{2}{*}{$\mathrm{O}(\mathrm{ALUM})$} & $32 \mathrm{e}$ & $\mathrm{x}=\mathrm{y}=\mathrm{z}$ & - & $0.174(6)$ & - & - \\
\hline & & Occup. & - & $0.037(12)$ & - & - \\
\hline
\end{tabular}

Displacement parameters were fixed for each refinement as follows:

$\operatorname{Ag}(\mathrm{I})=\operatorname{Ag}\left(\mathrm{I}^{\prime}\right)=\operatorname{Ag}\left(\mathrm{II}^{\prime \prime}\right)=\mathrm{Ag}(\mathrm{II})=\mathrm{Ag}(\mathrm{II})=\mathrm{Ag}(\mathrm{III})=\mathrm{Al}(\mathrm{ALUM})=\mathrm{O}(\mathrm{ALUM})$. 
Table 7. Selected interatomic distances $(\AA)$ and bond angles $\left(^{\circ}\right)$ derived from $\mathrm{Li}, \mathrm{Ag}$ LSX samples with standard uncertainties in parentheses.

\begin{tabular}{|c|c|c|c|c|}
\hline Atoms & $\begin{array}{r}\mathbf{L i}_{95.8} \mathrm{Na}_{0.2^{-}} \\
\text {LSX-450 }\end{array}$ & $\begin{array}{r}\mathbf{L i}_{54.0} \mathrm{Ag}_{41.8} \mathrm{Na}_{0.2^{-}} \\
\text {LSX-450 }\end{array}$ & $\begin{array}{r}\mathbf{L i}_{93.3} \mathrm{Ag}_{2.0} \mathrm{Na}_{0.7} \\
\text { LSX-350 }\end{array}$ & $\begin{array}{r}\mathrm{Li}_{93.3} \mathrm{Ag}_{2.0} \mathrm{Na}_{0.7}- \\
\text { LSX-450 }\end{array}$ \\
\hline \multicolumn{5}{|l|}{ Vector } \\
\hline $\mathrm{T}(1) \_\mathrm{T}(2)$ & $3.016(8)$ & $3.020(9)$ & $3.015(8)$ & $3.011(7)$ \\
\hline $\mathrm{T}(1) \_\mathrm{T}(2)$ & $3.069(8)$ & $3.034(10)$ & $3.070(8)$ & $3.036(8)$ \\
\hline $\mathrm{T}(1) \_\mathrm{T}(2)$ & $3.089(9)$ & $3.096(10)$ & $3.077(9)$ & $3.095(8)$ \\
\hline $\mathrm{T}(1) \_\mathrm{O}(1)$ & $1.708(12)$ & $1.637(9)$ & $1.731(11)$ & $1.639(8)$ \\
\hline $\mathrm{T}(1) \_\mathrm{O}(2)$ & $1.637(13)$ & $1.655(14)$ & $1.648(13)$ & $1.648(11)$ \\
\hline $\mathrm{T}(1) \_\mathrm{O}(3)$ & $1.627(13)$ & $1.637(9)$ & $1.609(13)$ & $1.630(8)$ \\
\hline $\mathrm{T}(1) \_\mathrm{O}(4)$ & $1.586(11)$ & $1.614(9)$ & $1.569(11)$ & $1.607(8)$ \\
\hline $\mathrm{T}(2) \_\mathrm{O}(1)$ & $1.617(14)$ & $1.700(9)$ & $1.604(14)$ & $1.706(8)$ \\
\hline $\mathrm{T}(2) \_\mathrm{O}(2)$ & $1.778(13)$ & $1.735(10)$ & $1.771(12)$ & $1.736(8)$ \\
\hline $\mathrm{T}(2) \_\mathrm{O}(3)$ & $1.759(15)$ & $1.729(9)$ & $1.771(14)$ & $1.730(8)$ \\
\hline $\mathrm{T}(2) \_\mathrm{O}(4)$ & $1.727(13)$ & $1.723(9)$ & $1.735(12)$ & $1.723(8)$ \\
\hline \multicolumn{5}{|l|}{ Angle } \\
\hline $\mathrm{O}(1) \_\mathrm{T}(1) \_\mathrm{O}(2)$ & $106.0(5)$ & $110.2(8)$ & $105.4(5)$ & $107.9(5)$ \\
\hline $\mathrm{O}(1) \_\mathrm{T}(1) \_\mathrm{O}(3)$ & $108.3(7)$ & $106.9(8)$ & $107.0(6)$ & $110.4(6)$ \\
\hline $\mathrm{O}(1) \_\mathrm{T}(1) \_\mathrm{O}(4)$ & $106.8(6)$ & $108.8(7)$ & $107.4(6)$ & $108.3(6)$ \\
\hline $\mathrm{O}(2) \_\mathrm{T}(1) \_\mathrm{O}(3)$ & $109.5(6)$ & $107.8(7)$ & $109.5(6)$ & $108.1(5)$ \\
\hline $\mathrm{O}(2) \_\mathrm{T}(1) \_\mathrm{O}(4)$ & $111.4(6)$ & $111.2(6)$ & $110.9(6)$ & $110.2(5)$ \\
\hline $\mathrm{O}(3) \_\mathrm{T}(1) \_\mathrm{O}(4)$ & $114.3(6)$ & $111.8(7)$ & $116.1(6)$ & $112.0(5)$ \\
\hline $\mathrm{O}(1) \_\mathrm{T}(2) \_\mathrm{O}(2)$ & $118.7(7)$ & $114.4(9)$ & $118.8(7)$ & $116.8(6)$ \\
\hline $\mathrm{O}(1) \_\mathrm{T}(2) \_\mathrm{O}(3)$ & $108.1(6)$ & $106.6(6)$ & $107.0(6)$ & $105.8(5)$ \\
\hline $\mathrm{O}(1) \_\mathrm{T}(2) \_\mathrm{O}(4)$ & $110.6(7)$ & $108.5(8)$ & $110.1(7)$ & $107.6(6)$ \\
\hline $\mathrm{O}(2) \_\mathrm{T}(2) \_\mathrm{O}(3)$ & $105.2(6)$ & $110.3(7)$ & $106.8(6)$ & $108.9(6)$ \\
\hline $\mathrm{O}(2) \_\mathrm{T}(2) \_\mathrm{O}(4)$ & $105.4(6)$ & $105.2(7)$ & $105.1(6)$ & $107.0(5)$ \\
\hline $\mathrm{O}(3) \_\mathrm{T}(2) \_\mathrm{O}(4)$ & $108.3(7)$ & $111.9(7)$ & $108.7(7)$ & $110.7(5)$ \\
\hline $\mathrm{T}(1) \_\mathrm{O}(1) \_\mathrm{T}(2)$ & $145.5(4)$ & $148.2(6)$ & 146.1(4) & $144.98(34)$ \\
\hline $\mathrm{T}(1) \_\mathrm{O}(2) \_\mathrm{T}(2)$ & $127.95(33)$ & $127.0(4)$ & $127.73(34)$ & $127.61(33)$ \\
\hline $\mathrm{T}(1) \_\mathrm{O}(3) \_\mathrm{T}(2)$ & $125.86(31)$ & $127.5(4)$ & $126.26(33)$ & $127.31(33)$ \\
\hline $\mathrm{T}(1) \_\mathrm{O}(4) \_\mathrm{T}(2)$ & $137.7(4)$ & $136.1(5)$ & $137.2(4)$ & $136.6(4)$ \\
\hline
\end{tabular}


Table 8. Selected interatomic distances $(\AA)$ derived from Li,Ag-LSX with standard uncertainties in parentheses.

\begin{tabular}{|c|c|c|c|c|c|}
\hline Atoms & $\begin{array}{r}\mathrm{Li}_{95.8} \mathrm{Na}_{0.2^{-}} \\
\text {LSX-450 }\end{array}$ & $\begin{aligned} & \mathrm{Li}_{54.0} \mathrm{Ag}_{41.8} \mathrm{Na}_{0.2} \\
& \text {-LSX-450 }\end{aligned}$ & $\begin{array}{r}\mathrm{Li}_{93.3} \mathrm{Ag}_{2.0} \mathrm{Na}_{0.7-} \\
\text { LSX-350 }\end{array}$ & & $\begin{array}{r}{ }_{3} \mathrm{Ag}_{2.0} \mathrm{Na}_{0.7^{-}} \\
\text {LSX-450 }\end{array}$ \\
\hline Li(I')_SI & $3.030(9)$ & $3.049(10)$ & \multicolumn{2}{|c|}{$3.031(9)$} & $3.044(8)$ \\
\hline $\mathrm{Li}\left(\mathrm{I}^{\prime}\right) \_\mathrm{Al}$ & \multirow{2}{*}{$\begin{array}{r}3.090(12) \\
1.893(4)\end{array}$} & $3.009(12)$ & \multicolumn{2}{|c|}{$3.073(12)$} & $3.040(10)$ \\
\hline $\mathrm{Li}\left(\mathrm{I}^{\prime}\right) \_\mathrm{O}(3)$ & & $1.890(5)$ & \multicolumn{2}{|c|}{$1.893(4)$} & $1.900(4)$ \\
\hline $\mathrm{Li}\left(\mathrm{I}^{\prime}\right) \operatorname{Ag}\left(\mathrm{I}^{\prime}\right)$ & \multicolumn{2}{|r|}{$1.78(14)$} & \multicolumn{2}{|c|}{$3.337(28)$} & $3.32(6)$ \\
\hline Li(II)_SI & $3.044(10)$ & \multirow{2}{*}{$\begin{array}{l}3.052(10) \\
3.148(12)\end{array}$} & \multicolumn{2}{|c|}{$3.046(10)$} & $3.078(8)$ \\
\hline Li(II)_Al & $3.174(11)$ & & \multicolumn{2}{|c|}{$3.166(11)$} & $3.136(9)$ \\
\hline $\mathrm{Li}(\mathrm{II}) \_\mathrm{O}(2)$ & $1.970(4)$ & $1.965(6)$ & \multicolumn{2}{|c|}{$1.964(4)$} & $1.978(5)$ \\
\hline Li(II)_Ag(II') & & - & \multicolumn{2}{|c|}{$2.38(12)$} & $2.28(24)$ \\
\hline Li(II)_Ag(II) & \multicolumn{2}{|r|}{$.87(25)$} & \multicolumn{2}{|c|}{$2.50(12)$} & \\
\hline Li(II)_Ag(II*) & \multicolumn{2}{|r|}{$1.42(15)$} & \multicolumn{2}{|c|}{ - } & $1.67(20)$ \\
\hline Li(II)_O(ALUM) & \multirow{2}{*}{$2.53(10)^{-}$} & $2.11(28)$ & & - & \\
\hline Li(III)_SI & & & 2.4 & & $2.48(7)$ \\
\hline Li(III)_Al & $3.31(8)$ & & 3.2 & & $2.49(7)$ \\
\hline Li(III)_Al & $2.54(10)$ & & 2.7 & & - \\
\hline Li(III)_O(1) & $2.68(12)$ & & 2.5 & & $2.57(8)$ \\
\hline $\mathrm{Li}(\mathrm{III}) \_\mathrm{O}(1)$ & $2.57(11)$ & & 2.7 & & $2.41(9)$ \\
\hline Li(III)_O(3) & $2.81(5)$ & & - & - & $2.72(4)$ \\
\hline Li(III)_O(4) & $2.11(12)$ & & 2.0 & & $2.19(9)$ \\
\hline Li(III)_O(4) & $2.23(12)$ & & 2.4 & & $2.30(8)$ \\
\hline Li(III)_Li(III) & $1.53(11)$ & & 1.6 & & $1.92(8)$ \\
\hline $\mathrm{Ag}\left(\mathrm{I}^{\prime}\right) \_\mathrm{O}(3)$ & & $2.60(10)$ & & - & - \\
\hline $\operatorname{Ag}\left(I^{\prime}\right) \quad \operatorname{Ag}(I I)$ & & $3.22(20)$ & & - & - \\
\hline $\operatorname{Ag}\left(I^{\prime}\right) \_A g\left(I^{\prime}\right)$ & & $3.02(24)$ & & - & - \\
\hline $\operatorname{Ag}\left(I^{\prime}\right) \_A l(A L U M)$ & & $1.85(14)$ & & - & - \\
\hline Ag(I')_O(ALUM) & & $2.28(19)$ & & - & - \\
\hline Ag(II')_Ag(II') & & - & 2.96 & & $3.2(4)$ \\
\hline $\mathrm{Ag}(\mathrm{II}) \_\mathrm{Si}$ & & $3.049(31)$ & & - & - \\
\hline $\mathrm{Ag}(\mathrm{II}) \_\mathrm{Al}$ & & $3.129(32)$ & & - & - \\
\hline $\mathrm{Ag}(\mathrm{II}) \_\mathrm{O}(2)$ & & $2.06(7)$ & & - & - \\
\hline Ag(II)_O(ALUM) & & $1.24(30)$ & & - & - \\
\hline $\mathrm{Ag}(\mathrm{II})^{*}{ }_{-} \mathrm{O}(2)$ & & $2.54(9)$ & & - & - \\
\hline $\mathrm{Ag}\left(\mathrm{II}^{*}\right) \_\mathrm{Ag}(\mathrm{II})$ & & $2.28(27)$ & & - & - \\
\hline $\mathrm{Ag}\left(\mathrm{III} \mathrm{I}^{\prime}\right) \_\mathrm{Si}$ & & $3.01(5)$ & & - & - \\
\hline Ag(III')_Al & & $2.93(5)$ & & - & - \\
\hline Ag(III')_O(4) & & $2.44(6)$ & & - & - \\
\hline Ag(III')_Ag(III') & & $1.18(5)$ & & - & - \\
\hline Ag(III')_Ag(III) & & $3.20(16)$ & & - & - \\
\hline Ag(III')_Ag(III) & & $2.26(14)$ & & - & - \\
\hline $\mathrm{Ag}(\mathrm{III}) \_\mathrm{Si}$ & & $2.05(13)$ & & - & - \\
\hline Ag(III)_Al & & $1.89(13)$ & & - & - \\
\hline Ag(III)_O(1) & & $.73(15)$ & & - & - \\
\hline Ag(III)_O(4) & & $2.48(12)$ & & - & - \\
\hline Al(ALUM)_O(ALUM) & & $2.08(27)$ & & - & - \\
\hline
\end{tabular}

Table 9. Selected interatomic bond angles (degrees) derived from Li,Ag-LSX with standard uncertainties in parentheses. 


\begin{tabular}{|c|c|c|c|c|}
\hline Atoms & $\begin{array}{l}\mathrm{Li}_{95.8} \mathrm{Na}_{0.2^{-}} \\
\text {LSX-450 }\end{array}$ & $\begin{array}{l}\mathrm{Li}_{54.0} \mathrm{Ag}_{41.8} \mathrm{Na}_{0.2^{-}} \\
\mathrm{LSX}-450\end{array}$ & $\begin{array}{l}\mathrm{Li}_{93.3} \mathrm{Ag}_{2.0} \mathrm{Na}_{0.7^{-}} \\
\mathrm{LSX}-350\end{array}$ & $\begin{array}{l}\mathrm{Li}_{93.3} \mathrm{Ag}_{2.0} \mathrm{Na}_{0.7}- \\
\mathrm{LSX}-450\end{array}$ \\
\hline $\mathrm{O}(3) \_\mathrm{Li}\left(\mathrm{I}^{\prime}\right) \_\mathrm{O}(3)$ & $118.52(25)$ & $119.998(14)$ & $119.14(17)$ & $118.70(22)$ \\
\hline $\mathrm{O}(3) \_\mathrm{Li}\left(\mathrm{I}^{\prime}\right) \_\mathrm{Ag}\left(\mathrm{I}^{\prime}\right)$ & - & $90.3(9)$ & - & - \\
\hline $\mathrm{O}(2) \_L i(\mathrm{II}) \_\mathrm{O}(2)$ & $118.95(17)$ & $118.94(31)$ & $118.90(17)$ & $118.42(22)$ \\
\hline O(2)_Li(II)_Ag(II') & - & - & $83.9(5)$ & $82.7(5)$ \\
\hline O(2)_Li(II)_Ag(II) & - & $84.0(9)$ & - & - \\
\hline $\mathrm{O}(2) \_\mathrm{Li}(\mathrm{II}) \_\mathrm{Ag}(\mathrm{II} *)$ & - & $96.0(9)$ & - & $97.3(5)$ \\
\hline SI_Li(III)_Al & $73.0(13)$ & - & $70.9(12)$ & $74.5(11)$ \\
\hline $\mathrm{O}(2) \_\mathrm{Ag}(\mathrm{II}) \_\mathrm{O}(2)$ & - & $110 .(6)$ & - & - \\
\hline $\mathrm{O}(2) \_\mathrm{Ag}(\mathrm{II}) \_\mathrm{Ag}(\mathrm{II} *)$ & - & 71.(6) & - & - \\
\hline
\end{tabular}


Table 10. Reported site occupancies for extraframework species in Li,Ag-LSX in units of silver/unit cell.

\begin{tabular}{|c|c|c|c|c|}
\hline Cation & $\begin{array}{l}\text { Li }_{95.8} \mathrm{Na}_{0.2-} \\
\text { LSX-450 }\end{array}$ & $\begin{array}{l}\mathrm{Li}_{54.0} \mathrm{Ag}_{41.8} \mathrm{Na}_{0.2-} \\
\mathrm{LSX}-450\end{array}$ & $\begin{array}{l}\mathrm{Li}_{93.3} \mathrm{Ag}_{2.0} \mathrm{Na}_{0.7-} \\
\mathrm{LSX-350}\end{array}$ & $\begin{array}{l}\mathrm{Li}_{93.3} \mathrm{Ag}_{2.0} \mathrm{Na}_{0.7}- \\
\mathrm{LSX}-450\end{array}$ \\
\hline $\operatorname{Li}\left(I^{\prime}\right)$ & 27.2 & 23.4 & 28.5 & 29.3 \\
\hline Li(II) & 33.9 & 40.3 & 34.9 & 34.9 \\
\hline $\mathrm{Li}(\mathrm{III})$ & 32.4 & - & 23.0 & 25.3 \\
\hline $\mathrm{Li}$ found & 93.5 & 63.7 & 86.4 & 89.5 \\
\hline Li predicted & 95.8 & 54.0 & 93.3 & 93.3 \\
\hline $\operatorname{Ag}\left(I^{\prime}\right)$ & - & 1.9 & - & - \\
\hline $\operatorname{Ag}\left(I I^{\prime}\right)$ & - & - & 1.7 & 0.9 \\
\hline $\operatorname{Ag}(\mathrm{II})$ & - & 2.0 & - & - \\
\hline $\operatorname{Ag}\left(\mathrm{II}^{*}\right)$ & - & 1.7 & - & 0.9 \\
\hline Ag(III) & - & 5.1 & - & - \\
\hline Ag(III') & - & 17.9 & - & - \\
\hline Ag Found & - & 28.6 & 1.7 & 1.8 \\
\hline Ag Predicted & - & 41.8 & 2.0 & 2.0 \\
\hline
\end{tabular}


Table 11. Conversion factor and cell density for the mixed $\operatorname{Li}_{x} \mathbf{A g}_{\mathrm{y}}$-zeolites.

\begin{tabular}{lll}
\hline Sorbent & $\begin{array}{l}\text { Conv. Factor } \\
(\mathbf{g} \text { molec/mmol uc) }\end{array}$ & $\begin{array}{l}\text { cell density } \\
(\mathbf{g} / \mathbf{u c}) \mathbf{x} \mathbf{1 0}^{\mathbf{2 0}}\end{array}$ \\
\hline $\mathrm{Li}_{94.5} \mathrm{Na}_{1.5} \mathrm{LSX}$ & 12.12047 & 2.012 \\
$\mathrm{Li}_{94.2} \mathrm{Ag}_{1.1} \mathrm{Na}_{0.7} \mathrm{LSX}$ & 12.21865 & 2.029 \\
$\mathrm{Li}_{92.0} \mathrm{Ag}_{3.5} \mathrm{Na}_{0.5} \mathrm{LSX}$ & 12.45768 & 2.068 \\
$\mathrm{Li}_{83.9} \mathrm{Ag}_{11.5} \mathrm{Na}_{0.6}-\mathrm{LSX}$ & 13.26673 & 2.203 \\
$\mathrm{Li}_{73.8} \mathrm{Ag}_{21.0} \mathrm{Na}_{1.2}-\mathrm{LSX}$ & 14.23573 & 2.363 \\
$\mathrm{Ag}_{9.7} \mathrm{Na}_{0.3} \mathrm{LSX}$ & 21.76031 & 3.613 \\
$\mathrm{Ag}_{85.7} \mathrm{Na}_{0.3}-\mathrm{X}$ & 20.69265 & 3.436 \\
\hline
\end{tabular}




\section{Figure Captions}

Figure 1. Unit cell, including cation sites, for faujasite zeolites

Figure 2. The position of extraframework sites in relationship to the sodalite cage in LiLSX zeolite.

Figure 3. The position of extraframework sites in relationship to the sodalite cage in $\mathrm{Li}, \mathrm{Ag}-\mathrm{LSX}$ zeolite. Silver was found in all sites (expect SII') for the $\mathrm{Li}_{54.0} \mathrm{Ag}_{41.8} \mathrm{Na}_{0.2^{-}}$ LSX-450 (i.e., dehydrated at $450^{\circ} \mathrm{C}$ ) sample. Silver was found in the SII' site only for the $\mathrm{Li}_{93.3} \mathrm{Ag}_{2.0} \mathrm{Na}_{0.7}$-LSX-350 (dehydrated at $350^{\circ} \mathrm{C}$ ) sample and in the SII' and SII* sites for $\mathrm{Li}_{93.3} \mathrm{Ag}_{2.0} \mathrm{Na}_{0.7}$-LSX-450 sample.

Figure 4. Single component adsorption isotherms, measured at $25 \mathrm{C}$, for $\mathrm{N}_{2}, \mathrm{O}_{2}$, and Ar on $\mathrm{Li}_{94.5} \mathrm{Na}_{1.5}$-LSX after vacuum dehydration at $350 \mathrm{C}$ for 4 hours.

Figure 5. $\mathrm{N}_{2}$ equilibrium isotherms measured at $25 \mathrm{C}$. This figure shows the enhancement in the $\mathrm{N}_{2}$ adsorption capacity for $\mathrm{Li}_{94.5} \mathrm{Na}_{1.5}$-LSX zeolite over that of $\mathrm{Li}_{77.0} \mathrm{Na}_{9.0} \mathrm{X}$ zeolite. Both isotherms were measured after vacuum dehydration at $350 \mathrm{C}$ for 4 hours.

Figure 6. Single component adsorption isotherms, measured at $25 \mathrm{C}$, for $\mathrm{N}_{2}, \mathrm{O}_{2}$, and Ar on $\mathrm{Ag}_{95.7} \mathrm{Na}_{0.3}$-LSX after vacuum dehydration at $450 \mathrm{C}$ for 4 hours.

Figure 7. $\mathrm{N}_{2}$ equilibrium isotherms measured at $25 \mathrm{C}$. This figure shows the enhancement in the $\mathrm{N}_{2}$ adsorption capacity for $\mathrm{Ag}_{95.7} \mathrm{Na}_{0.3}$ - LSX over that of $\mathrm{Ag}_{85.7} \mathrm{Na}_{0.3^{-}}$ $\mathrm{X}$. Both isotherms were measured after vacuum dehydration at $350 \mathrm{C}$ for 4 hours.

Figure 8. Equilibrium isotherms, measured at $25 \mathrm{C}$, for adsorption of $\mathrm{N}_{2}$ on various $\mathrm{Li}_{\mathrm{x}} \mathrm{Ag}_{\mathrm{y}}-\mathrm{X}-1.0$ zeolites. The amount adsorbed is given in molec/uc. This shows that the addition of increasing amounts of Ag results in a change in the general aspect of isotherm toward that of the near-fully $\mathrm{Ag}^{+}$-exchanged material.

Figure 9. Equilibrium adsorption isotherms, measured at $0 \mathrm{C}, 25 \mathrm{C}$, and $50 \mathrm{C}$, for $\mathrm{N}_{2}$ adsorption on $\mathrm{Li}_{9.2} \mathrm{Ag}_{1.1} \mathrm{Na}_{0.7}$-LSX zeolite after vacuum dehydration at $450 \mathrm{C}$.

Figure 10. Plots of $\ln (\mathrm{P})$ vs. $1 / \mathrm{T}$ at different coverages for $\mathrm{Li}_{94.5} \mathrm{Na}_{1.5}$-LSX (top) and $\mathrm{Li}_{94.2} \mathrm{Ag}_{1.1} \mathrm{Na}_{0.7}-\mathrm{LSX}$ (bottom).

Figure 11. Isosteric heat of adsorption of $\mathrm{N}_{2}$ on $\mathrm{Li}_{94.5} \mathrm{Na}_{1.5}-\mathrm{LSX}$ and $\mathrm{Li}_{94.2} \mathrm{Ag}_{1.1} \mathrm{Na}_{0.7-}$ LSX. 


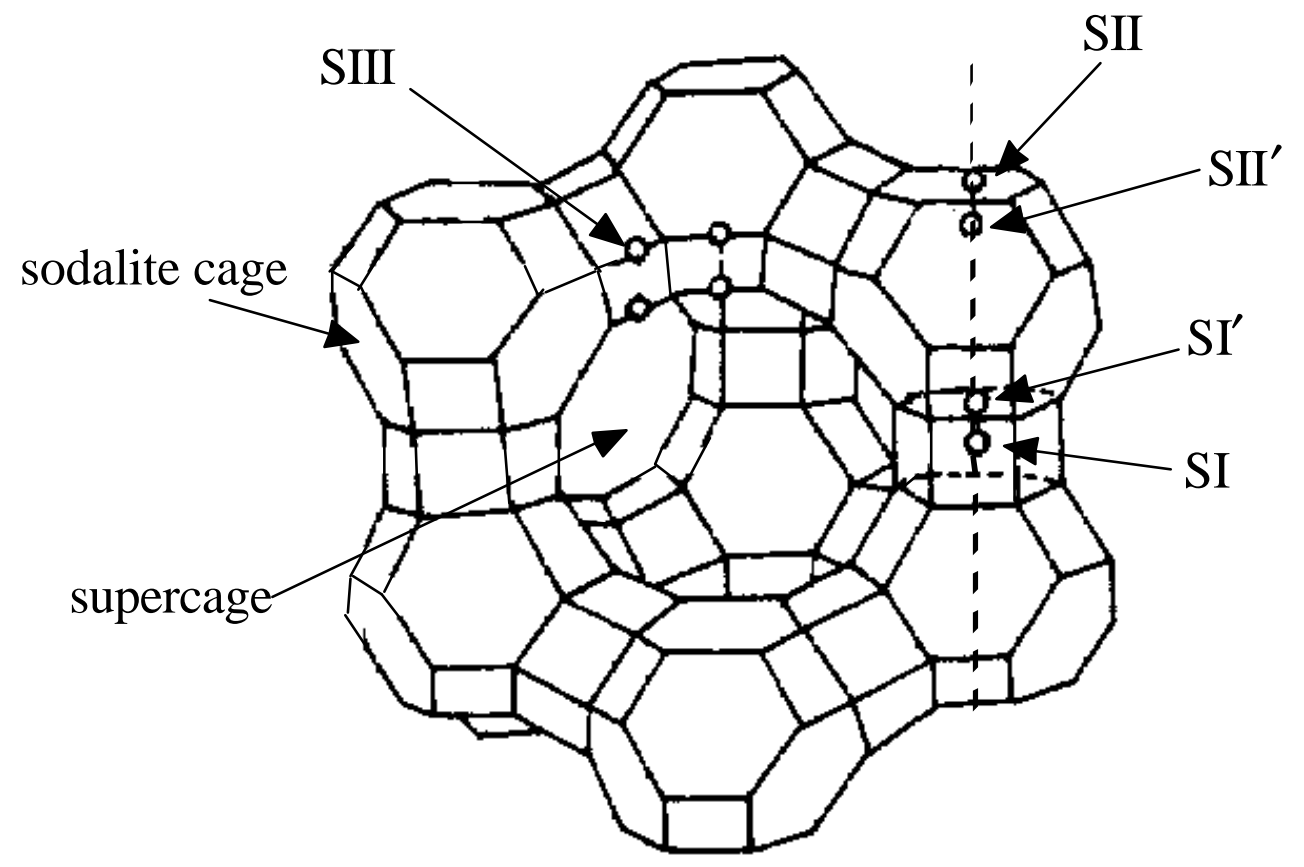

Figure 1. Unit cell, including cation sites, for faujasite zeolites. 


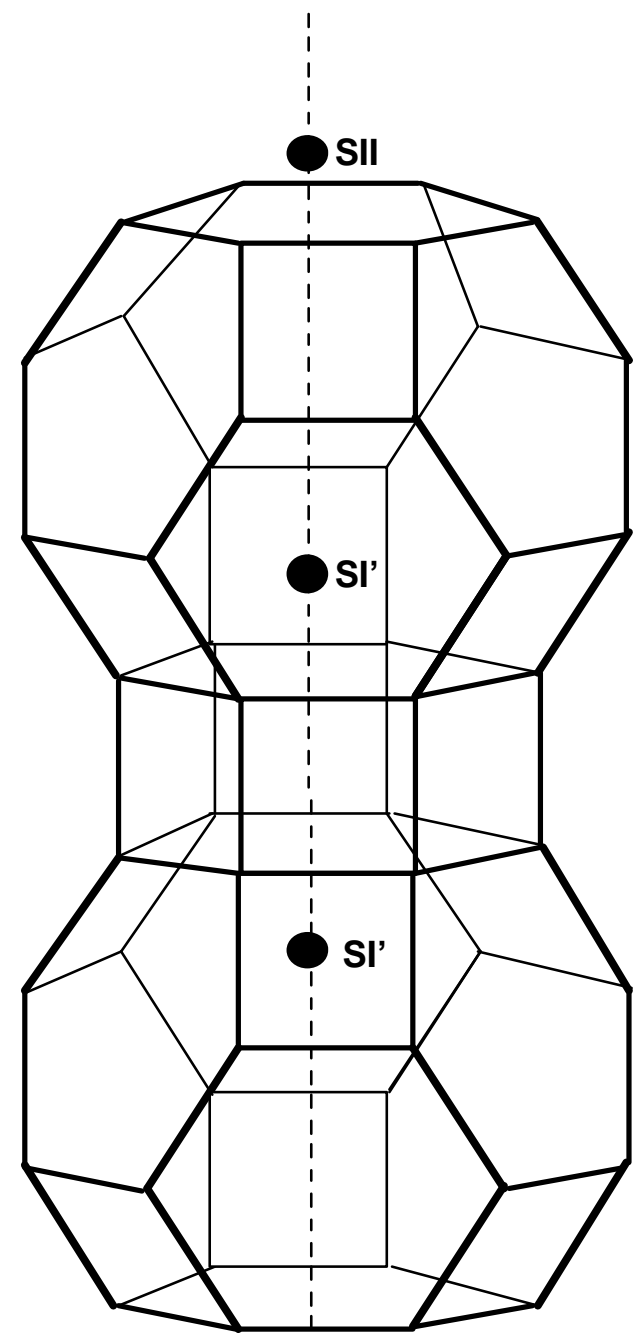

Figure 2. The position of extraframework sites in relationship to the sodalite cage in LiLSX zeolite. 


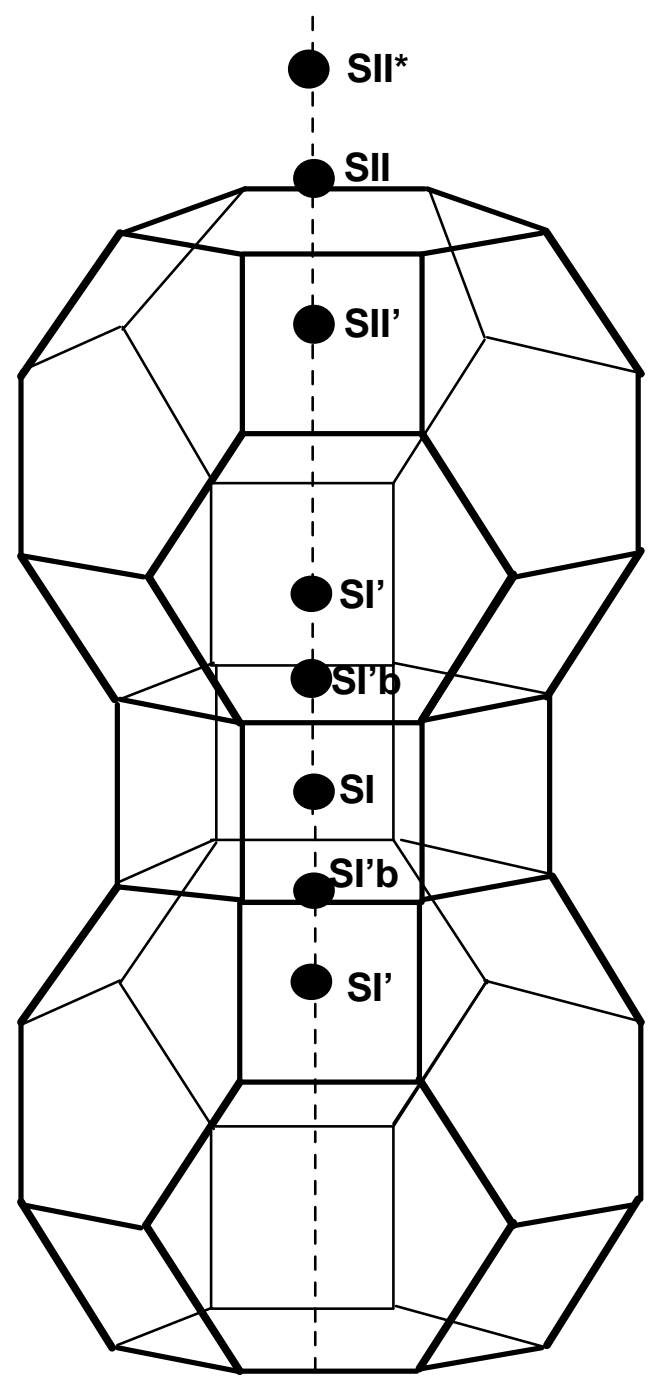

Figure 3. The position of extraframework sites in relationship to the sodalite cage in $\mathrm{Li}, \mathrm{Ag}-\mathrm{LSX}$ zeolite. Silver was found in all sites (expect SII') for the $\mathrm{Li}_{54.0} \mathrm{Ag}_{41.8} \mathrm{Na}_{0.2^{-}}$ LSX-450 (i.e., dehydrated at $450^{\circ} \mathrm{C}$ ) sample. Silver was found in the SII' site only for the Li ${ }_{93.3} \mathrm{Ag}_{2.0} \mathrm{Na}_{0.7}-\mathrm{LSX}-350$ (dehydrated at $350^{\circ} \mathrm{C}$ ) sample and in the SII' and SII* sites for Li ${ }_{93.3} \mathrm{Ag}_{2.0} \mathrm{Na}_{0.7}$-LSX-450 sample. 


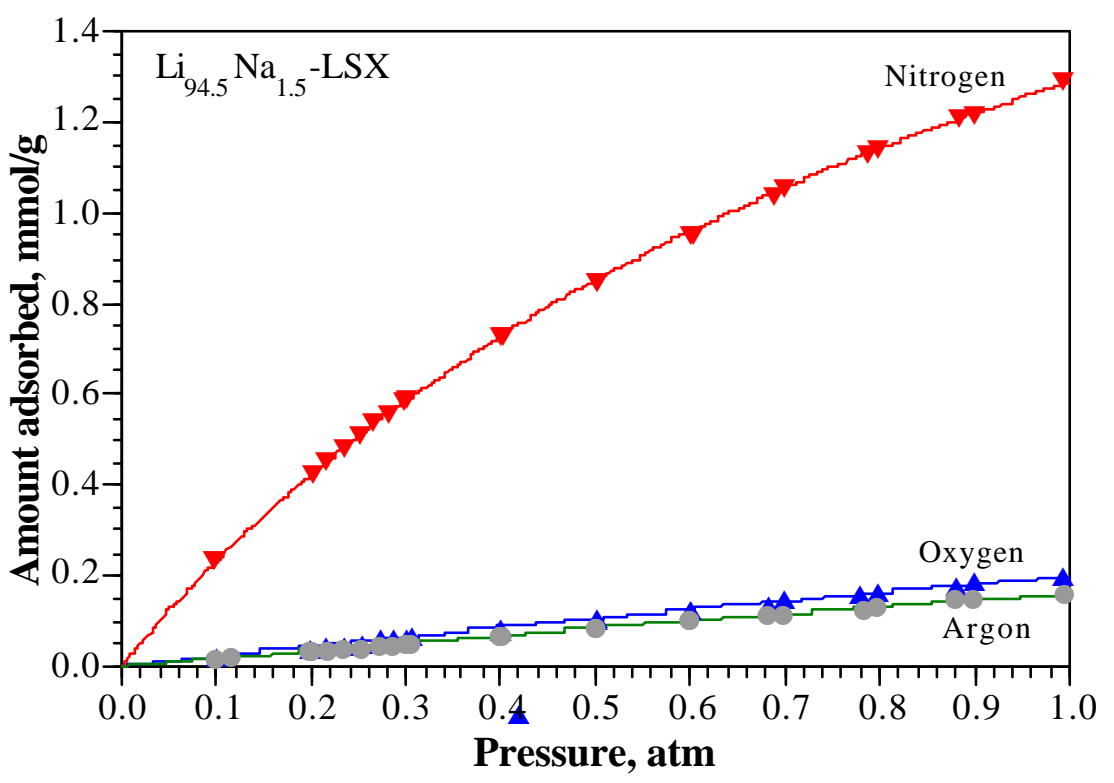

Figure 4. Single component adsorption isotherms, measured at $25 \mathrm{C}$, for $\mathrm{N}_{2}, \mathrm{O}_{2}$, and $\mathrm{Ar}$ on $\mathrm{Li}_{94.5} \mathrm{Na}_{1.5} \mathrm{LSX}$ after vacuum dehydration at $350 \mathrm{C}$ for 4 hours. 

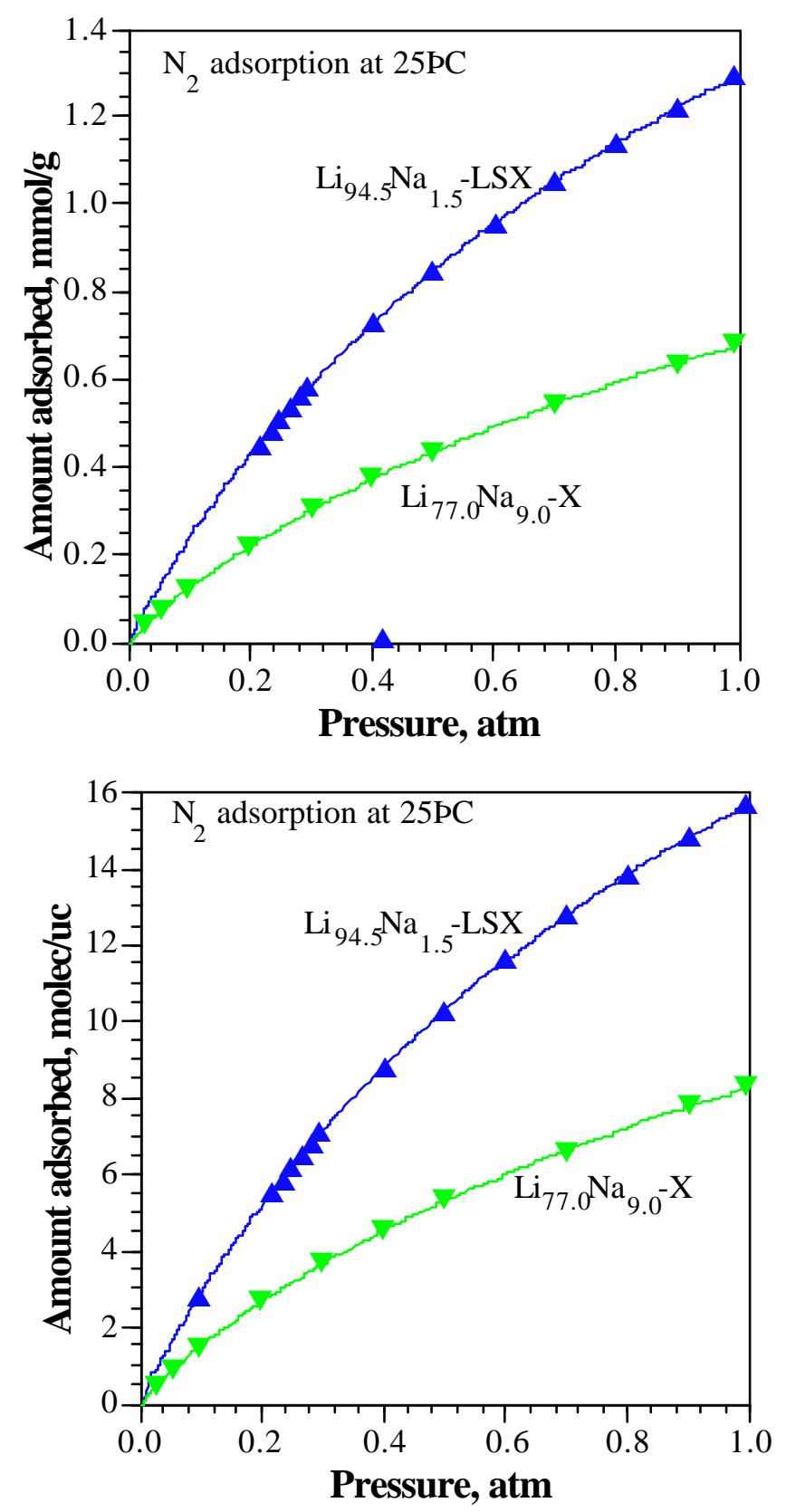

Figure 5. $\mathrm{N}_{2}$ equilibrium isotherms measured at $25 \mathrm{C}$. This figure shows the enhancement in the $\mathrm{N}_{2}$ adsorption capacity for $\mathrm{Li}_{94.5} \mathrm{Na}_{1.5}$ - $\mathrm{LSX}$ zeolite over that of $\mathrm{Li}_{77.0} \mathrm{Na}_{9.0}-\mathrm{X}$ zeolite. Both isotherms were measured after vacuum dehydration at $350 \mathrm{C}$ for 4 hours. 


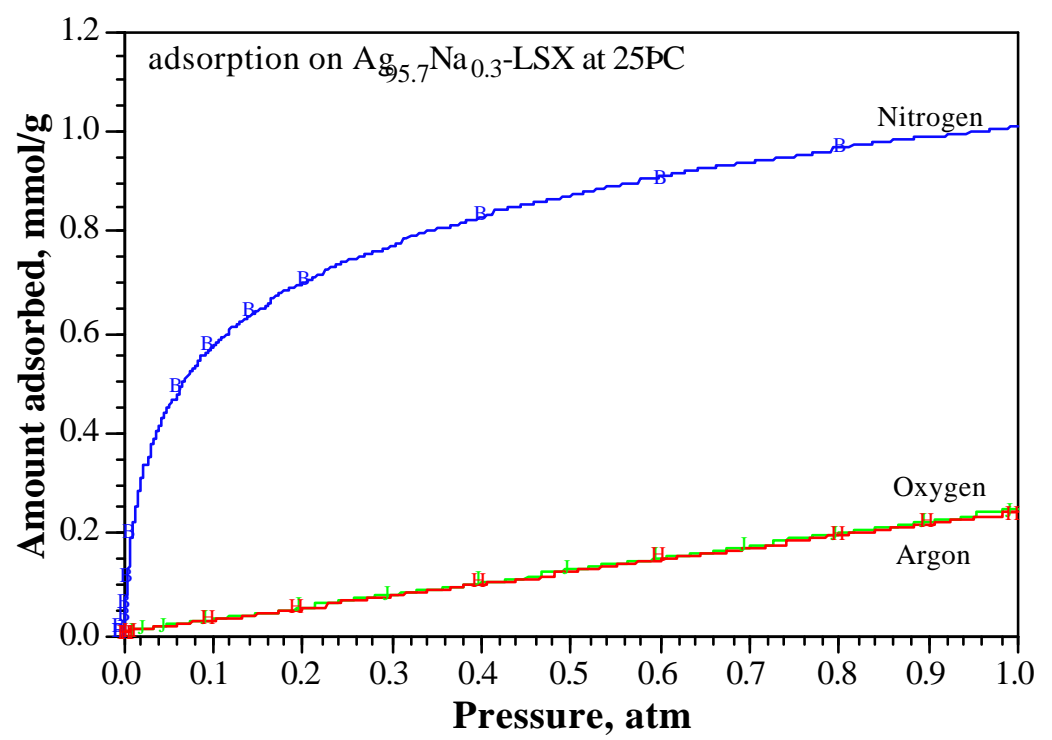

Figure 6. Single component adsorption isotherms, measured at $25 \mathrm{C}$, for $\mathrm{N}_{2}, \mathrm{O}_{2}$, and $\mathrm{Ar}$ on $\mathrm{Ag}_{95.7} \mathrm{Na}_{0.3}$-LSX after vacuum dehydration at $450 \mathrm{C}$ for 4 hours. 

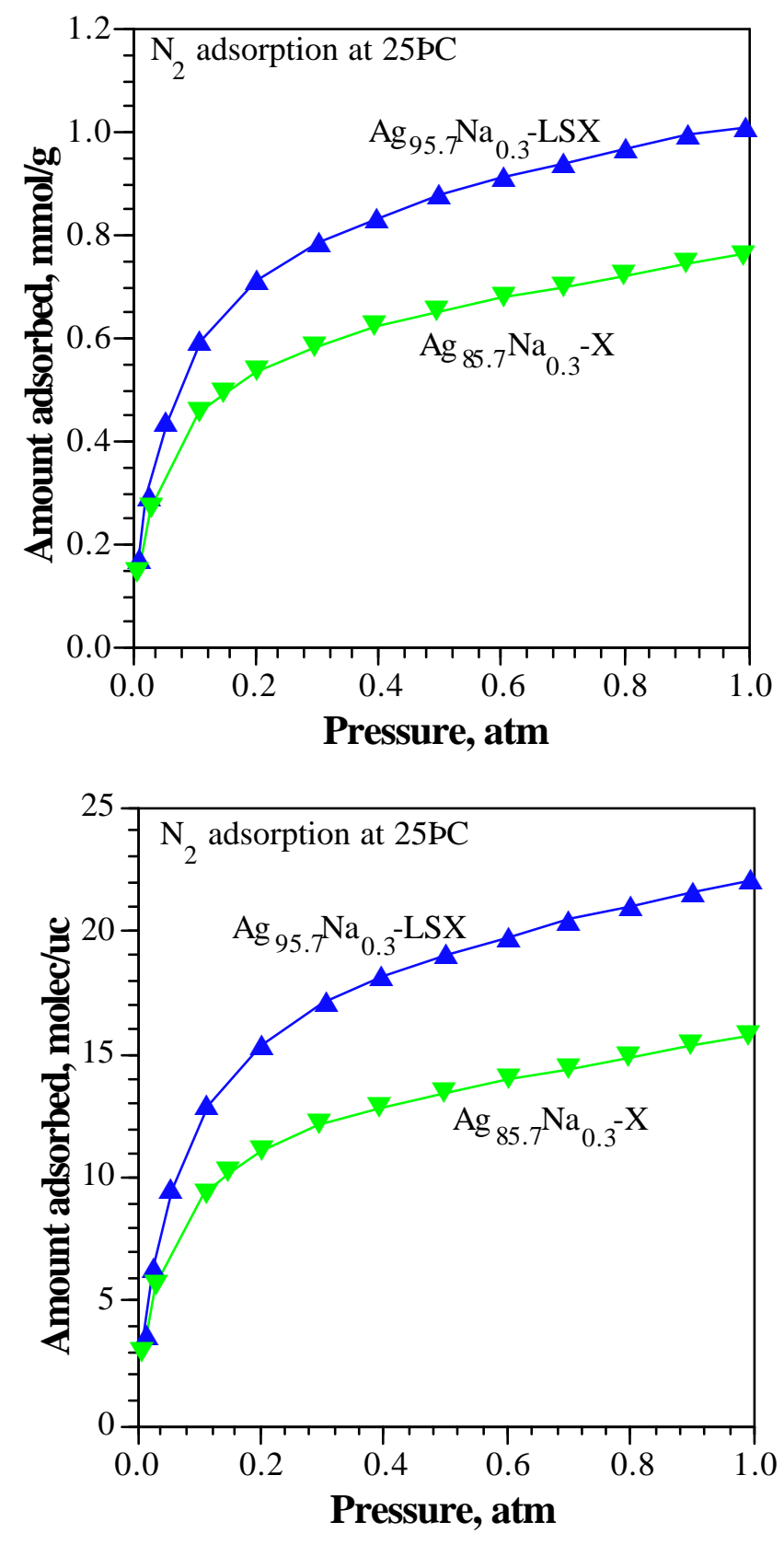

Figure 7. $\mathrm{N}_{2}$ equilibrium isotherms measured at $25 \mathrm{C}$. This figure shows the enhancement in the $\mathrm{N}_{2}$ adsorption capacity for $\mathrm{Ag}_{95.7} \mathrm{Na}_{0.3}-\mathrm{LSX}$ over that of $\mathrm{Ag}_{85.7} \mathrm{Na}_{0.3^{-}}$ $\mathrm{X}$. Both isotherms were measured after vacuum dehydration at $350 \mathrm{C}$ for 4 hours. 

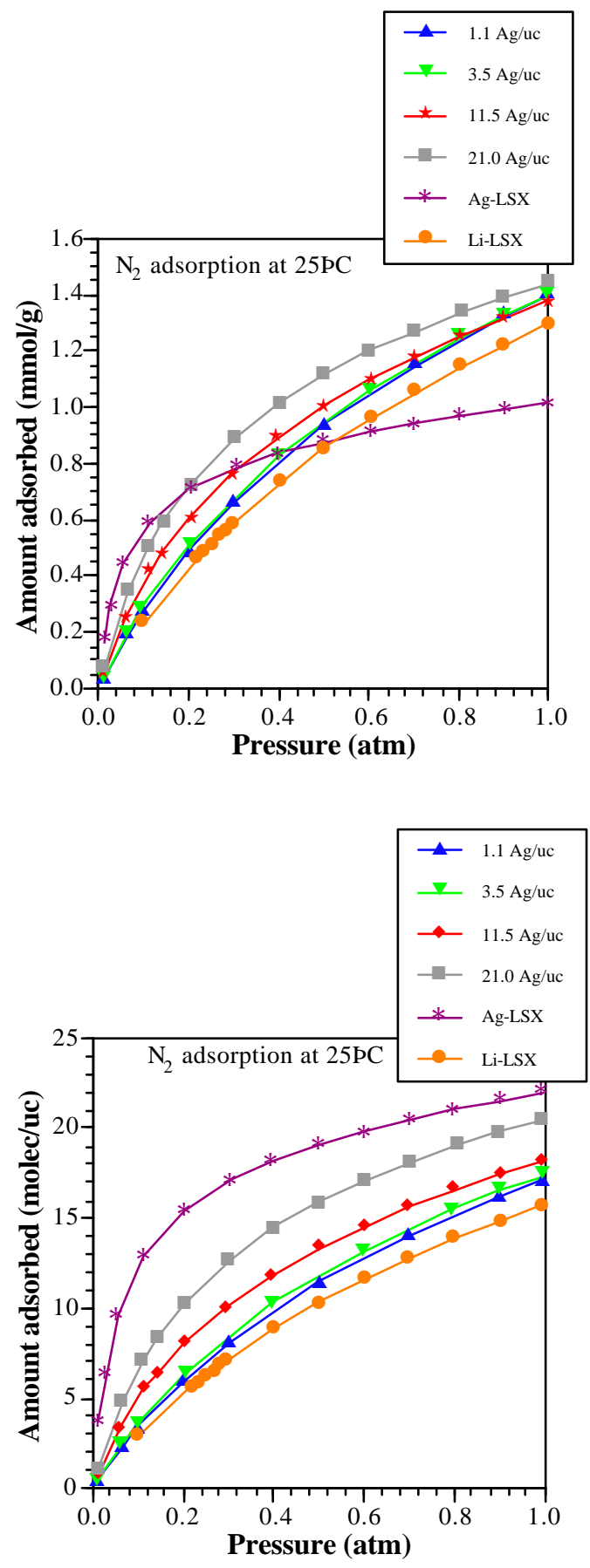

Figure 8. Equilibrium isotherms, measured at $25 \mathrm{C}$, for adsorption of $\mathrm{N}_{2}$ on various $\mathrm{Li}_{\mathrm{x}} \mathrm{Ag}_{\mathrm{y}} \mathrm{X}-1.0$ zeolites. The amount adsorbed is given in molec/uc. This shows that the addition of increasing amounts of $\mathrm{Ag}$ results in a change in the general aspect of isotherm toward that of the near-fully $\mathrm{Ag}^{+}$-exchanged material. 


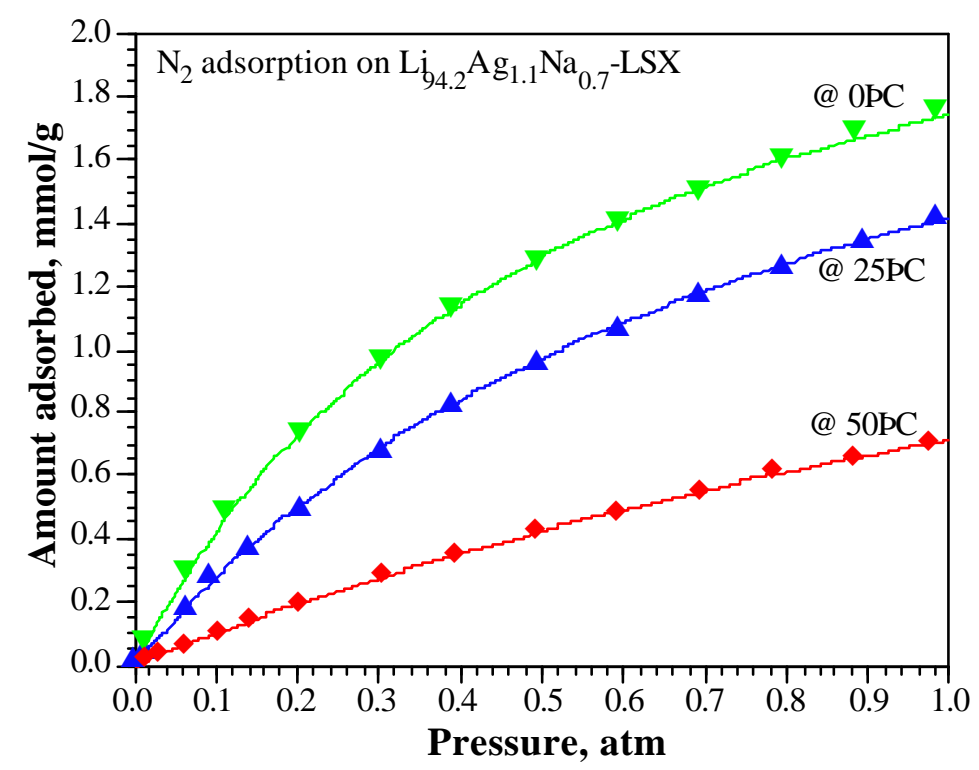

Figure 9. Equilibrium adsorption isotherms, measured at 0 C, 25 C, and 50 C, for $\mathrm{N}_{2}$ adsorption on $\mathrm{Lig}_{9.2} \mathrm{Ag}_{1.1} \mathrm{Na}_{0.7}-\mathrm{LSX}$ zeolite after vacuum dehydration at $450 \mathrm{C}$. 

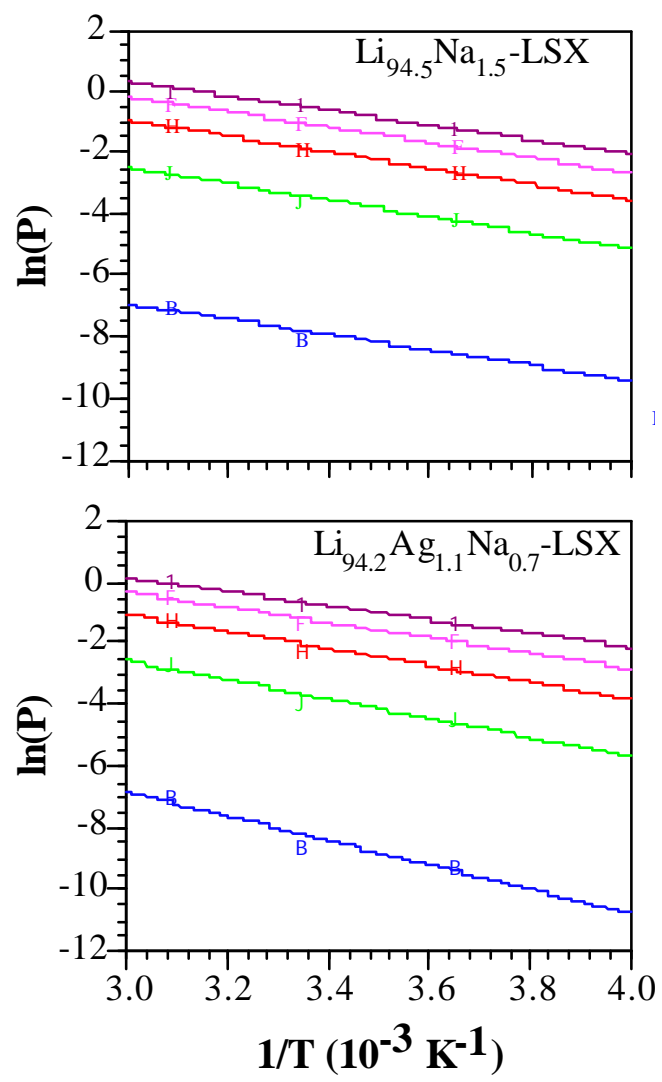

Figure 10. Plots of $\ln (\mathrm{P})$ vs. 1/T at different coverages for $\mathrm{Li}_{94.5} \mathrm{Na}_{1.5}$-LSX (top) and $\mathrm{Li}_{94.2} \mathrm{Ag}_{1.1} \mathrm{Na}_{0.7}-\mathrm{LSX}$ (bottom). 


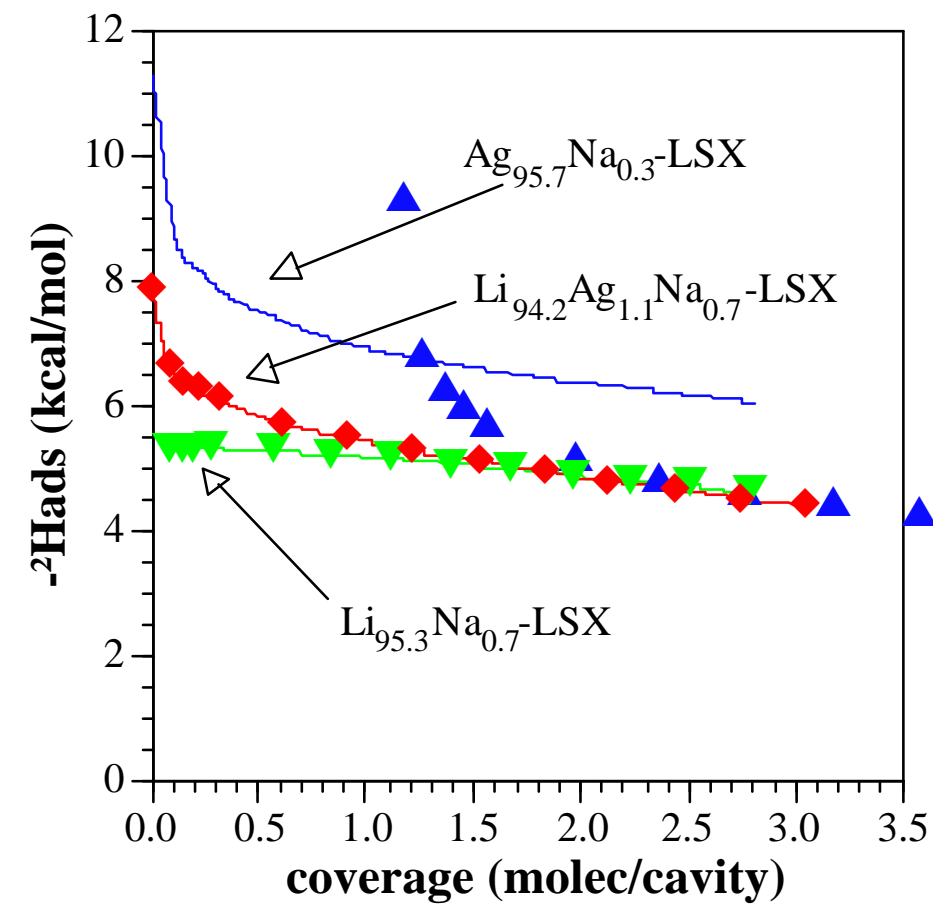

Figure 11. Isosteric heat of adsorption of $\mathrm{N}_{2}$ on $\mathrm{Li}_{94.5} \mathrm{Na}_{1.5}-\mathrm{LSX}$ and $\mathrm{Li}_{94.2} \mathrm{Ag}_{1.1} \mathrm{Na}_{0.7}-$ LSX. 


\section{CHAPTER 4}

Effects of Residual Water on the Adsorption of Atmospheric Gases in Li-X Zeolite: Experiment and Simulation 


\section{Introduction}

Nitrogen and oxygen consistently rank among the most abundantly produced chemicals in the United States and in the world. Historically, these gases have been produced via separation of air by cryogenic distillation; though, as adsorption systems have become more efficient and new, more effective sorbents have been synthesized. Separation by adsorption processes (e.g., pressure swing adsorption (PSA), and vacuum swing adsorption (VSA)) have become increasingly competitive and are already favorable for small-to-medium scale operations. ${ }^{1}$ Currently, approximately $20 \%$ of air separations are accomplished using adsorption technologies. $^{2}$

Since their introduction in the 1950's, synthetic zeolites have been used in numerous applications such as catalysis, ion exchange, drying, and separation by selective adsorption. In the separation of air, synthetic zeolites of type A and the faujasite analogs (types $\mathrm{X}$ and $\mathrm{Y}$ ) have typically been used. These zeolites are composed of silica and alumina tetrahedra which are joined together to form the truncated octahedral or sodalite structure. These sodalite units are connected with tertiary units to form the structured zeolite unit cell. While the $\mathrm{SiO}_{2}$ groups are electroneutral, the $\left(\mathrm{AlO}_{2}\right)^{-}$groups are not, and thus introduce a negative charge to the structure which is offset by the presence of a charge compensating, non-framework cation (e.g., $\left.\mathrm{Na}^{+}, \mathrm{Li}^{+}, \mathrm{Ca}^{2+}\right)$. Type $\mathrm{X}$ zeolites contain between 77 and $96 \mathrm{Al}$ per unit cell. The unit cell, including cation sites, for type $\mathrm{X}$ zeolite is shown in Figure 1.

It is known that the extra-framework cations in the zeolite are largely responsible for the nitrogen selectivity of these materials. ${ }^{3,4}$ These zeolites adsorb nitrogen preferentially to oxygen (usually at a ratio of about $4: 1$ ) due primarily to the interaction between the 
charge compensating cations of the zeolite and the quadrupole moment of the adsorbing gas $\left(\mathrm{N}_{2}\right.$ or $\left.\mathrm{O}_{2}\right)$. The quadrupole moment of $\mathrm{N}_{2}$ is approximately four times that of $\mathrm{O}_{2}$.

Kuhl reported a procedure for the synthesis of low silica X-type zeolite (LSX). This material is an aluminum saturated X-type zeolite with a silica-to-alumina ratio of 2.0 (or $\mathrm{Si} / \mathrm{Al}=1.0){ }^{5}$ Commercial $\mathrm{X}$-zeolite (which is typically available as the $\mathrm{Na}^{+}$form and known as 13X) is not aluminum saturated and contains 86 aluminum atoms per unit cell, while the low silica $\mathrm{X}$ zeolite contains 96 aluminum atoms per unit cell.

While it has long been known that $\mathrm{Li}^{+}$is among the strongest cations, with respect to its interaction with $\mathrm{N}_{2}{ }^{6}$, its use was greatly increased with two recent advances. Firstly, it was found that $\mathrm{Li}^{+}$ion-exchange in $\mathrm{X}$-type zeolite must exceed an approximate $70 \%$ occupancy threshold before the $\mathrm{Li}^{+}$has any effect on the adsorptive properties of the material. ${ }^{7-9}$ Secondly, a significant increase in the $\mathrm{N}_{2}$ adsorption capacity was seen in $\mathrm{Li}^{+}$ ion exchanged low silica X-type zeolites over that of the typical commercial material $(\mathrm{Si} / \mathrm{Al}=1.25)$. Because of these advances, $\mathrm{Li}-\mathrm{X}(\mathrm{Si} / \mathrm{Al}=1.0)$ is now the best sorbent in industrial use for separation of air by adsorption processes. ${ }^{2,10}$

Zeolites are also used extensively in drying operations as they have a strong affinity for water; and some molecules are tenaciously held. Zeolites have an extraordinary capacity to sorb water; in fact, a $4.5 \mathrm{~kg}$ can of dry Li-LSX, when exposed to moist air at room temperature, can adsorb as much as 2 liters of water. The adsorption of nonpolar gases is greatly affected by the presence of water or other polar molecules in the zeolite. Because of this, any water present in the air or in the zeolite prior to adsorption results in a decline in the capacity of the sorbent and thus a decline in the productivity of the PSA unit. Prior to separation, then, the zeolite must be dehydrated (or activated) and the air 
must be dried. Differential thermal analysis (DTA) of zeolite $\mathrm{X}$ has shown a continuous loss of water over a broad range of temperatures, starting at slightly above room temperature up to $623 \mathrm{~K}$ with a maximum at about $573 \mathrm{~K} .^{4}$

Because of the near limitless zeolitic structural possibilities, it seems probable that a zeolite can be tailored for nearly any desired gas separation. Ideally, molecular simulation of the gas adsorption would provide a quick and cost effective evaluation of potential sorbents. And, indeed, several studies have been reported in which grand canonical Monte Carlo simulations have been used to predict gas adsorption in zeolites. ${ }^{11-}$ 16 Razmus and Hall used Monte Carlo simulation to reproduce experimental single component adsorption isotherms for $\mathrm{N}_{2}, \mathrm{O}_{2}$ and $\mathrm{Ar}$ in $5 \mathrm{~A}$ zeolite. ${ }^{17}$ Watanabe et al. used Monte Carlo methods to study the air separation properties of zeolite types A, X, and Y; ${ }^{18}$ and Richards et al. used computer simulation to study the gas separation properties specifically of Li-X zeolite. $^{19}$

In this present work we have synthesized fully exchanged Li-LSX zeolite and measured the room temperature adsorption isotherms for $\mathrm{N}_{2}, \mathrm{O}_{2}$ and $\mathrm{Ar}$ after various degrees of dehydration. The effect of the residual water on the adsorption of these atmospheric gases was then simulated using Monte Carlo techniques.

\section{Experimental Details}

Materials. A binderless, fully hydrated K,Na-LSX zeolite ( $\mathrm{Si} / \mathrm{Al}=1$, Praxair, \#16193-42) was the starting material for these experiments. Helium $(99.995 \%$, prepurified), oxygen (99.6\%, extra dry), nitrogen (99.998\%, prepurified), and argon 
(99.998\% prepurified) were obtained from Cryogenic Gases. Deionized water was used for all ion-exchanges and for all washings.

Preparation of Li-LSX. The lithium zeolites were prepared by 5 consecutive static ion-exchanges using a 6.3-fold excess (over that necessary for full ion-exchange) of a 2.2 $\mathrm{M}$ solution of $\mathrm{LiCl}$. This was done in a $0.01 \mathrm{M}$ solution of $\mathrm{LiOH}$ at a $\mathrm{pH}$ 9. The lithium ion-exchange solution was heated to a mild boil and then allowed to cool and settle. The solution was decanted, a fresh $6.3 \mathrm{X} \mathrm{LiCl}$ solution was added, and the procedure was repeated for a total of 5 exchanges. After the final ion-exchange, the material was vacuum filtered and washed with copious amounts of deionized water until no free ions were present in the filter water (i.e., no $\mathrm{AgCl}$ precipitation upon treatment with $\left.\mathrm{Ag}^{+}\right)$. The resulting lithium exchanged zeolites were dried overnight at room temperature before being dehydrated in vacuo prior to measurement of adsorption isotherms.

Characterization. The composition of Li-LSX samples which had been synthesized using the prescribed procedure (given above) were characterized previously using neutron activation analysis (NAA) and inductively coupled plasma mass spectrometry (ICP-MS). ${ }^{20}$ The samples were found to be nearly fully $\mathrm{Li}^{+}$exchanged, containing, on average, less than one $\mathrm{Na}^{+}$per unit cell.

The adsorption isotherms were measured using a static volumetric system (Micromeritics ASAP-2010). Additions of the analysis gas were made at volumes required to achieve a targeted set of pressures. A minimum equilibrium interval of 9 seconds with a tolerance of $5 \%$ of the target pressure (or 0.007 atm, whichever is smaller) was used to determine equilibrium for each measurement point. The pressure transducers 
in the ASAP-2010 are accurate to $<0.2 \%$ for the pressures up to $1 \mathrm{~atm}$. The sample weights were obtained using a digital laboratory balance which is accurate to $\pm 0.01 \mathrm{~g}$.

\section{Monte Carlo Simulation}

The Cerius ${ }^{2}$ suite of software (Molecular Simulations, Inc.), utilizing both the canonical ensemble (fixed loading) and grand canonical ensemble (fixed pressure) Monte Carlo statistical mechanics methods, was used in these simulations. The "crystal builder" module was used to first construct the Li-LSX model, and the "sorption" module was then used for the gas adsorption simulations. The simulations were performed on a Silicon Graphics Indigo ${ }^{2}$ workstation running IRIX v.6.5.

Building the Li-LSX Model. The general structure of faujasite-type zeolite has been characterized; and while the possible locations of charge compensating cations are known, the precise locations and occupancies of these cations are usually not. Locating extraframework cations in zeolites has been the topic of numerous studies and is not a trivial endeavor. In this case, a Li-LSX model was built using structural data which was that given by Feurstein and Lobo from a characterization using Reitveld refinement of neutron diffraction patterns and solid-state NMR spectroscopy. ${ }^{21}$ Alternating $\mathrm{Si}$ and $\mathrm{Al}$ atoms assured obeyance of Lowenstein's rule which forbids Al-O-Al bridges. The $\mathrm{Li}$ cations were located as follows: 32 cations at site $\mathrm{Y}$ (opposite the hexagonal prism but located inside the cubooctahedron), 32 cations at site II (at the face of the single six-ring in the supercage), and 32 cations at site III (near the four-ring windows in the supercage). A $4 \AA$ charge-free "blocking atom" was added in the center of each of the 8 cubooctahedron. This effectively prevents the Monte Carlo algorithm from locating 
adsorption sites which are actually sterically inaccessible to $\mathrm{N}_{2}, \mathrm{O}_{2}$ and $\mathrm{Ar}$ (i.e., any cation residing at sites $\mathrm{I} \mathrm{I}^{\prime}$, and $\left.\mathrm{II}^{\prime}\right)$.

Simulation Details. A significant factor in the adsorption simulation is the selection of the forcefield (or potential energy model). The forcefield used in these simulations was a modified version of the Cerius ${ }^{2}$ Watanabe-Austin potential energy model. ${ }^{18,22}$ In this model, the total potential energy between the zeolite lattice and adsorbate molecules is written as the sum of the interaction between the adsorbate molecules and the zeolitic lattice oxygen and extraframework cations (AZ) and between adjacent adsorbate molecules (AA),

$$
\mathrm{U}_{\mathrm{AA}}=\mathrm{U}_{\mathrm{AZ}}+\mathrm{U}_{\mathrm{AA}}
$$

Both $\mathrm{U}_{\mathrm{AZ}}$ and $\mathrm{U}_{\mathrm{AA}}$ are written as sums of pairwise additive potentials, $\mathrm{u}_{\mathrm{ij}}$ in the form

$$
u_{i j}=4 \varepsilon_{i j}\left\lfloor\left(\frac{\sigma_{i j}}{r_{i j}}\right)^{12}-\left(\frac{\sigma_{i j}}{r_{i j}}\right)^{6}\right\rfloor+\left(\frac{q_{i} q_{j}}{r_{i j}}\right)
$$

where the first term is the familiar Lennard-Jones (L-J) 12-6 potential representing the repulsive and dispersive potential energies between sites " $i$ " and " $j$ ", and the second term represents the Coulombic interaction potential between point charges $\mathrm{q}_{\mathrm{i}}$ and $\mathrm{q}_{\mathrm{j}}$ of sites " $i$ " and " $j$ " separated by a distance $\mathrm{r}_{\mathrm{ij}} \cdot{ }^{18}$

Following the work of Razmus and Hall, ${ }^{17}$ Watanabe et al. used an empirical approach to parameterize this forcefield specifically for adsorption of $\mathrm{N}_{2}, \mathrm{O}_{2}$, and $\mathrm{Ar}$ in type A and faujasite zeolites. ${ }^{18}$ The dispersive part of the L-J 12-6 potential was written as

$$
u_{d i s}=-\beta_{i}\left(\frac{\alpha_{\imath} \alpha_{j}}{r_{i j}^{6}}\right)
$$


where $\beta_{\mathrm{i}}$ is an adjustable parameter characteristic of the adsorbate and $\alpha_{\mathrm{i}}$ and $\alpha_{\mathrm{j}}$ are the polarizabilities of the atoms of the adsorbate molecules and in the zeolite lattice respectively. The potential energy well depth, $\varepsilon_{\mathrm{ij}}$, is then written as

$$
\varepsilon_{i j}=\beta_{i}\left(\frac{\alpha_{i} \alpha_{j}}{4 \sigma_{i j}^{6}}\right)
$$

The L-J parameter, $\sigma_{\mathrm{ij}}$ for the adsorbate-zeolite interaction is given by the mixing rule,

$$
\sigma_{i j}=\left(\frac{\sigma_{i}+\sigma_{j}}{2}\right)
$$

The $\sigma_{\mathrm{j}}$ for the zeolite lattice are related to the van der Waals radii, $\mathrm{R}$, of the respective ions by

$$
R_{j}=2^{1 / 6} \boldsymbol{\sigma}_{j}
$$

and $\varepsilon_{\mathrm{ij}}$ is assumed to be a geometric combination of $\varepsilon_{\mathrm{i}}$ and $\varepsilon_{\mathrm{j}}$,

$$
\varepsilon_{\mathrm{ij}}=\left(\varepsilon_{\mathrm{i}} \varepsilon_{\mathrm{j}}\right)^{0.5}
$$

Some modification of these parameters was necessary to better fit our experimental data for adsorption of $\mathrm{O}_{2}$ and $\mathrm{Ar}$ in fully-dehydrated Li-LSX. The forcefield L-J parameters used in these simulations are given in Table 1. Existing Cerius ${ }^{2}$ models for all sorbates were used. ${ }^{22-25}$ In these existing models, the quadrupole moments for $\mathrm{N}_{2}(-1.2 \mathrm{x}$ $10^{-26}$ e.s.u.) and $\mathrm{O}_{2}\left(-0.4 \times 10^{-26}\right.$ e.s.u. $)$ were assigned by the use of three-site point charge models. The central point charge was given values of +0.810 and +0.224 , with the outer neutralizing charges being fixed at -0.405 and -0.112 for $\mathrm{N}_{2}$ and $\mathrm{O}_{2}$ respectively.

Another significant factor in adsorption smulation is the assignment of charges for the zeolite components. While Razmus and Hall were able to successfully predict single component adsorption isotherms, they were not able to correctly predict multi-component 
isotherms for the air components. ${ }^{17}$ The authors speculated that the electrostatic interaction between adsorbates and zeolite may have been incorrectly modeled due to errors in the estimation of the charge distribution within the zeolite. Watanabe et al. examined the effect of the charge assignment on the predicted $\mathrm{N}_{2} / \mathrm{O}_{2}$ selectivity for types A, X, and Y zeolites. ${ }^{18}$ They found the selectivity to be very sensitive to the size of the charges assigned to the extraframework cations. Razmus and Hall assumed a negative charge of -0.3333 for the oxygen atoms adjacent to cations and a neutral charge for the remaining oxygen in the 5A framework. Richards et al., when simulating adsorption of atmospheric gases in Li-X zeolite, assigned charges of $\mathrm{Li}(+1), \mathrm{Si}$ and $\mathrm{Al}(+1.583)$, and $\mathrm{O}$ $(-1) .{ }^{19}$ In this work we assigned charges to each of the atoms in the structure as follows: $\mathrm{Li}(+1), \mathrm{Si}(+2), \mathrm{Al}(+3)$, and $\mathrm{O}(-2)$.

The initial stage of the simulation was to load the Li-LSX model with a fixed number of water molecules. This was done using the "fixed loading" (canonical ensemble) option in the Cerius ${ }^{2}$ Sorption module. After the prescribed number of water molecules were loaded, a "fixed pressure" (grand canonical ensemble) simulation was run with standard Monte Carlo procedures for creation and destruction of molecules. The simulations were performed at room temperature $(298 \mathrm{~K})$ for 300,000 configurations. During the simulation, the sorbate molecules interact with the potential field generated by sorbate-framework energies and sorbate-sorbate energies; although, in this case, because we have simulated adsorption at very low coverages, the adsorbate-adsorbate interactions can be expected to be negligible. Molecular creation attempts were made at random points within the accessible portion of the zeolite lattice with the criterion that there be no overlapping sites (i.e., creations which resulted in interaction sites which were closer than 
half the sum of the van der Waal's radii of the two sites were rejected). Displacement and rotation of molecules were also performed with the same rejection criterion. For non-overlapping sites, the change in the potential energy accompanying the new conformation was calculated and subsequently accepted or rejected in accordance with standard acceptance probabilities. ${ }^{18,26}$

The Lennard-Jones potential for the adsorbate-zeolite interactions and both the Lennard-Jones and Coulombic terms of the adsorbate-adsorbate interactions were calculated using a mimimum image convention ${ }^{26}$ with a interaction cut-off distance of 12 $\AA$. The Coulombic term for the adsorbate-zeolite interaction was evaluated using the Ewald summation method. ${ }^{26}$

\section{Results and Discussion}

The unit cell of Li-LSX produced by the aforementioned procedure was characterized by a variety of techniques. The unit cell was compositionally characterized using neutron activation analysis and ICP/MS. The water content for fully hydrated Li-LSX was determined measuring the weight loss upon vacuum dehydration at $723 \mathrm{~K}$ for 24 hours. From this data, the unit cell of the material was approximated as $\mathrm{Li}_{96}\left(\mathrm{AlO}_{2}\right)_{96}\left(\mathrm{SiO}_{2}\right)_{96} \cdot 366 \mathrm{H}_{2} \mathrm{O}$.

We initially attempted to simulate the adsorption of $\mathrm{N}_{2}, \mathrm{O}_{2}$, and $\mathrm{Ar}$ in fully dehydrated Li-LSX. Adsorption isotherms were measured, at 298K, for each of these gases, after dehydration at $723 \mathrm{~K}$ for at least 24 hours. We then ran the Monte Carlo simulation, as described earlier, for adsorption under the same conditions. The results are given in Figure 2 and agreement was quite good. 
We next wanted to determine the effect of residual water on the adsorption of these atmospheric gases. In order to partially dehydrate the zeolite prior to measurement of the adsorption isotherms, samples were heated in a vacuum to varying temperatures and held for a minimum of 4 hours. Figure 3 shows the $\mathrm{N}_{2}$ adsorption capacity at $298 \mathrm{~K}$ and 100 $\mathrm{kPa}$ with various dehydration temperatures. This figure shows a gradual increase in adsorption capacity for samples which had been heated slightly above room temperature and a significant increase in adsorption capacity starting with samples which had been heated to about $480 \mathrm{~K}$ and up to $623 \mathrm{~K}$. Finally there is little increased capacity for those samples heated beyond $623 \mathrm{~K}$ indicating that the Li-LSX is near fully dehydrated after vacuum heating at $623 \mathrm{~K}$ for at least 4 hours.

Each of the samples was carefully weighed in a sealed analysis vial before and after heating in order to determine the extent of dehydration during heating. Equilibrium adsorption isotherms (at $298 \mathrm{~K}$ ) were then measured for $\mathrm{N}_{2}, \mathrm{O}_{2}$, and $\mathrm{Ar}$ on each of the partially dehydrated samples. The resulting adsorption capacity for each of these gases as a function of residual water is shown in Figure 4. One can see that very small amounts of water in the Li-LSX zeolite have a significant effect on the adsorptive capacity. This is most pronounced in Figure 4a., the $\mathrm{N}_{2}$ adsorption. The capacity for $\mathrm{N}_{2}$ drops from approximately 17.4 molecules $\mathrm{N}_{2}$ adsorbed per unit cell for the fully dehydrated material to less than 2 molecules adsorbed per unit cell when the sample contained approximately 32 residual water molecules per unit cell. This more than $90 \%$ loss of capacity comes as a result of retention only $12 \%$ of its water capacity. This phenomena, however, is easily explained. As mentioned earlier, it was found that $\mathrm{Li}^{+}$ion-exchange in X-type zeolite must exceed an occupancy threshold before the $\mathrm{Li}^{+}$has any effect on the adsorptive 
properties of the material. ${ }^{7-9}$ Structural characterizations of $\mathrm{Li}-\mathrm{X}$ have shown that $\mathrm{Li}^{+}$ prefer the cation sites SI' and SII. ${ }^{21,27}$ It is not until those preferred locations are occupied that the Li cation begins to occupy the less energetically favorable SIII locations. The adsorbate-zeolite interactions correspond only to those between the adsorbing gas and the surface oxygen and charge compensating cations. Since the alumina and silica groups are in a tetrahedral structure, the aluminum and silicon atoms of the zeolite framework are obscured by the oxygen atoms. ${ }^{28}$ Interactions between the adsorbate and the silicon and aluminum atoms are shielded and are therefore neglected. ${ }^{3}$ In faujasite zeolites, the cations in the beta-cages and the double 6-ring (D6R, the hexagonal prism) are sterically inaccessible to nitrogen; and so only the supercage cations (i.e., those in SII and SIII) are available to interact with nitrogen gas. However, the electric field around these supercage cations are partially shielded by the surrounding oxygen atoms. Because of this shielding, the electrostatic and induction interactions are expected to be lower than that of an isolated ion. Further, the dispersion forces acting on the molecule will be higher since adsorbate molecules also interact with oxygen atoms of the zeolite. ${ }^{28}$ Because of the small size of the lithium cation, it can sit crystallographically very low in the face of the single six-ring (SR6, the SII position) allowing the electric field generated to be nearly completely shielded by the surrounding framework oxygen. This explains why one must exchange in excess of 64 lithium cations into the $\mathrm{X}$ zeolite before there is any increase in the $\mathrm{N}_{2}$ adsorptive capacity; only the SIII $\mathrm{Li}^{+}$cations interact with the $\mathrm{N}_{2}$ molecules.

Because the SIII cations are in a high energy, low coordination environment they immediate coordinate with water when it is available. And so, the only cations available 
to interact with these atmospheric gases of interest are also the ones most likely to interact with residual water. So, while the zeolite can contain more than $250 \mathrm{H}_{2} \mathrm{O}$ molecules in each unit cell, it only takes 32 molecules to significantly diminish the adsorptive capacity of the Li-LSX zeolite.

Because of this observed phenomenon, we proceeded with our Monte Carlo simulation in the following way. In what will be referred to as simulation-1, we initially loaded the Li-LSX model with a fixed number of water molecules. For simulations where the loaded water was fewer than 32 molecules per unit cell, the "blocking atom" was kept at a diameter of $4 \AA$. This prevented any water molecules from entering the beta-cage and ensured coordination with the 32 available SIII lithium cations. For water loadings above 32 per unit cell, the "blocking atom" diameter was reduced to $0.1 \AA$ to allow residual water to enter the beta cage. After the desired number of water molecules were loaded, a "fixed pressure" (grand canonical ensemble) simulation was run with standard Monte Carlo procedures for creation and destruction of molecules but with the "blocking atom" diameter set again to $4 \AA$. The L-J parameters were the same as those used for the simulations of the fully dehydrated Li-LSX. Figures 5-7 show the results of these simulations (shown as N2-sim1, O2-sim1, and Ar-sim1 in Figures 5, 6 and 7 respectively). The results predict a higher adsorption than that of the experimental data.

Because of this, we adjusted the L-J parameters to better fit the $\mathrm{N}_{2}$ adsorption data. The adjusted L-J parameters are given in Table 2. The results of this second simulation, referred to as simulation-2, are also shown in Figures 5-7 (shown as N2-sim2, O2-sim2, and Ar-sim2 in Figures 5, 6 and 7 respectively). In this simulation, the L-J parameters for $\mathrm{Li}^{+}$were adjusted to fit the experimental data for $\mathrm{N}_{2}$ adsorption at $298 \mathrm{~K}$ and $100 \mathrm{kPa}$. 
The L-J parameters were adjusted only for those zeolites which contained 32 or fewer water molecules per unit cell. This was done since the first 32 water molecules immediately interact with the 32 available SIII $\mathrm{Li}^{+}$, affecting the interaction of those cations with the adsorbate molecules. Subsequent loadings of water molecules which may enter the beta cages have much less or no effect on the adsorption of the atmospheric gases.

Other approaches are also possible but are not attempted here. Since water has a strong dipole moment and is capable of strong hydrogen bonding with the framework oxygen, it is possible to alter the location of site $\mathrm{III} \mathrm{Li}^{+}$by water and consequently leads to other interactions. Further work is needed for identifying the precise structures of the zeolites with adsorbed water molecules.

The L-J parameters were adjusted such that both the length parameter $\left(\sigma_{i}\right)$ an the energy well depth $\left(\varepsilon_{\mathrm{i}}\right)$ for $\mathrm{Li}^{+}$adsorbate interactions were increased, and with the adjusted parameters, the simulation is in fair agreement with the experimental data. 


\section{Literature Cited}

[1] Yang, R. T.; Gas Separation by Adsorption Processes, Butterworth: Boston, 1987; reprinted (in paperback) by Imperial College Press: London and World Scientific Publishing Co.: River Edge, NJ, 1997.

[2] Rege, S. U.; Yang, R. T.; Limits for Air Separation by Adsorption with LiX Zeolite. Ind. Eng. Chem. Res. 1997, 36, 5358.

[3] Barrer, R. M.; Zeolites and Clay Minerals as Sorbents and Molecular Sieves, Academic Press, London, 1978.

[4] Breck, D. W.; Zeolite Molecular Sieves; R. E. Krieger Publishing, Malabar, FL, 1984.

[5] Kuhl, G. H.; Crystallization of Low-Silica Faujasite $\left(\mathrm{SiO}_{2} / \mathrm{Al}_{2} \mathrm{O}_{3} \quad\right.$ 2.0). Zeolites 1987, 7, 451 .

[6] McKee, D. W.; Separation of an Oxygen-Nitrogen Mixture. U.S. Patent 3,140,933 (1964).

[7] Chao, C. C.; Process for Separating Nitrogen from Mixtures Thereof with Less Polar Substances. U. S. Patent 4,859,217 (1989).

[8] Chao, C. C.; Sherman, J. D.; Mullhaupt, J. T.; Bolinger, C. M; Mixed Ion-exhanged Zeolites and Processes for the Use Thereof in Gas Separations. U. S. Patent $5,174,979$ (1992).

[9] Coe, C. G.; in Access in Nanoporous Materials, T. J. Pinnavaia and M. F. Thorpe (Eds.), Plenum Press, New York, 1995 (p. 213).

[10] Yang, R. T.; "Recent Advances and New Horizons in Gas Adsorption - with a Focus on New Sorbents", in Preprints Topical Conf. Separ. Sci. Tech. (Eds.: W. S. W. Ho and R. G. Luo) AIChE, New York, 1997 b (p. 14).

[11] Heuchel, M.; Snurr, R. Q.; Buss, E.; Adsorption of $\mathrm{CH}_{4}-\mathrm{CF}_{4}$ Mixtures in Silicalite: Simulation, Experiment, and Theory. Langmuir 1997, 13, 6795.

[12] Cracknell, R. F.; Gubbins, K. E.; Molecular Simulation of Adsorption and Diffusion in VPI-5 and Other Aluminophosphates. Langmuir 1993, 9, 824. 
[13] Van Tassel, P. R.; Phillips, J. C.; Davis, H. T.; McCormick, A. V.; Zeolite Adsorption Site Location and Shape Shown by Simulated Isodensity Surfaces. $J$. Mo.l. Graphics 1993, 11, 180.

[14] Goodbody, S. J.; Watanabe, K.; MacGowan, D.; Walton, J.; Quirke, N.; Molecular Simulation of Methane and Butane in Silicalite. J. Chem. Soc. Faraday Trans. 1991, 87 (13), 1951.

[15] Karavias, F.; Myers, A. L.; Monte Carlo Simulations of Adsorption of Non-Polar and Polar Molecules in Zeolite X. Molec. Simul. 1991, 8, 23.

[16] Woods, G. B.; Rowlinson, J. S.; Computer Simulations of Fluids in Zeolites X and Y. J. Chem. Soc. Faraday Trans. 2 1989, 85(6), 765.

[17] Razmuz, D. M.; Hall, C. K.; Prediction of Gas Adsorption in 5A Zeolites Using Monte Carlo Simulation. AIChE J. 1991, 37, 769.

[18] Watanabe, K.;Austin, N.; Stapleton, M.R.; Investigation of the Air Separation Properties of Zeolite Types A, X and Y by Monte Carlo Simulations. Molec. Simul. 1995, 15, 197.

[19] Richards, A. J.; Watanabe, K.; Austin, N.; Stapleton, M. R.; Computer Simulation of the Gas Separation Properties of Zeolite Li-X. J. of Porous Mater. 1995, 2, 43.

[20] Hutson, N. D.; Rege, S. U.; Yang, R. T.; Mixed Cation Zeolites: $\operatorname{Li}_{\mathrm{x}} \mathrm{Ag}_{\mathrm{y}}-\mathrm{X}$ as a Superior Adsorbent for Air Separation. AIChE J. 1999, 45, 724.

[21] Feuerstein, M.; Lobo, R. F.; Characterization of Li Cations in Zeolite LiX by SolidState NMR Spectroscopy and Neutron Diffraction. Chem. Mater. 1998, 10, 2197.

[22] Cerius $^{2}$ User Guide: Forcefield-Based Simulations, April 1997. Molecular Simulations Inc., San Diego, 1997.

[23] Murthy, C. S.; Singer, K.; Klein, M. L.; McDonald, I. R.; Pairwise Additive Effective Potentials for Nitrogen. Molec. Phys. 1980, 41, 1387

[24] Joshi, Y. P.; D. J. Tildesley, D. J.; Scaled-particle Theory for Adsorbed Hard-core Molecules Berichte der Bunsengesellschaft fuer Physikalische Chemie 1986, 9, 217.

[25] Jorgensen, W. L.; Madura, J.D; Solvation and Conformation of Methanol in Water. J. Am. Chem. Soc . 1983, 1051407.

[26] Allen, M. P.; Tildesley, D. J.; Computer Simulation of Liquids, Clarendon, Oxford, UK, 1987. 
[27] Herden, H.; Einicke, W. D.; Scholler, R.; Mortier, W. J.; Gellens, L. R.; Uytterhoeven, J. B.; Location of Li-ions in Synthetic Zeolites X and Y. Zeolites 1982, 2, 131.

[28] Jasra, R. V.; Choudary, N. V.; Bhat, S. G. T.; Correlation of Sorption Behavior of Nitrogen, Oxygen, and Argon with Cation Locations in Zeolite X. Ind. Eng. Chem. Res. 1996, 35, 4221. 


\begin{tabular}{|c|c|c|c|}
\hline Atom Type & $\sigma_{\mathrm{i}}(\AA)$ & $\varepsilon_{\mathrm{i}}(\mathrm{kcal} / \mathrm{mol})$ & \\
\hline $\mathrm{N}$ & 3.724 & 0.0723 & \\
\hline $\mathrm{O}$ & 3.424 & 0.1080 & \\
\hline $\mathrm{Ar}$ & 3.822 & 0.2380 & \\
\hline $\mathrm{Si}$ & 0.076 & 0.0370 & \\
\hline $\mathrm{Al}$ & 1.140 & 0.0384 & \\
\hline $\mathrm{Oz}(-\mathrm{Al})$ & 3.040 & 0.3342 & \\
\hline $\mathrm{Oz}(-\mathrm{Si})$ & 3.040 & 0.2018 & \\
\hline $\mathrm{Li}$ & 1.221 & 0.0087 & \\
\hline
\end{tabular}

\begin{tabular}{|c|c|c|c|}
\hline $\mathrm{H}_{2} \mathbf{0} / \mathrm{uc}$ & $\overline{\sigma_{i}(\AA)}$ & $\varepsilon_{\mathrm{i}}(\mathrm{kcal} / \mathrm{mol})$ & \\
\hline 0 & 1.221 & 0.0087 & \\
\hline 10 & 1.400 & 0.0087 & \\
\hline 15 & 1.800 & 0.0100 & \\
\hline 32 & 3.000 & 0.0200 & \\
\hline 50 & 3.000 & 0.0200 & \\
\hline 100 & 3.000 & 0.0200 & \\
\hline 150 & 3.000 & 0.0200 & \\
\hline
\end{tabular}




\section{Figure Captions}

Figure 1. Unit cell, including cation sites, for faujasite zeolites.

Figure 2. Comparison of experimental and simulation adsorption isotherms (measured at $298 \mathrm{~K}$ ) for (a) nitrogen, (b) oxygen, and (c) argon on fully dehydrated Li-LSX zeolite. These figures show very good agreement between experimental and simulated results.

Figure 3. Nitrogen adsorption capactiy (at $100 \mathrm{kPa}, 298 \mathrm{~K}$ ) versus dehydration temperature $(\mathrm{K})$. This figure shows a considerable loss of water (and corresponding increase in the $\mathrm{N} 2$ adsorption capacity) in the range of $500-570 \mathrm{~K}$.

Figure 4. Experimental amounts of $\mathrm{N}_{2}$ (a) and $\mathrm{O}_{2}$ and $\mathrm{Ar}(\mathrm{b})$ adsorbed at $100 \mathrm{kPa}$ and $298 \mathrm{~K}$ versus residual water in Li-LSX.

Figure 5. Experimental and simulated amounts of $\mathrm{N}_{2}$ adsorbed at $100 \mathrm{kPa}$ and $298 \mathrm{~K}$ versus residual water in Li-LSX. In simulation 1 (N2-sim1), existing force-field parameters were used. In simulation 2 (N2-sim2), the force-field parameters were adjusted to better fit the experimental data.

Figure 6. Experimental and simulated amounts of $\mathrm{O}_{2}$ adsorbed at $100 \mathrm{kPa}$ and $298 \mathrm{~K}$ versus residual water in Li-LSX. In simulation $1(\mathrm{O} 2$-sim1), existing force-field parameters were used. In simulation $2(\mathrm{O} 2$-sim2), the force-field parameters used in the nitrogen simulation 2 (from N2-sim2 in Figure 4) were used.

Figure 7. Experimental and simulated amounts of Ar adsorbed at $100 \mathrm{kPa}$ and $298 \mathrm{~K}$ versus residual water in Li-LSX. In simulation $1(\mathrm{O} 2$-sim1), existing force-field parameters were used. In simulation 2 (Ar-sim2), the force-field parameters used in the nitrogen simulation 2 (from N2-sim2 in Figure 4) were used. 


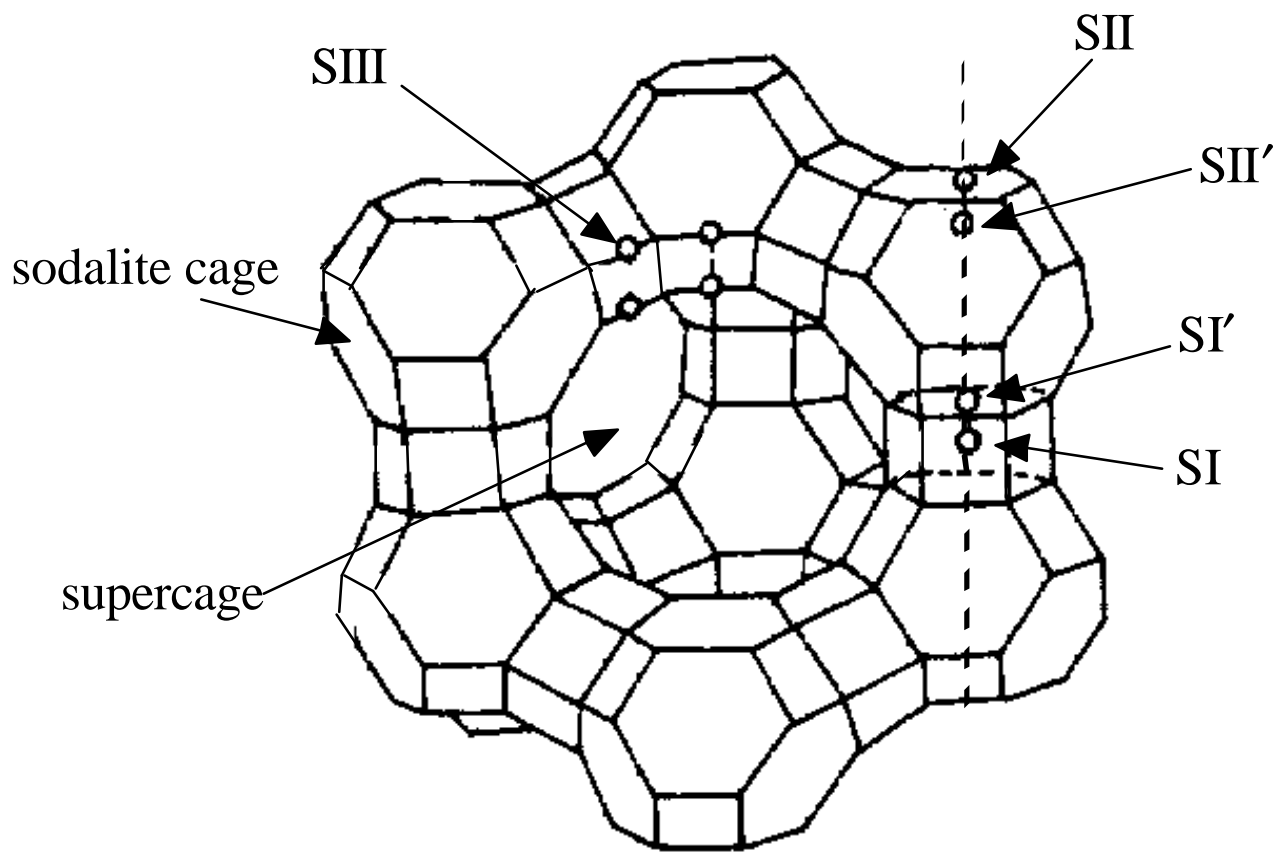

Figure 1. Unit cell, including cation sites, for faujasite zeolites. 

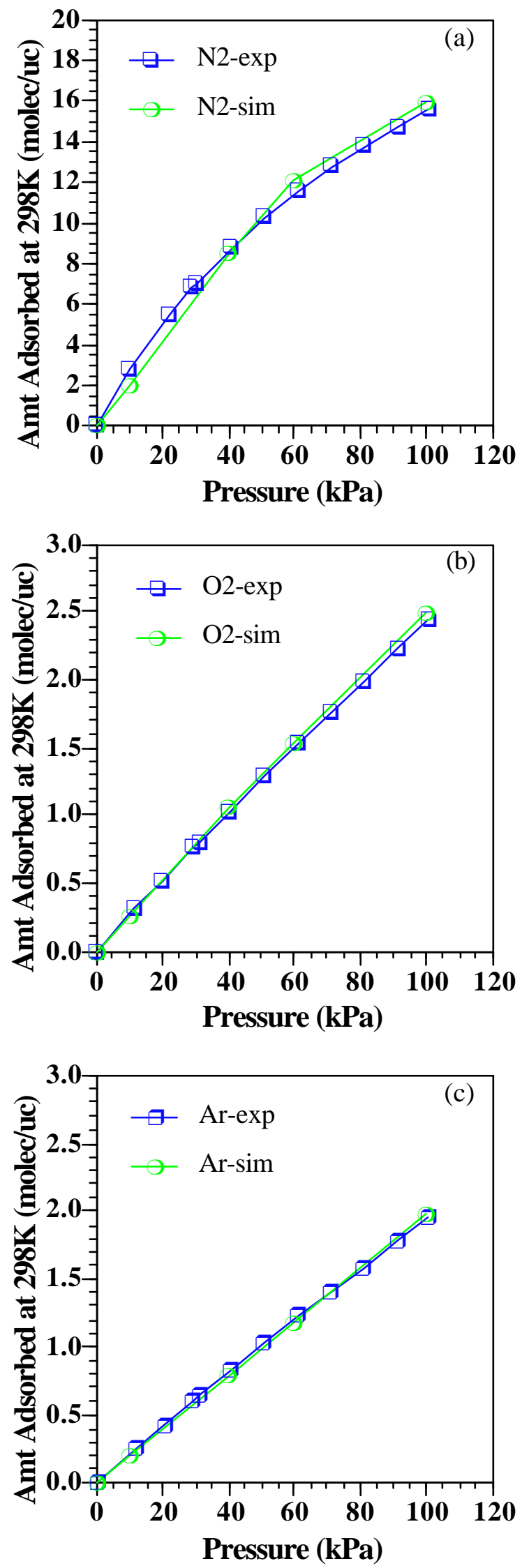
Figure 2. Comparison of experimental and simulation adsorption isotherms (measured at 298K) for (a) nitrogen, (b) oxygen, and (c) argon on fully dehydrated LiLSX zeolite. These figures show very good agreement between experimental and simulated results.

(NOTE: Figure 2 is on the previous page)

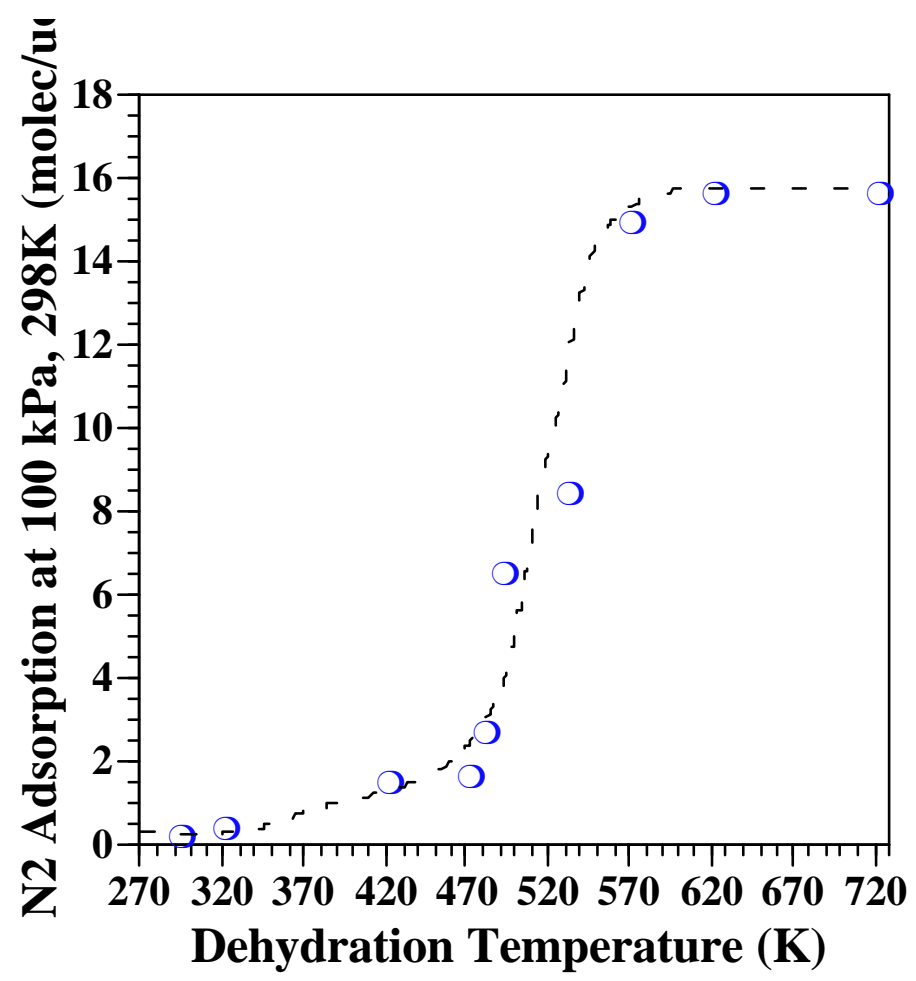

Figure 3. Nitrogen adsorption capactiy (at $100 \mathrm{kPa}, 298 \mathrm{~K}$ ) versus dehydration temperature $(\mathrm{K})$. This figure shows a considerable loss of water (and corresponding increase in the $\mathrm{N} 2$ adsorption capacity) in the range of $500-570 \mathrm{~K}$. 

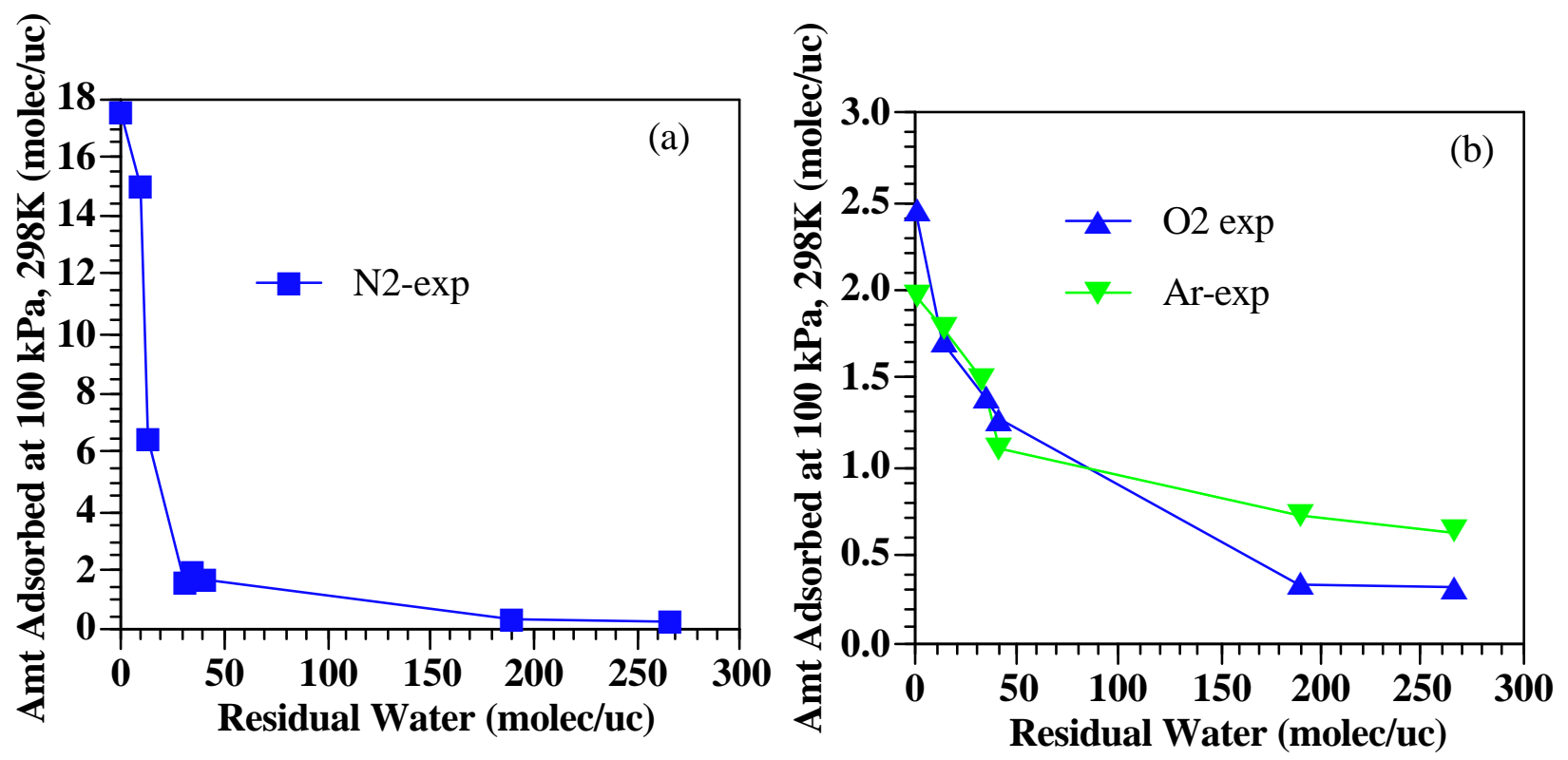

Figure 4. Experimental amounts of $\mathrm{N}_{2}$ (a) and $\mathrm{O}_{2}$ and $\mathrm{Ar}(\mathrm{b})$ adsorbed at $100 \mathrm{kPa}$ and $298 \mathrm{~K}$ versus residual water in Li-LSX. 


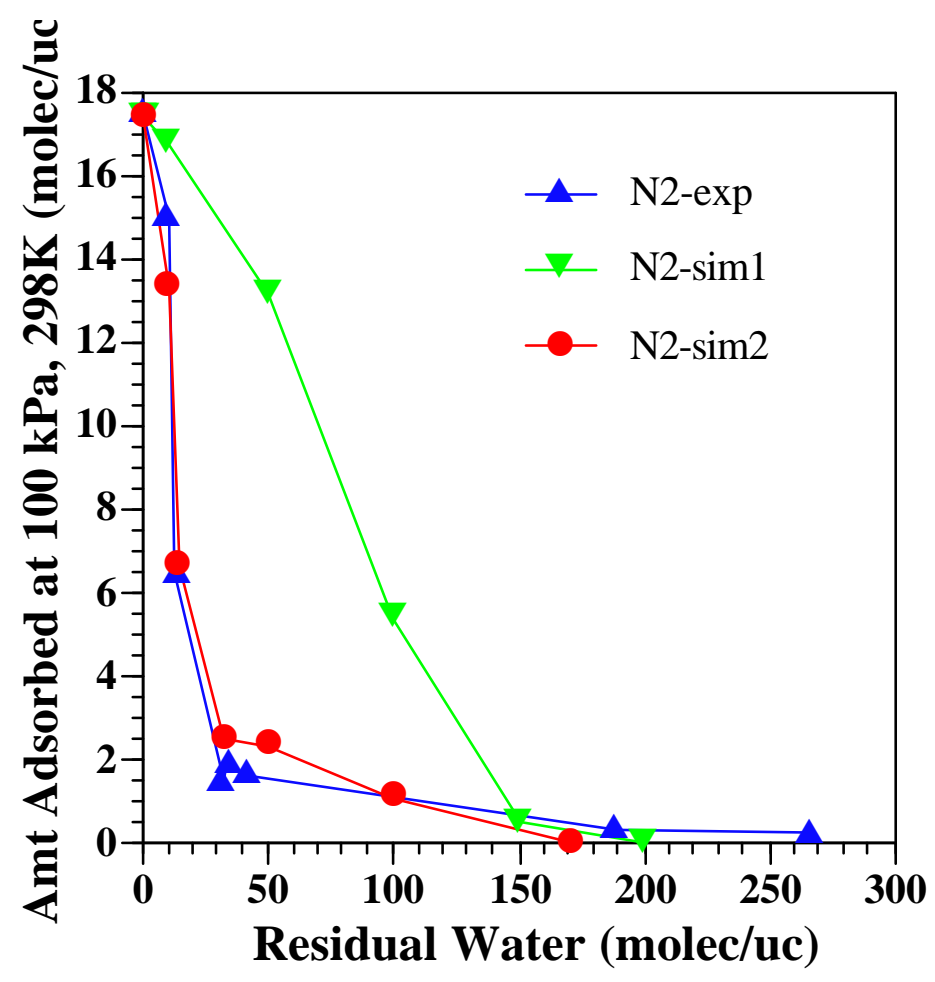

Figure 5. Experimental and simulated amounts of $\mathrm{N}_{2}$ adsorbed at $100 \mathrm{kPa}$ and $298 \mathrm{~K}$ versus residual water in Li-LSX. In simulation 1 (N2-sim1), existing force-field parameters were used. In simulation 2 (N2-sim2), the force-field parameters were adjusted to better fit the experimental data. 


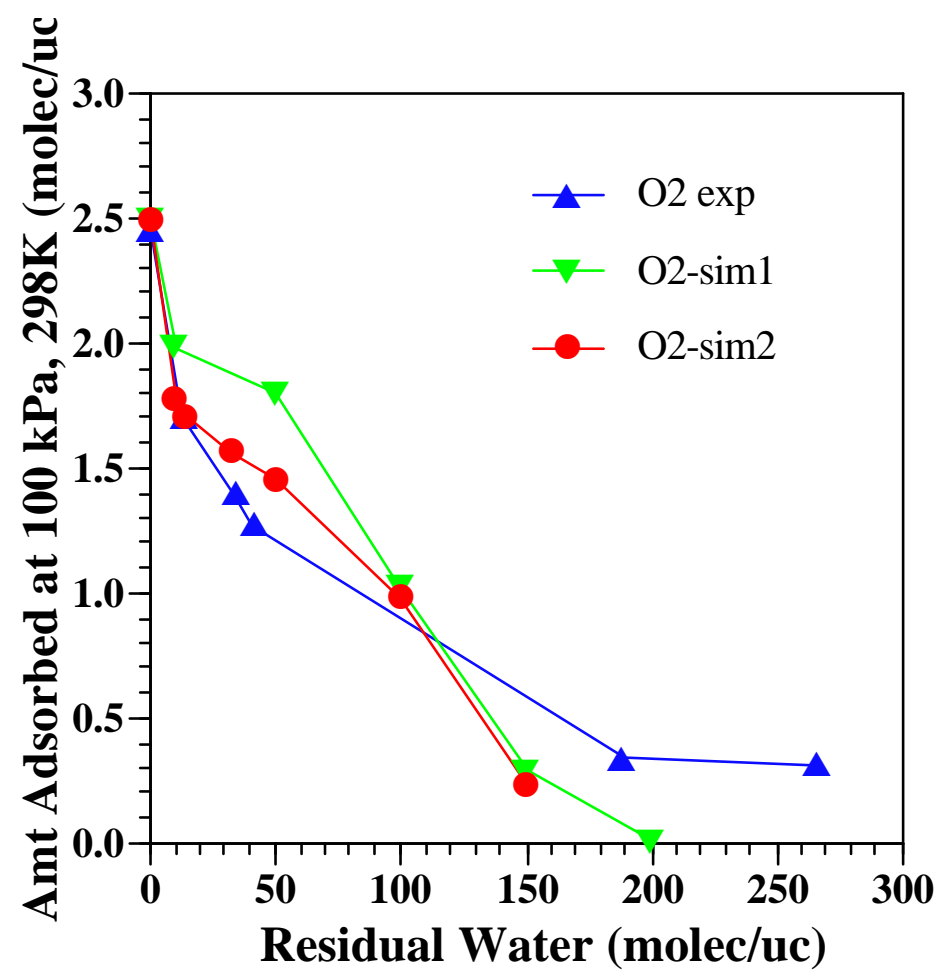

Figure 6. Experimental and simulated amounts of $\mathrm{O}_{2}$ adsorbed at $100 \mathrm{kPa}$ and $298 \mathrm{~K}$ versus residual water in Li-LSX. In simulation 1 (O2-sim1), existing force-field parameters were used. In simulation $2(\mathrm{O} 2$-sim2), the force-field parameters used in the nitrogen simulation 2 (from N2-sim2 in Figure 4) were used. 


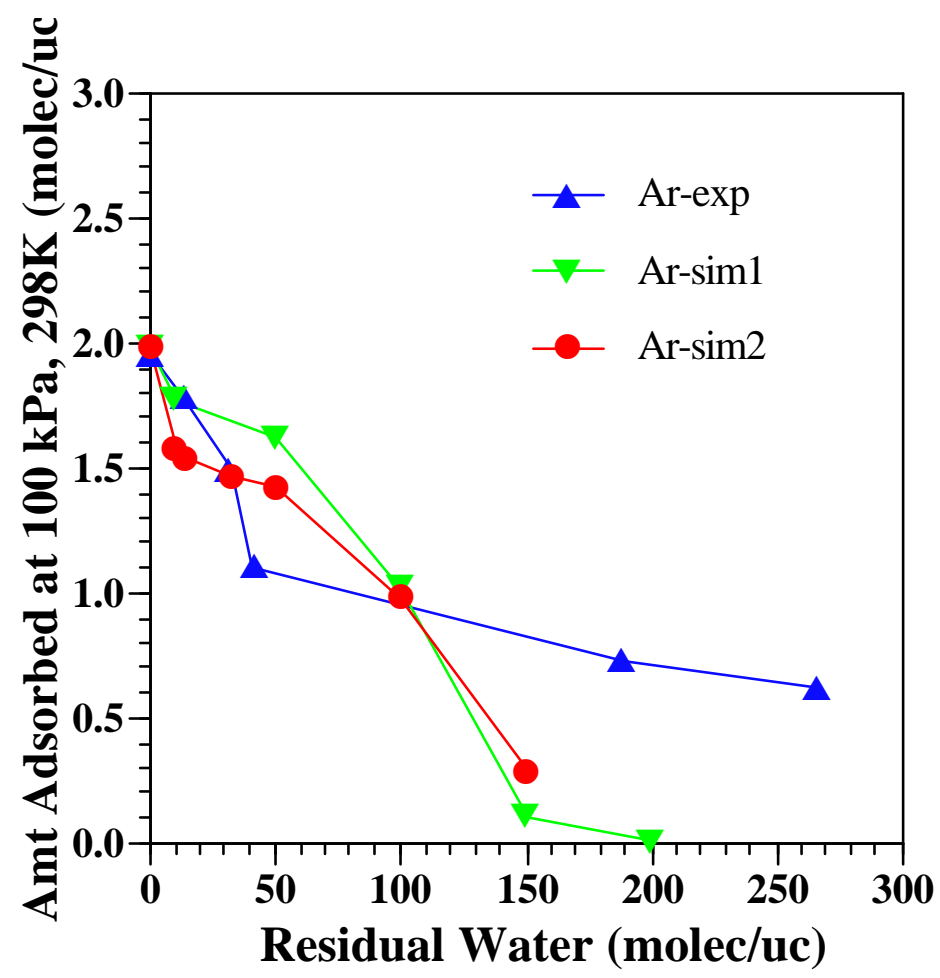

Figure 7. Experimental and simulated amounts of Ar adsorbed at $100 \mathrm{kPa}$ and $298 \mathrm{~K}$ versus residual water in Li-LSX. In simulation 1 (O2-sim1), existing force-field parameters were used. In simulation 2 (Ar-sim2), the force-field parameters used in the nitrogen simulation 2 (from N2-sim2 in Figure 4) were used. 


\section{CHAPTER 5}

Synthesis and Characterization of the Sorption Properties of Oxygen-Binding Cobalt Complexes Immobilized in Nanoporous Materials 


\section{Introduction}

Nitrogen and oxygen are two of the most abundantly produced chemicals in the world. These gases are produced by a number of processes, but, predominately by separation of air using cryogenic distillation. However, as adsorption systems have become more efficient and better sorbents have been developed, industrial production of nitrogen and oxygen by adsorption has become an increasingly important alternative technology. ${ }^{1}$

Commercial sorption-based air separation is normally conducted by the use of nitrogen-selective zeolites in pressure swing adsorption (PSA) systems. However, separation of air by adsorption of its less abundant component $\left(\mathrm{O}_{2}\right)$ is certainly more desirable; and researchers have searched, for some time, for a material that adsorbs oxygen preferentially to nitrogen for use in industrial adsorption systems. Carbon molecular sieves (CMS) can be used as an oxygen-selective material for kinetic separation of air in a PSA system. However, even the most effective CMS materials have poor $\mathrm{O}_{2} / \mathrm{N}_{2}$ selectivity and are usually used for production of enriched oxygen or nitrogen rather than for the production of very high purity gases. ${ }^{2}$

Since the 1940s, considerable work has been devoted to the study of oxygen-binding transition metal complexes, mostly in attempts to model important biological oxygen carriers such as hemoglobin and myoglobin. Because of their similarity to the natural heme proteins, $\mathrm{O}_{2}$-binding iron complexes have received the most attention; but, it is the oxygen carrying complexes of cobalt that have proven the most promising as potential oxygen sorbents for air separation. Several thorough reviews are available on this subject. $^{2-4}$ 
Pfeiffer described a compound of composition cobaltous bis-salicylaldehyde ethylenediamine that turned from a reddish color to black when exposed to air. ${ }^{2}$ Tsumakei then showed that the blackening was due to adsorption of oxygen from the air. ${ }^{2}$ He also showed that the sorption was reversible and that the oxygen could be driven off by heating in carbon dioxide. These results then stimulated a tremendous amount of work by Calvin and coworkers who synthesized and characterized a large number of cobalt chelates capable of binding oxygen. ${ }^{5-9}$ Among these compounds were cobaltous bis-salicylaldehyde ethylenediamine (Co(salen) or salcomine) and cobaltous bis(3-fluorosalicylaldehyde) ethylenediamine (Co(fluomine)). These compounds, shown in Figure 1, represent the most extensively studied of the oxygen-binding cobalt complexes.,10 Co(salen) has reversible oxygen-binding capability; and there have been several attempts to develop a system for oxygen production from air using Co(salen). The U.S. Air Force has attempted to develop the material for onboard oxygen support systems. Co(salen), however, is quickly deactivated by the presence of moisture. Many of the drawbacks of Co(salen) were reduced by the use of the compound Co(fluomine), which is stable in moisture and was studied extensively by the U.S. Air Force in the mid-70's for potential use in breathing air systems for crews of military aircraft. ${ }^{11,12}$ As with the Co(salen) material, the commercialization of $\mathrm{Co}$ (fluomine) has been hampered by the long term chemical instability of the complex.

Chen and Martell synthesized and characterized a large number of $\mathrm{O}_{2}$-binding cobalt Schiff base complexes. ${ }^{13,14}$ Dzugan and Busch characterized new oxygen-binding macrocyclic cobalt complexes. ${ }^{15}$ Ramprasad et al. reported a group of solid state crystalline cyanocobaltate complexes with reversible and very high oxygen-binding 
capacity. ${ }^{16}$ None of these materials has shown the necessary combination of reversibility, capacity and stability needed for use in industrial gas separations.

Recent research efforts have focused on steric hindrance as a means of protecting the oxygen-binding complex from oxidation and dimerization. The most promising approach has been to prepare the oxygen sorbent by entrapment or encapsulation as a solid state metal complex within the cages of a synthetic zeolite. ${ }^{17-24}$ None of these efforts, however, proved effective for separating oxygen from nitrogen due to instabilities and/or inadequate $\mathrm{O}_{2}$-binding capacity.

Although numerous transition metal complexes with oxygen-binding ability have been reported, none of these materials has achieved commercial success as a sorbent for air separation. All these materials have suffered from one or more of the following drawbacks that have prevented commercialization: (1) chemical instability, (2) unacceptable adsorption characteristics and/or (3) unacceptable cost. In this study we have synthesized complexes of known oxygen-binding ability (specifically $\mathrm{Co}$ (salen) and Co(fluomine)). We have also synthesized these materials using a modified synthesis technique that resulted in complexes that were attached (immobilized) to the surface of several porous substrates. The $\mathrm{O}_{2}$-binding capacity and the stability of these resulting sorbents were then characterized. The modified procedure involved two steps. The first step was to bond $\mathrm{Co}^{2+}$ on anion sites of a substrate, by ion exchange, to form a stable ionically bonded $\mathrm{Co}^{2+}$. This was followed by attaching ligands coordinatively to $\mathrm{Co}^{2+}$ that would give $\mathrm{Co}^{2+}$ the oxygen-binding ability. The details of this reasoning was given elsewhere. $^{25}$ 


\section{Experimental Details}

The Co(salen) used in these studies was prepared using procedures similar to those previously provided by Bailes and Calvin. ${ }^{9}$ The Co(fluomine) was prepared using modifications of procedures provided by Bailes and Calvin and Adduci. ${ }^{9,12}$ The immobilized $\mathrm{Co}($ salen) and $\mathrm{Co}$ (fluomine) sorbents were prepared using modifications of those procedures.

Materials. Several substrates with cation exchange capacities were used in the course of this work. They were (1) a binderless, hydrated type-X zeolite powder with a $\mathrm{Si} / \mathrm{Al}$ of 1.0 (sometimes referred to as LSX or low silica X-zeolite), (2) a mesoporous material, MCM-41 with Si/Al 5, and (3) a sulfonated polystyrene cation exchange resin (Rhom and Haas Amberlyst-15).

MCM-41 is a mesoporous material from the M41S family discovered in 1992 by researchers at Mobil Corporation. ${ }^{26}$ These silicate/aluminosilicate mesoporous molecular sieves have pore structures that are nearly as regular as those in zeolites; but, they are considerably larger; and, depending upon the amount of tetrahedrally coordinated aluminum in the framework structure, may also posses cation exchange capacity. ${ }^{27}$ The unit cell of low silica $\mathrm{X}$ zeolite is $\left(\mathrm{M}^{+}\right)_{96}\left(\mathrm{SiO}_{2}\right)_{96}\left(\mathrm{AlO}_{2}\right)_{96}$ while the unit cell of MCM-41 is $\left(\mathrm{M}^{+}\right)_{16}\left(\mathrm{SiO}_{2}\right)_{80}\left(\mathrm{AlO}_{2}\right)_{16}$ (where $\mathrm{M}^{+}$is the non-framework charge-compensating cation).

Helium (99.995\%, prepurified), oxygen (99.6\%, extra dry), nitrogen $(99.998 \%$, prepurified), and argon (99.99\%, prepurified) were obtained from Cryogenic Gases. Deionized water was used for all ion-exchanges and washings.

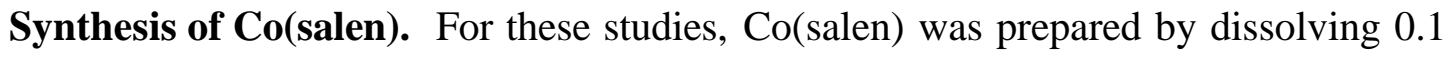
mol cobaltous acetate tetrahydrate (97\%, ACROS Organics) in $250 \mathrm{~mL}$ boiling DI water 
in a fume hood. To this cobalt solution 0.4 mol pyridine (99+\%, ACROS Organics) was then addd, followed by $0.1 \mathrm{~mol}$ of ethylenediamine (99\%, ACROS Organics). This mixture was then shaken thoroughly before $0.2 \mathrm{~mol}$ of salicylaldehyde (98\%, ACROS Organics) was added to it. Red crystals formed immediately. This material was heated out of contact with air for 2 hours before cooling, filtering and washing with copious amounts of DI water. The material was then dried in an oven at $100 \mathrm{C}$.

Synthesis of Co(fluomine). Co(fluomine) was prepared by dissolving $0.36 \mathrm{mmol}$ of cobaltous acetate tetrahydrate in $600 \mu \mathrm{L}$ DI water and heating to at least $70 \mathrm{C}$. Separately, $0.71 \mathrm{mmol}$ of 3-fluorosaliclyaldehyde (3-FSA, 97\%, Aldrich Chemicals) was dissolved in $600 \mu \mathrm{L} \mathrm{EtOH} \mathrm{(denatured,} \mathrm{Aldrich} \mathrm{Chemicals)} \mathrm{by} \mathrm{heating.} \mathrm{To} \mathrm{this} \mathrm{solution}$ $25 \mu \mathrm{L}$ of ethylenediamine was added followed immediately by $105 \mu \mathrm{L}$ of piperidine (99\%, Aldrich Chemicals). The material formed a yellow-orange crystalline material that dissolved with heating. The cobalt solution was then added to this material and the resultant solution was heated out of contact with air for 1 hour. The resulting red crystalline material was then filtered, washed with copious amounts of DI water and dried in an oven at $100 \mathrm{C}$.

Synthesis of Immobilized Complexes. Co(fluomine) was immobilized on three different substrates (as described earlier): LSX zeolite, mesoporous MCM-41, and ionexchange resin (IXR). The ion-exchange resin was washed with methanol prior to proceeding to the ion-exchange. With each of the immobilized complexes, the first step of the synthesis was Co(II) ion-exchange with the desired substrate. This was done by conventional ion exchange where the substrate was added to a $2 \mathrm{X}$ equivalent solution of cobaltous acetate $(0.08 \mathrm{M})$ in an Erlenmeyer flask and heated to a mild boil. The solution 
was allowed to cool and settle. The supernate was then decanted; and, the procedure was repeated. The resulting $\mathrm{Co}$ (II)-substrate was then filtered, washed with copious amounts of deionized water, and dried at 100 C overnight.

The next step of the synthesis was to slurry $0.2 \mathrm{~g}$ of the Co(II)-substrate in $6 \mathrm{~mL} \mathrm{DI}$ water. Separately, $0.71 \mathrm{mmol}$ of 3-fluorosaliclyaldehyde was dissolved in $600 \mu \mathrm{L} \mathrm{EtOH}$ as before by heating. To this solution $25 \mu \mathrm{L}$ of ethylenediamine was added followed immediately by $105 \mu \mathrm{L}$ of piperidine. The Co(II)-substrate slurry was then added to this material with good mixing; and, the resultant was heated out of contact with air for 1 hour. The resulting material, which had a brownish-red color, was then filtered, washed with copious amounts of DI water and dried in an oven at $100 \mathrm{C}$.

Characterization Methods. The samples were analyzed for Co content using an inductively coupled plasma mass spectrometer (ICP-MS, Hewlett Packard HP 4500). The samples were first digested in concentrated nitric acid solution at $100 \mathrm{C}$ for $20 \mathrm{~min}$. At the end of digestion, the samples were further diluted and filtered before analysis using ICP-MS. Analyses for C and F content were performed by Galbraith Laboratories (Knoxville, TN).

The adsorption isotherms were measured using a static volumetric system (Micromeritics ASAP-2010). Prior to measurement of isotherms, the samples were activated (deoxygenated) in a vacuum at $120-160 \mathrm{C}$ for a minimum of 1 hour. Oxygenated samples were black in color; while the activated/deoxygenated samples had a brownish red color. Additions of the analysis gas were made at volumes required to achieve a targeted set of pressures. A minimum equilibrium interval of 30 seconds with a 
tolerance of $5 \%$ of the target pressure (or $0.0066 \mathrm{~atm}$, whichever is smaller) was used to determine equilibrium for each measurement point.

$\mathrm{X}$-ray photoemission spectra were obtained from thin wafers of the zeolites using a Perkin-Elmer PHI 5400 ESCA system with a Mg anode. Samples of several types of Comaterials were prepared for XPS analysis by forming into very thin wafers using a laboratory press. The wafers were then degassed in the XPS staging cell at $10^{-8}-10^{-9}$ torr for two days at room temperature prior to analysis. A lack of surface charging was verified by measuring the binding energy of adventitious carbon. The generally accepted reference

for the binding energy of $\mathrm{C} 1 \mathrm{~s}$ photoelectrons is $285 \pm 0.2 \mathrm{eV}$.

\section{Results and Discussion}

Chemical Analysis. The results of the chemical analyses are shown in Table 1. The results show that the Co-LSX contained 18 wt $\%$ Co. This translates to approximately 47 Co cations per unit cell or about $98 \%$ ion exchange (of the total capacity). The Co(fluomine)-LSX sample contained $16 \mathrm{wt} \% \mathrm{Co}$, which is approximately 50 Co cations per unit cell or $104 \%$ of the ion exchange capacity. The Co(Fluomine)-MCM-41 sample had a Co content of $5.9 \mathrm{wt} \%$, which is approximately 7.6 Co cations per unit cell or $95 \%$ of the ion exchange capacity. The analyses of fluorine were used to determine the amount of $\mathrm{Co}$ (fluomine) in each of the samples since the chance for contamination from adventitious carbon is higher than that of the fluorine (and the carbon results were consistently in excess of what would be expected based on the fluorine analyses).

Based on the F analysis, the Co(fluomine)-LSX sample contained 10 Co(fluomine) molecules per unit cell or approximately 2 molecules per zeolite cavity. The 
Co(fluomine)-MCM-41 sample contained approximately 3.7 Co(fluomine) molecules per unit cell.

$\mathrm{O}_{2}$ Isotherms for $\mathrm{Co}\left(\right.$ salen) and $\mathrm{Co}\left(\right.$ fluomine). The $\mathrm{O}_{2}$ adsorption and desorption isotherms, measured at $25 \mathrm{C}$, for $\mathrm{Co}($ salen) are shown in Figure 2. These isotherms display a very noticeable and interesting hysteresis. The adsorption isotherm shows that very little $\mathrm{O}_{2}$ is adsorbed until the $\mathrm{O}_{2}$ pressure reaches a "threshold" amount at approximately $0.2 \mathrm{~atm}$. The adsorption isotherm then sharply rises to nearly the full $\mathrm{O}_{2}$ binding capacity of the complex. Very low pressure was then required to release the bound oxygen. The $\mathrm{O}_{2}$-binding capacity for the $\mathrm{Co}(\mathrm{salen})$ material was $1.06 \mathrm{mmol} / \mathrm{g}$, approximately $70 \%$ of the theoretical value of $1.55 \mathrm{mmol} / \mathrm{g}$ based on a $1: 2\left(\mathrm{O}_{2}: \mathrm{Co}^{2+}\right)$ adduct.

The $\mathrm{O}_{2}$ adsorption and desorption isotherms, measured at $25 \mathrm{C}$, for Co(fluomine) are shown in Figure 3. These curves are somewhat similar to those of the Co(salen), but do not have a similar hysteresis. The material strongly binds $\mathrm{O}_{2}$ at very low pressures, immediately adsorbing the full capacity at pressures $<0.1 \mathrm{~atm}$. However, at $25 \mathrm{C}$, the $\mathrm{O}_{2}$ could not be desorbed even at very low $\mathrm{O}_{2}$ pressures. The $\mathrm{O}_{2}$-binding capacity for the Co(fluomine) material was $1.13 \mathrm{mmol} / \mathrm{g}$, approximately $80 \%$ of the theoretical value of $1.39 \mathrm{mmol} / \mathrm{g}$ based on a $1: 2\left(\mathrm{O}_{2}: \mathrm{Co}^{2+}\right)$ adduct.

The $\mathrm{O}_{2}$ adsorption and desorption isotherms were also measured for the Co(fluomine) material at $0 \mathrm{C}$ and at $60 \mathrm{C}$. These, along with those measured at $25 \mathrm{C}$, are shown in Figure 4. All of these isotherms are quite different. The curves measured at $0 \mathrm{C}$ have a similar aspect to that measured at $25 \mathrm{C}$; but the capacity is considerably lower $(0.48$ $\mathrm{mmol} / \mathrm{g}$ versus $1.13 \mathrm{mmol} / \mathrm{g}$ ). The isotherms measured at $60 \mathrm{C}$, however, were quite 


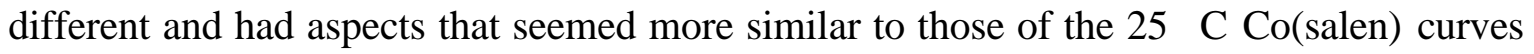
than to either of the other $\mathrm{Co}$ (fluomine) curves. Much like the $25 \mathrm{C} \mathrm{O}_{2}$ sorption curves for the $\mathrm{Co}($ salen) material, the $60 \mathrm{C}$ curves measured for the $\mathrm{Co}$ (fluomine) material contained a similar hysteresis. The adsorption curve had a similar 0.2-atm $\mathrm{O}_{2}$ pressure "threshold"; but the curve had a less sharp rise to the final capacity. Unlike the $25 \mathrm{C}$ and $0 \mathrm{C}$ Co(fluomine) curves, the $\mathrm{O}_{2}$ was desorbed at low pressure, again similar to the $\mathrm{Co}$ (salen). It is interesting that the greatest $\mathrm{O}_{2}$-binding capacity (of these three temperatures) is for that measured at $25 \mathrm{C}$. One explanation for this was the possible slow kinetics of binding at $0 \mathrm{C}$.

Adsorption on Co(fluomine)-LSX. Co(fluomine) was immobilized on the surface, or within the pore structure, of several materials. The $\mathrm{O}_{2}$ and $\mathrm{N}_{2}$ adsorption and desorption isotherms, measured at $25 \mathrm{C}$, for Co(fluomine)-LSX and for Co-LSX are shown in Figure 5. The isotherms for the Co-LSX zeolite are typical Langmuir-type isotherms. The curves for the immobilized complex on the zeolite are somewhat similar to those of the free $\mathrm{Co}$ (fluomine), but with a much lower capacity. As with the $\mathrm{Co}$ (fluomine), $\mathrm{O}_{2}$ was strongly bound at very low pressures; but unlike the free material the immobilized material did not immediately attain the full capacity. Rather, the $\mathrm{O}_{2}$ uptake steadily increased. The capacity at 1 atm for this material was $0.15 \mathrm{mmol} / \mathrm{g}$. Assuming that only two Co(fluomine) molecules may be placed in the zeolite supercage and given that other sites (such as those in the beta cages and hexagonal prisms) are too small to accommodate the complex and are sterically inaccessible to $\mathrm{O}_{2}$, the maximum $\mathrm{O}_{2}$ capacity expected is $0.57 \mathrm{mmol} / \mathrm{g}$ for a $1: 1\left(\mathrm{O}_{2}: \mathrm{Co}^{2+}\right)$ adduct and $0.29 \mathrm{mmol} / \mathrm{g}$ for a $1: 2\left(\mathrm{O}_{2}: \mathrm{Co}^{2+}\right)$ adduct. Because the zeolite itself has some $\mathrm{O}_{2}$-binding capacity, there is some enhancement of the 
$\mathrm{O}_{2}$ capacity of the Co(fluomine)-LSX from the zeolite matrix. However the zeolitic contribution is estimated to be only $0.028 \mathrm{mmol} / \mathrm{g}$. This estimate is based on the measured $\mathrm{N}_{2}$ and $\mathrm{O}_{2}$ capacities of fully exchanged $\mathrm{Co}^{2+}$-LSX zeolite. At $1 \mathrm{~atm}$, the $\mathrm{N}_{2}$ capacity of the Co-LSX is approximately two times that for $\mathrm{O}_{2}$. Therefore, the $\mathrm{O}_{2}$ contribution of the zeolite in the Co(fluomine)-LSX can be expected to be approximately on-half that of the $\mathrm{N}_{2}$ capacity (which was measured at approximately $0.057 \mathrm{mmol} / \mathrm{g}$ ). So, the $\mathrm{O}_{2}$-binding of the Co(fluomine) is approximately $0.123 \mathrm{mmol} / \mathrm{g}$, which is much less than the theoretical amount for a 1:1 adduct and less than that expected for a 1:2 adduct. It is possible that, because of the isolation of the $\operatorname{Co}($ fluomine) within the zeolite cavity, the complexes form 1:1 $\left(\mathrm{O}_{2}: \mathrm{Co}^{2+}\right)$ adducts rather than the 1:2 ones observed with the free complex. However, the observed capacities tend to indicate the formation of 1:2 adducts. It is also possible that there is some amount of Co(fluomine) attached to the outside surface of the zeolite. We have also considered the possibility that the Co(fluomine) is not attached to the zeolite matrix at all. Others have suggested an ion-exchange reaction in which the $\mathrm{Co}^{2+}$ of the zeolite are exchanged for protons in the free crystal (in that case, salen). ${ }^{25}$ This results in a simple physical mixture of the two. In other work in our lab, we synthesized what was essentially a physical mixture of LXS zeolite and Co(fluomine). The resulting oxygen adsorption isotherm did not look like those shown in Figure 5. Rather, the isotherm had exactly the same aspect of the free $\mathrm{Co}($ fluomine) material (shown in Figure 3); but the capacity was diluted.

From the shape of the $\mathrm{O}_{2}$ isotherm, it appears that, unlike the free $\mathrm{Co}$ (fluomine), the Co(fluomine)-LSX has not attained the full capacity at $1 \mathrm{~atm}$. The bound $\mathrm{O}_{2}$ on the Co(fluomine) could not be desorbed, even at low pressure. However, the Co(fluomine)- 
LSX material does show some degree of reversibility, though it is not fully reversible, and is not fully desorbed even at low pressures. The $\mathrm{N}_{2}$ adsorption isotherm was also measured for this Co(fluomine)-LSX material and is also shown in Figure 5. The reversibility and the continual increase with pressure of the isotherm are desirable characteristics for application, which give rise to a useful working capacity.

The $\mathrm{O}_{2}$ adsorption and desorption isotherms were also measured for the $\mathrm{Co}$ (fluomine)LSX material at $0 \mathrm{C}$ and at $60 \mathrm{C}$. These, along with those measured at $25 \mathrm{C}$, are shown in Figure 6. All of these isotherms are quite different from those of the free Co(fluomine). The curves measured at $0 \mathrm{C}$ have the highest capacity $(0.167 \mathrm{mmol} / \mathrm{g}$ at 1atm) of these materials and have a similar aspect to those of the Co(fluomine)-LSX measured at $25 \mathrm{C}$. The isotherms measured at $60 \mathrm{C}$ had very low capacity $(0.038$ $\mathrm{mmol} / \mathrm{g}$ ) and seemed to be more reversible than those measured at $0 \quad \mathrm{C}$ and $25 \mathrm{C}$.

\section{Adsorption on Co(fluomine)-MCM-41. The MCM-41 materials are} aluminosilicates but, unlike many zeolites, do not possess a natural selectivity for nitrogen over oxygen. The MCM-41 used in these studies contained a Si/Al 5. The $\mathrm{O}_{2}$ and $\mathrm{N}_{2}$ adsorption and desorption isotherms, measured at $25 \mathrm{C}$, for Co(fluomine)-MCM41 are shown in Figure 7. These curves are quite different from those of the free Co(fluomine) with nearly complete reversibility and much lower capacity $(0.107 \mathrm{mmol} / \mathrm{g}$ at $1 \mathrm{~atm}$ ). As with the $\mathrm{Co}$ (fluomine), $\mathrm{O}_{2}$ was strongly bound at very low pressures and, as with the Co(fluomine)-LSX, did not immediately attain the full capacity; but rather maintained a positive slope through $1 \mathrm{~atm}$. The positive slope, again, yields a sorbent working capacity and is useful for application. The theoretical capacity for this material is $0.49 \mathrm{mmol} / \mathrm{g}$ for a $1: 1\left(\mathrm{O}_{2}: \mathrm{Co}^{2+}\right)$ and $0.25 \mathrm{mmol} / \mathrm{g}$ for a $1: 2\left(\mathrm{O}_{2}: \mathrm{Co}^{2+}\right)$ adduct. These 
values assume 3.6 molecules of Co(fluomine) per unit cell of the MCM-41. The actual capacity of this material at $1 \mathrm{~atm}$ oxygen pressure and $25 \mathrm{C}$ is less than the theoretical amount for both the 1:2 adduct and the 1:1 adduct. Although the pore structure of the MCM-41 is much more open than the LSX zeolite, it may not be possible for a Co(fluomine) molecule to attach at every ion-exchange site. And, much more oxygen may be bound at higher pressures (than 1 atm). The $\mathrm{O}_{2}$-binding of this material was much more reversible than either the Co(fluomine)-LSX or the neat Co(fluomine) complex. This may be an indication of the formation of $1: 1$ adducts since the free Co(fluomine) form 1:2 adducts and is very difficult to desorb.

Adsorption on Co(fluomine)-IXR. The $\mathrm{O}_{2}$ and $\mathrm{N}_{2}$ adsorption and desorption isotherms, measured at $25 \mathrm{C}$, for $\mathrm{Co}$ (fluomine)-IXR are shown in Figure 8 . These curves most closely resemble those of the Co(fluomine)-MCM-41 with nearly complete reversibility but with much lower capacity $(0.03 \mathrm{mmol} / \mathrm{g}$ at $1 \mathrm{~atm})$. As with all of other materials, $\mathrm{O}_{2}$ was strongly bound at very low pressures. But, as with all of the other immobilized samples, the sample did not immediately attain the full capacity; but rather has a positive slope through $1 \mathrm{~atm}$. The $\mathrm{N}_{2}$ adsorption isotherm was also measured for this Co(fluomine)-IXR material and is shown in Figure 8. The theoretical capacity for this material is about $1.2 \mathrm{mmol} / \mathrm{g}$ for a $1: 1\left(\mathrm{O}_{2}: \mathrm{Co}^{2+}\right)$ and $0.6 \mathrm{mmol} / \mathrm{g}$ for a $1: 2\left(\mathrm{O}_{2}: \mathrm{Co}^{2+}\right)$ adduct. These values assume $100 \%$ ion-exchange of $\mathrm{Co}^{2+}$ with the ion-exchange resin (with a cation exchage capacity of $4.7 \mathrm{meq} / \mathrm{g}$ ) and subsequent conversion to $\mathrm{Co}$ (fluomine). The actual capacity of this material, at $0.03 \mathrm{mmol} / \mathrm{g}$ at $25 \mathrm{C}$ and $1 \mathrm{~atm}$, is considerably lower than the theoretical amount. 
It is worth noting here that other substrates were tried with no success. Several types of intercalated clays (or pillared interlayered clays, PILCs), with varying pore sizes and cation exchange capacities were used. In each case the final synthesized material was the familiar red color of the unoxygenated $\mathrm{Co}$ (fluomine); but contained no $\mathrm{O}_{2}$-binding capacity over that of the PILC that contained no complex. Co(fluomine) was also synthesized in type $\mathrm{X}(\mathrm{Si} / \mathrm{Al} \quad 1.25)$ and in type $\mathrm{Y}$ zeolites. The $\mathrm{O}_{2}$-binding capacity and the general aspect of the isotherms were the same as for that of the type $\mathrm{X}(\mathrm{Si} / \mathrm{Al} \quad 1)$.

The Nature of the Bond. Although the $\mathrm{O}_{2}$-binding transition metal complexes have been extensively studied, the nature of their bond formation has long been the subject of some controversy. Vaska showed that almost all currently known transition metal dioxygen complexes can be divided into two types according to the characteristics of the dioxygen ligand. ${ }^{29}$ The types are the (type I) superoxo $\left(\mathrm{O}_{2}{ }^{-}\right)$and the (type II) peroxo $\left(\mathrm{O}_{2}{ }^{2-}\right)$ complexes. These complexes are further classified as to whether the dioxygen is bound to one metal atom (type a) or bridges two metal atoms (type b). These are shown in Figure 9.

Several previous studies have attempted to attach $\mathrm{O}_{2}$-binding complexes to substrates. Others have attempted to build the complex within the supercage of type X or Y zeolite, the so called "ship in a bottle" synthesis. In the earliest work of Drago and coworkers the most abundant cobalt species formed in their synthesis was the ion $\left[\mathrm{Co}(\mathrm{CN})_{6}\right]^{-3}$, which does not have oxygen-binding capacity. ${ }^{22,23}$ However, a limited amount of the $\mathrm{O}_{2}$-binding complex $\left[\mathrm{Co}(\mathrm{CN})_{4}\right]^{-2}$ was also formed. The EPR spectrum of the deoxygenated samples is significantly different from that of the oxygenated sample that contains the dioxygen adduct. From EPR spectrum of the deoxygenated sample, Taylor et al. were able to 
identify the complex as the square-planar $\left[\mathrm{Co}(\mathrm{CN})_{4}\right]^{-2}$ complex with an axial position occupied by a framework oxygen. ${ }^{23}$ This complex was stable to repeated cycling in air and, even in the low concentrations achieved, increased the amount of oxygen adsorbed over that of the pure Na-Y zeolite.

Because of the apparent success of Drago and coworkers in stabilizing their cyanocobaltate complex by anchoring to framework oxygen in zeolite $\mathrm{Y}$, we attemped to do the same with $\mathrm{Co}$ (fluomine). Table 2 gives the experimental and theoretical $\mathrm{O}_{2}$ binding capacities for the free $\mathrm{Co}$ (fluomine) and $\mathrm{Co}$ (salen) complexes and for the Co(fluomine) attached to the various substrates. One can see by comparing the experimental results to the predicted values, the free $\operatorname{Co(fluomine)~and~} \operatorname{Co}($ salen) form 1:2 $\left(\mathrm{O}_{2}: \mathrm{Co}^{2+}\right)$ adducts (type $\mathrm{Ib}$ shown in Figure 9). This is consistent with previously reported results. $^{2}$ In the case of the Co(fluomine)-LSX, it is possible that the complex forms 1:1 $\left(\mathrm{O}_{2}: \mathrm{Co}^{2+}\right)$ adducts (type Ia in Figure 9) rather than the 1:2 ones observed with the free complex. This is due to the isolation of the Co(fluomine) within the zeolite cavity that prevents interaction between $\operatorname{Co}$ (fluomine) molecules. It is also possible that there is some amount of $\mathrm{Co}$ (fluomine) attached to the outside surface of the zeolite or some free Co(fluomine) forming 1:2 adducts. Unlike the $\mathrm{X}$ zeolite, the MCM-41 does not have a cavity structure; but, rather a channel structure with large pore openings (of approximately $40 \AA$ in diameter). This open pore structure may not isolate the complexes and thus will allow the formation of 1:2 $\left(\mathrm{O}_{2}: \mathrm{Co}^{2+}\right)$ adducts. However, it is difficult to determine from the experimental capacity the type of bonding in this material. The same can be said for the Co(fluomine)-IXR since the measured capacity is very low. 
X-Ray Photoemission Spectroscopy Analysis. X-ray photoemission spectroscopy (XPS or ESCA) is a surface analytical technique whereby electrons photoemitted from atomic core levels are detected as a function of energy. The shifts of core-level energies give information on the chemical environment of the atoms (oxidation state) and the surface (composition). Since this technique has been used to describe the electronic environment in a large number of transition metal complexes, an investigation using XPS seems appropriate for the study of charge distribution in oxygen-binding cobalt complexes and those same complexes immobilized on or in meso- and microporous solids.

The reaction whereby these materials are formed is generally believed to be an oxidative addition wherein the cobalt ion is oxidized to a certain extent that is dependent on the electronic nature of a given cobalt(II) precursor. Burness et al. studied several $\mathrm{O}_{2}$ binding cobalt complexes in an effort to make correlations between cobalt core-electron binding energies and parameters such as reversible vs. irreversible behavior, and the differences, if any, between $\mu$-peroxo and superoxo complexes. ${ }^{30}$ The authors presented unambiguous evidence that the cobalt(II) ion is oxidized during the oxygenation process, though the electron transfer from cobalt to dioxygen is likely not $100 \%$.

We have measured XPS spectra for $\mathrm{CoCh}, \mathrm{Co}^{2+}$ ion-exchanged $\mathrm{X}$ zeolite, free Co(fluomine), and Co(fluomine)-LSX. The Co(fluomine) sample was in an oxygenated state since heat is required in order to deoxygenate and the samples were not heated in the staging cell. The Co-LSX sample did not contain adsorbed oxygen since it is easily desorbed in high vacuum; and the Co(fluomine)-LSX sample, based on the adsorption and desorption isotherms (in Figure 5), should be partially oxygenated since it is not fully 
reversible. The XPS spectra are shown in Figure 10; and the $2 \mathrm{p}_{3 / 2}$ binding energy (in eV) for these compounds, and some other reference compounds are given in Table 3 . It was not our intention in this work to determine the oxidation state of the cobalt in these complexes. Rather, we wanted to look at the XPS binding energy shift in order to determine differences in the electronic nature of the central cobalt that may be attributed to binding of the cobalt at the axial position to the substrate (in this case, $\mathrm{X}$ zeolite). The $2 \mathrm{p}_{3 / 2}$ binding energy for $\mathrm{Co}$ in $\mathrm{CoCh}_{2}$ and $\mathrm{Co}-\mathrm{LSX}$ were the same at $784.5 \mathrm{eV}$. That of the $\mathrm{Co}$ (fluomine) was $780.5 \mathrm{eV}$ that is very similar to that measured previously for $\mathrm{Co}$ (salen) at $780.0 \mathrm{eV} .{ }^{30}$ The $2 \mathrm{p}_{3 / 2}$ binding energy for Co in Co(fluomine)-LSX was $782.0 \mathrm{eV}$ that is between that of Co-LSX and the free Co(fluomine). This difference may be an indication of binding of the cobalt center of the $\mathrm{Co}$ (fluomine) to framework oxygen in the zeolite.

Stability Testing. The most prohibitive problem facing the commercialization of $\mathrm{Co}$ (salen), $\mathrm{Co}$ (fluomine), and other $\mathrm{O}_{2}$-binding complexes has been the chemical instability due to autoxidation. Three general mechanism may be involved in the autoxidation of the oxygen carrying complexes: (i) dimerization of the complex, (ii) irreversible oxidation of the ligand, and/or (iii) irreversible oxidation of the central coordinating Co atom. ${ }^{2}$

The samples were found to be very stable to exposure to atmospheric moisture. There was no noticeable decrease in the binding capacity after exposure to atmospheric oxygen and moisture. In order to test the stability to repeated oxygenation and deoxygenationm the samples were subjected to an aggressive stability test. Each of the samples was subjected to oxygenation and deoxygenation cycles in a thermogravimetric analyzer (TGA). The samples were first activated by heating to $120 \mathrm{C}$ in a pure $\mathrm{Ar}$ atmosphere. 
The samples were then alternatively exposed to 1 atm $\mathrm{O}_{2}$ and $1 \mathrm{~atm}$ Ar at $60 \mathrm{C}$ for 15 minutes each. After 90 cycles, the samples were removed from the TGA and reactivated at $120 \mathrm{C}$ in a vacuum. The oxygen adsorption and desorption isotherms were then measured; and the sample was then returned to the TGA for continued cycling.

In each of the free and immobilized Co(fluomine) syntheses described earlier piperidine was added as the last step. This was done in order to follow previously reported procedures. ${ }^{9}$ The piperidine (and pyridine in the synthesis of $\mathrm{Co}$ (salen)) is added in order to coordinate to the $\mathrm{Co}^{2+}$ at the axial position that allows the ligands in the equatorial positions to move into the appropriate position to allow $\mathrm{O}_{2}$-binding. However, we were concerned that the $\mathrm{Co}^{2+}$, which was initially bound to the substrate via ionexchange, was moving from the substrate to the piperidine. We subsequently synthesized $\mathrm{Co}$ (fluomine)-LSX without the use of piperidine and measured the resulting $\mathrm{O}_{2}$ adsorption isotherm. There was no difference in the $\mathrm{O}_{2}$-binding capacity or in the stability of the Co(fluomine)-LSX that was made using piperidine (p) when compared to those measured for the Co(fluomine)-LSX that was synthesized using no piperidine (np). A plot of the results of the stability testing is shown in Figure 11. 


\section{Literature Cited}

1. Yang, R.T., Gas Separation by Adsorption Processes; Butterworth, Boston, 1987; reprinted (in paperback) by Imperial College Press, London and World Scientific Publishing Co., River Edge, NJ, 1997.

2. Li, G. Q.; Govind, R.; Separation of Oxygen from Air Using Coordination Complexes: A Review. Ind. Eng. Chem. Res. 1994, 33, 755.

3. Jones, R. D.; Summerville, D. A.; Basolo, F.; Synthetic Oxygen Carriers Related to Biological Systems. Chem. Rev. 1979, 79, 139.

4. Niederhoffer, E. C.; Timmons, J. H.; Martell, A. E.; Thermodynamics of Oxygen Binding in Natural and Synthetic Dioxygen Complexes. Chem. Rev. 1994, 84, 137.

5. Calvin, M.; Bailes, R. H.; Wilmarth, W. K.; The Oxygen-Carrying Synthetic Chelate Compounds. I. J. Am. Chem. Soc. 1946, 68, 2254.

6. Hughes, E. W.; Wilmarth, W. K.; Calvin, M.; The Oxygen-Carrying Synthetic Chelate Compounds. V. Equilibrium with the Solid Compounds. J. Am. Chem. Soc. 1946, 68, 2273.

7. Barkelew, C. W.; Calvin, M.; Oxygen Carrying Synthetic Chelate Compounds. II. The Rates of Oxygenation of the Solid Compounds. J. Am. Chem. Soc. 1946, 68, 2257.

8. Wilmarth, W. K.; Aranoff, S.; Calvin, M.; The Oxygen-Carrying Synthetic Chelate Compounds. III. Cycling Properties and Oxygen Production. J. Am. Chem. Soc. 1946, 68, 2263.

9. Bailes, R. H; Calvin, M.; The Oxygen-Carrying Synthetic Chelate Compounds. VII. Preparation. J. Am. Chem. Soc. 1947, 69, 1886.

10. Calvin, M.; Martell, A. E.; Chemistry of the Metal Chelate Compounds, PrenticeHall, New York, 1952.

11. Boscola, E. J.; In-Flight Oxygen Generation for Aircraft Breathing Systems. J. Aircraft 1974, 11, 444.

12. Adduci, A. J.; The Case of Aircraft $\mathrm{O}_{2}$ System Based on Metal Chelates. Chemtech 1975, 6, 575 .

13. Chen, D.; Martell, A. E.; Dioxygen Affinities of Synthetic Cobalt Schiff Base Complexes. Inorg. Chem. 1987, 26, 1026. 
14. Chen, D.; Martell, A. E.; Sun, Y.; New Synthetic Cobalt Schiff Base Complexes as Oxygen Carriers. Inorg. Chem. 1989, 28, 2647.

15. Dzugan, S. J.; Busch, D. H.; Synthesis and Characterization of New Cobalt Dioxygen Carriers Based on a Familar Macrocyclic Ligand. Inorg. Chem. 1990, 29, 2528.

16. Ramprasad, D.; Pez, G. P.; Toby, B. H.; Markley, T. J.; Pearlstein, R. M.; Solid State Lithium Cyanocobaltates with a High Capacity for Reversible Dioxygen Binding: Synthesis, Reactivity and Structures. J. Am. Chem. Soc. 1995, 117, 10694.

17. Lunsford, J. H.; The Formation, Characterization, and Catalytic Activity of Transition Metal Complexes in Zeolites: The P. H. Emmett Award Address. Catal. Rev. - Sci. Eng. 1975, 12 (2), 137.

18. Howe, R. F.; Lunsford, J. H.; Electron Paramagnetic Resonance Studies of Some Cobalt Amine Oxygen Adducts in Zeolite Y. J. Am. Chem. Soc. 1975, 97, 18.

19. Howe, R. F.; Lunsford, J. H.; Oxygen Adducts of Cobalt(II)-Ethylenediamine Complexes in X- and Y-Type Zeolites. J. Phys. Chem. 1975, 79, 1836.

20. Imamura, S.; Lunsford, J. H.; Separation of Oxygen from Air by $\left[\mathrm{Co}^{\mathrm{II}}(\mathrm{byp})(\text { terpy })\right]^{+2}$ Complex in Zeolite Y. Langmuir 1985, 1, 326.

21. Herron, N.; A Cobalt Oxygen Carrier in Zeolite Y. A Molecular "Ship in a Bottle". Inorg. Chem., 1986, 25, 4714.

22. Drago, R. S.; Bresinska, I.; George, J. E.; Balkus, K.; Taylor, R. J.; Entrapment of an Anionic Stable Moisture Resistant Oxygen Carrier in Zeolite Y. J. Amer. Chem. Soc. 1988, 110, 304.

23. Taylor, R.J.; Drago, R. S.; George, J. E.; Characterization of a Cobalt(II) Cyanide Complex inside Zeolite Y that Reversibly Binds Oxygen. Inorg. Chem. 1989, 111, 6610 .

24. Taylor, R.J.; Drago, R. S.; Hage, J. P.; A Reversible $\mathrm{O}_{2}$-binding System: $\mathrm{Co}(\mathrm{CN}) 5^{-3}$ Inside Zeolite. Inorg. Chem. 1992, 31, 253.

25. Yang, R. T., Recent Advances and New Horizons in Adsorption - With a Focus on New Sorbents, Prep. Topical Conf. Separ. Sci. Tech. (W.S.W. Hoand R. G. Luo, eds.), AIChE, New York, pp. 14-23 (1997).

26. Kresge, C.T.; Leonowicz, M. E.; Roth, W.J.; Vartuli, J.C.; Beck, J.S, Ordered Mesoporous Molecular Sieves Synthesized by a Liquid-Crystal Template Mechanism. Natture, 1992, 359, 710. 
27. Zhao, X. S.; Lu, G. Q.; Millar, G. J., Advances in Mesoporous Molecular Sieve MCM-41. Ind. Eng. Chem. Res. 1996, 35, 2075.

28. Briggs, B.; Shea, M. P.; Practical Surface Analysis. Volume 1. Auger and X-ray Photoemission Spectroscopy, John Wiley and Sons, NY, 1990 (p. 543).

29. Vaska, L., "Dioxygen-Metal Complexes: Toward a Unified View", Acct. Chem. Res. 1976, 9, 175.

30. Burness, J. H.; Dillard, J. G.; Taylor, L. T.; An X-Ray Photoelectron Spectrsocopic Study of Cobalt(II) Schiff Base Complexes and Their Oxygenation Products. J. Am. Chem. Soc. 1975, 97, 6080.

31. Wagner, C. D.; Riggs, W. M.; Davis, L. E.; Moulder, J. F.; Mullenberg, G. E.; Eds.; Handbook of X-ray Photoelectron Spectroscopy, Perkin-Elmer Corporation, 1979. 
Table 1. Results of chemical analyses for some selected samples.

\begin{tabular}{lccc} 
Sample & Co & C & F \\
& wt\% & wt\% & wt\% \\
\hline Co-LSX & 18.0 & - & - \\
Co(flo)-LSX & 16.0 & 13.51 & 2.04 \\
Co(flo)-MCM-41 & 5.9 & 11.97 & 1.88 \\
\hline
\end{tabular}

Table 2. Experimental $\mathrm{O}_{2}$ capacities (at $25 \mathrm{C}, 1 \mathrm{~atm}$ ) for various $\mathrm{O}_{2}$-binding materials compared to the theoretical capacities for $1: 1$ and $1: 2\left(\mathrm{O}_{2}: \mathrm{Co}^{2+}\right)$ adducts.

\begin{tabular}{lccc} 
Material & $\begin{array}{c}\text { Experimental } \\
\mathbf{O}_{2} \text { capacity } \\
\text { mmol/g }\end{array}$ & $\begin{array}{c}\text { Theoretical } \\
\mathbf{1 : 1} \text { adduct } \\
\mathbf{m m o l} / \mathbf{g}\end{array}$ & $\begin{array}{c}\text { Theoretical } \\
\mathbf{1 : 2} \text { adduct } \\
\text { mmol/g }\end{array}$ \\
\hline Co(salen) & 1.06 & 3.1 & 1.55 \\
Co(fluomine) & 1.13 & 2.78 & 1.39 \\
Co(fluomine)-LSX & 0.123 & 0.57 & 0.29 \\
Co(fluomine)-MCM-41 & 0.107 & 0.49 & 0.25 \\
Co(fluomine)-IXR & 0.03 & 1.23 & 0.616
\end{tabular}

NOTE: The experimental capacity is that measured at $25 \mathrm{C}$ and $1 \mathrm{~atm}$, the $\mathrm{Co}$ (fluomine)-LSX result is corrected to account for the natural $\mathrm{O}_{2}$ capacity for Co-LSX. The theoretical amounts for the Co(fluomine)-LSX assume two Co(fluomine) molecules per zeolite cavity. The Co(fluomine)-MCM-41 theoretical amounts assume $3.7 \mathrm{Co}$ (fluomine) molecules per unit cell. The Co(fluomine)-IXR theoretical amounts assume $100 \% \mathrm{Co}^{2+}$ ion exchange and subsequent conversion to $\mathrm{Co}$ (fluomine). The cation exchange capacity for the LSX zeolite is $7.4 \mathrm{meq} / \mathrm{g}$; the MCM-41 is $1.48 \mathrm{meq} / \mathrm{g}$; and the ion-exchage resin is $4.7 \mathrm{meq} / \mathrm{g}$. 
Table 3. X-ray photoemission spectroscopy (XPS) $2 \mathrm{p}_{3 / 2}$ binding energy (eV) for various cobalt species.

\begin{tabular}{lc} 
Cobalt Species & $\mathbf{2 p}_{\mathbf{3} / \mathbf{2}} \mathbf{B E}(\mathbf{e V})$ \\
\hline $\mathrm{Co}(\mathrm{II}) \mathrm{Ch}$ & 784.5 \\
$\mathrm{Co}(\mathrm{II})-\mathrm{LSX}$ zeolite & 784.5 \\
$\mathrm{Co}($ fluomine $)-\mathrm{LSX}$ & 782.0 \\
zeolite & 780.5 \\
$\mathrm{Co}($ fluomine $)$ & 780.0 \\
$\mathrm{Co}(\text { salen })^{30}$ & 778.0 \\
$\mathrm{Co}$ metal $^{30}$ & 782.8 \\
$\mathrm{Co}(\mathrm{II}) \mathrm{F}_{2}{ }^{31}$ & 782.4 \\
$\mathrm{Co}(\mathrm{II}) \mathrm{F}_{2} \bullet 4 \mathrm{H}_{2} \mathrm{O}^{31}$ & 782.3 \\
$\mathrm{Co}(\mathrm{III}) \mathrm{F}_{3}{ }^{31}$ &
\end{tabular}




\section{Figure Captions}

Figure 1. The molecular structure for $\mathrm{Co}($ salen) [for $\mathrm{X}=\mathrm{H}]$ and $\mathrm{Co}$ (fluomine) [for $\mathrm{X}=\mathrm{F}$ ].

Figure 2. Oxygen adsorption and desorption isotherms, measured at $25 \mathrm{C}$ for Co(salen).

Figure 3. Oxygen adsorption and desorption isotherms, measured at $25 \mathrm{C}$ for Co(fluomine).

Figure 4. Oxygen adsorption and desorption isotherms, measured at $0 \mathrm{C}, 25 \mathrm{C}$, and $60 \mathrm{C}$ for $\mathrm{Co}$ (fluomine).

Figure 5. Oxygen and nitrogen adsorption isotherms, measured at $25 \mathrm{C}$, for Co-LSX and Co(fluomine) on LSX zeolite.

Figure 6. Oxygen adsorption and desorption isotherms, measured at $0 \quad \mathrm{C}, 25 \mathrm{C}$ and $60 \mathrm{C}$ for Co(fluomine) on Low Silica X zeolite.

Figure 7. Oxygen and nitrogen adsorption isotherms, measured at $25 \mathrm{C}$, for CoFluomine-MCM-41.

Figure 8. Oxygen and nitrogen adsorption isotherms, measured at $25 \mathrm{C}$, for Co(fluomine) on Ion Exchange Resin Amberlyst-15.

Figure 9. Types of Metal-dioxygen geometries. ${ }^{30}$

Figure 10. X-ray photoemission spectra (XPS) for various cobalt species.

Figure 11. Stability curves for various $\mathrm{O}_{2}$-binding materials after oxygenation and dexoygenation cycling. The materials were each cycled for 15 minutes each in 1 atmosphere $\mathrm{O}_{2}$ and $\mathrm{Ar}$ at 60 C. The materials are Co(fluomine), Co(fluomine)-LSX synthesized with the use of piperidine (p), Co(fluomine)-LSX synthesized without the use of piperidine (np), and $\mathrm{Co}$ (fluomine)-MCM-41. 


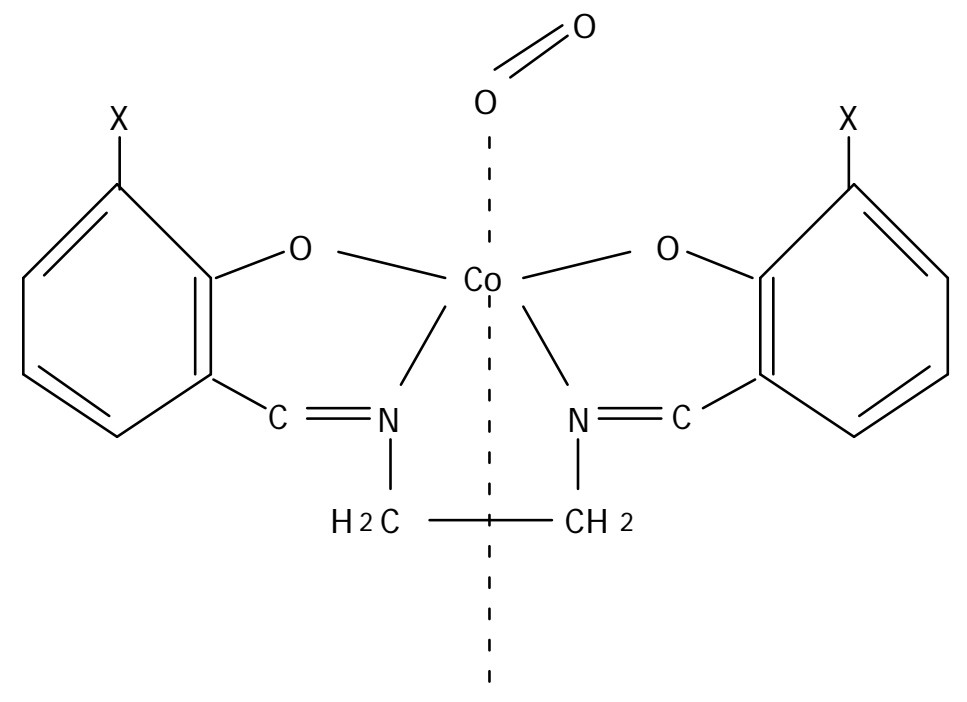

Figure 1. The $\mathrm{Co}($ salen) [for $\mathrm{X}=\mathrm{H}]$ and $\mathrm{Co}$ (fluomine) [for $\mathrm{X}=\mathrm{F}]$ molecule. 


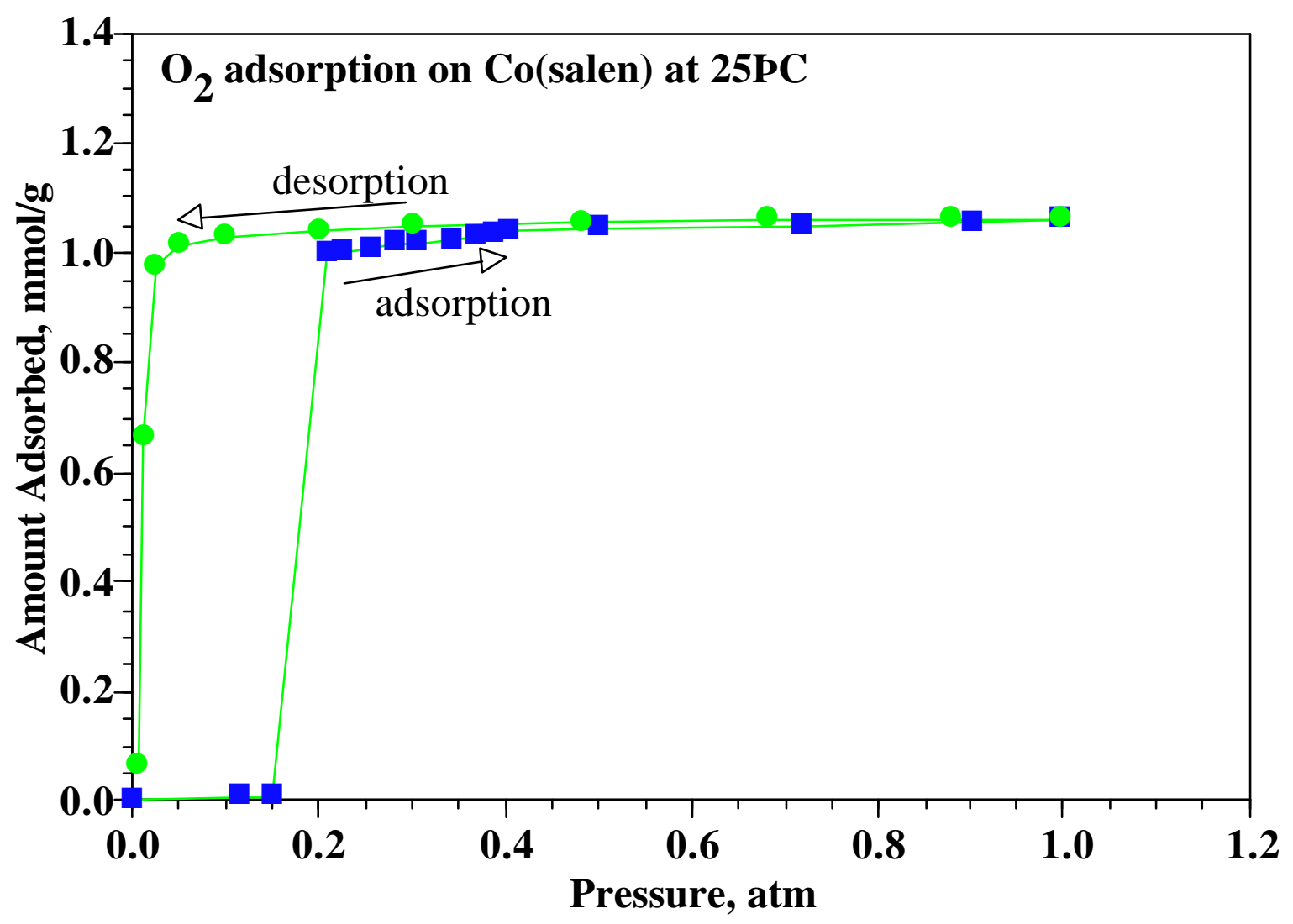

Figure 2. Oxygen adsorption and desorption isotherms, measured at $25 \mathrm{C}$ for Co(salen). 


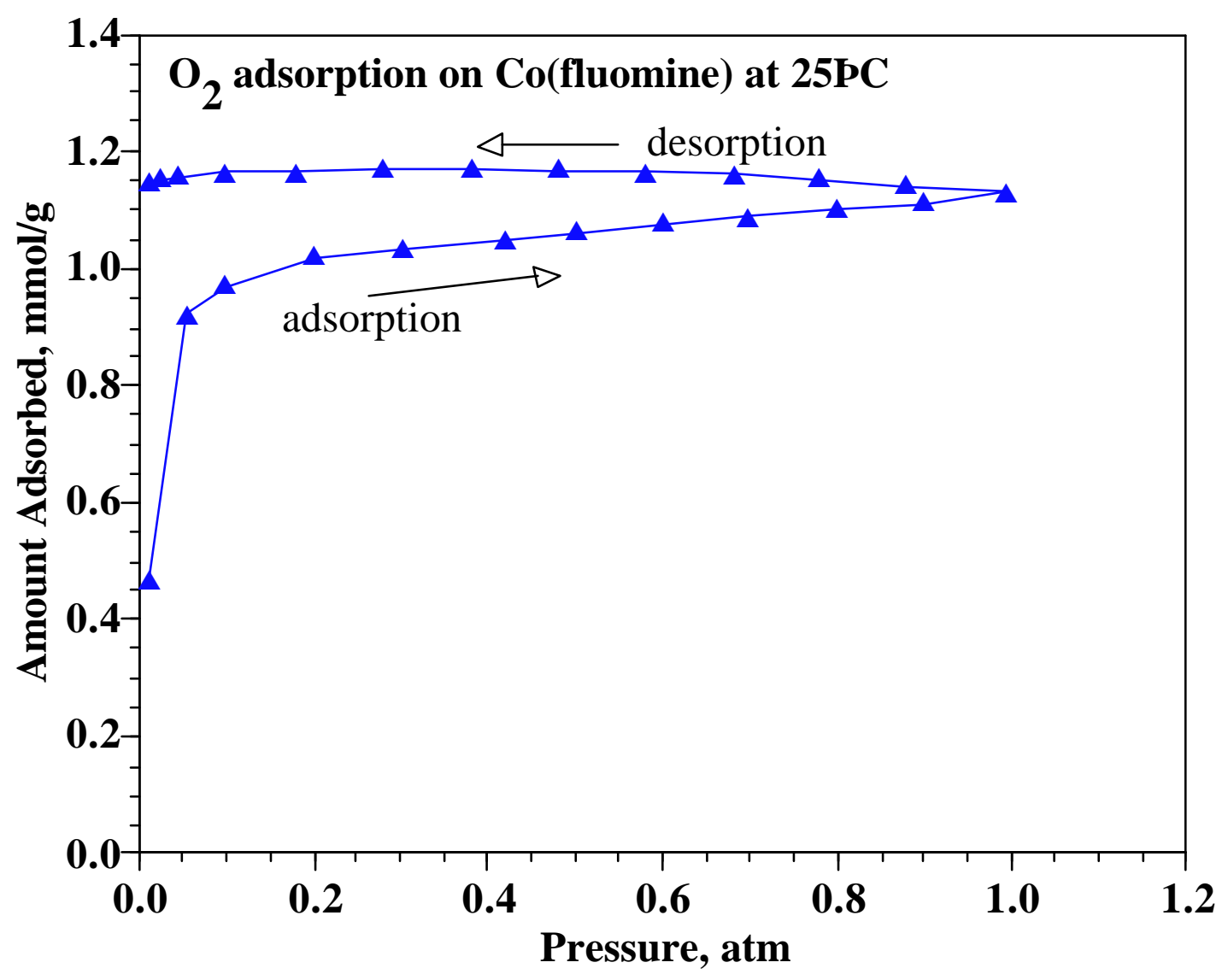

Figure 3. Oxygen adsorption and desorption isotherms, measured at $25 \mathrm{C}$ for Co(fluomine). 


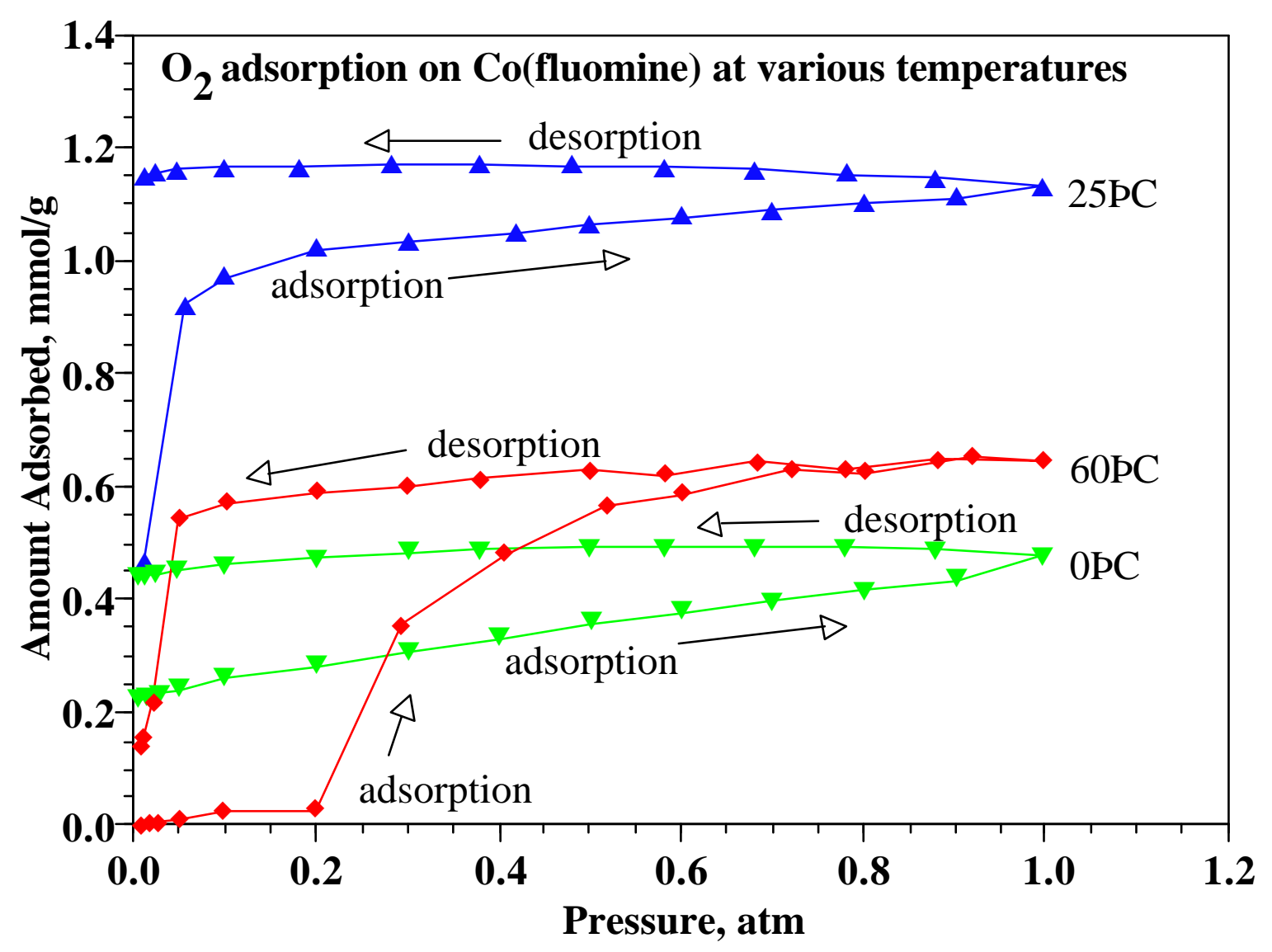

Figure 4. Oxygen adsorption and desorption isotherms, measured at $0 \mathrm{C}, 25 \mathrm{C}$, and $60 \mathrm{C}$ for $\mathrm{Co}$ (fluomine). 


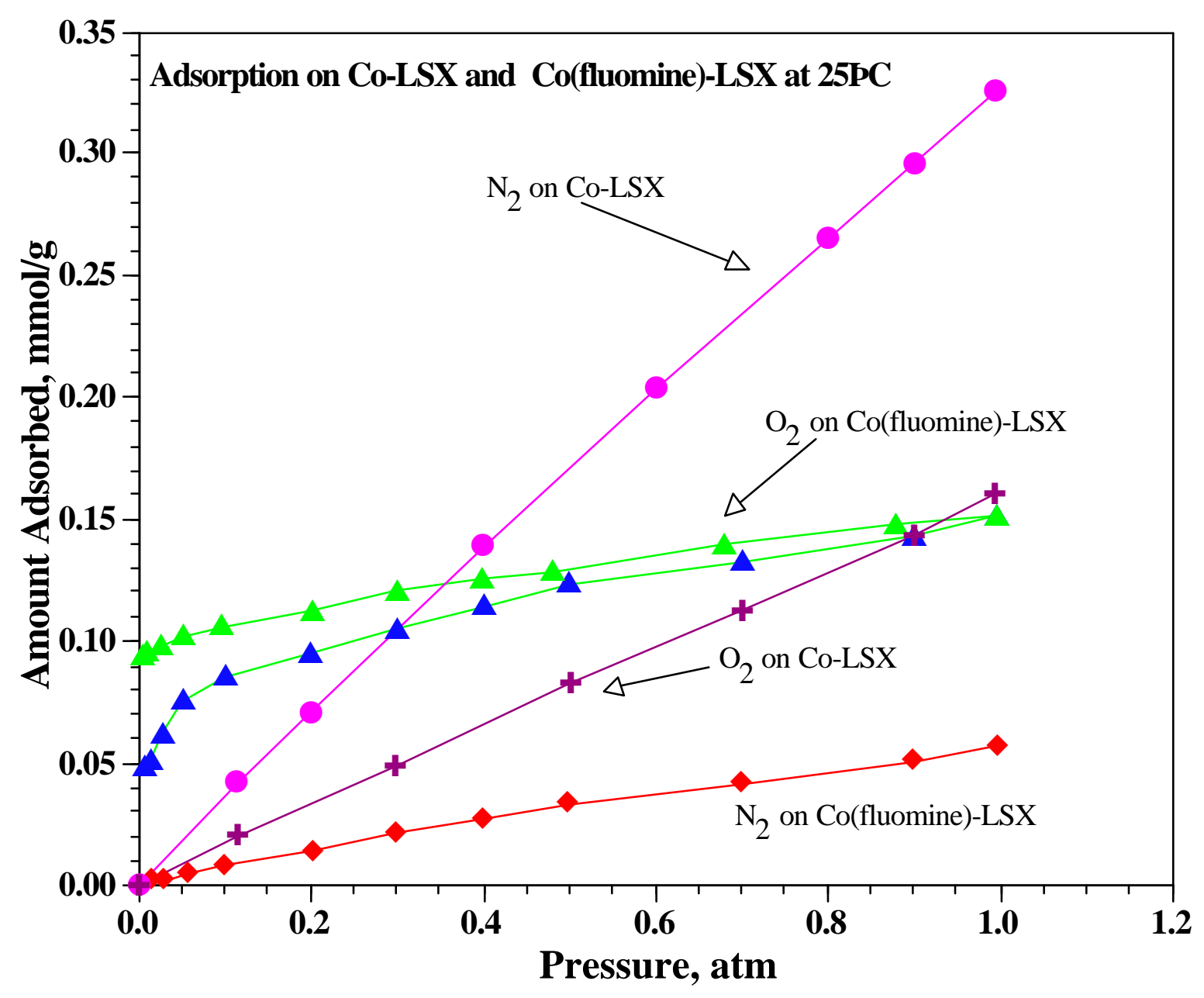

Figure 5. Oxygen and nitrogen adsorption isotherms, measured at $25 \mathrm{C}$, for Co-LSX and Co(fluomine) on LSX zeolite. 


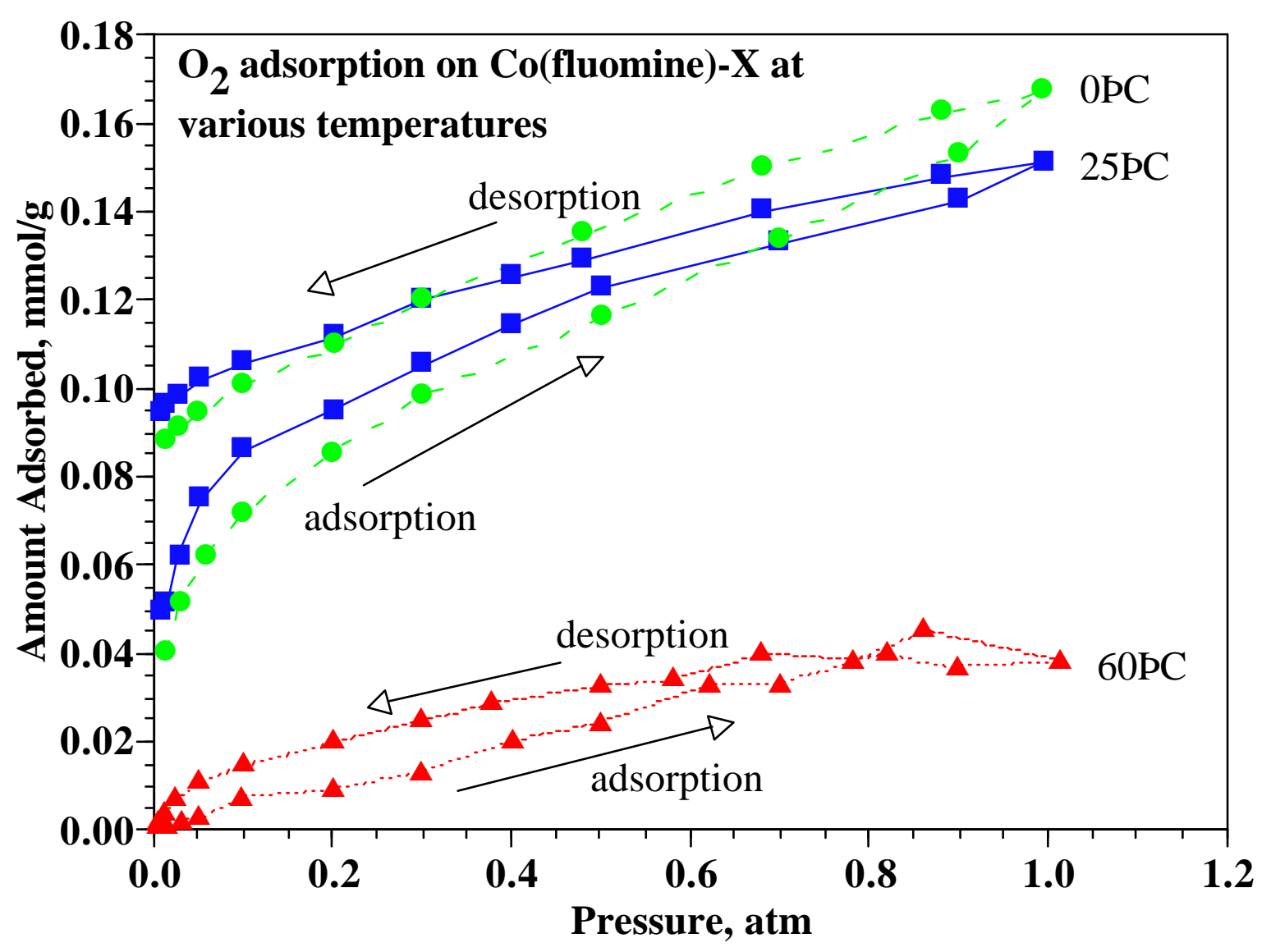

Figure 6. Oxygen adsorption and desorption isotherms, measured at $0 \quad \mathrm{C}, 25 \mathrm{C}$ and $60 \mathrm{C}$ for Co(fluomine) on Low Silica X zeolite. 


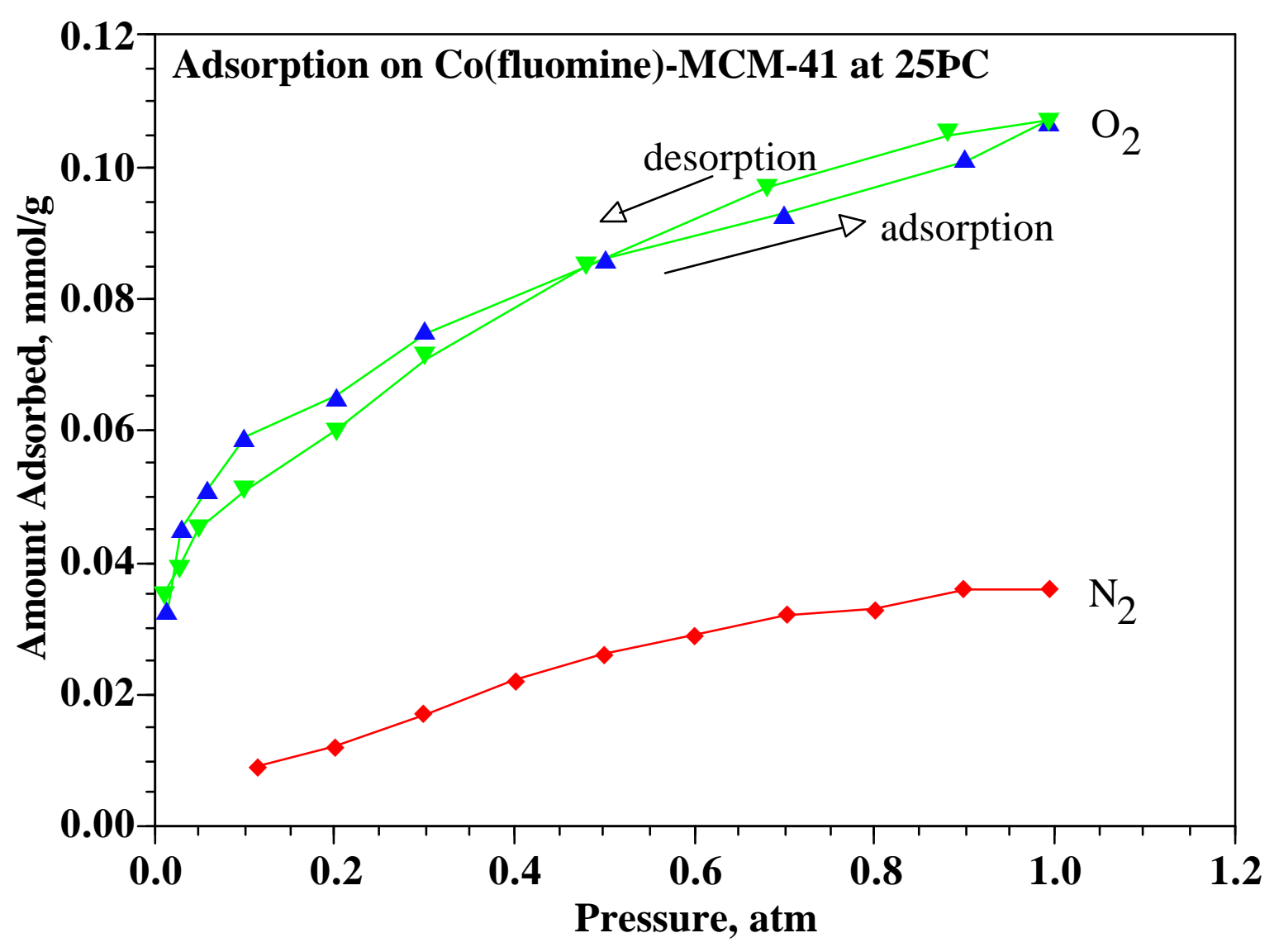

Figure 7. Oxygen and nitrogen adsorption isotherms, measured at $25 \mathrm{C}$, for CoFluomine-MCM-41. 


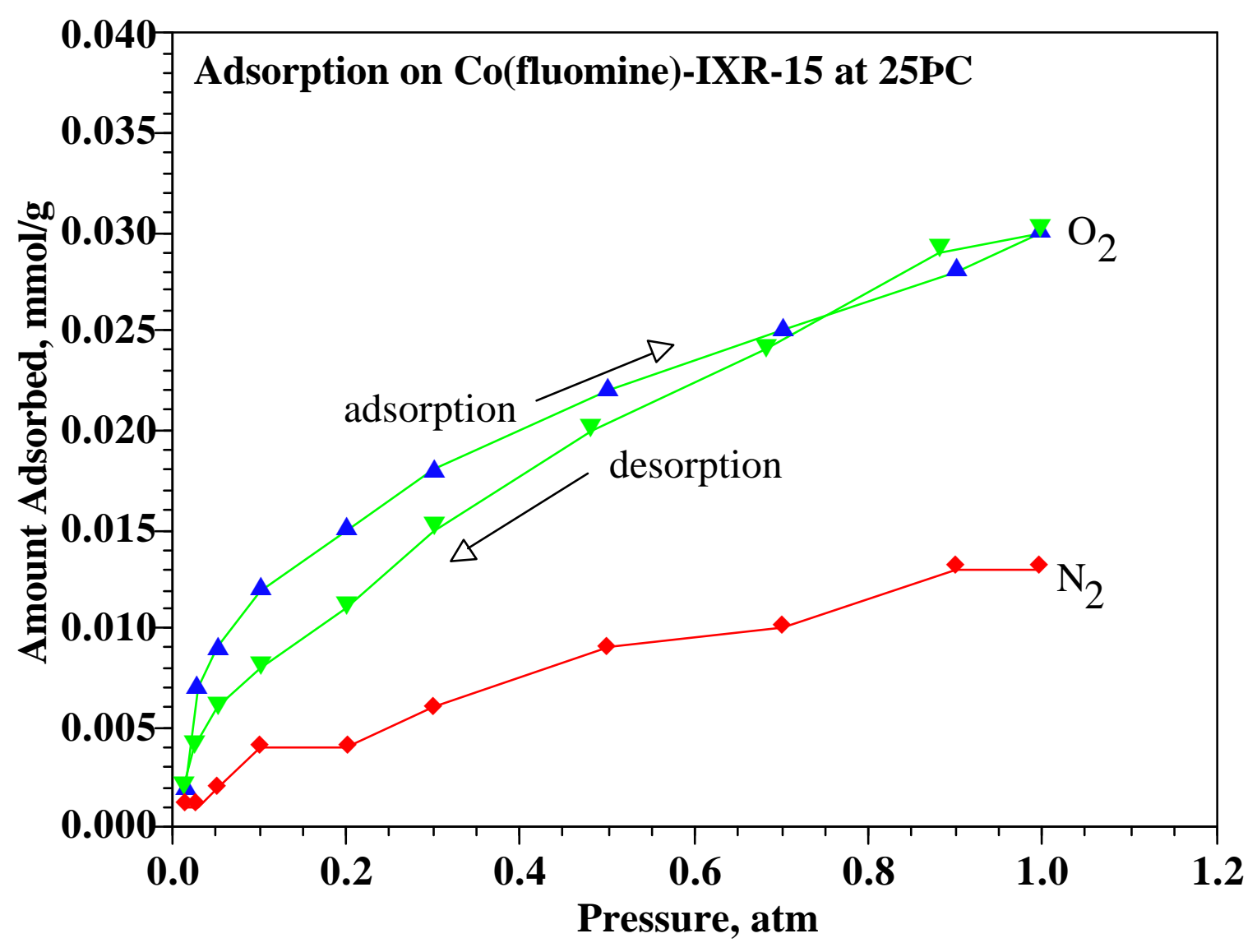

Figure 8. Oxygen and nitrogen adsorption isotherms, measured at $25 \mathrm{C}$, for Co(fluomine) on Ion Exchange Resin Amberlyst-15. 


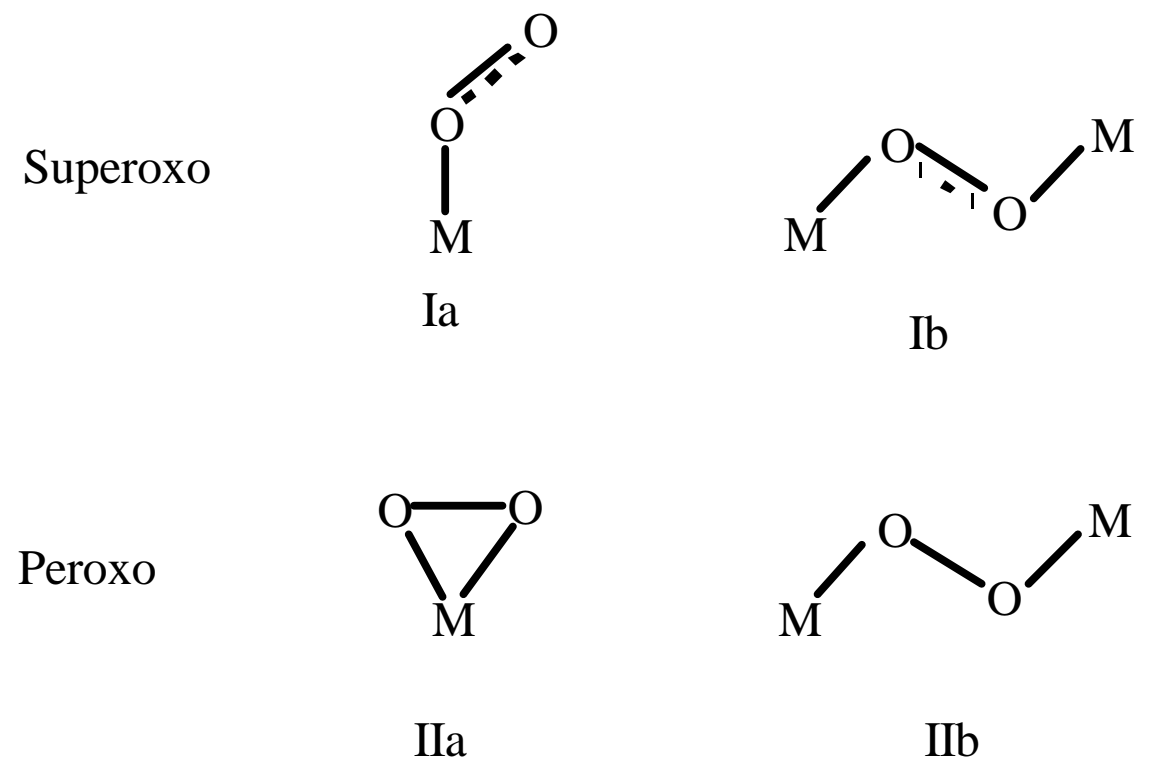

Figure 9. Types of Metal-dioxygen geometries. ${ }^{32}$ 


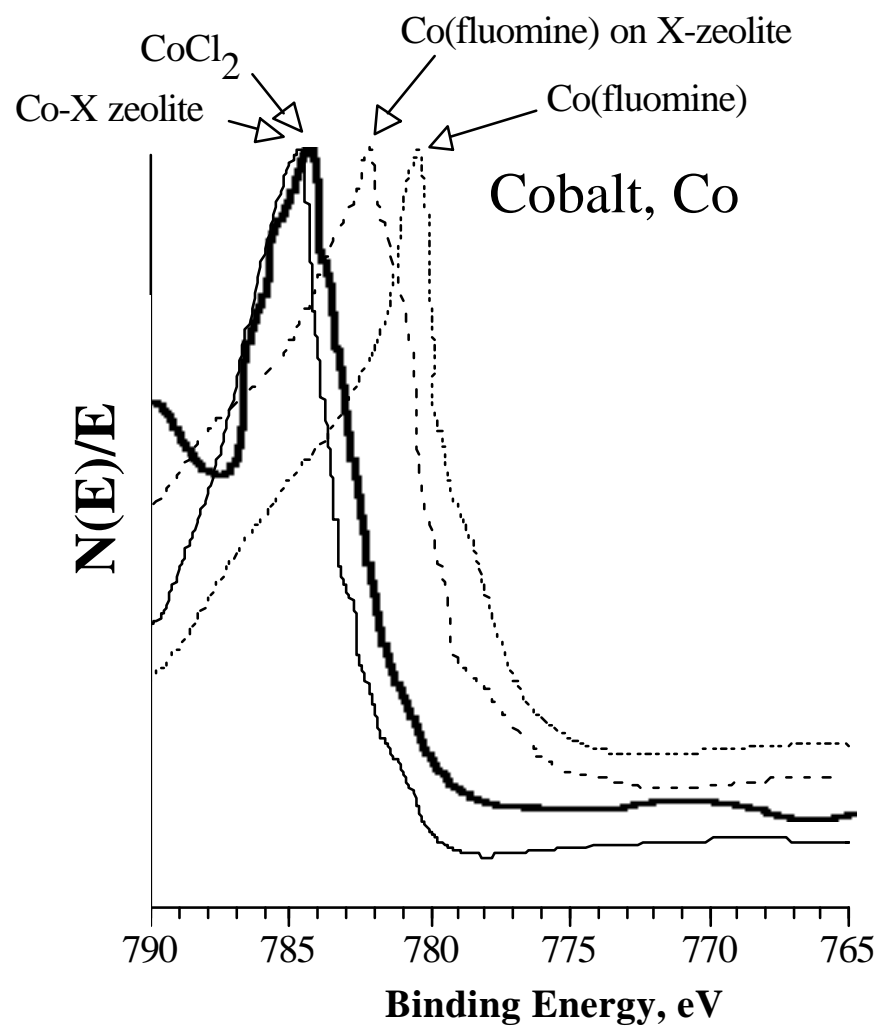

Figure 10. X-ray photoemission spectra (XPS) for various cobalt species. 


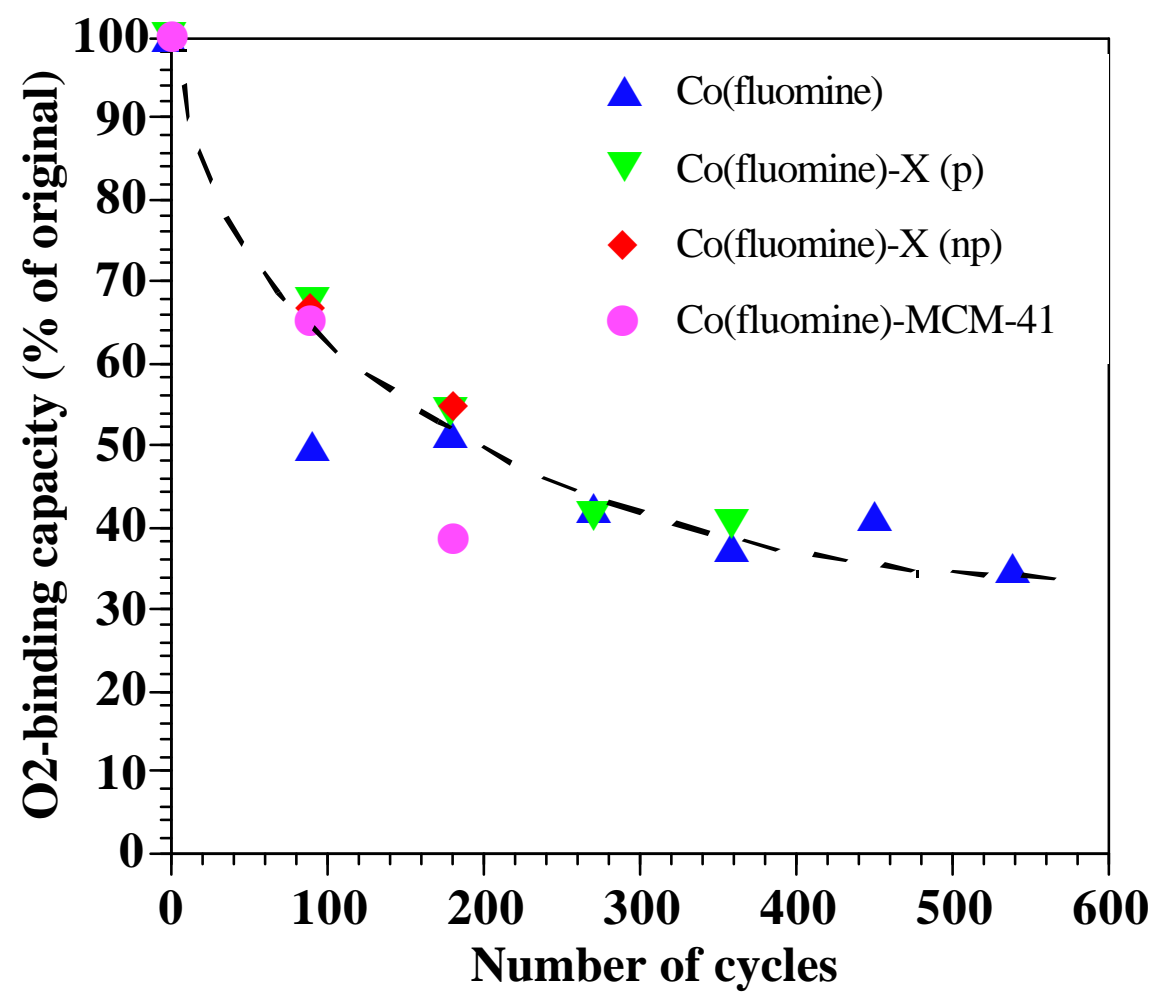

Figure 11. Stability curves for various $\mathrm{O}_{2}$-binding materials after oxygenation and dexoygenation cycling. The materials were each cycled for 15 minutes each in 1 atmosphere $\mathrm{O}_{2}$ and $\mathrm{Ar}$ at 60 C. The materials are Co(fluomine), Co(fluomine)-LSX synthesized with the use of piperidine (p), Co(fluomine)-LSX synthesized without the use of piperidine (np), and Co(fluomine)-MCM-41. 


\section{CONCLUSION}

The adsorptive capacity of silver ion-exchanged faujasites can be affected by the specific conditions under which they are dehydrated. Low silica $\mathrm{X}$ zeolites seem to be especially sensitive to the dehydration conditions. Silver ion-exchanged Y zeolites had a low capacity for nitrogen adsorption due to a lack of easily accessible supercage cations. Silver ion-exchanged $\mathrm{X}$ zeolite had a much higher nitrogen adsorption capacity as expected since it contains readily accessible supercage cations in site III locations. However, the Ag-X zeolite did not show enhancement of the nitrogen adsorption with dehydration temperatures above 350 C. The silver ion-exchanged low silica X zeolites had a high nitrogen adsorption capacity which was enhanced with the presence of silver in site II* locations. Silver in this location in more easily accessible to the sorbate molecules than those in the more usual site II locations. The presence of these site II* cations seems to be affected by the dehydration temperature with the Ag-LSX-350 sample containing fewer SII* cations than that of the Ag-LSX-450 sample. The formation of these SII* cations seems to be the result of thermally induced cation and/or cluster migration from site I locations to locations fully in the sodalite cage.

Mixed Li,Ag ion-exchanged zeolites have been synthesized and treated in ways that promote the formation of intracrystalline silver clusters. These samples were structurally characterized using Rietveld refinement of neutron powder diffraction data. Structural characterization revealed the presence of cations in a novel site II* in mixed Li,Ag-LSX zeolites that were vacuum dehydrated at 450 C. Cations in this site II* are more interactive with the atmospheric sorbates of interest than silver at the conventional 
site II location. Vacuum dehydration at $450 \mathrm{C}$ induced thermal migration of $\mathrm{Ag}^{+}$from site II to site II* and gives rise to the superior properties for air separation.

The effects of residual water on adsorption properties are studied. Li-LSX zeolite $(\mathrm{Si} / \mathrm{Al}=1.0)$ is chosen because it is currently the best sorbent in industrial use for air separation. In this present work we have synthesized fully exchanged Li-LSX zeolite and measured the room temperature equilibrium adsorption isotherms for $\mathrm{N}_{2}, \mathrm{O}_{2}$ and $\mathrm{Ar}$ after various degrees of dehydration. The effect of the residual water on the adsorption of these atmospheric gases was then simulated using Monte Carlo techniques. Very small amounts of water in the Li-LSX zeolite have a significant effect on the adsorptive capacity of these atmospheric gases with the capacity for $\mathrm{N}_{2}$ dropping from approximately 17.4 molecules $\mathrm{N}_{2}$ adsorbed per unit cell for the fully dehydrated material to less than 2 molecules adsorbed per unit cell when the sample contained 32 residual water molecules per unit cell, an indication that the $\mathrm{N}_{2}$ molecules only interact with the supercage SIII Li ${ }^{+}$cations.

In Chapter 5, we describe the syntheses and adsorption properties of oxygen selective sorbents. We have measured $\mathrm{O}_{2}$ and $\mathrm{N}_{2}$ adsorption and desorption isotherms for $\mathrm{Co}$ (salen), and Co(fluomine), and for Co(fluomine) immobilized on LSX zeolite, on MCM-41, and on ion-exchange resin. The immobilized samples were prepared by first ion exchange with $\mathrm{Co}^{2+}$, followed by attachment of fluomine ligand. Attempts to increase the stability by attaching the cobalt center of $\operatorname{Co}($ fluomine) complex were not successful. However, we were able to improve the characteristics of the binding isotherm to make the oxygenation significantly more reversible, as well as to obtain a possible slope for the binding isotherm, both were desirable for applications. The Co(fluomine)-MCM-41 
seemed especially promising in this regard as the adsorption isotherm was nearly completely reversible. 